\title{
Constructing Contrast
}

Juxtaposition as a tool for formal construction in my own creative practice, explored through the music of Stravinsky and Donatoni

By

Glen Downie

An exegesis submitted to the New Zealand

School of Music in partial fulfilment of the

requirements for the degree of Master of Musical

Arts in Composition

NEW ZEALAND SCHOOLF OF MUSIC 
(c) 2017

Glen Downie

ALL RIGHTS RESERVED 


\section{Abstract}

Juxtaposition and Superimposition are two techniques that I have adopted as a core feature of my creative practice. This exegesis examines the origins of these techniques through the analysis of two $20^{\text {th }}$ century works, Igor Stravinsky's Symphonies of Wind Instruments (1920/1947) and Franco Donatoni's Tema (1981), examining how the role all musical parameters, including timbre, pitch, rhythm and gesture, combine to create unique and perceptible shapes which can be purposefully juxtaposed, recombined and shuffled to create musical form. The influence and effect of these compositions is then discussed in relation to an analysis of the major work of my accompanying portfolio: Hot Coals for orchestra (2016/2017), demonstrating how ideas taken from the preceding analyses are developed further, and influence not just the resulting aesthetic, but also the construction and process of composition itself. 


\section{Acknowledgements}

Thanks to everyone who has helped me through my period of study. Big thanks to my supervisors Michael Norris and Dugal McKinnon, to my friends Hannah Blumhardt, Kirsten Strom and Luka Venter, who helped me through foreign language texts, and to all the performers who have graciously given their time and energy to my compositions. 


\section{Contents}

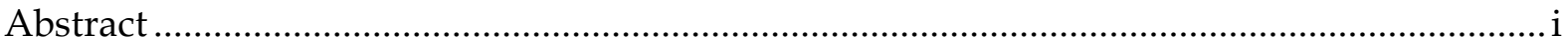

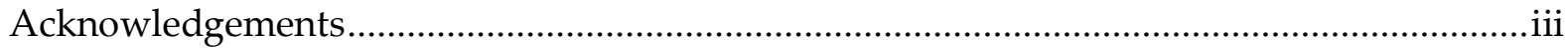

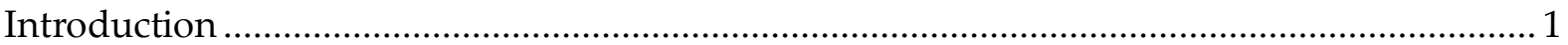

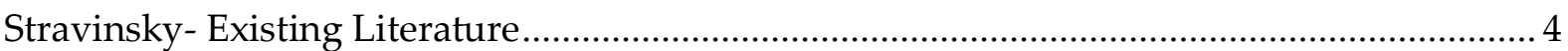

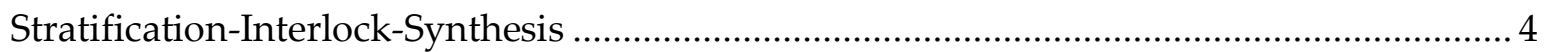

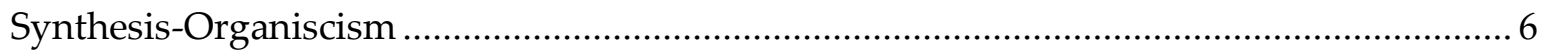

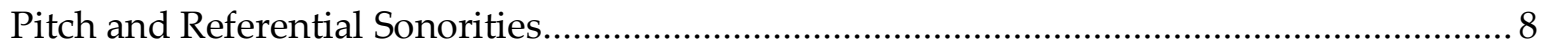

Stravinsky: Symphonies of Wind Instruments - Analysis......................................................... 9

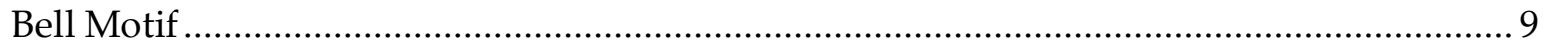

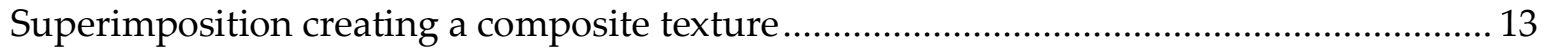

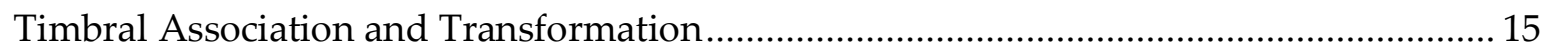

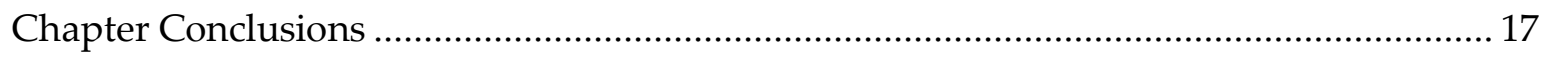

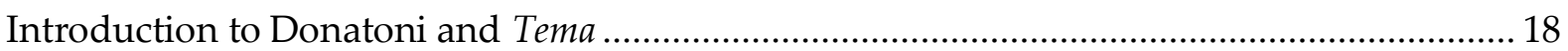

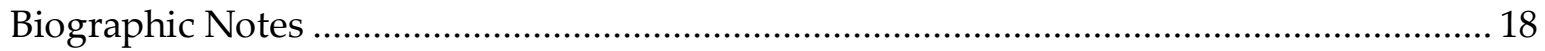

'Preserving the Fragment'- Bradley D. Decker's discussion and Terminology regarding

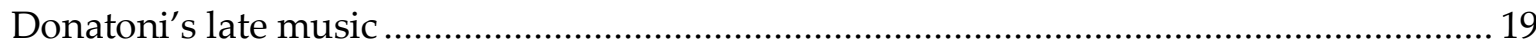

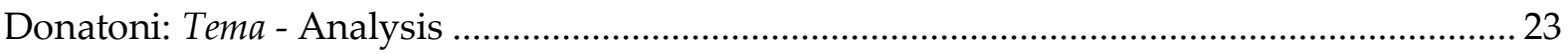

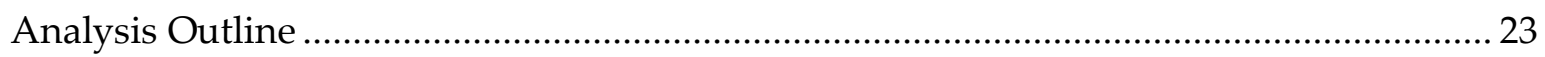

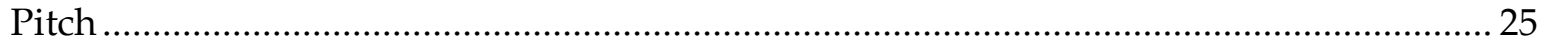

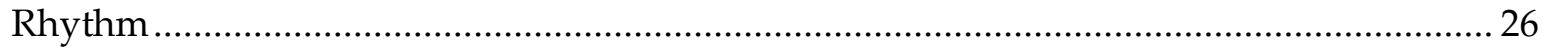

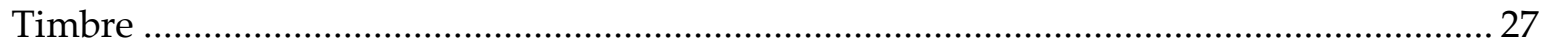

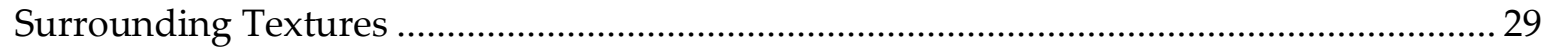

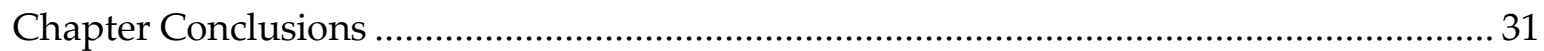

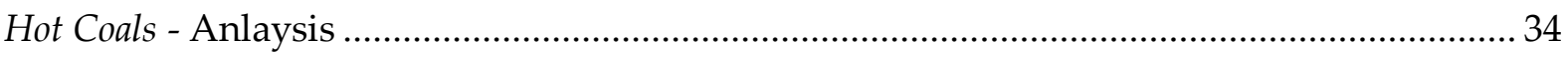

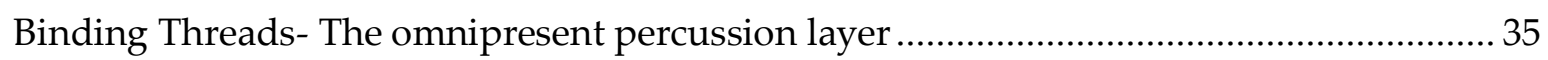




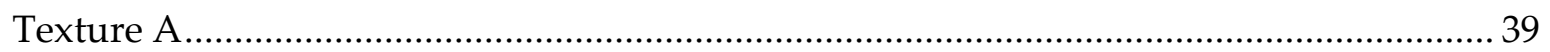

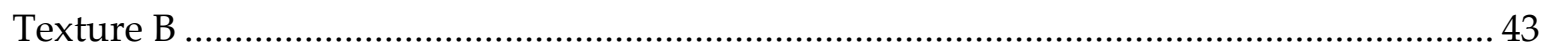

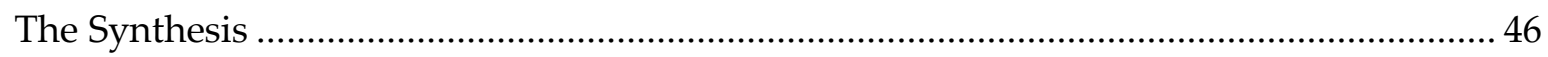

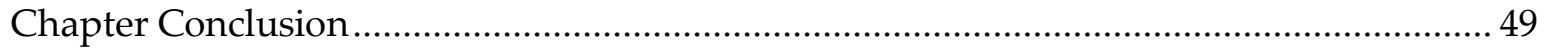

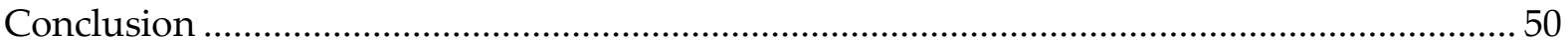

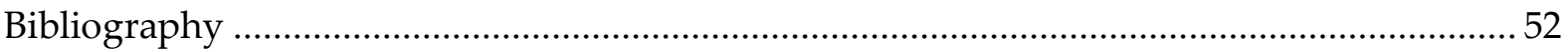

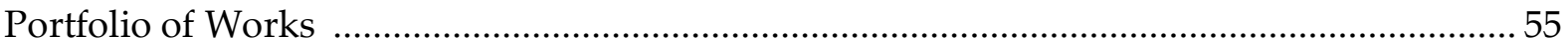

Accompanying CD of Works (attached to back) 


\section{Introduction}

Juxtaposition and superimposition offer a range of creative possibilities, and fruitful avenues of exploration for my creative practice. In this exegesis, exploration of Igor Stravinsky's use of juxtaposition and superimposition in the Symphony of Wind Instruments (1920/1947), and Franco Donatoni's extension of similar principles in Tema (1981), will lead to the discussion of various approaches to the use of juxtaposition and superimposition in my orchestral work Hot Coals.

Juxtaposition and superimposition are terms that suggest a highly constructive approach to composition, one in which the artifice and awareness of the medium has a direct and audible impact on the aesthetic. To achieve this effect, one must use a collection of highly contrasting/disjunct materials. These materials can exist at all levels of the composition, they may be a single motif or cell within a section or the perceptual gestalt of an entire section of activity itself. In both cases, it is important that these units can be rearranged, jumbled and yet still be perceptually related, not in an organic way, but as a fixed set of possibilities. As Kramer states in The Time of Music: “We learn the permutations allowable by a context, but not their succession [...] What we have, then, is a narrow range of possibilities, within which unpredictability reigns". ${ }^{1}$ Although Kramer uses this to argue the music is nondevelopmental and static, I believe that the changes in this lead to a more dynamic and controlled sense of growth, similar to when Horlacher claims "If a fragment or a 'block' has a shape, its successive repetitions may be conceived as developments of that shape: as connective responses, they may be expansions, compressions, and closures of previous music". ${ }^{2}$ However, both Horlacher and Kramer (both writing on Stravinsky) note that a listener infers an abstract set of rules and possibilities from the material presented, as exact repetitions (at least in combination) are rare. Neither can we predict, nor reduce the materials interaction down to a concrete formula, but instead we process an overall shape or

\footnotetext{
${ }^{1}$ Jonathan Kramer, The Time of Music (New York: Schirmer Books, 1988), 223.

${ }^{2}$ Gretchen Horlacher, Building Blocks: Repetition and Continuity in the Music of Igor Stravinsky (Oxford: Oxford University Press, 2011), 32.
} 
texture (also echoed by Kielian-Gilbert). ${ }^{3}$ What this creates is a form in which the relationships between the first tier of musical blocks, on the macro-level, become the focus, and the clear delineation between these musical areas and their 'artificial' or collage like placement create a musical argument. But these processes can also work at the micro-level, and can create a sense of formal growth and change.

It is important to note that, despite the major surface disruptions, often the highly contrasting material within the two works examined, Stravinsky's Symphonies of Wind Instruments (1920/1947) and Donatoni's Tema (1981) can be seen to originate from a single source, ${ }^{4}$ creating an element of variation. In fact, Robert Craft has called the Symphonies a theme and variations, ${ }^{5}$ whilst Donatoni's title: Tema, also suggests a similar comparison. What becomes fascinating, by means of the formal construction, is the juxtaposition and superimposition of these variations into larger, more kaleidoscopic forms, in which the interaction of these distinct ideas appear within the temporal vicinity of each other and create a musical dialogue. This also allows for the form of a piece to grow, a growth by the relationships of material, and not necessarily the transformation of the material itself, which is usually a constructive and compositional tool, worked out during the process of composition, and not demonstrated within the composition itself for listeners to observe.

The relationships between the different blocks can create effects that are horizontal (juxtaposition) or vertical (superimposition). Both are important, and the point at which they blur, becomes the most fascinating. What this compositional practice espouses is a clarity of material, material which may always be in flux at the microlevel, but it's role within the larger structure and its sonic implications are always apparent. For my own work, these principles allow exploration of many different musical parameters and aesthetics, and although each piece concentrates on a limited set of ideas, between pieces (and even within pieces) these ideas can be varied exponentially. The works in my portfolio present a range of

\footnotetext{
${ }^{3}$ Marianne Kielian-Gilbert, "The Rhythms of Form: Correspondence and Analogy in Stravinsky's Designs," Music Theory Spectrum 9 (Spring 1987): 42-66.

${ }^{4}$ Leo Somfai, "Symphonies of Wind Instruments (1920). Observations on Stravinsky's Organic Construction," Studia Musicologica Academiae Scientiarum Hungaricae 14, no. 1/4 (1972): 355-83.

${ }^{5}$ Frank Scheffer, The Final Chorale, DVD (Juxtapositions, 2005). 18.50-19.40
} 
different aesthetics, from a pastiche jazzy piano work Broken Record, which is modal and rhythmically swung, to Hot Coals, an orchestral work concerned with timbre, texture and complex rhythmic interplay. Both these works (and others within the portfolio) offer different approaches to juxtaposition and superimposition, but share the general guiding principle. In each case the character of the work can become highly concentrated, something I strive towards: to capture the essence of a musical idea and push it no further than the point at which it loses its identity, but still creating constant flux and change within the defined parameters. It is this affect which these techniques allow.

All analyses will examine the macro-structure, how the block like construction manifests itself in the overall form of the piece, but predominantly how it influences the inner workings of each section itself, explaining how juxtapositions and superimpositions exist at all levels of the compositions. To this effect we will examine all musical features that are used to create and stabilise the character of the material and how they are contrasted, separated and combined. This means pitch, ${ }^{6}$ rhythm, texture and timbre will all be examined when they help define the character and identity of a musical unit, and how contrast is used to construct, through juxtaposition and superimposition, a musical dialogue and sense of growth.

\footnotetext{
${ }^{6}$ Discussions on pitch will use traditional terminology as well as terminology from Forte's set theory, see: Allen Forte, The Structure of Atonal Music, (New Haven and London: Yale University Press, 1973).
} 


\section{Stravinsky- Existing Literature}

There is a large pool of existing literature discussing the music of Stravinsky, including specific analyses of the Symphonies of Wind Instruments. First, I will layout the ideas found in Edward T. Cone's 'The Progress of a Method'7 which sets a precedent that many analysts either build on, or react to. His article deals specifically with the macro-structure, the juxtapositional form of the Symphonies, rather than the micro-level, or the way units within single blocks or sections have also been constructed through juxtaposition. Secondly, I will place the literature in relation to two opposing schools of thought: those that hold a more traditional musicological view, using their analyses to attempt to find unity and an inner logic across the work (more akin to my own thinking); and those who embrace the structural disparities, criticising those analytical attempts as irrelevant and archaic.

\section{Stratification-Interlock-Synthesis}

Edward T. Cone offers a lucid, albeit brief, discussion of the works harmonic cohesion and voice leading. However, although it roughly touches on the motivic juxtapositions as a formal component, Cone's main concern is that of harmonic similarity (also the primary concern of Straus) ${ }^{8}$ which for him validates the composition despite its formal divisions. This stance is criticised by Jonathan Cross in The Stravinsky Legacy, ${ }^{9}$ the author declaring that Cone places unnecessary value on the idea of formal cohesion, something Cross refers to as archaic. Cross goes on to call the block like, discontinuous structure the "structural paradigm of the $20^{\text {th }}$ century", ${ }^{10}$ placing this structure as the most important break from the organic, developmental character of the romantic period.

However, there are three dominant concepts of Cone's argument that have, for the most part, been adopted and extended by other analysts (including Cross) of the Symphonies of Wind Instruments. It should be noted that Cone uses the Symphonies as the prima facie of these

\footnotetext{
7 Edward T. Cone, "The Progress of a Method," in Perspectives on Schoenberg and Stravinsky: Revised Edition, ed. Edward T. Cone and Benjamin Boretz (New York: W.W. Norton \& Company Inc., 1972). ${ }^{8}$ Joseph Straus, "A Principle of Voice Leading in the Music of Stravinsky," Music Theory Spectrum 4 (Spring 1982): 106-24.

${ }_{9}^{9}$ Jonathan Cross, The Stravinsky Legacy, 1st ed. (Cambridge: Cambridge University Press, 1998).

${ }^{10}$ Ibid., 80.
} 
concepts, but goes on to apply them to other works of Stravinsky, right up to the late serial period.

These key concepts are:

- Stratification- "By Stratification I mean the separation of in musical space of ideas-or better, of musical areas-juxtaposed in time; the interruption is the mark of this separation. The resultant layers of sound may be differentiated by glaring contrast, as at rehearsal Nos. 1 and 2 of the Symphonies, where changes of instrumentation, register, harmony, and rhythm, reinforce one another."

- Interlock- "To take the simplest possible case, consider two ideas presented in alternation: A-1, B-1, A-2, B-2, A-3, B-3. Now one musical line will run through A-1, A-2, A-3; another will correspondingly unite the appearances of B. Although heard in alternation, each line continues to exert its influence even when silent. As a result, the effect is analogous to that of polyphonic strands of melody: the successive timesegments are as if it were counterpointed one against the other."

- Synthesis- "Some sort of unification is the necessary goal toward which the entire composition points, for without it there is no cogency in the association of the component areas."11

Out of the three concepts above, the first is perhaps the most widely discussed, the level at which surface disruption is apparent, but I would like to explore the consequences of the interlock and more importantly the synthesis. Although the horizontal juxtaposition is a very clear and dominant aspect of the piece, I believe that the thematic connections and variations that are juxtaposed are, although less apparent, an important aspect of the technique, and the mixture of the two is crucial to the piece's unity.

${ }^{11}$ Cone, “The Progress of a Method." pp. 156-158 


\section{Synthesis-Organiscism}

The extension of Cone's 'synthesis' idea is, perhaps, most thoroughly employed by Somfai, ${ }^{12}$ who offers a rather extensive analysis, touching on a myriad of different musical parameters. The main concern is motivic (cellular) variation, linking all the material throughout the different, often contrasting sections of the piece, back to the final chorale, as well as aspects of organic development within the sections. Explanation of these variants are given primarily through the analysis of pitch (including the interrelationship of the melodic and the harmonic), although the use of rhythm/metre (including additive rhythm and polymetres) and the use of smaller blocks of material being juxtaposed and 'recombined', are not only examined between the sections (the process Cone called 'stratification') but within a section itself.

This is where I find the importance of the analysis to lie: where it shows how Stravinsky uses juxtaposition within a section. Somfai lays out the concepts of the mono-, bi- and polymetricality (also discussed by van den Toorn). ${ }^{13}$ Often, the concepts of different metrical streams are a consequence of juxtaposition and superimposition, more than a predetermined constructive scheme, as the simultaneous presentation of motifs/cells that reinforce differing metres, are the result of an assemblage of existing material, rather than a form filled with content. This also applies to the horizontal arrangement which Somfai describes as 'feet' as in poetry, and adds when "the 'feet' exchange places, they become extended or contracted". ${ }^{14}$ This is important to my analysis and to the significance this has when we move forward to examine Donatoni's Tema.

This block like structure, referring to the internal construction of sections (which contrasts it from most other analyses) is examined by the introductory clarinet theme which opens the piece, among others, to be discussed further on. Somfai's main argument is that literal repetition is non-existent in the Symphonies, even though they may "rouse the feeling of exact recapitulation" ${ }^{15}$ and that even though this is the case, the traditional devices of

\footnotetext{
12 Somfai, "Symphonies of Wind Instruments (1920). Observations on Stravinsky's Organic Construction."

${ }^{13}$ Pieter C. van den Toorn, The Music of Igor Stravinsky (New Haven: Yale University Press, 1983).

${ }^{14}$ Somfai, "Symphonies of Wind Instruments (1920). Observations on Stravinsky's Organic

Construction," 363.

15 Ibid., 369.
} 
development and variation (in their classical senses) are avoided. ${ }^{16}$ This is because traditional development is seen as a process of continual transformation, like a chain of logic, in which motifs lead the way through logical harmonic progressions, an aspect which is denied by the macro-level organisation implied by 'stratification'. Nor does the work exhibit a traditional variation form as the work does not present a line of different character developments that are presented one after the other, the 'stratification' breaking the order up, and even when ideas are recapitulated (the interlock), as mentioned previously, they appear the same, even though they are not exact. The consequence of this is that Somfai labels the microlevel variation as 'organic development' and 'functional variation'.17

Kramer, in the Time of Music, analyses the Symphonies in much the same manner, relying "on cellular analytic techniques, as devised by Messiaen and reported by Boulez and Jean Barraque" ${ }^{18}$ although actively rejecting any relationship to development or organicism, noting: "We learn the permutations allowable by a context, but not their succession" and hence "This is why I call the music nondevelopmental [sic]" ${ }^{19}$ There are many interesting observations in his cellular analysis, but his overall argument, that the piece can be understood in moment form ${ }^{20}$ is too reliant on the surface interruptions, ignoring the many clear connections listeners can infer across the piece. He also argues, paradoxically, in 'Moment Form in the Twentieth Century', ${ }^{21}$ that if there is a unity to found in the piece, it comes from ratios of durations between blocks within the piece. This argument is heavy handed, and Kramer segments the music in counterintuitive ways to make a laboured point.

\footnotetext{
${ }^{16}$ A concept dealt with other authors such as Kielian Gilbert

17 Somfai, "Symphonies of Wind Instruments (1920). Observations on Stravinsky's Organic Construction," 370.

${ }^{18}$ Kramer, The Time of Music, 223.

19 Ibid.

${ }^{20}$ Moment Form is a post-war term coined by Stockhausen, to describe music in which perception is always in the moment, and not referenced to other sections within the same piece ${ }^{21}$ Jonathan D. Kramer, "Moment Form in Twentieth Century Music," The Musical Quarterly 64, no. 2 (April 1978): 177-94.
} 


\section{Pitch and Referential Sonorities}

Another crucial observation of Somfai is that "The tonal material of successive themes often add up to dodecaphonic fields".22 This will lead nicely into the discussion of Donatoni and the processes I use to construct harmonic material in my own work, often using 12 tones, but segmented into smaller regions which are juxtaposed against each other in fixed harmonic fields. The voicing and relationship between the pitches becomes important and can be viewed through different lenses, such as Straus relating everything back to a specific tetrachord (unordered pitch set 0245), ${ }^{23}$ whilst van den Toorn describes a more poly-tonal approach, showing the juxtaposition of different tonal chords and modal/scalic segments. These approaches both offer perspectives in which juxtaposition is the rearrangement of abstract pitch collections, over the more immediate juxtapositions of specific motifs or cells, in which gesture and rhythm play a crucial role. This approach to juxtaposition can also be applied more globally and structurally across different parameters, outside of recognisable features. Also related to the above is the referential sonority, this is often uniquely voiced in pitch space, as well as being orchestrated uniquely.

\footnotetext{
22 Somfai, "Symphonies of Wind Instruments (1920). Observations on Stravinsky's Organic Construction," 377.

${ }^{23}$ Straus, "A Principle of Voice Leading in the Music of Stravinsky."
} 


\section{Stravinsky: Symphonies of Wind Instruments - Analysis}

The overall form of the piece, and the presentation of the stratification-interlock-synthesis is shown below (Fig. 1). This shows Cone's concepts in action, with the various colours representing the return of similar material. Note the graph is not proportional, showing only the return and relationship of material, and numbers correlate with rehearsal marks (where they co-align with sections). ${ }^{24}$ One major feature of the following analysis will be on the superimposition and juxtaposition that you can see represented in Figure 1 at [15]. The analysis will firstly examine aspects of the 'bell motif' ${ }^{25}$ which opens the piece (the green block), which has been discussed many times before and will reference previous theorists, to get a feel for how juxtaposition has been employed within a section. Secondly, the 'pastoral'26 section (the multicoloured layer from [15] to [23]), will be examined, demonstrating how multiple layers retain their unique identity, despite appearing simultaneously, through superimposition. All musical parameters, including pitch, rhythm, and timbre, that contribute to this identity and separation of distinct layers will be discussed to show how the concepts of juxtaposition manifest themselves and differ from a traditional counterpoint.

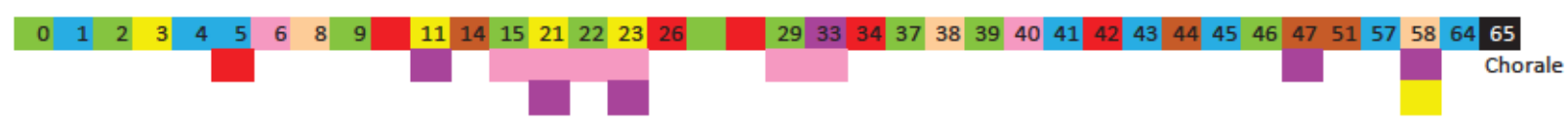

Figure 1

\section{Bell Motif}

The opening 'bell' motif in the clarinet, is one of the most striking and recognisable motifs of the work. The most identifiable characteristics being: the strident timbre of the clarinets high register, it's fall of a minor third (contour), it's grace note decoration, and the rhythmicmetric implications. We can segment this first appearance into two phrases ( $x$ and $y)$, and

\footnotetext{
${ }^{24}$ Rehearsal mark numbers will appear within square brackets throughout e.g. [15]

${ }^{25}$ Eric Walter White, Stravinsky: A Critical Survey (London: John Lehmann, 1947), 97.

${ }^{26}$ Eric Walter White, Stravinsky: The Composer and His Works (Berkeley and Los Angeles: University of California Press, 1966), 255.
} 
further limit the material down to further components, which are laid out in Fig. 2. These are:

1. the accented crotchet

2. the quaver movement down a minor third

3. the quaver movement following the interval pattern $+6,-1,-2$, with passing and neighbour grace notes (these are essential to the gestural identity and not merely decoration).

Somfai shows his take of the recombination of units on each iteration, showing how exact repetition is avoided, and states: "We accept the variations as being identical because the building components are all present, even though they are differently distributed and put together" ${ }^{27}$ An example of this is comparing the first instance to the third at [9], chosen because they are significantly varied than the first and second. The first follows the pattern (using the component numbers above): 1.1.2.1.2. 3. Whilst the third instance, uses the components described in the following order: 1. 2. 3. 2. 1. 3, see the comparison in Figure 2. Processes such as these (similar to what Boulez has described as tiling in the Rite of Spring) ${ }^{28}$ return at every iteration (the green blocks in Fig. 1). This shows juxtaposition, used horizontally, to construct a section, using a collection of limited/fixed and related materials which retain their characteristic identity. This shows that horizontal juxtaposition is at work, on the micro-level as well as the macro-level, but contrasts with the latter as the macro-level juxtaposition is one in which contrasts are exaggerated.

\footnotetext{
${ }^{27}$ Somfai, "Symphonies of Wind Instruments (1920). Observations on Stravinsky's Organic Construction."

${ }_{28}$ Pierre Boulez, Stocktakings from an Apprenticeship, ed. Paule Thevenin, trans. Stephen Walsh (Oxford: Clarendon Press, 1966).
} 
$(x)$

(y)

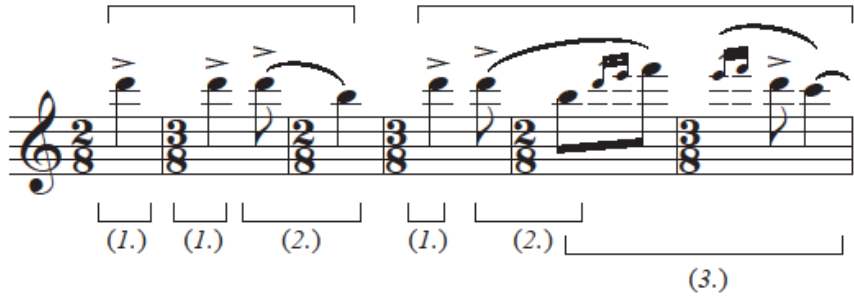

(x)

(y)

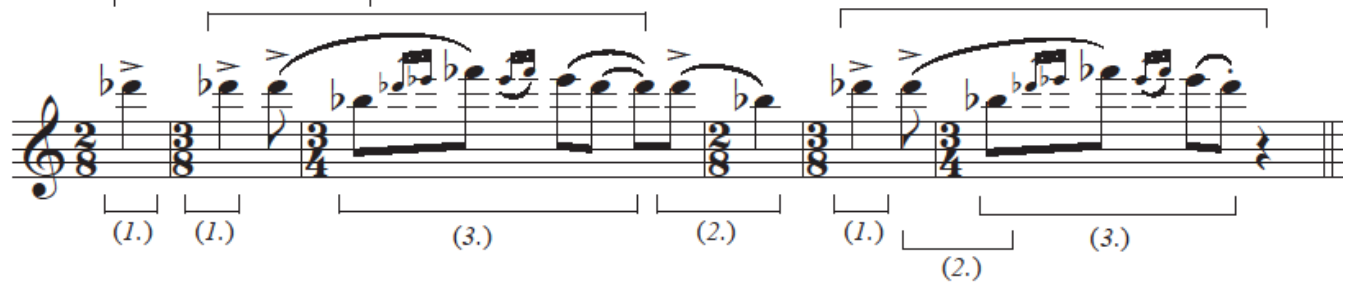

Figure 2

1) Reduction from score

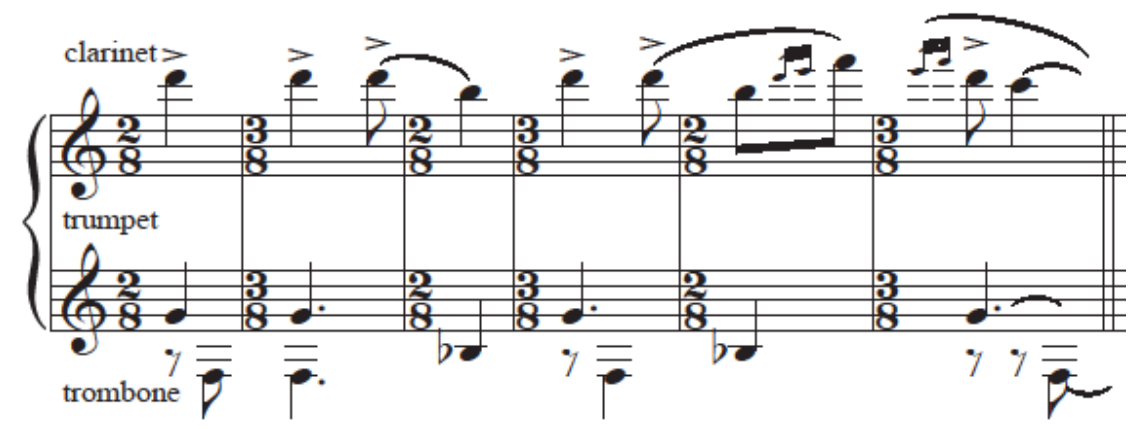

2) van den Toorn simplication

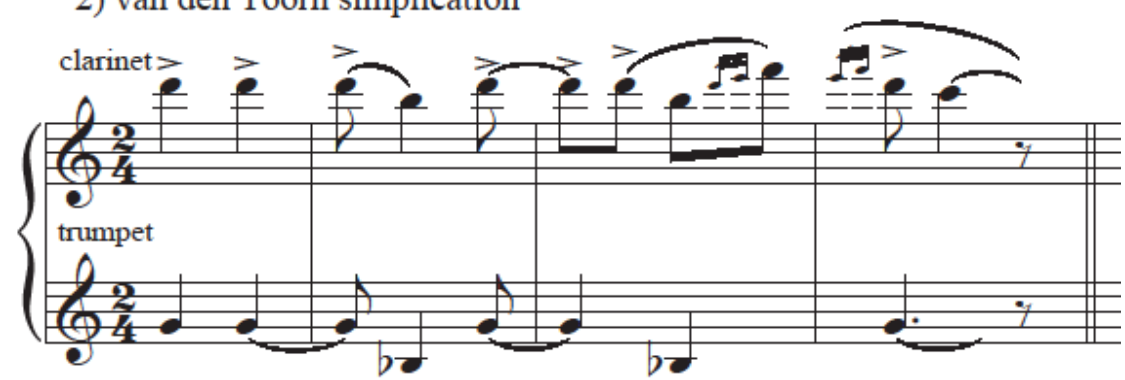

3) My simplification

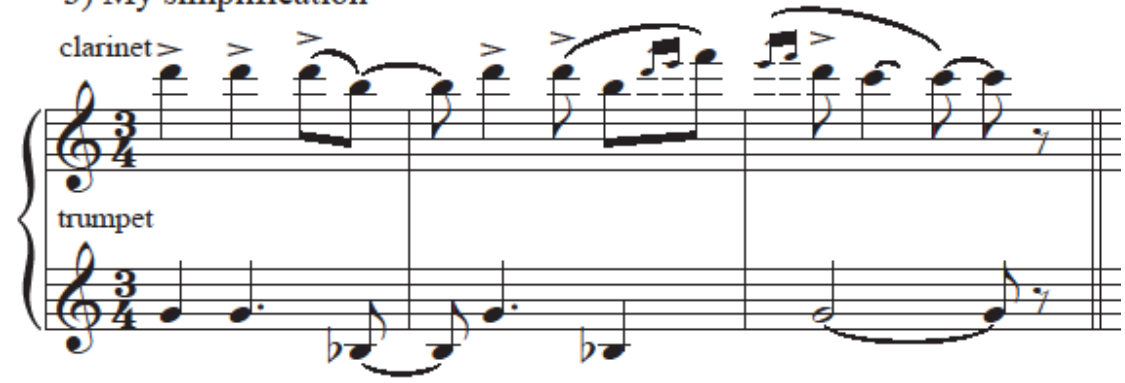

Figure 3 
Returning to the first iteration, I will analyse the rhythmic-metric implications as this has a large impact on how this motif is separated from the underlying layer at [15]. van den Toorn says the 'bell' motif falls into what he calls the first rhythmic type (of two in the music of Stravinsky generally) which he describes as:

"a changing (often rapidly changing) meter in which the fragments, lines, or parts fixed registrally and instrumentally in repetition, share the same irregular rhythmic-metric periods as defined by the changing meter, and are hence synchronised unvaryingly in vertical (or 'harmonic') coincidence. (In reality, this is often a kind of rapid block development, with all the reiterating fragments proceeding en masse, and with the blocks of relatively short duration)" ${ }^{29}$

van den Toorn analyses the activity of the first few blocks, starting with the 'bell' motif and continuing past the chorale chord, as falling into periods of two (including throughout successive blocks), implying the rhythmic-metric identity of the motif is perceptually heard in 2/4, whilst the brass punctuations (which follow the written metre, in alternations of 2/8 and 3/8) are heard as syncopations against the clarinet. This method of understanding the perceived metrical implications divorced from the page is a useful method, but taking this approach, I conclude an alternative reading which is that this motif is heard in $3 / 4$. You can compare my analysis with van den Toorn in Fig. 3.

The reasoning behind my grouping into three bars, is that the third accent on the quaver leading to the slurred downward leap, signals the conclusion of a phrase, rather than the start of a new bar. ${ }^{30}$ Secondly the second unit of the phrase begins on the B, and under $3 / 4$ falls on a downbeat. Thirdly, the phrase ends on the final note at the beginning of the third phrase with the D acting as an appoggiatura. But the predominant reason is that it helps us understand the structural implication that makes itself apparent at [15], which will be examined below. In fact, the section from [11] to [37] is immediately preceded by a varied recurrence of the bell motif.

\footnotetext{
${ }^{29}$ van den Toorn, The Music of Igor Stravinsky. 138

${ }^{30} \mathrm{Although}$ it is common for phrases to cross bars in classical music, the purpose of this exercise is to emphasise how the phrase is heard.
} 


\section{Superimposition creating a composite texture}

The first two bars of [15] start off as a free-flowing counterpoint between the $1^{\text {st }}$ flute and the $2^{\text {nd }}$ clarinet (this timbre recalls the earlier section at [6] in which the $1^{\text {st }}$ flute plays in counterpoint with the $2^{\text {nd }}$ and $3^{\text {rd }}$ flute). This counterpoint begins in $3 / 4$ and the entry of the $1^{\text {st }}$ clarinet is of particular interest, as although in the second bar after [15], all the $1^{\text {st }}$ clarinet does is imitate the flute motif that launched the counterpoint an octave above, its presence asserts itself as an intrusion into the 'pastoral' section, for the following reasons:

- the instrumental colour (the clarinet in its high register) is strongly associated with the opening 'bell' motif because of its strident appearance in the opening of the piece

- the gestural qualities: the use of grace notes, again, strongly associated with the second phrase of the opening 'bell' motif

- The general downward contour of quaver minor thirds and major seconds

- the metric-rhythmic type following 3/4 emphasis explained above

$(x)$

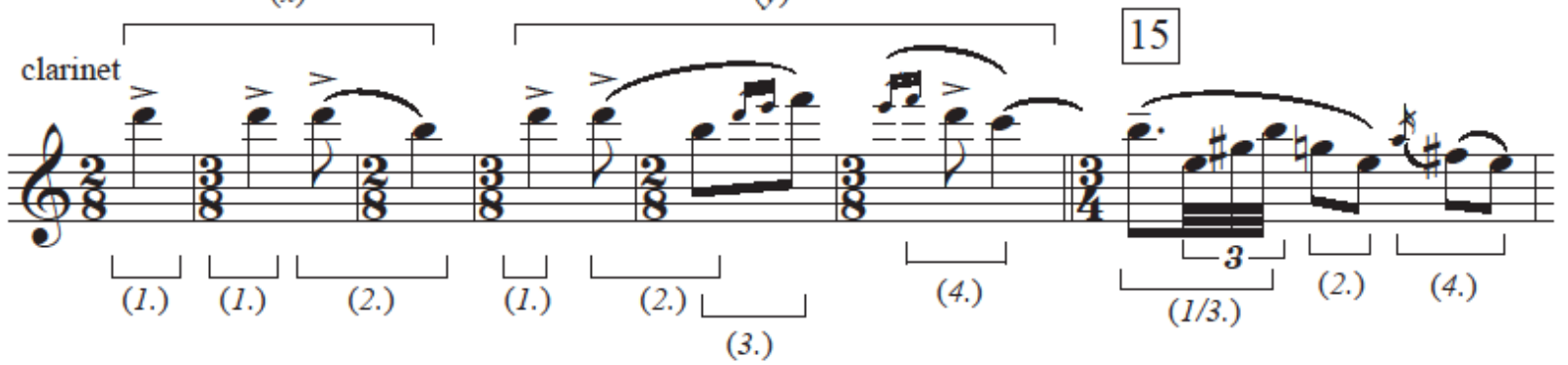

Figure 4

In Figure 4 we can see how the material from the 'bell' motif has resurfaced, despite the addition of new material that it is juxtaposed with. This new material can be seen to be gesturally related however, to the accented crotchet and the grace note figure, and although the overall pitch collection is different because of this, you can see the overall components and interval contour relate to the original appearance, as well as the $3 / 4$ emphasis which is evident in the construction and the metre. This is a clear instance of the influence of two previously unique and horizontally separated sections, being superimposed simultaneously, yet despite this simultaneous occurrence, each layer has retained its strong perceptual 
identity. This creates a paradox in that both layers simultaneously relate to each other (imitation and pitch content being the major contributors to this) whilst simultaneously being separated because of the influence of previously heard material. This separation is based on: two separate rhythmic-metric layers, that of the $1^{\text {st }}$ clarinet having little to do with the continuing counterpoint, which in some ways lies outside of any metrical considerations, and is based more upon a single unit of pulse (the quaver). ${ }^{31}$ Added to this is the contrast of the instrumental colours:

- the $1^{\text {st }}$ flute playing mezzo forte within its middle register

- the second clarinet playing piano within its low to mid register

- and the $1^{\text {st }}$ clarinet playing fairly high, at mezzo forte

The low dynamic of the 2nd clarinet and the flute (the flute playing mezzo forte instead of piano like the clarinet for balance) blend and create a soft layer, whilst the 1st clarinet colour strongly contrasts with this, still retaining its stringency despite only playing mezzo forte. Thus, rhythm and instrumental colour have cued the most distinctive audible connection to previous sections and created the most separation when they appear together. The motif interrupts a total of two other times: at [18] the second phrase being slightly varied, and at [22] which is exact, but never again appears in its full phrase in the other two instruments (although fragments of it appear) throughout their counterpoint, despite the flute instigating it to begin; this further reinforces their separation. This layering of highly contrasting material becomes more of a feature in Donatoni's Tema, and my own Hot Coals, which will be discussed in the following chapters.

There is one other superimposed motif across this section, (the oboes and cor anglais playing in compound metres), which appear alternately with the high clarinet (represented by the yellow in Fig. 1). Again, thanks to timbre, pitch and rhythmic-metric implications, it is perceived as different to the other two layers. This will be discussed further in the next subchapter on timbral transformation.

${ }^{31}$ This will also emerge as an important factor in the music of Donatoni 
A final remark on the 'bell' motif: despite the differing pitch collections, the emphasis of the $\mathrm{B}$ in the $1^{\text {st }}$ clarinet foreshadows the next transposition of 'bell' motif around [27], which also emphasises the B. This is particularly interesting in relation to Horlacher's Building Blocks in which the author argues for a concept of 'ordered succession'. ${ }^{32}$ This means that the order and repetition of juxtapositions become an important indicator at creating an audience's perception of form, showcasing elements that create tension, and predict closure, rather than each block or section presenting a static unmoving quality which abounds through the literature on Stravinsky. ${ }^{33}$

Taking the above example, we have one texture (the counterpoint of the flute and clarinet) above which two contrasting elements are superimposed in alternation. Taking the clarinet interruption examined above, there are three appearances, the first and the last identical, the middle appearance not quite so. I believe this to be a good example of Horlacher's 'ordered succession'. We have a statement, and a recapitulation, with the recap announcing it's the end of the section due to its literal repetition. Both the first [15] and last [22] end with a descending major second, as it does in the conclusion of the original 'bell' motif. The second time of the repeat [18], the contour ends in an ascending major second, which leaves us waiting for a resolution, of which happens at [22]. We then move into a transition to a more literal copy of the original bell motif (back into the realm of horizontal juxtaposition).

\section{Timbral Association and Transformation}

Timbral association plays an important role in the Symphonies as was evident with the 'bell' motif. Many sections of the Symphonies bear resemblance to each other through the instrumental colours and groupings alone, regardless of whether other musical material is shared or not. Often instrumental colours undergo slight changes upon each return, yet because of stratification and interlock, these changes are not always easily perceived, and allow our musical memory to associate and connect material, whilst also avoiding a true sense of recapitulation and allowing the piece to grow and move in new directions. These timbral changes are more obvious when juxtaposed right next to each other, as is the case just past [13]. This shift occurs within the period between [11] and [15], and is principally

\footnotetext{
${ }^{32}$ Horlacher, Building Blocks: Repetition and Continuity in the Music of Igor Stravinsky, 55.

${ }^{33}$ See Kramer and Straus in particular
} 
signalled by the change in timbre (from trumpets to double reeds), yet it is not as abrupt and disjointed as many of the other formal blocks within the piece, as it displays an exact repetition of the pitch and rhythmic material.

From [11] to Just before [14], the main material is the trumpet motifs shown in Figure 5. The trumpets play homophonically, outlining compound rhythmic material (appearing in 9/8 and 6/8). The trumpets and the double reeds have similar timbral qualities, obviously

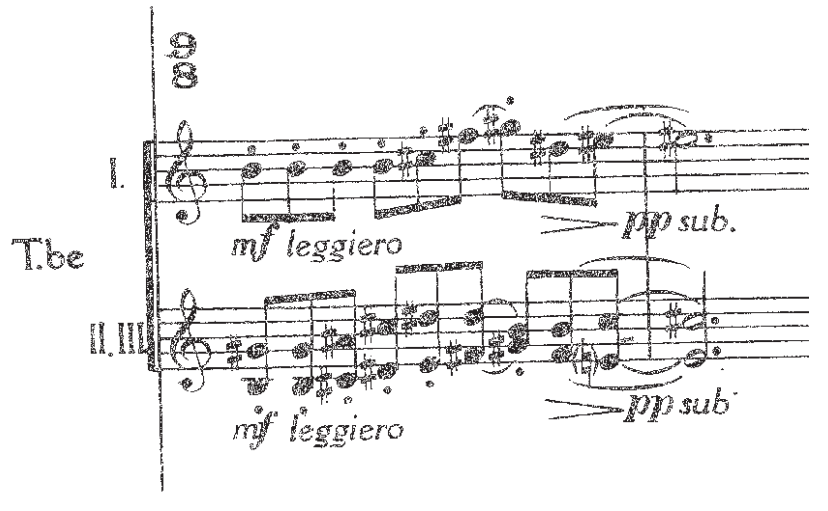

Figure 5 different, but not as strikingly different as the difference between the 'bell' motif and the chorale chord at [1]. This difference is minimised further as the material is an exact repetition of the motif, as opposed to wildly contrasting material. One bar after [13] shows us that the pitch and rhythmic material has been juxtaposed onto a new timbre, but unlike the trumpets, which are always within a compound metre, the material starts to be juxtaposed with smaller rhythmic units from the bassoon melody at [8], which are taken from simple duple time. This creates a juxtaposition between the compound and simple rhythmic material (juxtaposed horizontally) which has been guided by timbral association. This is because the addition of the bassoon in the tenor clef register (first heard at [8]) and our association of the rhythmic material to the colour of the bassoon in that register, allows the material to resurface and alternate with the oboe material.

After the bassoon, we lead straight into [15] with flute playing the counterpoint described above. This inverses the relationship at [8] where the bassoon follows the flute, and shows the juxtaposition is follows a timbral relationship. These compound rhythmic units and their associated pitch material, (in the trumpets and oboes), consist of the second layer that superimposes itself upon the clarinet/flute counterpoint at [15], alternating with the 'bell' motif. The musical materials of the timbre, pitch (contour and collection) and compound metre emphasis, help separate it from the contrapuntal layer and the 'bell' motif. 


\section{Chapter Conclusions}

This bringing together of previously stratified ideas through superimposition, whilst constantly shuffling elements of rhythm, pitch, and timbre, to continually create ever more musical invention, starts to approach a continuous process of 'synthesis'. It is common to view the end chorale as the synthesis of the material - the point of presentation in the composition of which all ideas are derived - "but the process is by no means confined to the end of a movement; sometimes it is at work from the beginning" ${ }^{\prime 4}$ as the processes discussed above allude to, in which the recombination of elements from contrasting components represent an ongoing synthesising of elements, guided by timbral recognisability. Although this block of activity is a small part of the Symphonies, and perhaps the most complex in terms of its layering, this approach tends to permeate the whole of Donatoni's Tema which will be discussed in the following chapter.

${ }^{34}$ Cone, "The Progress of a Method," 158. 


\section{Introduction to Donatoni and Tema}

Donatoni's Tema, of 1981, is a work that takes the principles discussed in the preceding chapter on Stravinsky's Symphonies of Wind Instruments, (stratification-interlock-synthesis) and extends them to allow a more fluid and multi-layered structure, through the incorporation of constant superimpositions, and the juxtaposition of parameters including extended timbral development. Translating to 'theme', the piece plays on the idea of a theme and variations, but unlike a standard theme and variations, where a line-up of variants are presented, they are presented over each other, against each other, and recombined to form new sets of relationships with each other (like we saw in the Symphonies). This idea of using juxtaposition to enhance a sense of formal growth starts to approach where my composing practice begins.

\section{Biographic Notes}

Franco Donatoni (1927-2000) was a post-war avant-garde composer, who, before his most idiosyncratic late period (the second or 'joyous' period, starting c.1978), ${ }^{35}$ had experimented with many of the trends of the era, such as serialism, aleatoricism, and automatism. ${ }^{36}$ Many of the works of the preceding period, foreshadow the more juxtapositional language to follow, displaying the use of 'panels' ${ }^{37}$ block like formal structures, and the homophonic use of orchestral groupings. This is evident in Halbreich's analysis of the 1974 piece: Duo pour Bruno in which 10 panels are constructed of 13 bars on either side of a 'battuta-cerniera centrale' [central hinge-bar], and at each return this central bar becomes more disruptive and destructive, ${ }^{38}$ showing how Donatoni uses juxtaposition to create direction and growth, even before the late period. However, in general this earlier period is defined as formalistic, with the blocks being filled with automatic processes, or being determined by aleatoric events, Halbreich noting that Donatoni felt that "The intervallic content loses its melodic/harmonic

\footnotetext{
35 Salvatore Colazzo, "Dal nulla il molteplice. I lavori solistici con le loro proliferazioni," in Donatoni (Torino: EDT, 1990), 110-29.

${ }^{36}$ David Osmond-Smith, "Donatoni, Franco," Grove Music Online, Oxford Music Online (Oxford University Press), accessed May 29, 2017, $<$ http://www.oxfordmusiconline.com/subscriber/article/grove/music/07992>. ${ }^{37}$ Harry Halbreich, "Tre capolavori orchestrali di Franco Donatoni. 'Voci'-'Duo pour Bruno'-'Arie', "' in Donatoni (Torino: EDT, 1990), 194-214.

38 Ibid. 205
} 
features, its substance, it's devitalised".${ }^{39} \&^{40}$ It was this element that made Donatoni change his practice, to create form from the recognisability and inner character of the content, summed up nicely by Colazzo on the 1979 piece About:

\begin{abstract}
"This piece [About] manipulates, as usual, material already used previously, but manifests an intention to recognise the different characteristics of the instruments employed, so guitar chords are grafted onto the long-held bows of the violin and the viola; the automatisms must become sounding games that are able to be perceived, whilst retaining an evident plasticity; or also when different automatisms interweave in simultaneous processes, the perceptible polyphony is not lost." ${ }^{41} \mathcal{E}^{42}$
\end{abstract}

As this quote implies, many features of serial and process based systems remain, but with an increased focus on using these to enhance the gesture, timbre and other perceptible qualities. This naturally lends itself to juxtaposition, because as the material retains its character when material is juxtaposed or superimposed, it allows relationships to build in listeners minds between the contrasting identities. 1981s Tema is a prime example of the music of this period (to be discussed further on).

\title{
'Preserving the Fragment'- Bradley D. Decker's discussion and Terminology regarding Donatoni's late music
}

In 'Prezenza di Bartók', ${ }^{43}$ Donatoni describes four main concepts that he examines in the Fourth String Quartet of Bela Bartók, these are:

1. Exposition of the cell and growth of the organism

\footnotetext{
${ }^{39}$ Halbreich, “Tre capolavori orchestrali di Franco Donatoni. 'Voci'-'Duo pour Bruno'-'Arie'," 196. 40 "... Donatoni parle di intervalli devitalizati, come un nervo devitalizzato dal dentista quando il dente fa troppo male."

${ }^{41}$ Colazzo, “Dal nulla il molteplice. I lavori solistici con le loro proliferazioni," 121.

42 "Esso manipola, come al solito, materali già precedentemente usati, ma manifesta una intenzione di tener conto delle differenti caratteristiche degli strumenti impiegati, sicché su accordi della chittara si innestano le lunghe arcate del violino e della viola: gli automatisimi debbono diventare abili giochi fonici ed effeti di plastica evidenza; oppure quando differenti automatisimi si intrecciano in processi simultanei non si perdela percettbilità polifonica."

${ }^{43}$ Franco Donatoni, “Presenza di Bartok," Il sigaro di Armando, 1982, 87-91.
} 
2. Growth and not development: conservation of the fragment

3. Juxtaposition of the organisms: mutation, not evolution

4. Stasis of the pulse, continuous tempo, "nocturnal" conditions, sound (or noise), whisper, vibration as if timbral mobility in an immobile space. ${ }^{44}$

Donatoni's writing style is difficult to interpret, often leaning towards the philosophical, and realising concrete manifestations of these ideas within the music is difficult. Even so, one can see how terms like growth (purposefully contrasted with development), mutation, and juxtaposition, demonstrate Donatoni's own awareness and intent towards a juxtapositional language. This is where Bradley D. Decker's 'Preserving the Fragment', ${ }^{5}$ becomes a very enlightening article, which clearly explains how these principals can be applied to Donatoni's late chamber music.

He identifies two main concepts, which will be explained below, and will aid with the analysis of Tema. Although the article discusses these techniques, which Decker terms 'codes'46 in relation to the music of Bela Bartók, he also notes the similarity of Cone's stratification to these 'codes', although only with a brief footnote. ${ }^{47}$ Interestingly, Osmond Smith claims that upon Donatoni's first encounters with modern music, he was not 'engaged' 48 by Stravinsky or Schoenberg, but was taken by the fourth quartet of Bartók (as mentioned above). It can be strongly argued, of course, that Bartók was himself heavily influenced by Stravinsky.

The first concept Decker outlines are 'panels'. Panels, a term used by Donatoni himself and other commentators, are smaller fragments taken from longer stretches of music, which are then taken out of their original context and shuffled with other panels from other contexts. ${ }^{49}$ This is not dissimilar to certain procedures in traditional western art music, such as in a

\footnotetext{
${ }^{44}$ Ibid., 89.

${ }^{45}$ Bradley D. Decker, "Preserving the Fragment: Franco Donatoni's Late Chamber Music," Perspectives of New Music 46, no. 2 (2008): 158-89.

${ }^{46}$ Ibid., 160.

47 Ibid., 186.

48 Osmond-Smith, "Donatoni, Franco."

${ }^{49}$ This is a different use of the term 'panel' than that of Halbreich mentioned earlier, with his use applying to larger sections
} 
sonata, in which an exposition is stated fully formed, and the development takes smaller motivic fragments from the exposition and plays with them in new configurations, e.g. motivic units from the primary subject meeting those from the secondary subject. However, unlike the sonata, they appear exact and unmodified. Decker discusses two contrasting panels in the work Rima, labelled X and Y, noting: “These two panels are not only linearly juxtaposed. Donatoni obliges these two panels to vertically interact to create a composite texture".$^{50}$ This follows nicely from the example shown in the Symphonies of Wind Instruments with the clarinet bell motif, being superimposed upon other contrasting textures discussed in the preceding chapter. However, although Stravinsky shows glimpses of this technique, with most of the Symphonies showcasing a more linear approach to juxtaposition, Donatoni takes this principle of superimposition much further as a predominant structural feature of the work. It is important to note panels can be taken from a single instrument, or from a group of instruments working homophonically. This trait of instrumental families, or distinct colour combinations working in parallel, is one of the defining characteristics of Donatoni's late music in particular, and noted by many commentators including Halbreich, ${ }^{51}$ Colazzo, ${ }^{52}$ and Boulez. ${ }^{33}$

This concept of panels can be applied to a motif in its entirety, or isolated into composite parameters, e.g., Decker describes pitch panels ${ }^{54}$ in which frozen-register pitch collections add stability among motivic material of differing timbral and rhythmic character. Contrastingly: "an interval panel code builds gestures using unordered pitch intervals that, when summed, create a constant" ${ }^{55}$ Like Stravinsky, a gamut of approaches to creating character and identifiability are used to heighten contrast, setting the conditions for juxtaposition to be perceived. Stravinsky uses these two ideas, with the fixed voicing of the chord that appears at [1] being used to create one referential sonority, whilst the linear use of octatonic scales, with no sense of fixed vertical chord tones (as appears in the flute/clarinet counterpoint at [15]), offer another referential sonority. Unlike Stravinsky however, this procedure

\footnotetext{
${ }^{50}$ Decker, “Preserving the Fragment: Franco Donatoni's Late Chamber Music," 164.

${ }^{51}$ Halbreich, "Tre capolavori orchestrali di Franco Donatoni. 'Voci'-'Duo pour Bruno'-'Arie'," 199.

${ }^{52}$ Colazzo, "Dal nulla il molteplice. I lavori solistici con le loro proliferazioni," 121.

${ }^{53}$ Pierre Boulez, "Franco Donatoni: Tema," in Franco Donatoni. Gravità Senza Peso., ed. Candida Felici (Lucca: LIM, 2015), 291.

${ }^{54}$ Decker, "Preserving the Fragment: Franco Donatoni's Late Chamber Music," 169.

${ }^{55}$ Ibid., 170.
} 
demonstrates that the pitch content can be divorced from its original motivic whole, and juxtaposed and combined with the rhythm of another panel, showing all parameters may be divorced and recombined in this way. However, in these cases, audible traces of the original are still present.

The second major concept is that of Filters. ${ }^{56}$ Filtering is created by the addition and subtraction of material into an already familiar entity, Decker noting: "Filter codes achieve 'growth without development' by gradually evolving a figure, gesture, melody or harmonic texture, while preserving its identity, through a process, of rebuilding, or reducing of musical entities" ${ }^{57}$ Additive filtering could be vaguely compared to a decoration of a skeleton melody, with the original melody on reappearance being further decorated by an addition of pitch material and/or an increase of rhythmic density, although the structural rhythm and tones are still found within. Although in this case, the gestural, timbral and rhythmic character is generally left unchanged. Subtractive filtering works in the opposite manner. This process may be literal or skewed, ${ }^{58}$ in that it may appear exact, with more material filling in space, or may be slightly displaced, but without losing its perceptual relationship to its earlier outing. Again, this can be applied to the gesture or motive as a whole, or apply only to aspects of it, such as an addition to the original pitch collection or more rhythmic activity around a structural rhythm etc.

The term panel, used by many commentators because of Donatoni's use, has tended to be used to mean different things by different authors. Because of this I will refer to the large structural sections, as 'blocks', and use 'panel' in the way described above, to refer to smaller motivic units from within those blocks. When the component parts of an identifiable block are distinct as separate layers (through superimposition), I will refer to them as layers.

\footnotetext{
56 Ibid., 173.

57 Ibid.

58 Ibid., 177.
} 


\section{Donatoni: Tema - Analysis}

Franco Donatoni's Tema displays concepts of juxtaposition, at both the formal (macro) and motivic/cellular (micro) level. The piece is a series of discrete formal blocks lasting roughly between 12 and 22 bars each, which contain highly individualised textures. These textures are identified primarily through the use of timbre, and their unique combination of motivic material, being highly uniform and consistent within itself, and contrasting heavily to its former and latter neighbours. Below is a formal graph of the piece, showing each of these unique blocks. However, each block can be shown to be made up of even smaller units and layers, which are highly identifiable to a listener, Bradley D. Decker noting: “internal characteristics of a gesture may change over time, but the gesture's identity remains consistent" ${ }^{\prime \prime}$ These smaller fragments cross the boundaries of the formal blocks, and it is new combinations of pre-existing (previously heard) material, which create these unique identifiable blocks, or in Decker's words "The different strands interact through changing juxtapositions, thus creating new musical contexts as they combine in the panels". ${ }^{60}$ In this sense, I believe that the piece (and Donatoni's late music generally) builds upon Cone's ideas of stratification-interlock-synthesis in a much more nuanced and kaleidoscopic manner, in which combinations are superimposed and contrasted with each other in much closer proximity, with the work being in constant renewal as these three processes play themselves out both continuously and simultaneously.

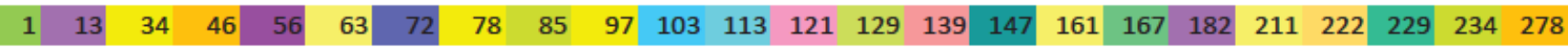

Figure 6

\section{Analysis Outline}

Tema, of 1981 is scored for flute, oboe, clarinet, bassoon, 2 horns, 3 violins, 2 violas and cello, and as mentioned falls into Donatoni's late or 'joyous' period. Many of Tema's main textural blocks are defined by groups of instrumental families working together, often hocketing short, staccato semiquaver rhythms against opposing instrumental groupings, around a shared semiquaver pulse, or as Boulez puts it: “At times there are perfectly recognisable,

\footnotetext{
59 Ibid., 160.

60 Ibid., 161.
} 
homogeneous chunks that use instrumental families in isolation or working against one other". ${ }^{61}$ The rhythms are for the most part related to equal divisions, and do not include irregular rhythms (tuplets). These instrumental groups may also be subdivided into smaller subsections of instrumental families, and blended with similar subsections from other families with similar timbre, e.g. viola I playing semiquaver tremolo patterns sul tasto, viola II playing sul tasto long-held trill notes, and the cello playing pizzicato, each blended with an aspect of the woodwind instruments (see bar 72 of Tema). I would like to focus my analysis on an interesting layer, which is defined by the two horns, not working homophonically, but working polyphonically against each other, yet, still retaining the sense of a single layer (on the basis of timbre) around which other instrumental groups are organised.

I will examine the internal pitch, rhythm and timbre of the layer, and how the layer combines into the overall texture over three occurrences, each in a separate block. The first between bb. 13-33, the second between bb. 103-112 and the third between bb.183-210. In the formal diagram above (not proportional) is laid out the clearly delineated blocks of activity, the colours correspond to material that is almost exact or related, with different shades representing combinations of material. We can see where the horn layers lie. One can also see at bar 56 and 72 there is similar material, which will also be touched on, but firstly focus will directed onto the three blocks mentioned above.

First some general observations: The horn parts provide a sustained layer, holding long notes with grace note and semiquaver flourishes in-between changing notes. They work independently rhythmically, often canonically/imitatively and in contrary motion. This is an anomaly in the rest of the work in which the horns, (and most other instrumental groupings) are often playing in rhythmic unison. This relationship also tends to go through a process of timbral transformation, both within the horns, and also by transferring timbral qualities to other instrumental groupings throughout the work.

Secondly, I will examine how the return and recombination of layers from different blocks, result in a perpetual synthesis. ${ }^{62}$ This synthesis perhaps differs from Cone's original

\footnotetext{
${ }^{61}$ Boulez, "Franco Donatoni: Tema," 291.

${ }^{62}$ See Previous Chapter on Stravinsky
} 
conception in that it is achieved through further fragmentation, until the largest number of the textures and panels start to interact within one block (b. 273). This is the least economical. It achieves its unity and synthesis through the concentration of the material meeting each other, even though the fragments remain identifiable. This has more in common with what happens in my piece Hot Coals examined in the next chapter.

\section{Pitch}

To begin with we will examine the pitch of the first and last instances of the horn texture (bb. 13-33; 183-210) leaving bb. 103-112 until later. This is as the first and last instances were originally chosen by ear and are aurally identifiable because they exist within a similar texture in which the horn layer is extremely clear and separated from its surrounding activity. In contrast, the middle occurrence is subsumed into a larger texture, and only through analysis did the relationships become apparent (more on this later). To recap, the horn texture consists of the horns playing contrapuntally. Because there are two horns, two pitch classes are always being sustained simultaneously, often for large stretches of time. This means that the pitch becomes an important aspect of its character, especially as the surrounding content is more focused on fleeting gestures and rhythms. In both instances, interval class 2 is the predominant simultaneous interval, and whilst other intervals appear (with no obvious pattern), none feature to the same extent that interval class 2 does. The table below maps the interval classes sounding between the two horns in bars 13-16 (note neighbouring notes of the same pitch within the grid are tied), and as is evident, the reoccurrence of interval class 2 is the most predominant reoccurring interval.

\begin{tabular}{|l|l|l|l|l|l|l|l|l|l|l|l|l|l|l|}
\hline $\mathrm{H} 1$ & $\mathrm{C} \#$ & $\mathrm{~Eb}$ & $\mathrm{~Eb}$ & $\mathrm{Ab}$ & $\mathrm{G}$ & $\mathrm{G}$ & $\mathrm{C \#}$ & $\mathrm{C \#}$ & $\mathrm{D}$ & $\mathrm{D}$ & $\mathrm{Ab}$ & $\mathrm{Ab}$ & $\mathrm{Bb}$ & $\mathrm{Bb}$ \\
\hline $\mathrm{IC}$ & 2 & 4 & 2 & 3 & 2 & 3 & 2 & 1 & 2 & 6 & 1 & 3 & 1 & 2 \\
\hline $\mathrm{H} 2$ & $\mathrm{~B}$ & $\mathrm{~B}$ & $\mathrm{~F}$ & $\mathrm{~F}$ & $\mathrm{~F}$ & $\mathrm{~Eb}$ & $\mathrm{~Eb}$ & $\mathrm{C}$ & $\mathrm{C}$ & $\mathrm{A}$ & $\mathrm{A}$ & $\mathrm{B}$ & $\mathrm{B}$ & $\mathrm{C}$ \\
\hline
\end{tabular}

Comparing to the beginning of b. 183-186 (below) we see again that the most reoccurring interval class is 2 .

\begin{tabular}{|l|l|l|l|l|l|l|l|l|l|l|l|l|l|l|}
\hline $\mathrm{H} 1$ & $\mathrm{G}$ & $\mathrm{Eb}$ & $\mathrm{Eb}$ & $\mathrm{A}$ & $\mathrm{A}$ & $\mathrm{D}$ & $\mathrm{D}$ & $\mathrm{G}$ & $\mathrm{G}$ & $\mathrm{C \#}$ & $\mathrm{C \#}$ & $\mathrm{Bb}$ & $\mathrm{Bb}$ & $\mathrm{G}$ \\
\hline $\mathrm{IC}$ & 1 & 5 & 2 & 4 & 2 & 4 & 2 & 3 & 2 & 6 & 5 & 2 & 7 & 2 \\
\hline $\mathrm{H} 2$ & $\mathrm{Ab}$ & $\mathrm{Ab}$ & $\mathrm{Db}$ & $\mathrm{Db}$ & $\mathrm{Bb}$ & $\mathrm{Bb}$ & $\mathrm{E}$ & $\mathrm{E}$ & $\mathrm{F}$ & $\mathrm{F}$ & $\mathrm{Ab}$ & $\mathrm{Ab}$ & $\mathrm{F}$ & $\mathrm{F}$ \\
\hline
\end{tabular}


What we are seeing is not a literal repeat, but because of the same instruments, interacting in the same way as before, and because the pitch consists a sort of cycle that constantly emphasises interval class 2, it exemplifies a unique identity and pattern, but that pattern allows for a constant sense of change and possibilities, like the recombination of the 'bell' motif in Stravinsky. Because of stratification, the changed features of these two instances (appearing at opposite ends of the work) are minimised, in the sense that a listener has had a large chunk of the piece to process in the middle of these two appearances, meaning all that is retained is a memory of what the initial relationship was. This means, what is primarily heard is the similarity and not the changes, which are nonetheless important for playing with your memory and its expectations.

This can be interpreted as a version of Decker's filtering, as it shows a reoccurring feature (interval class 2), on which adjoining features (additional interval classes) are added, subtracted or follow some kind of process of filtration.

\section{Rhythm}

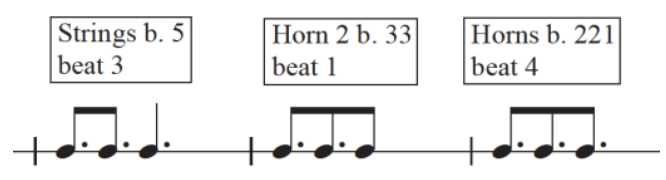

Figure 7
There are a handful of key reoccurring rhythms that appear across many sections in Tema, including in the horn sections examined above. These are first introduced in the beginning block bars 1-12, in which the strings play homophonically with no surrounding material, which directly precedes the first sustained horn block. Shown above is an example of one of these rhythms that appears in the second horn part at bar 33. (fig. 7) from the second dotted quaver. This exact rhythm can be seen to originate in the strings (working in rhythmic unison) at the third beat of bar 5 , and I have shown another occurrence in the second appearance of the final appearance of the horn texture. Almost all the rhythms throughout the piece can be seen as juxtapositions of three units: the semiquaver, quaver, and dotted quaver (or a relationship of two and three), similar to the way the units of the 'bell' motif shuffled to create variations. These key rhythms that reappear, can be considered a panel, and I have purposefully shown the rhythm outside of the context of its beat placement in the bar, as examples of this rhythm appear in different placements across beats/bars, starting anywhere within a semiquaver 
pulse. In these examples, what we see is each individual instrument, or groups of instruments working together, articulating the rhythms using these units.

However, one aspect apparent in the in the horn textures, as a result of

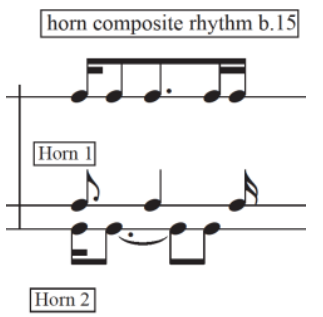
them playing contrapuntally, is that these key rhythms or panels, are articulated between them as a grouping, by changes of pitch rather than of articulation. This is shown in bar 115 (Fig. 8), where we see how the two rhythms of horn one and two add up towards a composite rhythm,

Figure 8 which bears more resemblance to the rhythmic panels throughout the rest of the piece, which is pointed out by Michel..$^{63}$ This rhythmic activity is also articulated by one of the surrounding layers of flute/clarinet, although it retains its separation as an independent layer based on timbre (discussed below).

\section{Timbre}

The Timbre and texture go through multiple processes of change, without disturbing the initial identity (except in one important instance described below). If we compare the sustained horn texture at b. 13, to that at b. 183, you'll notice that the horns in the second instance play con sord. Even so, because the horns are singled out and conceived as a single layer, playing in the same manner as at 13 , we connect them as a similar timbre, because we still associate the sound made, to the same instrument. But this is a modified sound, even if it is slight, and as mentioned before these details are perhaps obfuscated by the stratification, but help the form by making changes for the sake of freshness and invention.

So how did we arrive at this timbral transformation? Was it simply because of the stratification and the large temporal distance between the two blocks, or was there something that approached this change? I believe part of the answer is the result of the block at b. 103. At bar 103 the horns are playing independently from each other, like at b. 13 and b. 183, but unlike the other two instances where the horns are perceived as their own layer, at b. 103 they are subsumed into a full ensemble texture, in which no grouping displays

\footnotetext{
${ }^{63}$ Pierre Michel, "Franco Donatoni: Tema (1981) Pour Douze Instruments," in Franco Donatoni. Gravità Senza Peso., ed. Candida Felici (Lucca: LIM, 2015), 281.
} 
identity or independence. Boulez discusses this texture noting: "it's a line deliberately without profile, neutral, staying always in the same register, always extremely soft and that's why each group takes on this unexceptional [anonyme] character". ${ }^{64}$ It is the mixture of all these neutral lines together, that allow the ensemble to blend, and the use of con sord. horns first appears in order to allow them to blend into this homogenous group.

The material is similar, with the two horns imitating each other by the semitone (which results in sounding interval alterations between whole tones and semitones) not dissimilar to the intervallic relationships discussed before, and displaced by a quaver. The rhythm panels found throughout the piece, and between the horns, are stated fully by each instrument, and these panels are spread throughout the entire ensemble, but never synchronously, creating an effect not dissimilar to that of Ligeti's micropolyphony, also noted by Pierre Michel. ${ }^{65}$ This creates a structural marker as it lies roughly $1 / 3$ through the piece (and a halfway point between b. 13 and b. 183), ${ }^{66}$ helped by the fact that the pulse and the instrumental groups have been dissolved as to be imperceptible, contrasting so significantly to the remainder of the piece as to carry extra weight. It is here that the change of timbre has first appeared and carried on to b. 183. There are of course other sections that do not use stopped horns in between, but these bear no importance as the material is so dissimilar that the sections are not related to the three discussed above.

Another timbral connection is the appearance of the clarinet with the bassoon. I have made this connection because like the two horns, the clarinet and bassoon work as a duo; they offer similar timbres, with the clarinet's chalumeau sound close to the open sound of the horn, and the reedy bassoon close to the stopped horn, but the blend particularly has a similar timbral quality. The first instance of this instrumental grouping is at b. 55 , where the horns offer a symbolic passing of the torch, transferring a pairing of a similar timbre, to another, a process observed in the Symphonies. This is achieved by the horns punctuating (with short staccato notes) in unison, the changing notes of the clarinet and bassoon, whilst the latter group sustain their tones. At b. 72 the clarinet/bassoon duo appear without the horns and have assimilated the contrapuntal nature the horns first displayed in $b$. 13. In this

\footnotetext{
${ }^{64}$ Boulez, "Franco Donatoni: Tema," 291.

${ }^{65}$ Michel, “Franco Donatoni: Tema (1981) Pour Douze Instruments,” 276.

${ }^{66}$ See Figure 6
} 
sense, it both replicates what has come before, and hints at what is to follow, aiding the timbral transformation. The pitch content is different, but the strong timbral character remains, a case of one of the elements being divorced, in this case the timbre and pitch, and being recombined, or juxtaposed, with parameters from different sections. Once again, this process happens through stratification and interlock, it is not laid out as a continuous, organic transfer, but one that is separated by interrupting blocks of activities.

\section{Surrounding Textures}

Returning to blocks bb. 13-33 and bb. 183-210, we will examine the surrounding layers. In each of these examples the surrounding layers bear similarity to their previous instance, but have, like the horn layer, gone through some transformations which appear on their return. At b. 13 the flute and clarinet articulate the change of horn notes, but because of the timbre and gesture (short staccato semiquavers decorated with grace notes) appear as a separate layer. This is not unlike the process described in the previous section, in which the horns articulated the clarinet/bassoon long-held tones, showing a gradual evolution in timbre (across blocks), whilst the material maintains its gestural characteristics. In this sense, we see the use of two functions, a short articulation and long-held notes. This abstract relation becomes an identifiable feature, which allows slight changes and variation in timbre without losing its fundamental identity, as the functions remain the same. As stated above, the use of timbral evolution is always sonically connected to the previous instances, so that the timbre still remains familiar even when it has changed.

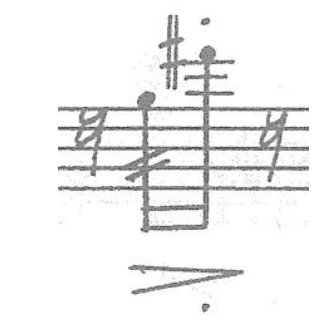

Figure 9

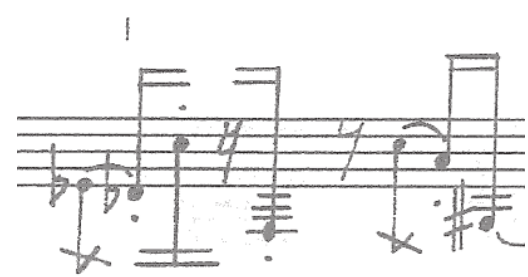

Figure 10

These short woodwind punctuations (fig. 9) are responding in alternation with the strings, playing sul pont. and homophonically, with the gestures consisting of two semiquavers, the first tremolo and the second staccato (fig. 10). There are also occasional long-held crescendo/tremolo strings, remnant panels from the opening section of the piece, always 
played by violin and viola. This string layer represents a separate strand, the third strand identified that has been delineated by timbre: the horns, the winds, and the strings, another nod to the working together of instrumental groupings. Yet connections remain between these layers, such as the change in horn notes being articulated by the winds (a rhythmic connection); and timbral connections such as the short staccato winds, in the lower register, a more hollow timbre, being alternated by the occasional col legno battuto in the strings (another woody, punctuated timbre), but remain independent, rhythmically.

These features undergo a process of growth within the block by addition of material, rather than of development. In a way that all the original material can be taken as segments from the original, with the gesture transforming from a tremolo semiquaver, to a staccato semiquaver, into two tremolo semiquavers towards a staccato semiquaver, with tremolo semiquaver being added to each repeat, and the material becoming more dense and active within a smaller temporal space. This compares to the example of the 'bell motif' in the Stravinsky chapter, which undergoes transformation only by the shuffling of existing material, including repetition through the addition of constitute elements, or subtracting elements, making the old constituent parts meet at different junctions.

Although speculation, this shows a process of composition and is related inversely to the concept of filtering, outlined by Decker above. The material was probably composed and varied first, and then fragments were slowly introduced from it, a reverse filtering, one that is a process of revelation and not a process that demonstrates itself within the piece itself. This allows audiences to find connections and play a mental game, but also gives coherence and unity to a superficially fragmented surface.

The second appearance at b. 183 holds a similar relationship of ideas as the first occurrence discussed above. The main feature is the long notes held by the horns, playing contrapuntally. However, we are missing the original string gesture, and are left with the woodwind punctuations that were originally for flute and clarinet, but have now been expanded into two surrounding layers. In this sense, the two surrounding layers recall the same gestural identity as only one layer previously, but, with slight timbral changes and rhythmic independence (they hocket against each other) they exist separately. However, the 
rhythmic relationship with the changing tones in the horn remains intact, influencing both surrounding strands.

The first layer consists of flute, oboe, and violins. The second layer of clarinet bassoon, violas and cello. All string instruments play pizzicato, this allows them to blend in with the hollow woody timbres of the wind instruments which they double (which mostly occupy the low and mid registers). But it also shows a gradual change in that the timbre crosses instrumental families into new blends, but retaining the timbral essence and gestural identity to previous material. In the latter half of the block (defined as the same block as the horns still continue their identity) the staccato layers disappear and some material from a previous block (that of bb. 147-156) is superimposed over the section.

\section{Chapter Conclusions}

The role of pitch, timbre, rhythm and gesture are combined to create highly differentiated blocks of activity, much like that of Stravinsky. In this piece however, superimposition and the layering of textures have been embraced to be a feature that permeates the entire work, and the combinations of the layers, or the collection of disjunct material in close vicinity, becomes a major feature of the blocks themselves. The recombination and juxtaposition of different parameters has been shown by the use of rhythm panels that are not only articulated homophonically, but have been spread over a contrapuntal texture, which is still defined by its timbral profile. This is similar to the flute/clarinet counterpoint of Stravinsky at [15] in which the counterpoint is perceived as one layer. We can also see that aspects of pitch have become more fluid, and that the recombination of new intervals within familiar ones extends and allows the piece to grow and be in flux. Timbral transformations occur (although always aurally related), allowing a sonically rich timbral counterpoint to occur across the stratified and interlocked blocks.

All of these features were observed in Stravinsky's Symphonies of Wind Instruments although they have been extended to allow a more nuanced and fluctuating sense of form and material, without having to develop the material through a logical progression. The piece still demonstrates the interaction of limited and contrasting materials, often linked by a common pulse on top of which rhythmic, pitch and gestural ideas still retain their autonomy. However, the combinations have become more blurred and abstracted, and can 
be viewed as a sort of continuous synthesis. This concept is taken further in my orchestral Hot Coals which will be explored in the next chapter. 


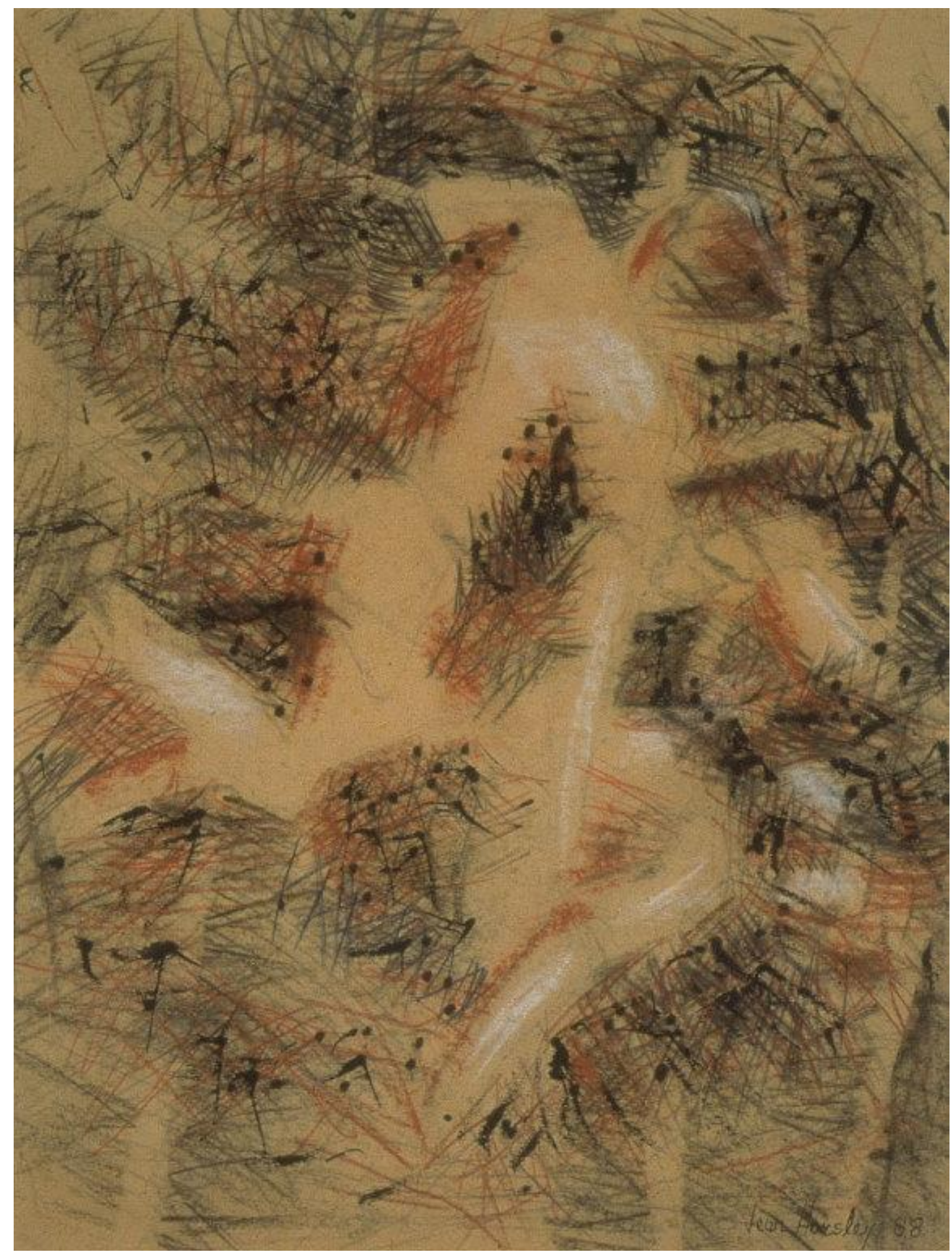

Figure 11 Hot Coals by jean Horsley ${ }^{67}$

67 Jean Horsley, Hot Coals, charcoal, conte crayon, and chalk on paper, 1988, Chartwell Gift Collection, Auckland Art Gallery, https://www.aucklandartgallery.com/explore-art-and-ideas/artwork/12734/hot-coals. 


\section{Hot Coals - Anlaysis}

Hot Coals, the major work of my accompanying portfolio, is a work for orchestra, specifically: flute, alto flute, 2 oboes, clarinet, bass clarinet, 2 bassoons, 4 horns in F, 2 trumpets in $\mathrm{Bb}, 2$ trombones, bass trombone, percussion (most importantly brushed snare drum) 6 violas, 6 cellos, and 4 contrabasses. The work was written for the Auckland Philharmonia Orchestra, with the brief to write a response to a local artwork housed in the Auckland Art Gallery. I chose Jean Horsley's Hot Coals. ${ }^{68}$

In many respects, this artwork offers many similarities with the working methods and structural aesthetics that have been discussed so far in the analyses of Stravinsky and Donatoni, with juxtaposition being a key element of her work. Ensing notes that Horsley "often [worked] on smaller panels which are then put together to make a composite" 69 , and although Hot Coals is not one of these works, it nonetheless shows the structural aesthetic and influence of this mode of thinking, but also with the addition of gestural elements of abstract expressionism.

Firstly, some general comments on Jean Horsley's Hot Coals (fig.11). The first noticeable governing principal is economy: this can be seen in the limited range of colours, consisting only of black, white, and two shades of orange; whilst the style of strokes consists mostly of short, thin, and sharp lines. However, the arrangement of these elements creates something truly visually striking. In fact, one of the key features is one that is created purely by an absence- the geometrical patterns of light orange - perceptible only from the absence of the scratched lines which dominate the painting. These figures can be seen in many different lights, depending on the focus of the viewer (both physical and mental), in fact, my perspective radically changed depending on the distance I stood from the image. One can imagine the shapes to be human figures, performing some sort of dance or ritual, around a coal fire (a view reinforced by an all-encompassing view) but one can equally indulge in its

\footnotetext{
68 Ibid.

${ }^{69}$ Riemke Ensing, "Who's Afraid of Red Yellow Blue?: The Career of Jean Horsley," Art New Zealand 63 (Winter 1992): 76.
} 
abstract qualities (more dominant when standing closer).

Taking these figures, one sees something that is highly distinct, every instance is recognisably made from the same elements (or absence of elements) yet is displaced by its exact shape, position, and angle in relation to each other. This juxtaposition of material that is recognisably the same, yet is presented in a way that creates contrast, inspired the orchestral piece Hot Coals, and we can see the parallels to the music analysed thus far.

The macro-structure of Hot Coals can be represented by two sections. The first, a percussion layer, on which alternating blocks of contrasting material are superimposed (b. 1-104), this lasts for around 3/4s of the piece, and secondly, the synthesis (b. 105-127), in which material from all the blocks interact around an established pulse (for the first time). We can see in Figure 12 how the principles of stratification-interlock-synthesis are employed, but also how the superimposition creates a thread that binds all the other contrasting material around it (note the graph is not proportional). The following chapter will be divided into explanations of a) the percussion layer (purple) b) texture A (pink), one of the major textural blocks c) texture B (green), a contrasting major textural block, and d) the synthesis (yellow). The percussion layer is discussed because of its dominance, and the two contrasting textures that alternate above it have been chosen as they are the most substantial, in terms of length, density, and complexity of process, but as seen in the diagram, there are others which will be brought into the discussion on the synthesis.

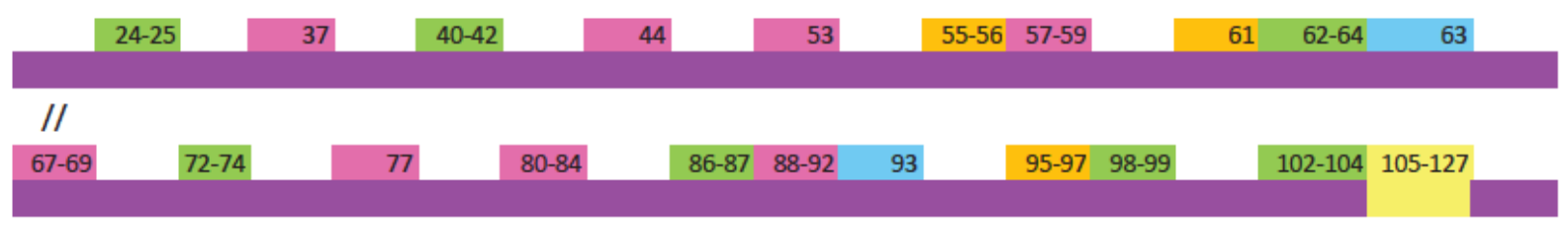

Figure 12

\section{Binding Threads- The omnipresent percussion layer}

At the structural core of the work lies the omni-present percussion, consisting of sizzle cymbal (scraped, brushed and struck, with brushes and mallets), snare drum with brushes 
(both struck and brushed) and Bass Drum. This layer, which continues roughly $3 / 4$ of the work, was the first to be composed, and most of the rest of the piece, especially rhythmically, is in response to this layer.

One can make a comparison of the detailed brush work in the percussion and the gestural and textural effect of the strokes in the artwork. In both works this texture is a predominant force which dominates the work. The erratic, inconsistent nature of this texture led to the use of irrational rhythms, and as the piece progresses, these generally become denser, demonstrating larger subdivisions of beats and articulating more of those subdivisions (see examples below).

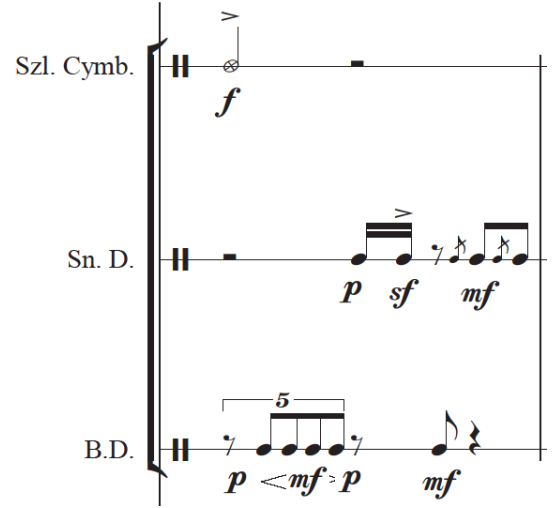

Figure 13 b. 16

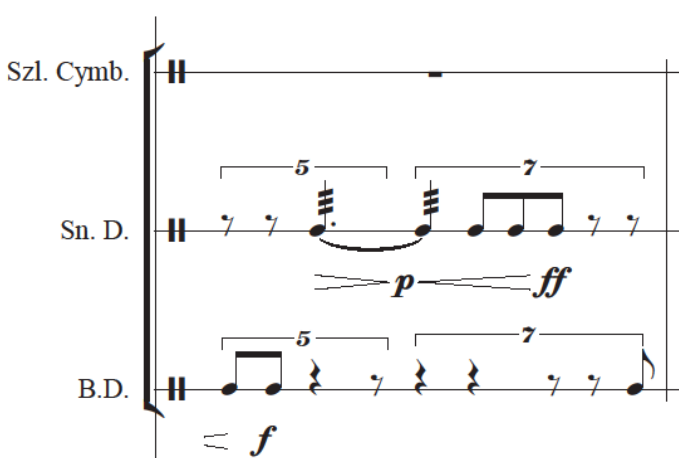

Figure 14 b. 60

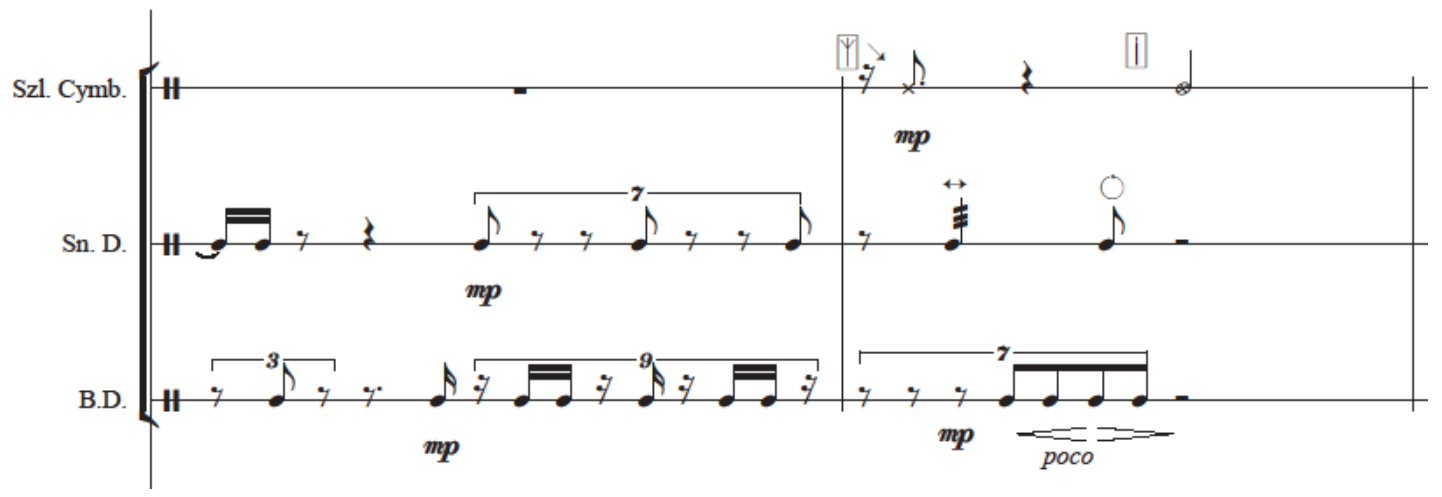

Figure 15 bb. 101/102

This layer provides the first recognisable timbral area of activity, or block. It is defined by the features of the instrumental group, which include:

- Unpitched rhythmic material 
- A play between sustained material (brushed snare, sizzle cymbal) and short attacks

- Sonically rich, noisy textures with an emphasis on high frequency

The percussion rhythm is initially conceived as a single line, a rhythm that flows from each instrument in the section to the other, which cannot be divorced into a counterpoint of lines, but orchestrated between different sonorities; in this sense, it is pointillist. Although it is the case that the rhythm was written intuitively as a single entity, retrospectively it is possible to see the emergence of a constructive method. As mentioned above, the tuplet subdivisions get larger as the piece progresses, but this is a gradual change, and each moment contains flux, alluding to an instability of tempo and pulse. This is created by the juxtaposition of tuplet types in a horizontal order (see fig. 13). These 'panels', taking terminology from the Donatoni chapter, are predominantly two crotchet beats, or one minim beat (I like to think of the pulse as 30 minims per minute, but for practicalities sake, it is conducted in crotchets). In general, the instruments very rarely strike together, even when they are within a single tuplet division, such as in figure 14, although this starts to change as the piece progresses, where different tuplet divisions are superimposed, breaking down the single line concept and creating a tension and conflict, evident in figure 15. At all times, the matrix of possibilities remains open to the composer, and the method of inventing rhythms within a tuplet panel is free (even though there are key unchanging rhythms which reoccur). This means the ordering and arrangement (or juxtaposition) of the different tuplet types is free, as well as the content. This second point offers a point of departure from the music of Stravinsky and Donatoni, but one can see how the organisation of these blocks of activity, has been used to create a formal growth, an example of Donatoni's "growth without development". ${ }^{70}$

This approach can be compared to Boulez's discussion of what he calls 'tiling' in Stravinsky's Rite of Spring in which he states: "this Introduction [of the Rite of Spring] with its remarkable aggregations of individual developments, to the complex structure that results,

${ }^{70}$ Donatoni, “Presenza di Bartok." 
and to the phenomenon of 'tiling' - the layering of developments on top of one another", ${ }^{71} \mathrm{a}$ process which is similar to the superimposition discussed in both the Symphonies and Tema.

In many ways, it can also be compared to Decker's concept of 'codes' in the music of Donatoni, ${ }^{72}$ in that the contrast has moved from a concrete set of ideas being juxtaposed, to the juxtaposition of abstracted processes. In each case, however, the idea remains perceptible, and as Kielian-Gilbert notes of Stravinsky: "Descriptions of such "gestures," however, often focus narrowly on material content (themes, motives, and the like) and miss the recurrent patterns and relationships, their rhythms of shaping. In viewing rhythm as patterns of succession, however, one should not downplay the specific content of those patterns: they are both audible "things" and inseparable from the temporal whole". ${ }^{73}$ What this represents then is a homogenous timbre, in which all the components work together to create the perceived idea.

Although this percussion section is viewed as homogenous, it is also decorated and developed across other instrumental groups. This is evident in the aeolian sounds in the brass writing, and the bowing across the bridge of the strings. The brass provides two major functions: the first is a rhythmic articulation of the percussive rhythms (see bb. 18/19) which may appear in unison or imitatively, and the second is to hold and colour the sustain of the sizzle cymbal or a continuous brushing sound (bb. 5/6). This second function is the way that the strings behave when bowing across the bridge.

The second decoration of this layer, which opens the piece, is the sul pont. solo strings. The quality of the sul pont., displaying a shimmering of harmonics, paired with irrational rhythms, matches the chaotic sizzle of the cymbal. These solo figures are sparse, but as the number of strings and their frequency of appearance start to increase, it alludes to another main block of activity that is one of the centre pieces of the work: Texture A. This concept of singling out certain features from larger textures, divorcing them from that texture, and

\footnotetext{
${ }^{71}$ Boulez, Stocktakings from an Apprenticeship, 64.

${ }^{72}$ See previous chapter

${ }^{73}$ Kielian-Gilbert, "The Rhythms of Form: Correspondence and Analogy in Stravinsky's Designs," 43.
} 
using them as the genesis of a highly distinct block of activity, is a feature evident in Donatoni's Tema. These flourishes in the strings also present the first pitched material; all the pitch material is generated from the same matrix, even though it is treated extremely differently to create contrast, which will be explored in the discussion of the next two blocks.

\section{Texture A}

The first and most substantial block of activity, designated texture A, is the sul pont. strings doubling the flutes (with the contrabasses and bass clarinet sharing a similar relationship but less frequently). The violas, divided into six, harmonise the c flute, whilst the cellos, also divided into six, harmonise the alto flute, and the contrabasses, divided into four, harmonise the bass clarinet. You can see the reiterations of this texture starting in bars 37, 43, 53, 57, 67, $77,80,88$ and 90 . The basis of the rhythm, as we can see by comparing the percussion layer to the rhythmic activity in bars 57-59, are rhythms based around the subdivisions but not necessarily the rhythms within the percussion. Another approach is imitations of certain key reoccurring rhythms, creating canonic rhythms in which the same rhythm is used but offset, this is evident in the semiquaver rhythms of bar 57 between the cellos and snare drum. One such important key rhythm, the nonuplet rhythm introduced in the strings (imitating the snare drum a bar before) at b. 37 (fig. 17), appears with the same pitch material (but often in different combinations), in various outings, reiterated exactly (at least rhythmically) in bars $43,53,58,59,69,81,84$ and 90 . This rhythm becomes a vital ostinato figure at [M], in the synthesis which begins b. 105 .

The perceptible features of this section include:

- Breathy, overtone heavy, unstable flute playing

- Rapid contrast between highly articulated playing and slurring

- Sudden jolting, changes in dynamics

- Sul pont. string playing

- Divisi strings, but with each string group playing in rhythmic unison

- Highly saturated and close harmony (often featuring voice crossing) 
- High tessitura registers of all the strings (contrasted with the low flutes, a reversal of roles)

- Rhythms taking from the activity of the percussive layer

Structurally this block of activity can be divided into two to three separate groupings, which are identified above as the violas/flute, cellos/alto flute and contrabass/bass clarinet. Each of these can be thought of as their own panels, and the relationship between the groups a micro-level variable. Despite this, the texture is highly unique and identifiable through the instrumental grouping and playing techniques, which give it a unique sound profile. These characteristic references never change leading to a sonic identity, but there is an element of micro-development: a) with each reiteration getting longer, lower, and denser (Although after $[\mathrm{H}]$ - the thickest, longest and most complex statement - it thins back out, whilst keeping the general shift downwards in register), and b) the harmonic complex becomes more chromatically dense in the following fashion.

The pitch structure of all the elements in Hot Coals originates from a twelve-tone row (Fig. 16). This tone row is segmented into four groups of trichords: $3-10,3-8,3-8,3-5$. The first, a diminished triad; the second and third, a whole tone and a tritone; and the fourth, a semitone and a perfect fourth. These were chosen as they all contain an open quality, three of the four feature a tritone, an interval that occurs as a major motivic entity (linked to the nonuplet rhythm mentioned above), and yet only one appearance of a semitone (except where the segments meet). Each of these trichords is used as an unordered pitch-class set, which can be combined into larger sets. Because the violas and cellos divide into six, hexachords are used in the first instances. Transposition of the original pitch of the row is generally unused (but a process of extending these segments will be discussed further on).

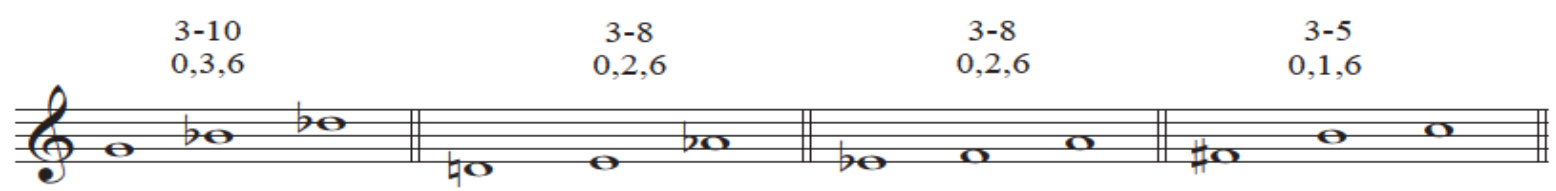

Figure 16 


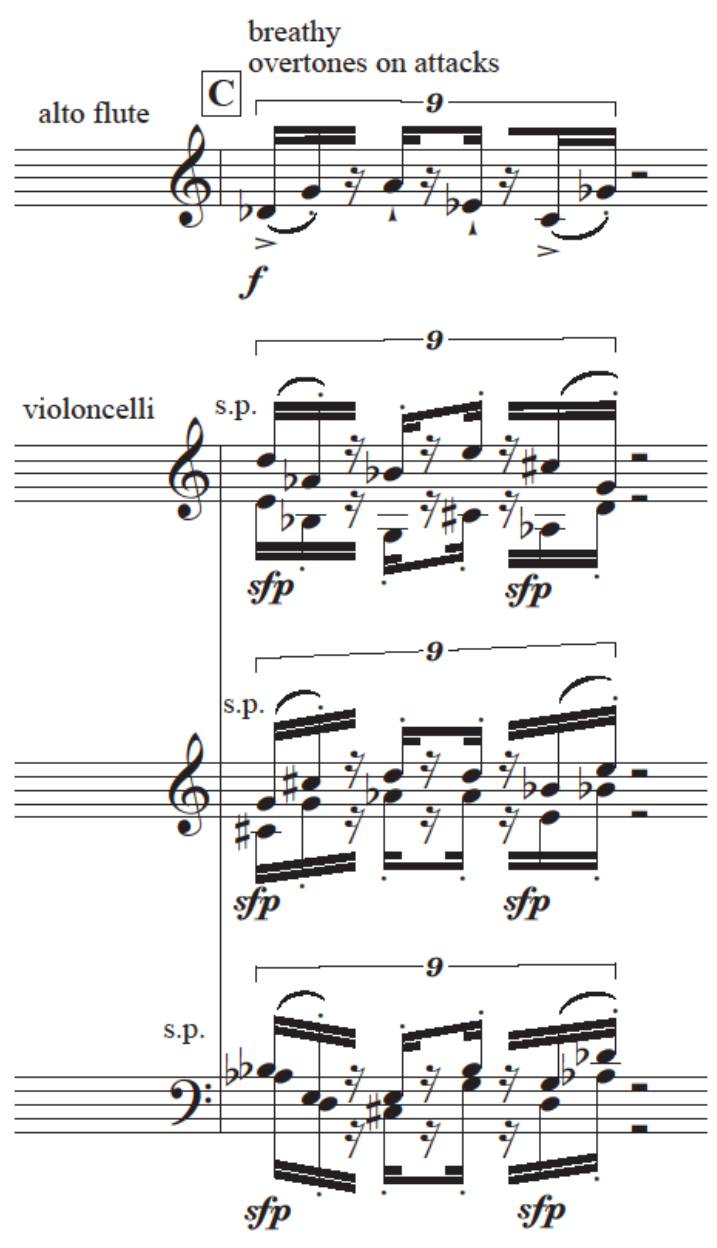

Figure 17
The first example of this texture is rehearsal mark C (Fig. 17). In this simple example, we can see the basic motif contained in the alto flute and spread between the fifth and sixth cello, which consists of the first two three note sets combined. The harmonisation is also based on the hexachord outlined by the alto flute motif, and so each articulation presents a juxtaposition of the same pitches, with only the voicing changing.

At b. 43 we have an identical repetition of the motif and harmonisation, but this time it is superimposed by the violas and flute playing in counterpoint with the original panel. This contrapuntal block is made from a combination of the two remaining trichords, in a similar fashion to the first; the order of pitches is eroded and the panel is now the unordered pitch class set of the hexachord, but is still influenced by the grouping of the original trichords. Like the process of rhythm, the constructive method becomes the superimposition and juxtaposition of restricted possibilities. As is explored in Donatoni, the use of 'codes' to inform and create a cohesive, perceptibly unique block of activity, whilst allowing it to have an inner sense of change and dynamism, over the duration of the piece, allows the sense of 'growth without development'. Like Stravinsky however, this growth is constantly cut off, so that at each return the differences are downplayed, yet still add a freshness and difference to offset the perceptible similarities.

A similar process continues with each reiteration, e.g. at [E], a literal repetition of the nonuplet motif, but with an appendix, which develops the rhythm, and extends the 
harmony by moving through the blocks of the row. However, this simple process starts to give way to further processes (outlined below), until a highly complex set of relationships starts to build, creating a chromatic density, not only between the contrasting string groups, but also within them, yet still retaining the basic intervallic relationships between the pitches set out in the original row. Methods include:

- The opposing string groups fulfilling the different segments of the row

- Opposing groups moving in different directions through the segments

- The segments being reordered

- One string group moving through all the segments within one reiteration

- Each individual part within the group starting in a different segment

- The extension of the trichords from within to form larger sets of which all the processes above can be applied (this will be explored further in the next paragraph)

This increasing chromaticism creates a directional element, as every time the texture returns, it becomes thicker to the point of being a perceptible textural change, without losing its fundamental characteristics. Even so, because of the construction of the row, there is still an openness and harmonic quality that remains, despite the immense chromatic saturation, close voicing and voice crossing, because of the process outlined below.

One aspect that is used to develop the pitch which becomes very evident at $[\mathrm{H}]$, is to extend the trichords to four and five note sets through rotation. ${ }^{74}$ As evident in figure 18 (The four note sets only), we get larger segments that exaggerate the intervallic qualities of the original: The diminished chord is a repeating interval cycle which results in a diminished seven chord, the 3-8s transform into whole tone segments, etc. So, as the textures become increasingly dense and chromatic, the structure of these interval relationships are not only retained, but also exaggerated.

\footnotetext{
${ }^{74}$ Ernst Krenek, "Extents and Limits of Serial Techniques," The Musical Quarterly 46, no. 2 (April 1960): $210-32$.
} 


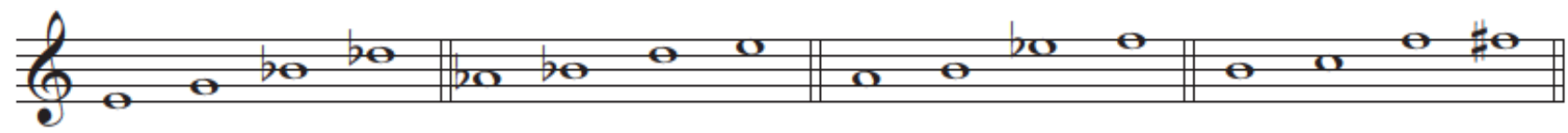

Figure 18- Rotation 1

At bars $88 / 89$ in the $1^{\text {st }}$ and $2^{\text {nd }}$ contrabass (Fig.19), one of the final reiterations of the sul pont. string texture, is an example of how complex the juxtaposition of the different sets has become by this point in the piece (compared to the first instance at [C]). Evident in only these two parts, is the frequency of change within a small area of duration, and the myriad forms of combinations of sets. This can be extrapolated to the entire complex of arrangements between the individual string parts, and the groups. As per the diagram, the first contrabass is a combination of rotation two's set b \& c (green), and rotation two's c and $\mathrm{d}$ (purple), we can see the frequency in which it changes is very high, being fully exposed over four crotchets, and the second contrabass shows how it can be broken down into smaller sets, including (in order): $r 1 d, c, b$, and R2a (it should be noted that the sets do not have to complete themselves to move on). Between the two contrabassi, chromatic saturation is achieved, but the key intervals remain in modules, which are juxtaposed against more and more elements.

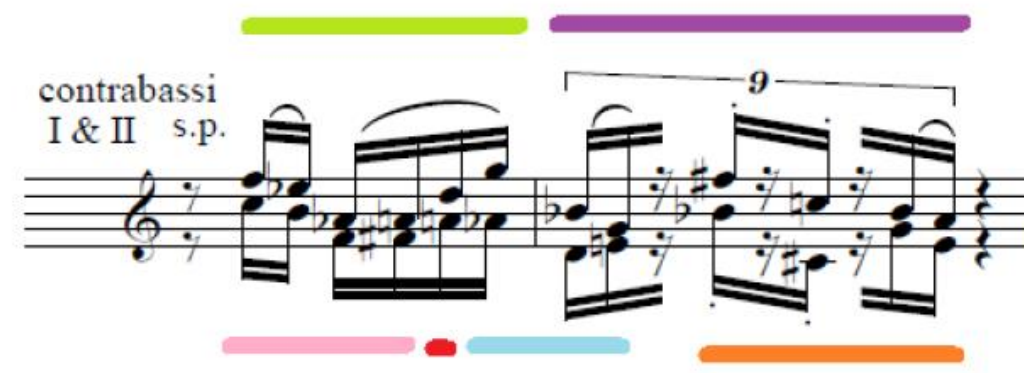

Figure 19 bb. 88/89

\section{Texture B}

Comparatively, the second major block of activity, texture B, is defined by its significant contrast to the first. This reoccurs alternately with texture A, and can be found in bars 24,40 , 
$62,72,86,98$ and 102, usually lasting only two or three bars. Unlike texture A, the treatment of pitch material is sparse. Although originating from the same tone row, the process of revealing all pitch classes happens slowly over each reiteration, the first two instances consisting of only a single pitch. Referring to the tone row (Fig. 16) and comparing to figure 20 , which details the pitch and exact voicing of all occurrences of texture $B$, we can see that a window/frame is slowly moving over the row. This process continues on each return, moving through different subsets of the original row. This row, as shown in texture A, is modular, remembering that once each three-note segment is reached, the pitches can appear in any order, leaving a large amount of creative freedom. This modular approach can also be compared to the percussion writing analysed above, and also to Donatoni's codes, specifically additive filtering as described by Decker. ${ }^{75}$ Subsets can be formed from within the combination of sets, e.g. looking at [G] we see a pentachord which is combined from the first two trichords of the modular row, eliminating the $G$ and showing the expression of all notes of combinations is not necessary. Ultimately, this process leads to a ten-note chord [K] that transitions us into the synthesis (b. 105). The string chord at Bar 16 has been included for comparison to $[\mathrm{K}]$ as it is almost an exact replica in terms of harmony and voicing (with some minor differences). The string chord appears as part of the flourishes that come out of the opening percussive layer and so is perceptibly part of that block of activity, yet it is also the first vertical use of pitch, and mirrors the final use of pitch for the first section at $[\mathrm{K}]$. This shows an example of an almost identical voicing, but because of the timbral differences (b. 16 being a short stab in the sul pont. strings and $[\mathrm{K}]$ sustaining over 3 bars across all colour sections of the orchestra) they are perceived to belong to different blocks of activity, showing how the timbre informs important perceptual relationships and defining characteristics.

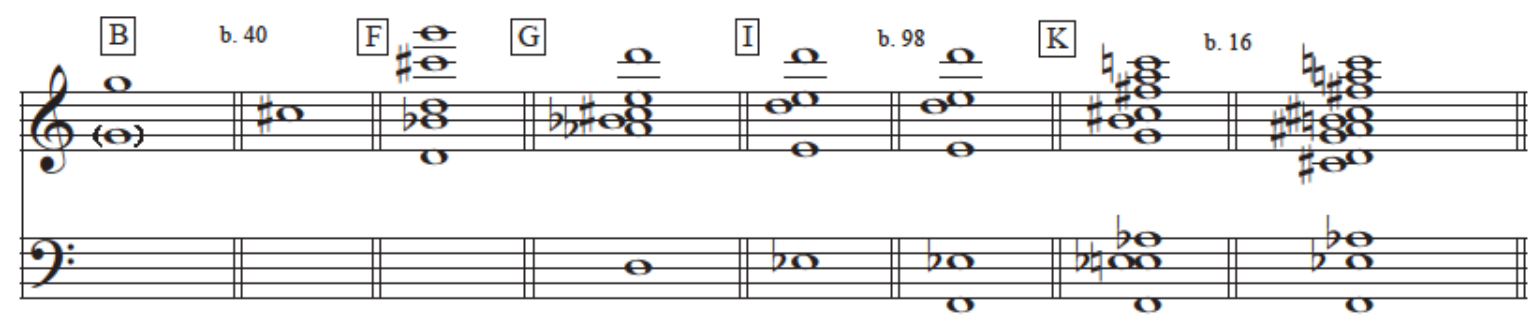

Figure 20

75 See pp. 24-27 
This simple process allows the treatment of material to be contrasted significantly to texture A. It is static in nature, the pitches are sustained and are voiced widely across the orchestra, often being fixed to certain registers and with a clear tone. We can see how this simplicity reflects the antithesis of texture A, in which chromatically dense, close voiced harmonies, disguised by fickle timbres, are constantly shifting through a myriad of voicings and juxtapositions of itself within a single phrase. Another important distinction is there is often a felt pulse; this may be overt or subtle, symmetrical or asymmetrical, but compared to both the percussion layer and texture $\mathrm{A}$, in which the juxtaposition of different tuplet groups and dense rhythmic dissonance erodes any sense of steady pulse, texture B displays a highly perceptible and stable feature.

A sense of development, therefore, is achieved over each reiteration through the addition and subtraction of pitches, different rhythmic emphases, but predominantly, by the colouring of the orchestra. This is another contrasting feature to texture A, whereas the exact instrumentation and colour combinations were a defining feature of texture $\mathrm{A}$, texture $\mathrm{B}$ often varies in subtle instrumental characters, so what about these features stays the same, and allows it it's unique identity?

In all cases of texture B, there are three major functions which have been alluded to above, these are:

- the sustain

- $\quad$ The colouring

- The pulse

Reviewing texture B at its appearance at $[\mathrm{B}]$ we see cellos and basses performing the sustain, in harmonics; the oboes also contribute to the sustain, but also add a fluctuation to the note through colour fingerings; the pizz. violas and harp provide both a colouring to the note and a pulse (at a different rate but within the same division); and a major contributor to the pulse is the percussive slapping of the bass and cellos. The second instance at 40 appears in a similar fashion, but on a C\# (one of the pitches from the first trichord) and coloured differently, although the functions noted above: sustain, colour/fluctuation, pulse; remain. 
However, the ultimate character stays the same, retaining a sustained atmospheric nature, by the pairing together of the three functions, creating a general orchestral character. These three functions can be juxtaposed through different combinations, with the roles being transferred by connecting colours, allowing a development through orchestration. An example of this is how the pizzicato in the violas at [B] is transferred to the cellos at b. 40 . Both feature a stringent character, because of the register the pitch resides in with the shorter length of string, but there is a slight difference in timbre because of the different instruments, but highly related sonically. Secondly the fluctuating oboes at [B] with its nasal stringent sound, is transferred to the whispa muted trumpet at b. 40. The colours are being subtly evolved, but still audibly in relation to the reiterations that are presented before. The static, widely spaced voicings allow the orchestration to take on this important function, as there are no pitch contours, allowing the perceptible changes to be within the sounds themselves.

\section{The Synthesis}

Taking from Cone's synthesis, ${ }^{76}$ Hot Coals ends with a section which amalgamates many of the features found in all the preceding textures (including those not discussed), with smaller and smaller fragments colliding into a more unified and discursive musical discourse. These fragments often meet within the space of beats or less, in contrast to their separation over multiple bars beforehand, even being superimposed to sound at the same time in combinations previously unheard, and featuring tight hocketing between distinct instrumental groupings.

Whereas previously the percussion layer had presented a continuous layer, a texture which had its own internal logic, on which other layers were superimposed, now the persistently erratic percussion layer has given way to a clearly defined pulse. This simplifying of the central reference point means less attention is drawn to the inner detail of the texture and the connections made within it (as well as between superimposed blocks) but more to a solid perception of the rhythmic relationships the fragments have to the pulse. Before, when the

\footnotetext{
${ }^{76}$ See chapter 1
} 
rhythms were juxtaposed against differing pulses (the effect of differing tuplet subdivisions), they appeared in flux, without clear reference points, what the pulse establishes then, is something which binds all the material into more perceptible and comprehensible rhythmic relationships.

The first major feature is the re-emergence of the nonuplet rhythm, first introduced meaningfully by the strings at $[\mathrm{C}]$. Both the pitch and rhythm is repeated exactly (compare fig. $17 \mathcal{E} 21)$, but the timbre and density has changed. The strings play in unison, naturale, and in the lower register, doubled by the bass clarinet and bassoons, a considerably different timbre to the dense voicings playing sul pont. in the higher registers of the instrument, doubled with unstable flutes. This has synthesised some of the more substantial tones from texture B, whilst still holding onto the familiar instrumental relationships, such as the strings working together rhythmically, the doubling of the bass clarinet, although the flutes are phased out and replaced by bassoons, but also by the rhythmic exactness. This exact repetition appears in bars 108, 111 and 122. A similar repetition happens across 114-116 as an ostinato that repeats on the first beat of the $3 / 4$ bar every time. But if we compare this to bar 108 , we can see the pitch classes are the same, but the order of the relationships has been reassembled and juxtaposed in a different manner. Each dyad, a tritone, keeps its relationship as an entity, a panel, because of their close rhythmic proximity, but these panels have been reordered.

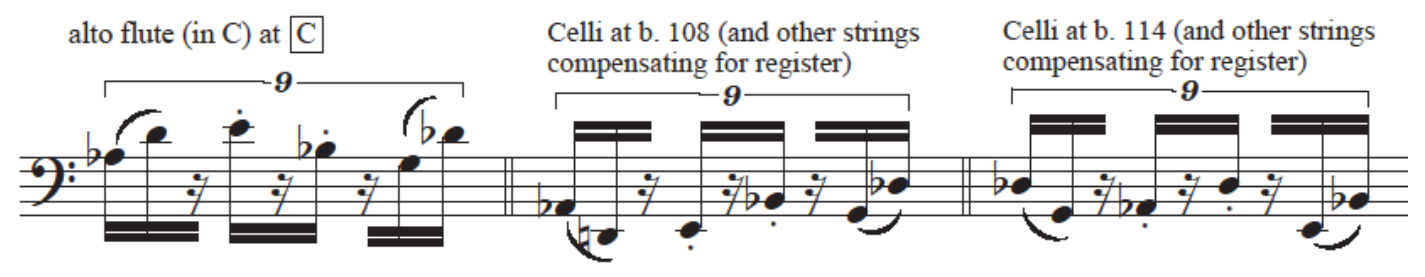

Figure 21

It is also possible also to see how these fragments or 'panels' have been divorced from the nonuplet rhythm altogether and placed within the musical discourse. We see the B flat-E dyad in 105, the A flat-D dyad in 106, as well as a combination of the two in the third beat of b. 106. These both take on the rhythmic character of a triplet against the pulse, but at different rates. The two pitches, as a dyad, stay together rhythmically, even when they are 
divorced from the nonuplet. In bar 113 we see how the rhythm has been spilt into two groups of three, separated by a crotchet rest. The first half is the same rhythm as the first occurrence, but perceived at a different rate to the pulse, as even semiquavers, whilst the second half speeds up to triplet semiquavers, approaching the speed of the original nonuplet statement.

These rhythmic and pitch fragmentations, allow a sense of hocketing and interplay between the different instrumental families. E.g. the dyad fragmentation starts to infiltrate the brass writing in particular, with their rhythmic profile taking off from the strings in pairs. We can see an example of this in bar 106, where the horns on beat 4, carry on the sextuplet rhythm introduced in the strings at the end of beat 3. A similar process happens in bar 11, where you can see the same dyad pair (rhythmically and pitch wise) in the horns, with the first unit repeating twice before the second unit is reached. A process not unlike additive filtering. ${ }^{77}$ These fragments are repeated exactly at bar 118 and 119. It is possible to see other fragments reappearing constantly throughout this synthesis, such as the three-two pattern across the winds and brass, many appear unchanged, but sometimes they are rhythmically altered to fit different divisions of pulse, as we saw in the strings. We can see how the processes of texture A have started to define the wind and brass, with the fast tuplet figures imitating and filling in the implied rhythmic space and the close, dense voicing now attributed solely to them, in opposition to the strings.

One texture apparent in the first section, but only in a minor role, hence not analysed in the preceding pages, provides a low-end background; the harp, con sord. trombones, and stopped horns. Early examples of this can be found in bar 55, 61 and [J]. All of the sharp rhythmic activity around the pulse, is superimposed upon these low sustained brass chords, which occasionally articulate rhythmic time, often completing triplet figures, and pulsating with crescendi, with the added timbre of bass drum and tam-tam.

${ }^{77}$ See chapter 2 


\section{Chapter Conclusion}

Hot Coals demonstrates many approaches to juxtaposition in its constructive elements, as shown by the preceding analysis. The influence of juxtaposition is apparent in the macrostructure of the work, as well as at the micro-level, that is, within perceptible textural units themselves. The use of reoccurring rhythms and pitch combinations are always in sight, but may be rendered in a multitude of ways to create constant perceptual contrast. All elements: pitch, rhythm, timbre, can be divorced and recombined, being both a constructive tool, as well as a perceptual element for a listener, without the changes being easily pinned down. The techniques of superimposition and juxtaposition are used to create something that has a flow, direction, and consistency, through the economy and re-occurrence of limited material. Parallels can be made between the working methods and analytical discussions made thus far, especially with the music of Donatoni, but also in the shadow of Stravinsky, and although the piece also encompasses a wide range of aesthetics that stray from both of those composers, nonetheless a structural parallel, and perhaps a middle ground between the organicists and the collagists, is evident in this work. 


\section{Conclusion}

In the preceding analyses, juxtaposition has been shown to be a highly versatile tool for constructing a musical dialogue. The exact function and methods employed have been shown to be as varied as one's imagination will allow. However, common to all the musical examples examined, the recognisability of material, and hence its ability to be contrasted, is vital to the formal design. Through the constant contrasts and the stratification-interlock system, the return of familiar material is allowed room to change and create a nuanced sense of form. We saw how this change is also constructed through a process of juxtaposition, the recombination of cells and units appearing differently each time, but never repeating exactly. From the simple juxtaposition of units found in Stravinsky's 'bell' motif, to the highly malleable and complex juxtapositions of row segments found in Hot Coals.

Timbre has been shown to aid the musical discourse considerably, with slight changes in timbre, playing off similarity whilst also exploring difference, particularly evident in Donatoni's Tema, and in texture B of Hot Coals, both instances displaying a juxtaposition of functions, allowing minute details of timbre to shift. This more abstracted idea of juxtaposition also manifests itself in the rhythm of Hot Coals, which shows a shift from the very clear and fixed material found in Stravinsky's Symphonies, and even Donatoni's Tema, to a rearrangement of tuplet panels, in which the panels are more a set of formal possibilities, allowing the content to flux and create a directional change.

The creative possibilities still left to explore using juxtaposition and superimposition of contrasting material are endless, and will provide a strong foundation moving forward in my own creative practice. Although all the works in the accompanying portfolio are fully notated works, I can imagine the same principles being used to create form in improvisational contexts, Richard Barrett being someone who has done interesting work in this area, and to explore ideas further in this direction (as well as continuing notated works). The foundation laid out in Stravinsky's Symphonies of Wind Instruments, has created a wealth of possibilities for composers to explore, Cross, has discussed the many influences that Stravinsky and the Symphonies in particular, casts over the $20^{\text {th }}$ century. ${ }^{78} \mathrm{I}$ believe Donatoni's

\footnotetext{
${ }^{78}$ Jonathan Cross, The Stravinsky Legacy, 1st ed. (Cambridge: Cambridge University Press, 1998).
} 
Tema displayed ways of taking these juxtapositional forms and creating something constantly fluid and inventive, whilst remaining highly economic and unified. These principles I have adopted into my own writing and offered ways to not only adopt, but also to extend and be creative and highly individualised in my creative processes. 


\section{Bibliography}

Boulez, Pierre. “Franco Donatoni: Tema.” In Franco Donatoni. Gravità Senza Peso., edited by Candida Felici. Lucca: LIM, 2015.

- - - Stocktakings from an Apprenticeship. Edited by Paule Thevenin. Translated by Stephen Walsh. Oxford: Clarendon Press, 1966.

Colazzo, Salvatore. "Dal nulla il molteplice. I lavori solistici con le loro proliferazioni." In Donatoni, 110-29. Torino: EDT, 1990.

Cone, Edward T. "The Progress of a Method." In Perspectives on Schoenberg and Stravinsky: Revised Edition, edited by Edward T. Cone and Benjamin Boretz. New York: W.W. Norton \& Company Inc., 1972.

Cross, Jonathan. The Stravinsky Legacy. 1st ed. Cambridge: Cambridge University Press, 1998.

Decker, Bradley D. "Preserving the Fragment: Franco Donatoni's Late Chamber Music." Perspectives of New Music 46, no. 2 (2008): 158-89.

Donatoni, Franco. “Presenza di Bartok." Il sigaro di Armando, 1982, 87-91.

- - - Tema, 133236, (Milano: Ricordi, 1981).

_- - , Tema, Ensemble InterContemporain, dir. Pierre Boulez, Erato LC 0200 (1990)

Ensing, Riemke. “Who's Afraid of Red Yellow Blue?: The Career of Jean Horsley.” Art New Zealand 63 (Winter 1992): 76-79.

Forte, Allen. The Structure of Atonal Music. New Haven and London: Yale University Press, 1973.

Halbreich, Harry. “Tre capolavori orchestrali di Franco Donatoni. 'Voci'-'Duo pour Bruno''Arie'." In Donatoni, 194-214. Torino: EDT, 1990.

Horlacher, Gretchen. Building Blocks: Repetition and Continuity in the Music of Igor Stravinsky. Oxford: Oxford University Press, 2011. 
Horsley, Jean. Hot Coals. Charcoal, conte crayon, and chalk on paper, 1988. Chartwell Gift Collection. Auckland Art Gallery. https://www.aucklandartgallery.com/explore-art-andideas/artwork/12734/hot-coals.

Kielian-Gilbert, Marianne. “The Rhythms of Form: Correspondence and Analogy in Stravinsky's Designs." Music Theory Spectrum 9 (Spring 1987): 42-66.

Kramer, Jonathan. The Time of Music. New York: Schirmer Books, 1988.

Kramer, Jonathan D. "Moment Form in Twentieth Century Music." The Musical Quarterly 64, no. 2 (April 1978): 177-94.

Krenek, Ernst. "Extents and Limits of Serial Techniques.” The Musical Quarterly 46, no. 2 (April 1960): 210-32.

Michel, Pierre. “Franco Donatoni: Tema (1981) Pour Douze Instruments.” In Franco Donatoni. Gravità Senza Peso., edited by Candida Felici, 273-89. Lucca: LIM, 2015.

Osmond-Smith, David. “Donatoni, Franco." Grove Music Online. Oxford Music Online. Oxford University Press. Accessed May 29, 2017.

<http://www.oxfordmusiconline.com/subscriber/article/grove/music/07992>.

Scheffer, Frank. The Final Chorale. DVD. Juxtapositions, 2005.

Somfai, Leo. “Symphonies of Wind Instruments (1920). Observations on Stravinsky's Organic Construction." Studia Musicologica Academiae Scientiarum Hungaricae 14, no. 1/4 (1972): 355-83.

Straus, Joseph. "A Principle of Voice Leading in the Music of Stravinsky." Music Theory Spectrum 4 (Spring 1982): 106-24.

Stravinsky, Igor, Symphonies of Wind Instruments (1947 Revised Version), B \& H 17144, (Boosey \& Hawkes, 1948).

Stravinsky, Igor, Symphonies of Wind Instruments, The Netherlands Wind Ensemble, dir. Edo de Waart, Sony 442 583-2 (1994).

Toorn, Pieter C. van den. The Music of Igor Stravinsky. New Haven: Yale University Press, 1983. 
White, Eric Walter. Stravinsky: A Critical Survey. London: John Lehmann, 1947.

- - - Stravinsky: The Composer and His Works. Berkeley and Los Angeles: University of California Press, 1966. 


\title{
Constructing Contrast
}

\author{
By
}

\section{Glen Downie}

\begin{abstract}
A portfolio of original compositions submitted to the
New Zealand School of Music in partial fulfilment of the requirements

for the degree of Master of Musical Arts in Composition
\end{abstract}

New Zealand School of Music

Victoria University of Wellington 


\section{Contents}

- Broken Record for solo piano

- Cepheid II for accordion solo

- Gorzanis frammenti for solo guitar

- Chimera for violin and harp

- Three Miniatures for clarinet, tuba and accordion

- Hot Coals for orchestra

The order of all works has been organised in order of ensemble size first, and duration second.

Recordings of all the works exist in the same order on an accompanying CD, which are a mix of workshop, studio, and concert performances. This can be found attached at the back of the document.

Thanks to the performers: Liam Wooding (piano), Agne Dukstaite (accordion), Jake Church (guitar), Laura Barton (violin), Michelle Velvin (harp), Simonas Tamulis (clarinet), Mika Kurtinaitis (tuba), The Auckland Philharmonia \& Hamish McKeich (conductor) 


\section{Broken Record}

Broken Record is a short piano study that explores the use of repetition and juxtaposition. The piece mostly consists of an ostinato that is broken down and fragmented. The resulting fragments are then rearranged, appearing in new configurations. The composition consists of a very limited set of material which is often defined by unique combinations of pitch, register, dynamic, articulation and rhythm, and these riffs interrupt and break down the steadiness of the ostinato. 
Glen Downie

\section{Broken Record}

for solo piano 
All notes stacatto, unless

marked with tenuto or

slurred

$.=82 \quad . \quad=. \stackrel{3}{.}$
Broken Record

for solo piano
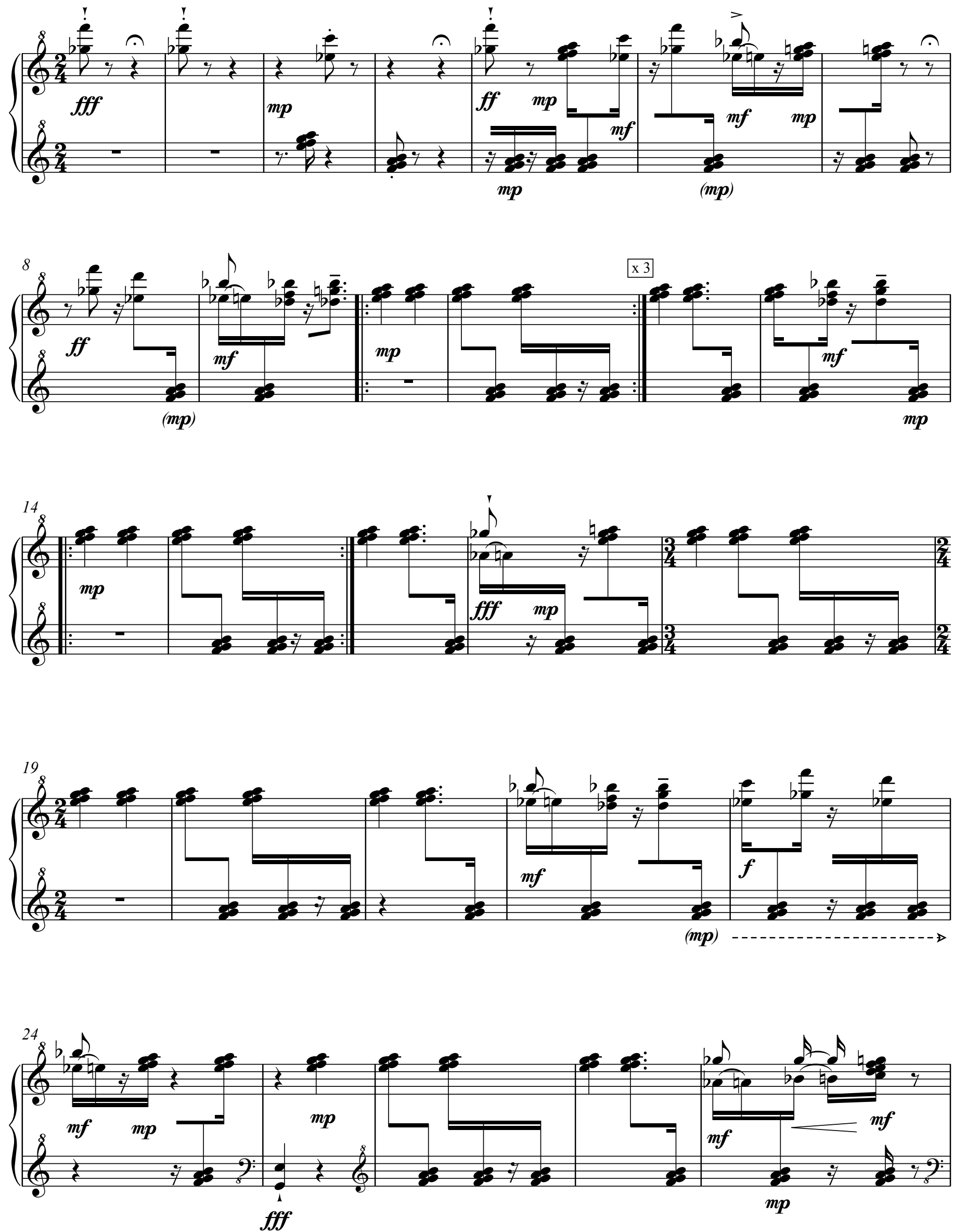

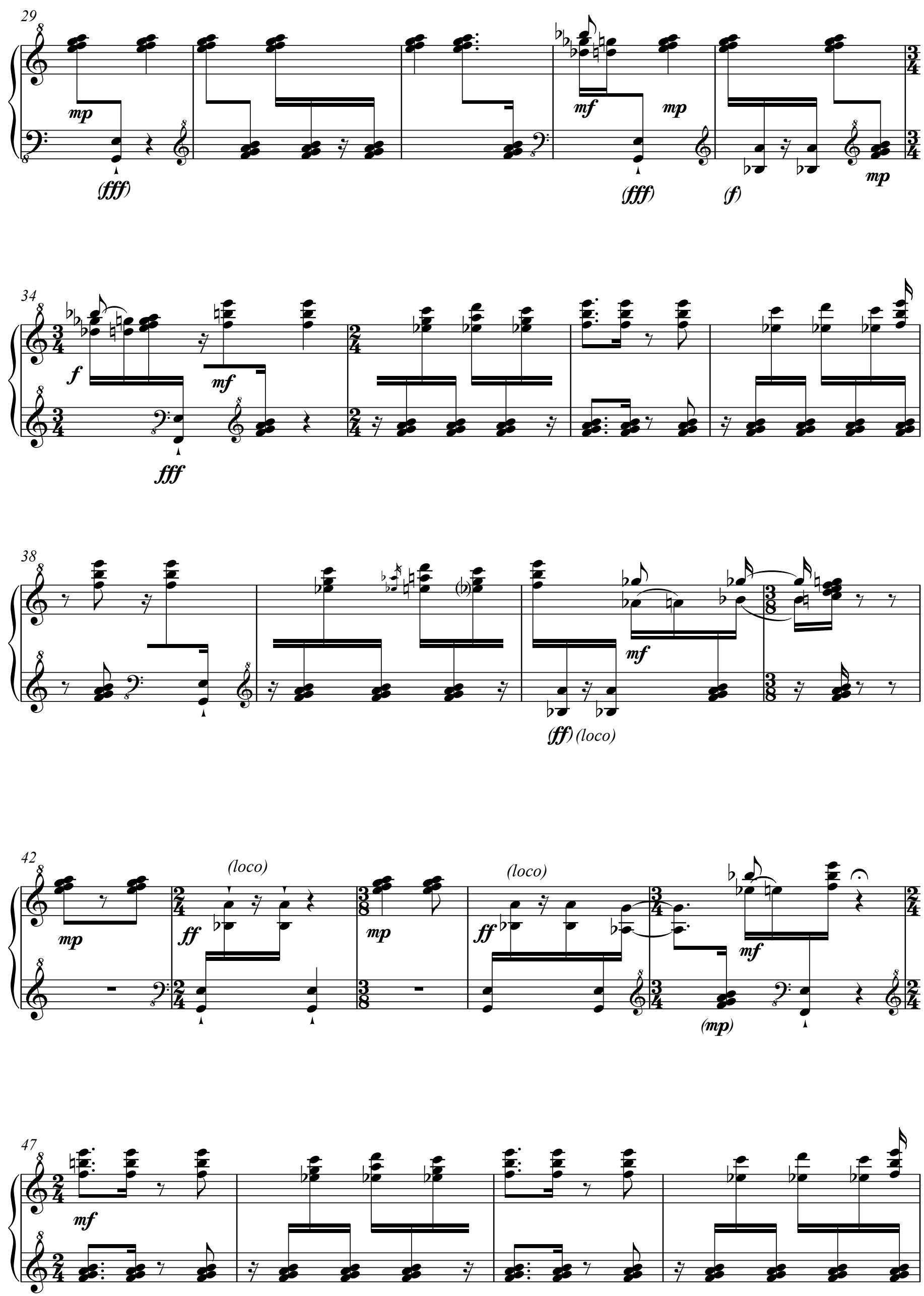

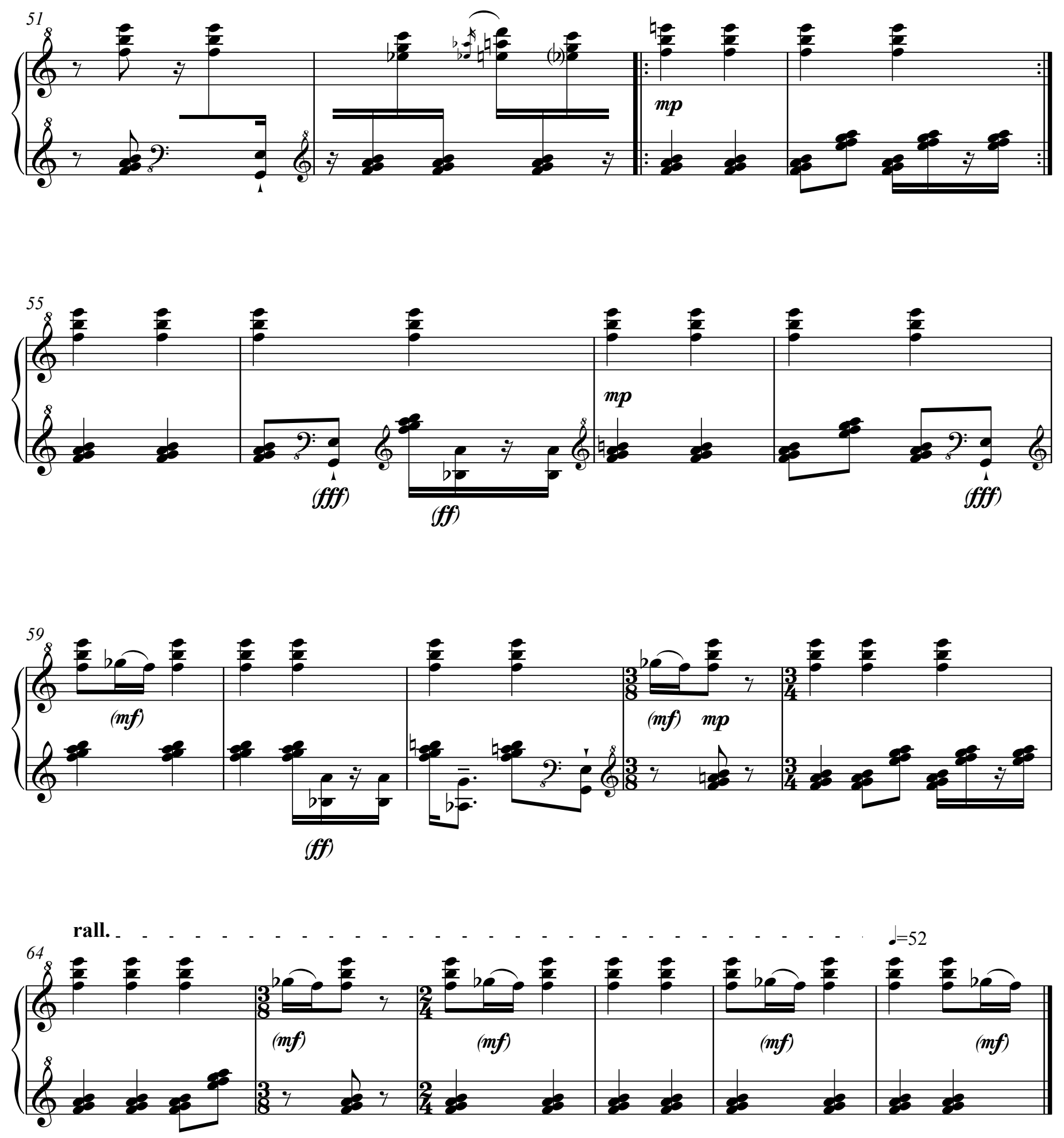


\section{Cepheid II}

Cepheid II is a sister piece to an earlier organ work called Cepheid. Long, slow tones open the work creating a timbral shimmering, slowly, this texture is superimposed with very short, quiet articulated notes, creating a separation between the sustained layer and that of pointillist activity. One idea also briefly explored in this work is the juxtaposition of the same pitches played on the different manuals of the accordion. This idea is explored further in the Three Miniatures. 
Glen Downie

Cepheid II

for accordion solo 


\section{Cepheid II}

for accordion solo
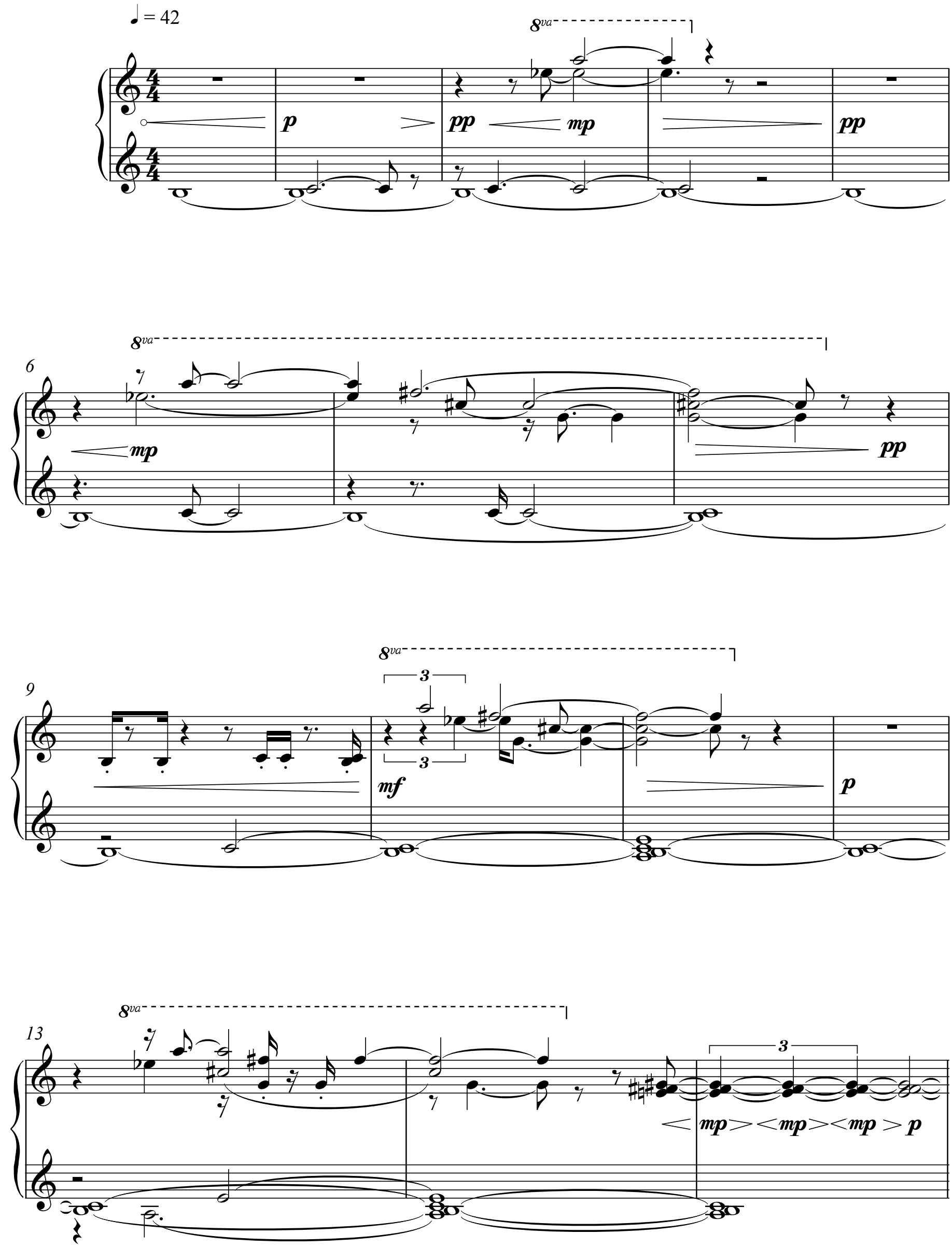


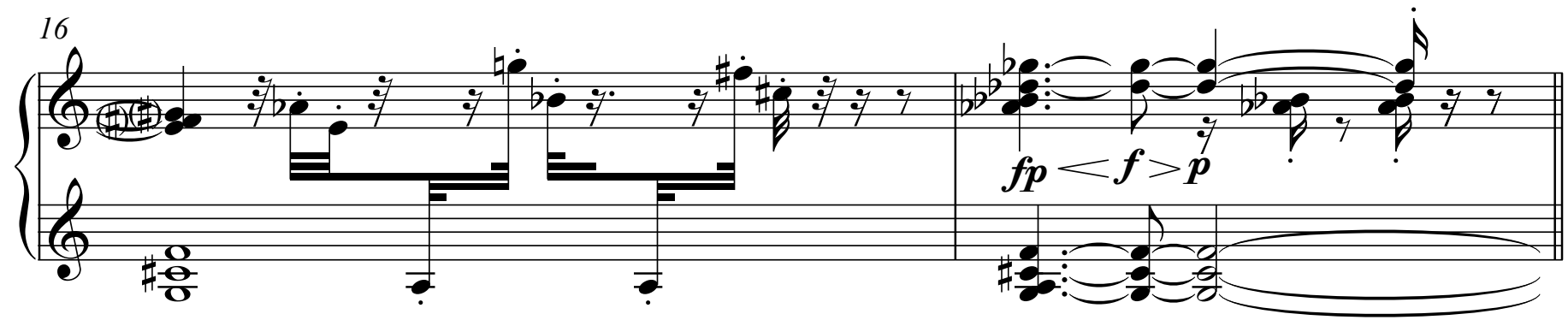

short
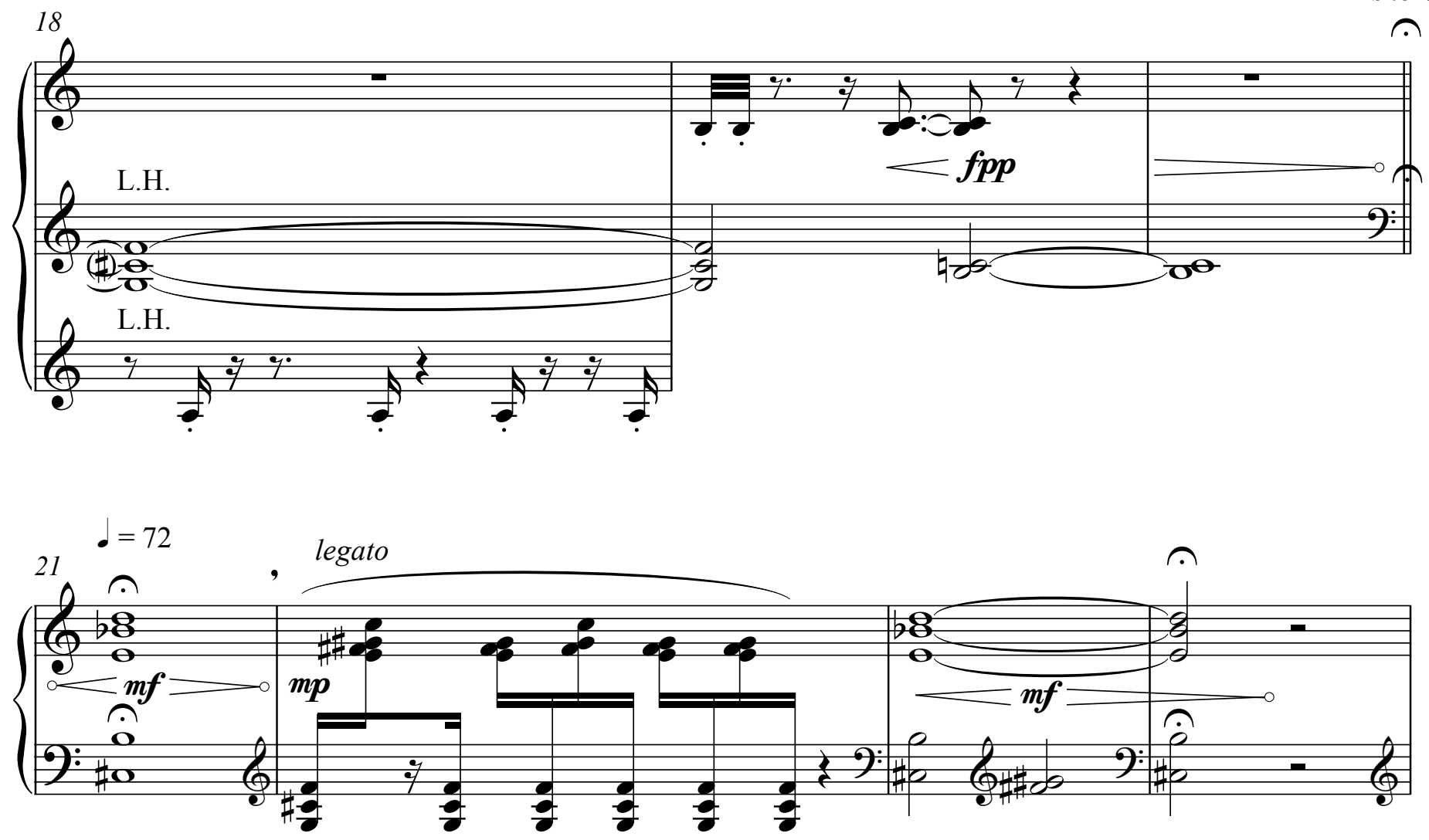

legato
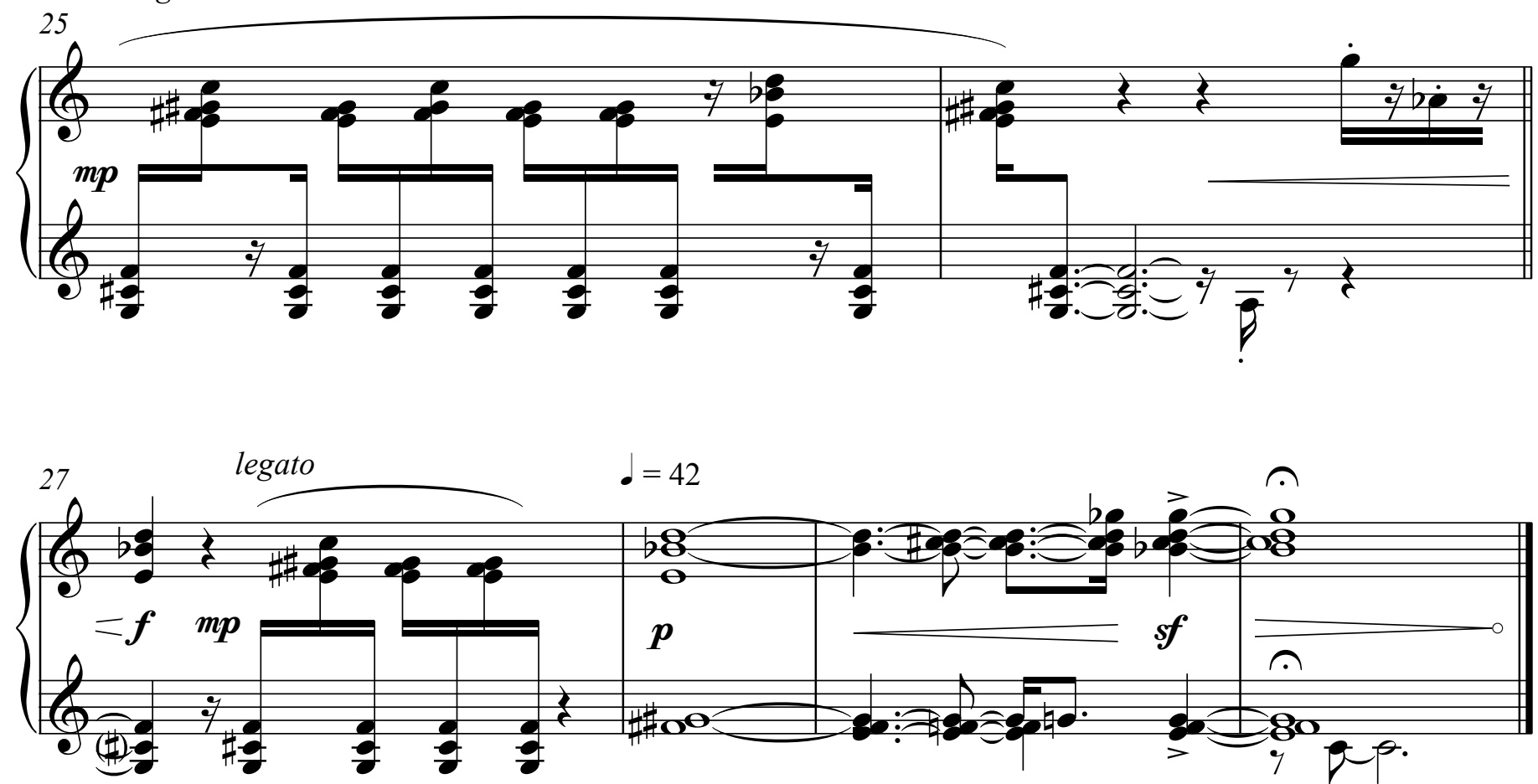
Glen Downie

Gorzanis frammenti

For solo guitar

Dedicated to, and edited by Jake Church 


\section{Glen Downie}

\section{Gorzanis frammenti}

Edited by Jake Church

\section{Contextual Notes:}

The Gorzanis frammeni take source material from three Neapolitan love songs by Giacomo Gorzanis, originally for voice and lute. These are Questi capelli, Alma per t'afiggli and Donna gentil, all from II primo libro di napolitane che si cantano et sonano in leuto of 1570 . Each movement takes melodic fragments as the starting point for new compositions.

Taking inspiration from just intonation, and the experimentation of tuning systems of the medieval and renaissance period, the guitar is tuned so that each pair of strings sound just fifths. As the variety of tuning systems reveal, natural discrepancies between certain intervals abound, depending on the intervals you wish to be pure (thirds or fifths), as changing one will compromise the other. These discrepancies, are particularly evident on fretted string instruments and were part of the compositional process and inspiration of the piece. This is particularly evident in the first and third movements.

The structure of the piece presents a degradation of the original material, becoming increasingly abstracted.

This piece is dedicated to guitarist Jake Church, who first approached me to write a piece, and helped immeasurably during the writing process.

\section{Performance Directions:}

- The guitar, as per tradition sounds one octave lower than written. Harmonics are written at written pitch

- Each pair of strings should be tuned so that the fifths between them sound just. That is the fifths are slightly wider than equal tempered fifths.

vib.

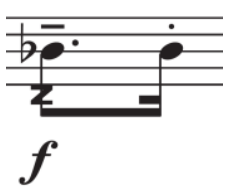

vib. with a $z$ through the stem indicates a wide and fast transverse vibrato

(5) (6)

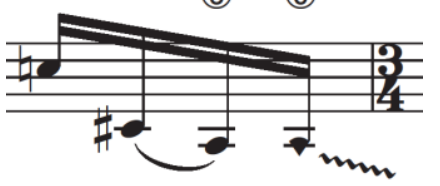

A triangle notehead denotes to hammer-on without plucking the string.

A wavy line represents an indeterminate gliss. Short, sharp and releasing the finger pressure whilst moving down the frets 


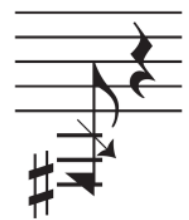

(scratch)
A harmonic scratch shows the position of the node, and directs you to scrape this nodal point with the fingernail

A cross notehead denotes a ghost note- touch the string at the position of the note and pluck the string, the resulting sound will be a dead and percussive

又

Donna gentil non so:

- Leave harmonics from the second movement ringing into the beginning of the third

- The dynamic range of the harmonics in the third movement will be limited, the dynamics provided are relative and for the shaping of phrasing

- In the middle section where dynamics are not notated, the performer is free to play with dynamics ad libitum

- Bracketed (de)crescendi denote to (de)crescendo gradually over the repeats

- Some finger noise is to be expected where the tempo in the third movement increases, although the guitarist should always aim for the purest tone possible

- Repeat suggestions are approximate 


\section{Notes from the Editor}

In the creation of this composition, I worked closely with the composer, going through aspects of notation, technique, and the exploration of timbres, to discover a musical work through the guitar. As collaborators, Glen and I were working towards an 'integrative' collaborative model, which entailed developing a friendly, professional, and social rapport, where mutual trust, respect and commitment were fundamental to the compositional process. In other words, we aimed toward a shared vision, which took longer than expected because of the number of obstacles collaborators must conquer to understand the other's perspective. Conquering these obstacles exposed the character of both people involved and the musical identity of this work; if collaborators are fully invested towards a joint-musical-expression the developing art work will flourish.

My editorial notes are for the aid of other performers, trying to relay helpful advice concerning fingering, tone, positions, extended techniques etc, that I have learned both in the collaborative process and in the act of preparation and learning. These will significantly aid the performer in learning the piece both technically, and in the understanding the composer's intentions.

The way I approach playing this piece is by acknowledging its macro direction and the individual characteristics of each movement. The first movement requires space and a subtle sense of self-indulgence, embrace the time between phases and the micro-dissonances created by the tuning. Focus on the lyrical melody and tone production. In contrasting fashion, imagine the second movement as competing dialogues between two voices, creating a fast paced and aggressive stuttered flow. Give the sound some bite and place more attention in the rhythm. This segues to the third movement, which involves emphasising the sonic space in the higher partials. I hear this movement as reverberant over-tones resonating from the previous movements. I recommend a very light touch in the left hand and square/ponticello attack in the right hand to achieve clarity within the laissez vibrer harmonic atmosphere. Conceptualising the work in this manner will ensure a consistent execution of the composer's intentions. 


\section{I}

Edited by Jake Church

Questi capelli d'oro

Glen Downie

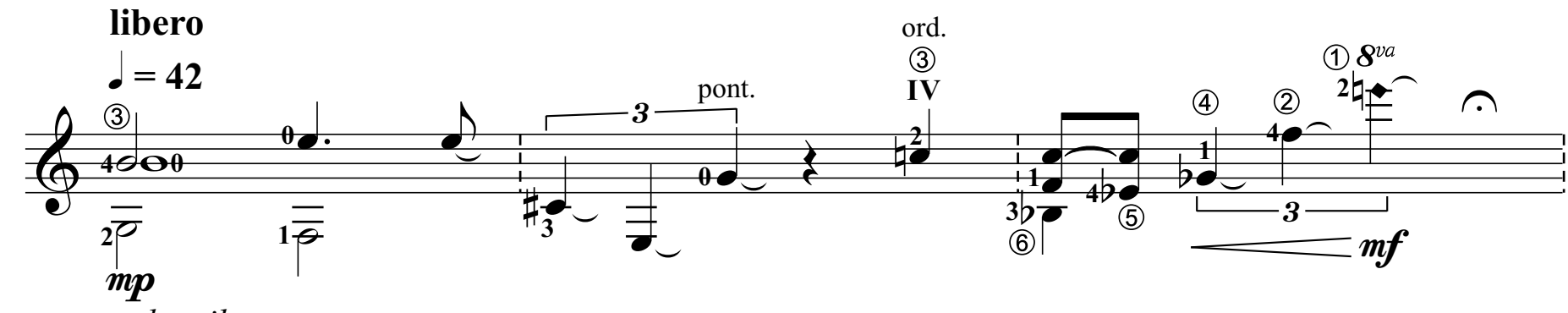

molto vib.
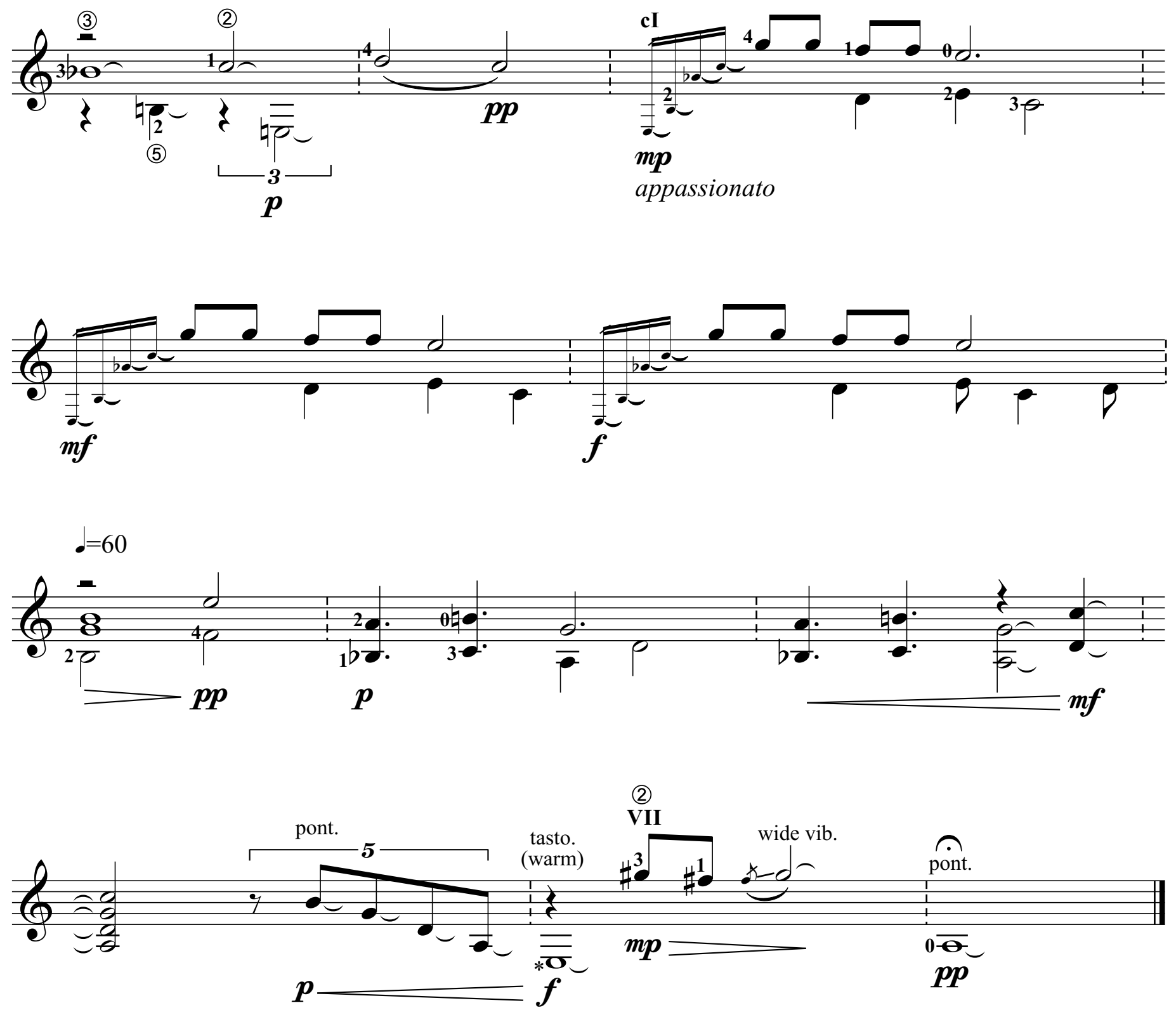

* Use L.H. $p$ and $i$ to pinch and pluck sixth string (like a soft bartok pizz.) over the harmonic-node on the XII fret, to create a round-bell like sound. 


\section{II}

Alma perché t'affliggi

$d=108$

(9)
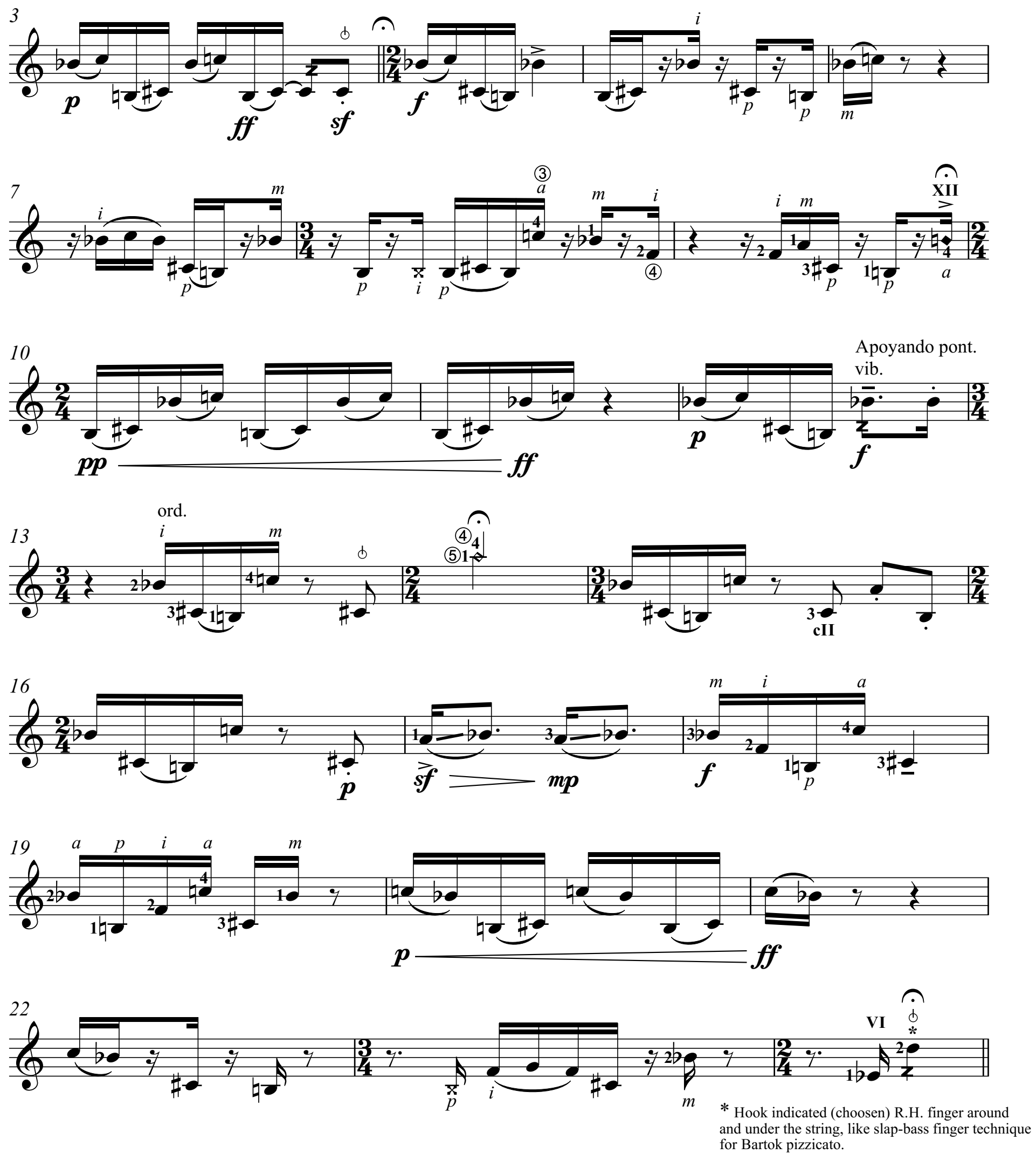

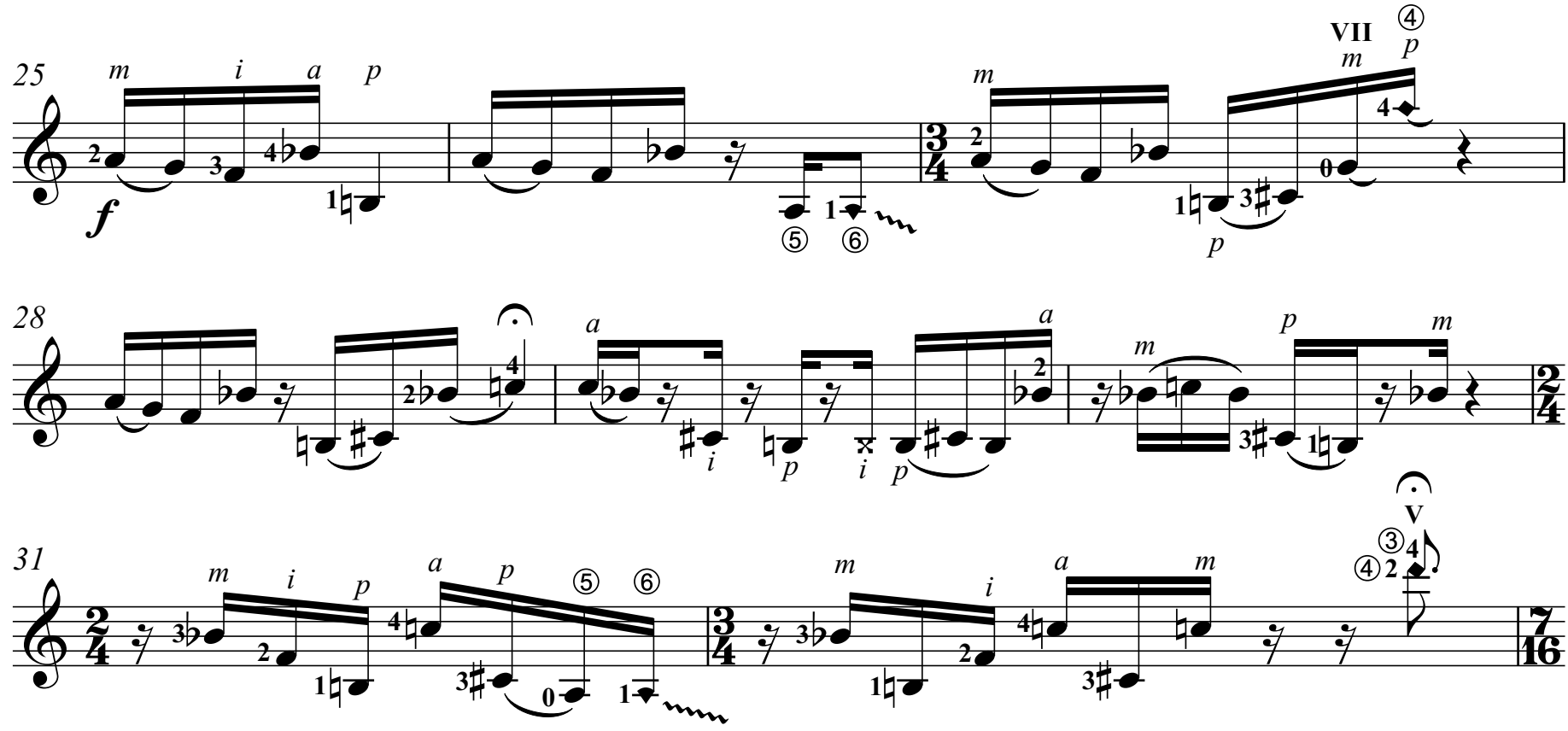
CVII-----------
CVII ---.-- - - - t

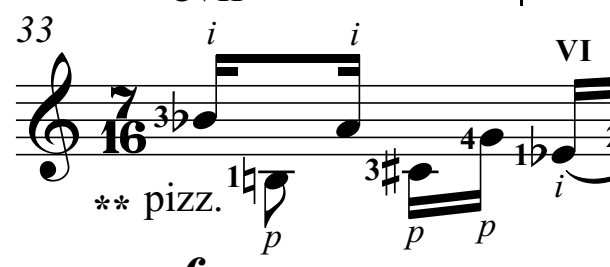

sfp
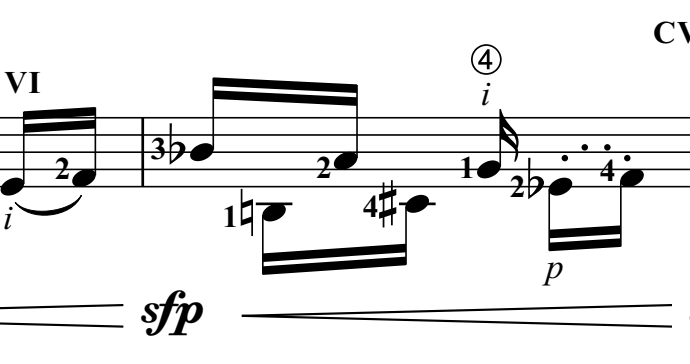

(6)
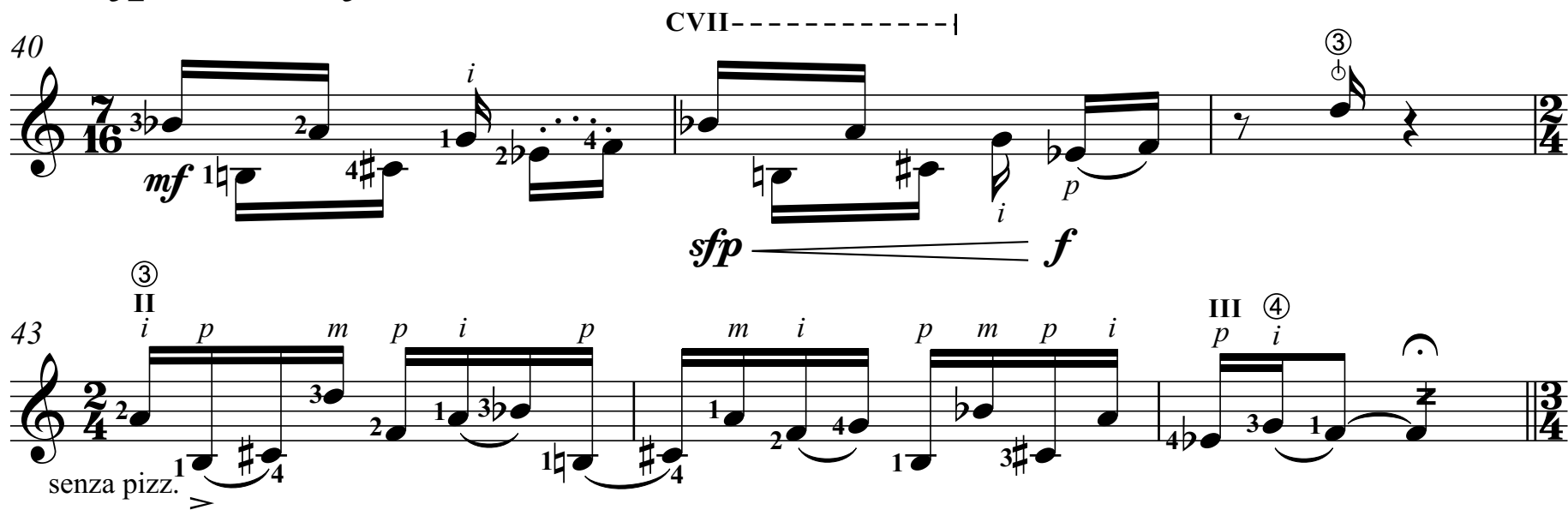

(1)
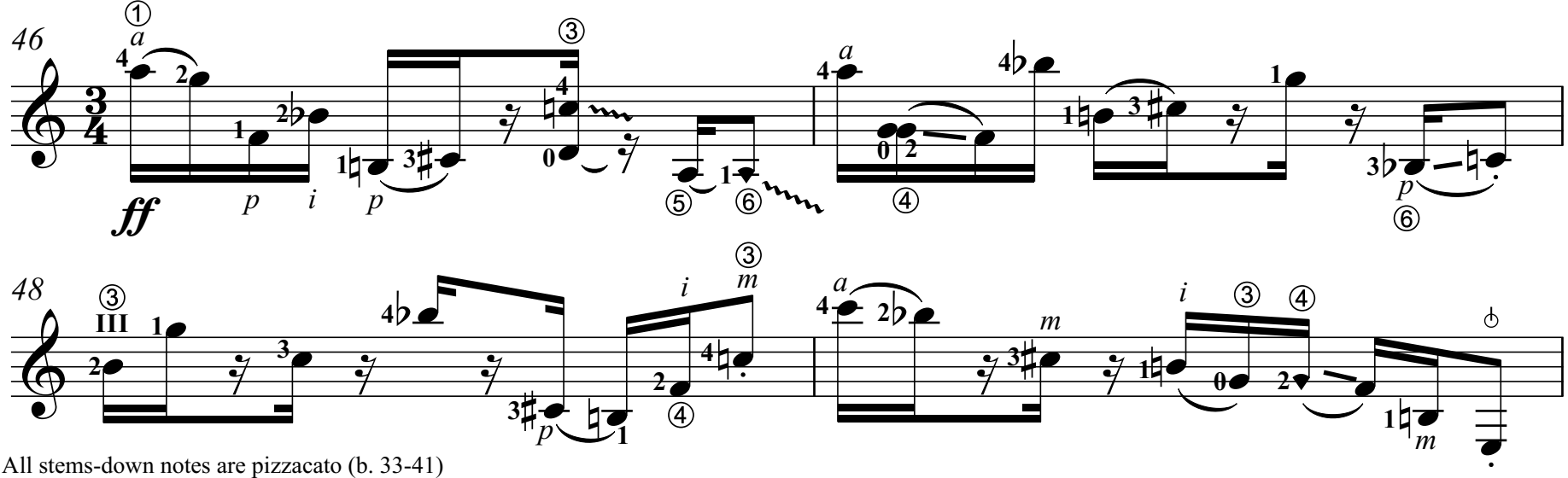
(6)

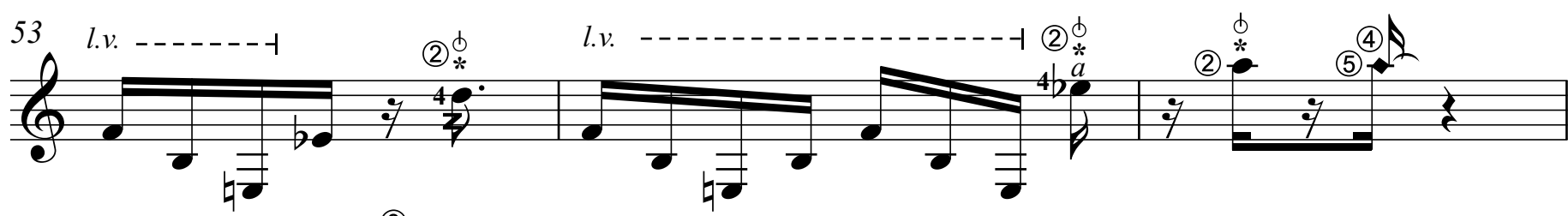

III

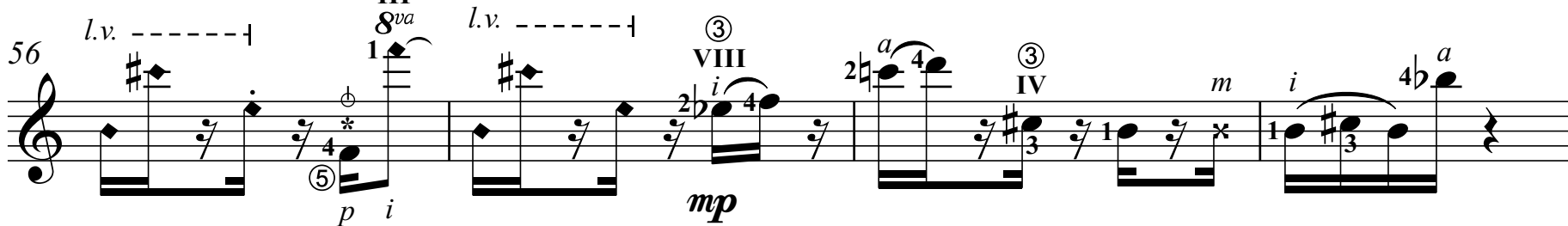
(polp.)
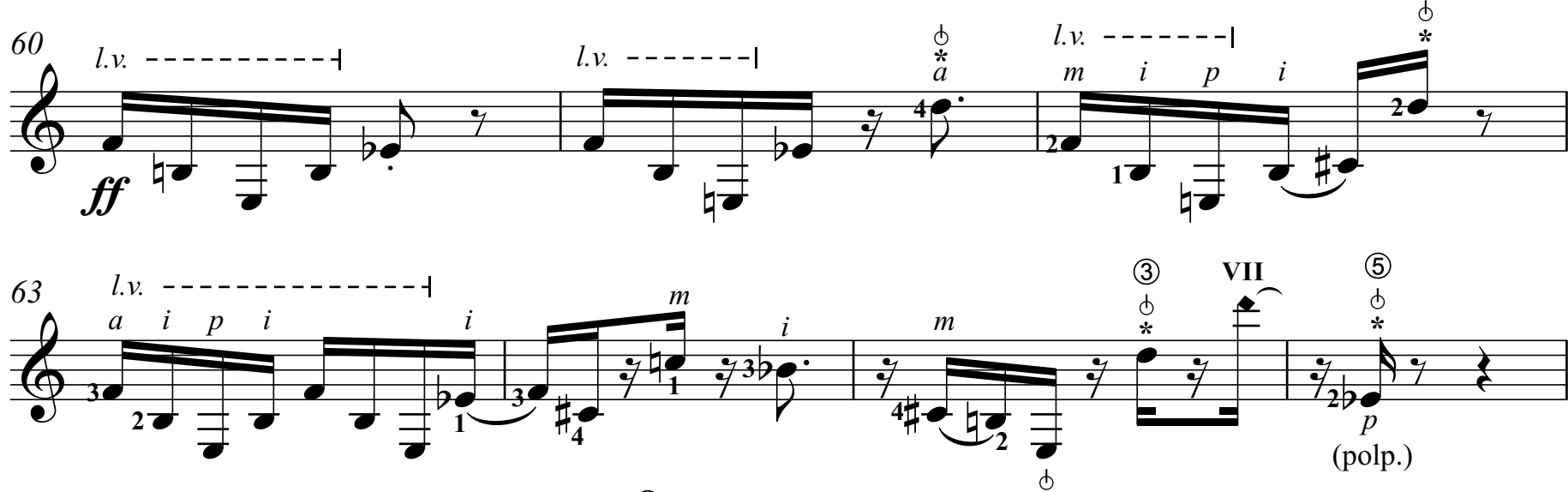

(3) (3)

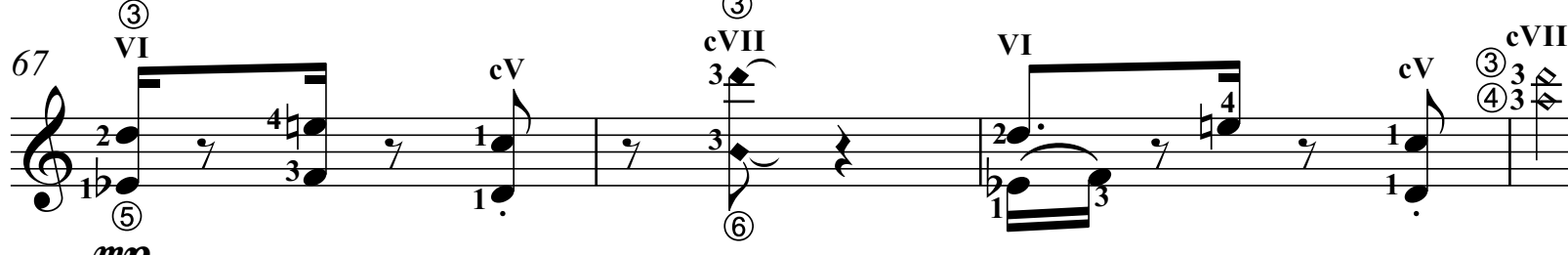

$m p$

(art.harm.)
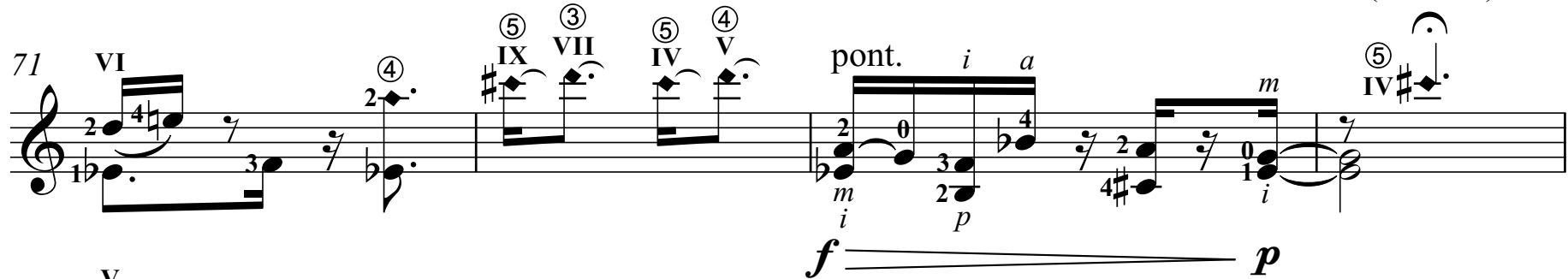

(9)

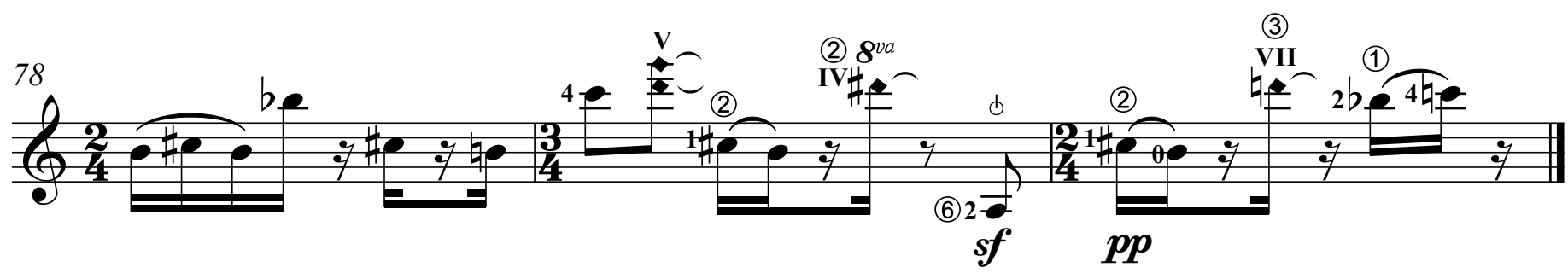




\section{III}

$\cdot=32$

Donna gentil non so

l.v. sempre (3) (4) (6)

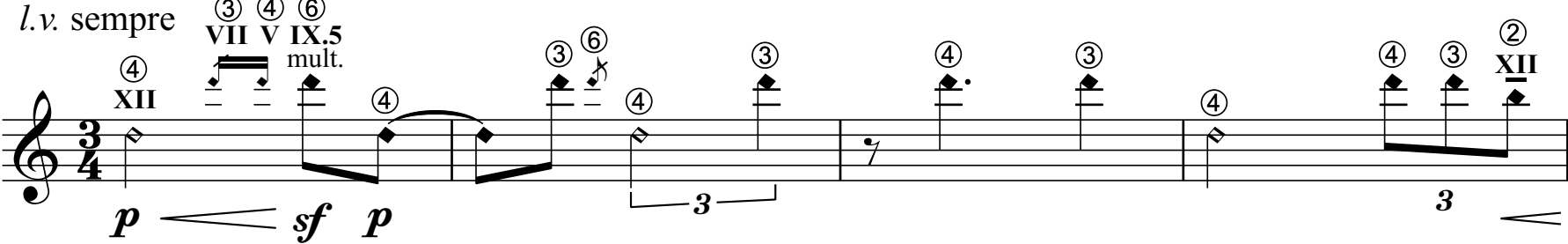

(4)

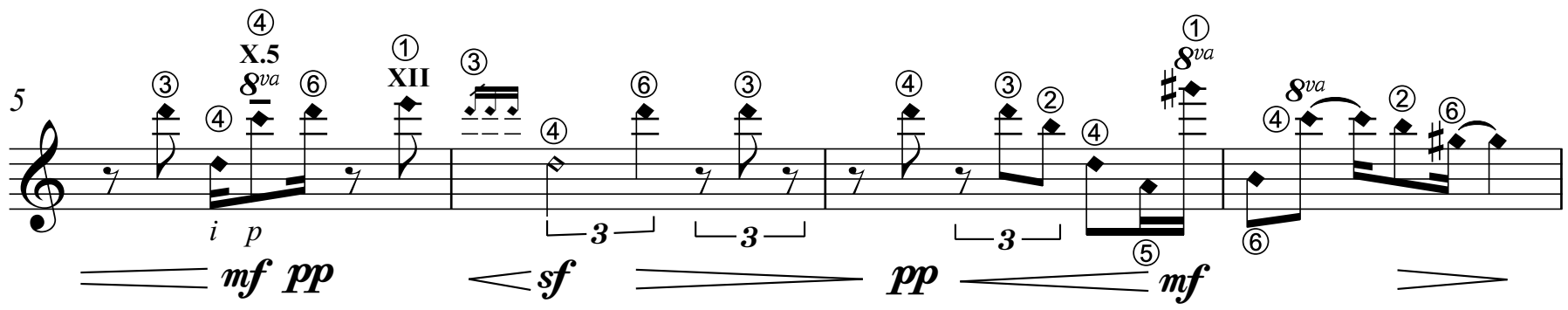

(4)

IV

(scratch)

(3)

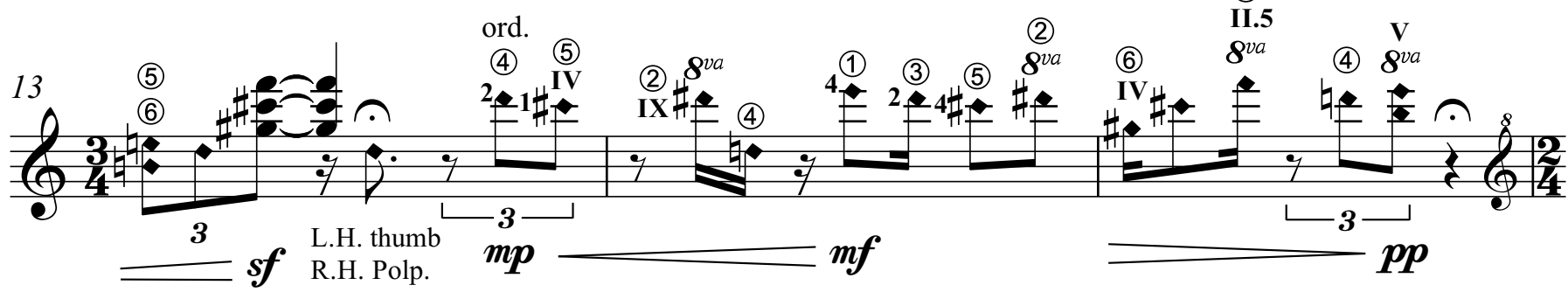

accel. -
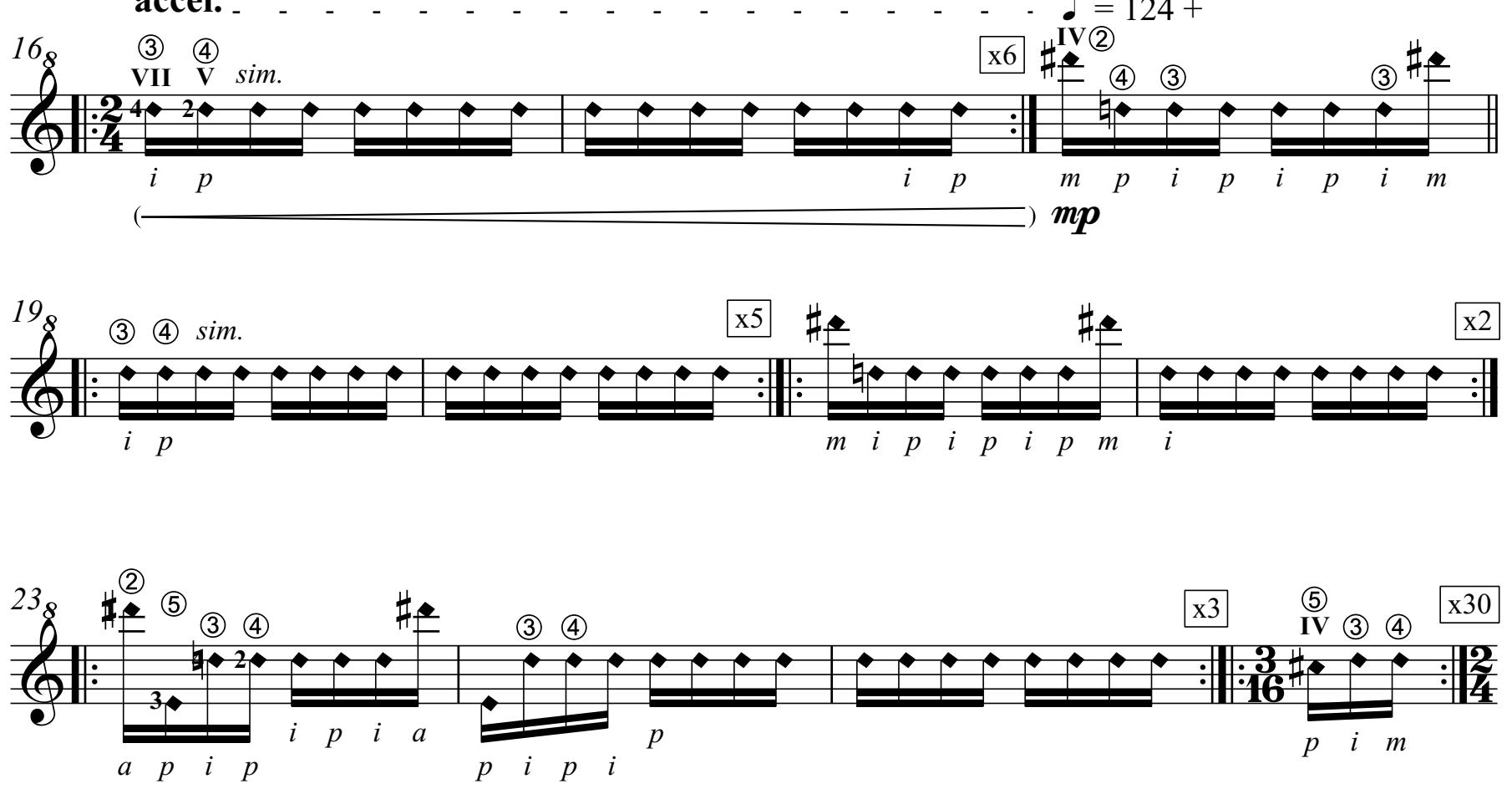


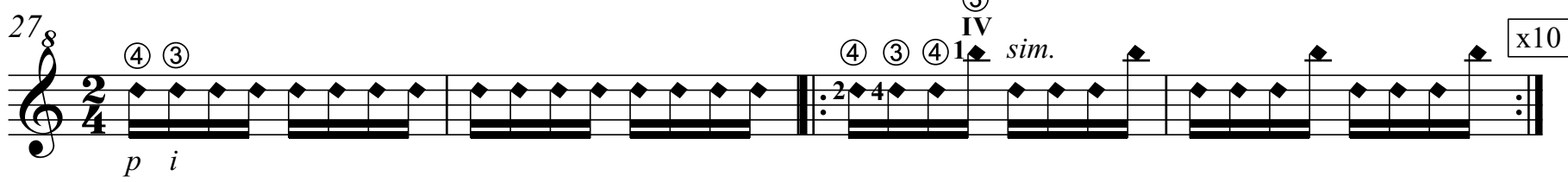
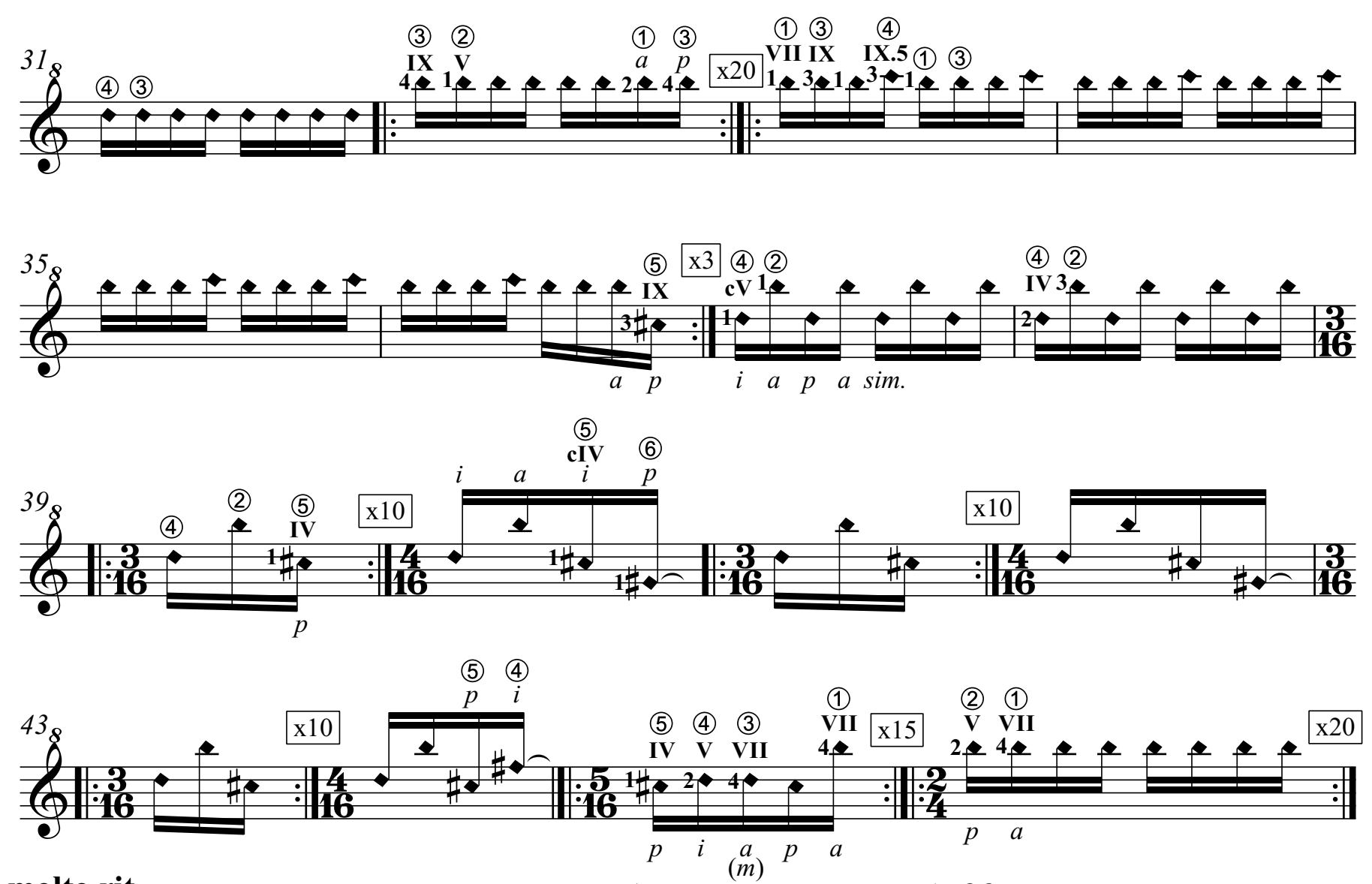

molto rit.

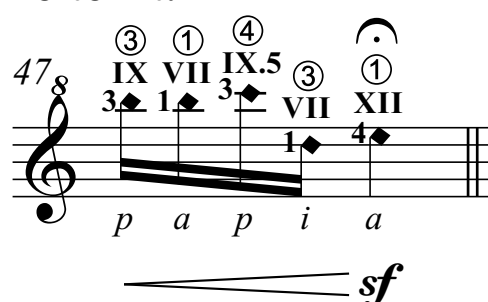

A tempo

(4) (3)

) $p p$

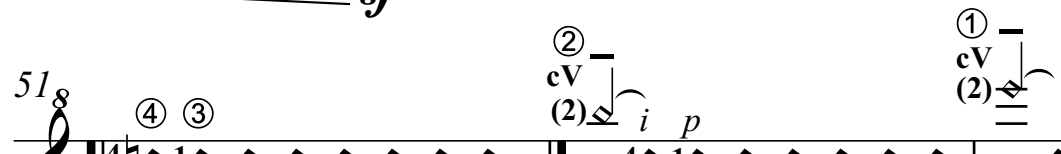

(4) (3)

$p i$

(5) (3) (4)

(2)

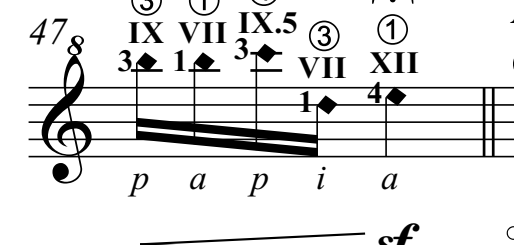
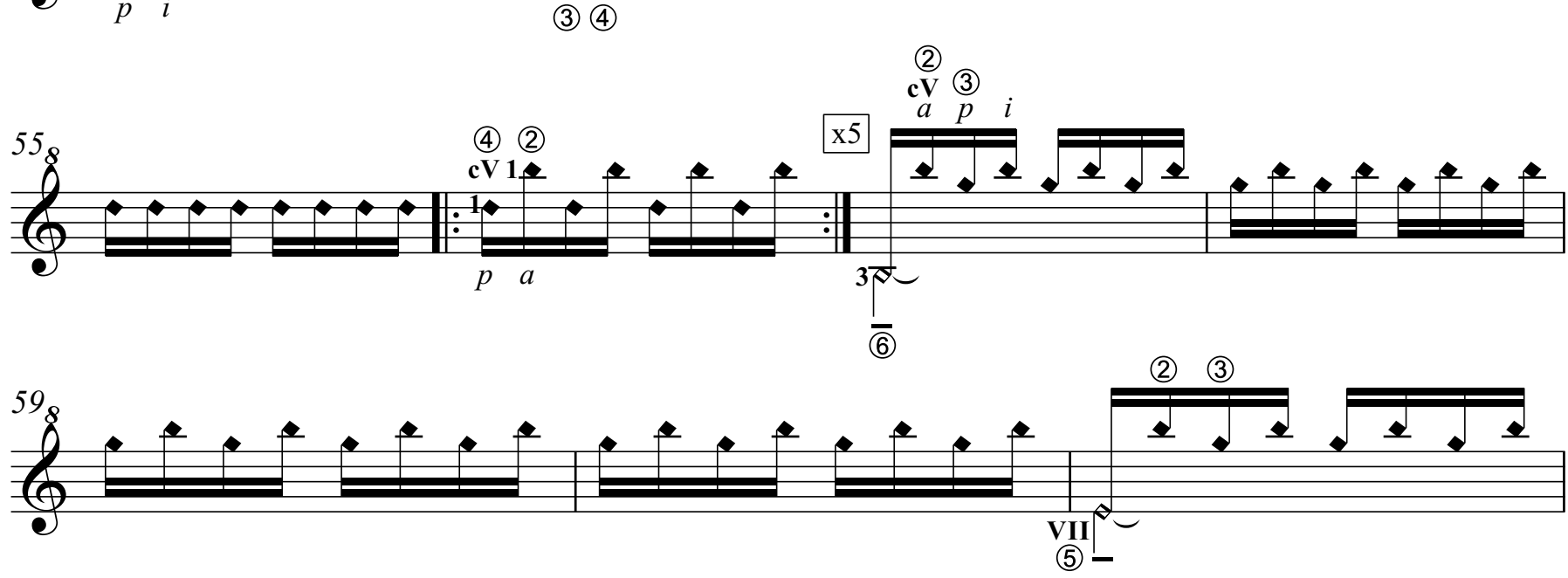

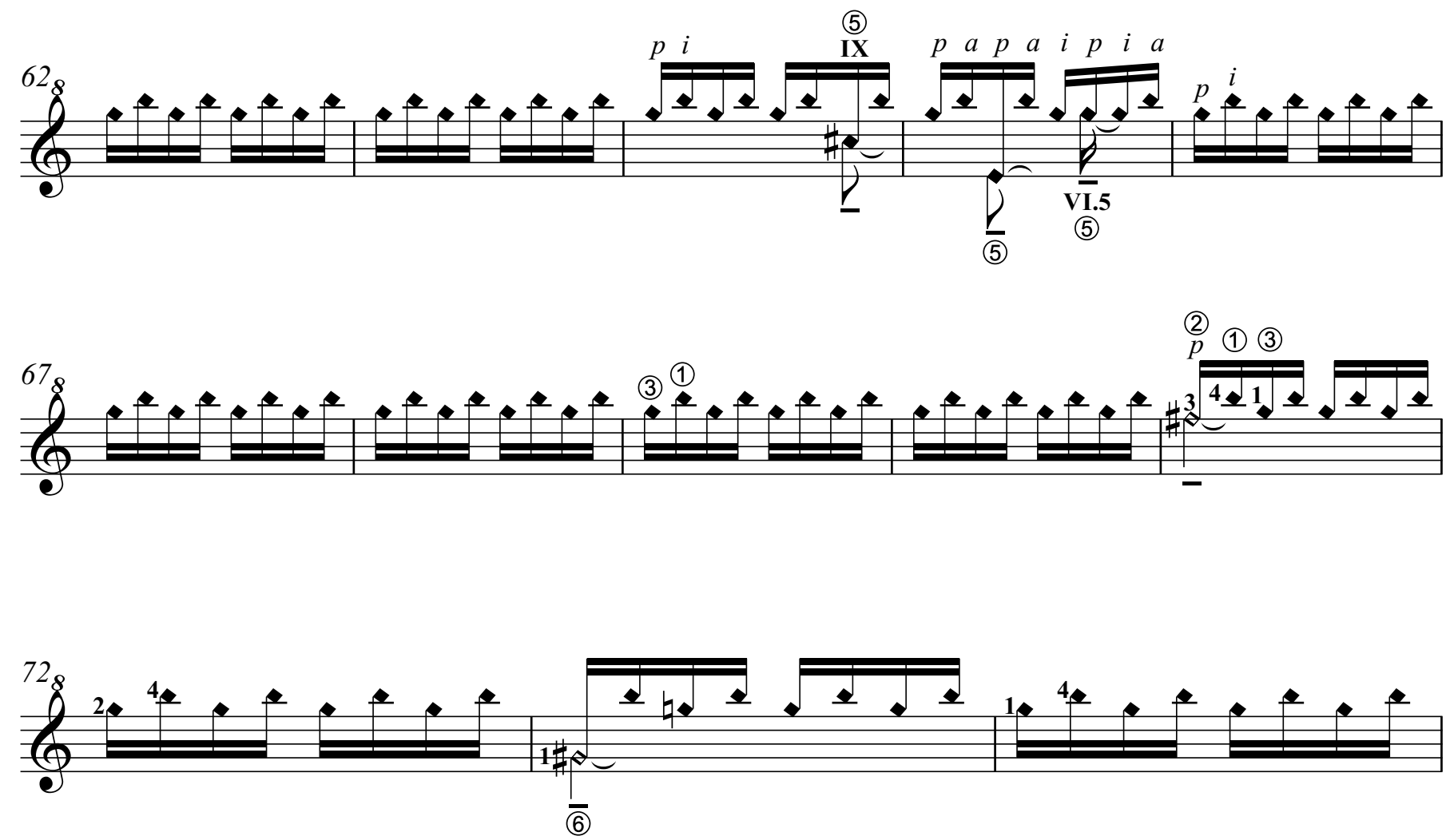

(1) (3)

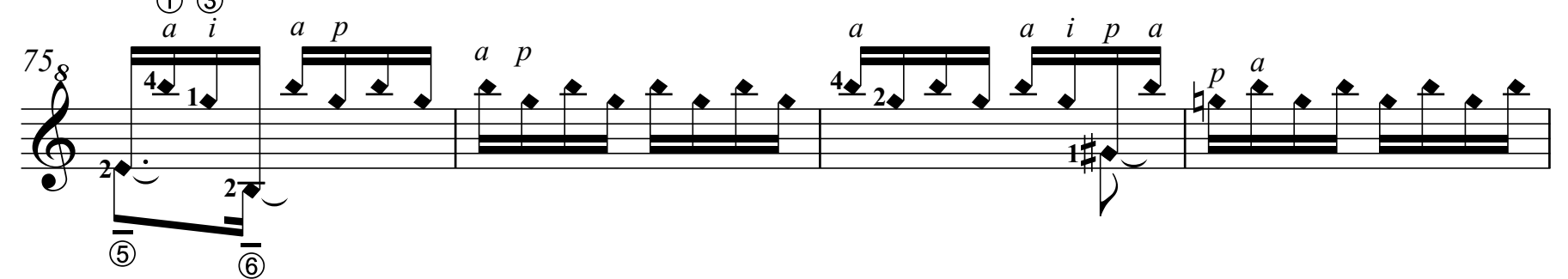

(3) (1)

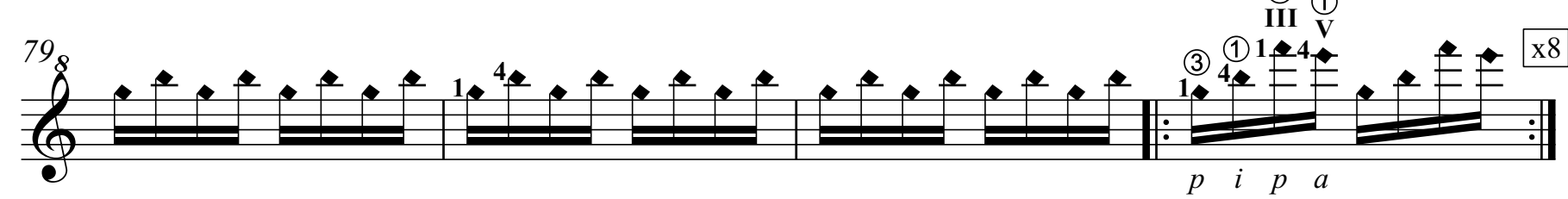

rit. ๖ $=62$ (over repeats)

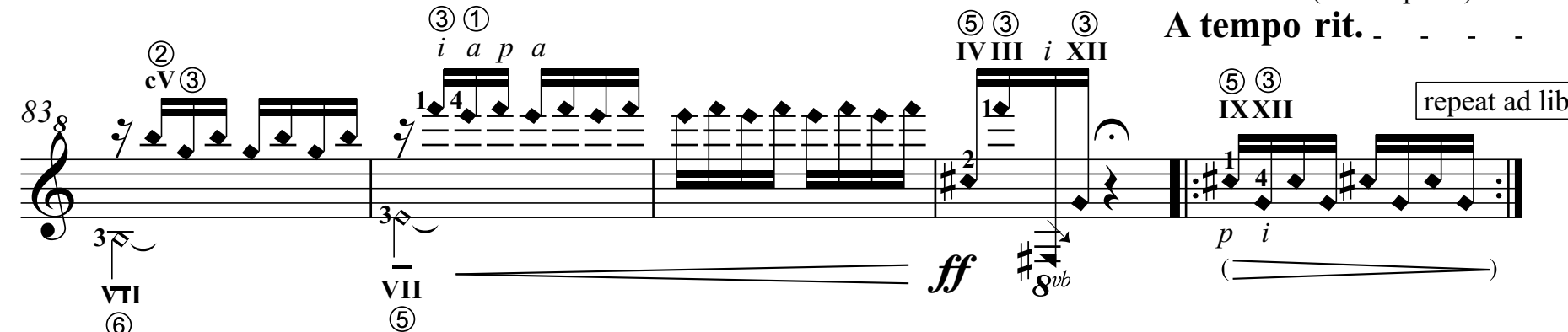
๖ $=42$

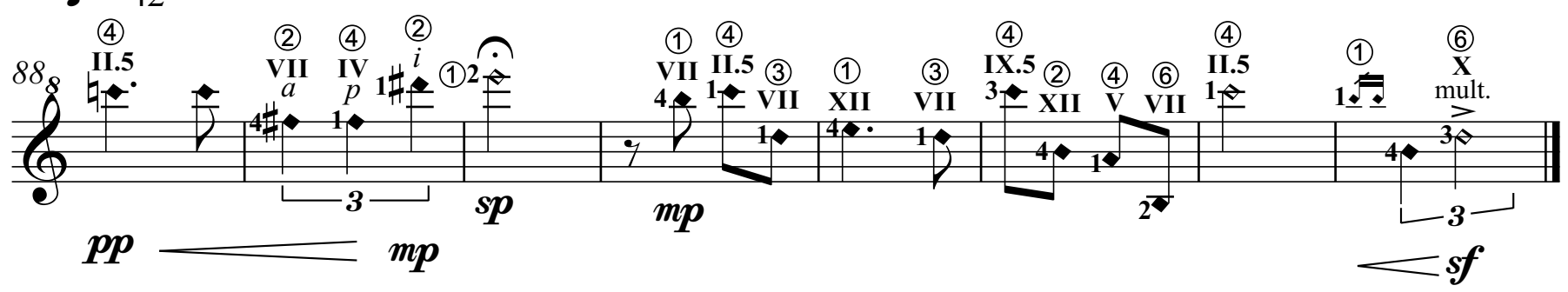




\section{Chimera}

Chimera for violin and harp, is a single movement work in three parts. Each part varies and contrasts

significantly, but each is based upon a variation of similar simple units and cells. In the beginning the opening harp pattern goes through multiple rearrangements of the same units, never appearing exactly, but always made of the same parts (similar to the 'bell' motif od Stravinsky discussed in the accompanying exegesis). Upon this a violin melody is superimposed, consisting of mostly foreign notes of the harps mode, these minor third units $\mathrm{f}$, a flat $\& \mathrm{~g}$, b flat become crucial to the middle section.

The middle section consists of a stratification and interlock (see the exegesis for more detail) in which contrasting blocks of material alternate with each other. These blocks of material are displaced rhythmically, but again are always the same units being played off one another.

The third section superimposes the opening violin melody, including characteristic gestures from the second section, over a harp chorale which slowly becomes more harmonically rich. The originating material for the harp chorale is taken from juxtaposing different chords together from existing material in the first and second sections. 


\section{Glen Downie}

\section{Chimera}

for Laura Barton and Michelle Velvin 
In the first section the performers are free to play with lots of rubato, although note values still hold their approximate lengths,

performers are encouraged to draw out long notes and speed up and slow down quaver patterns

Fermatas are to be held at the performers discretion, but roughly around a dottted minim 


\section{Chimera}

for Laura Barton and Michelle Velvin

Tempo rubato c. $\downarrow=42-52$

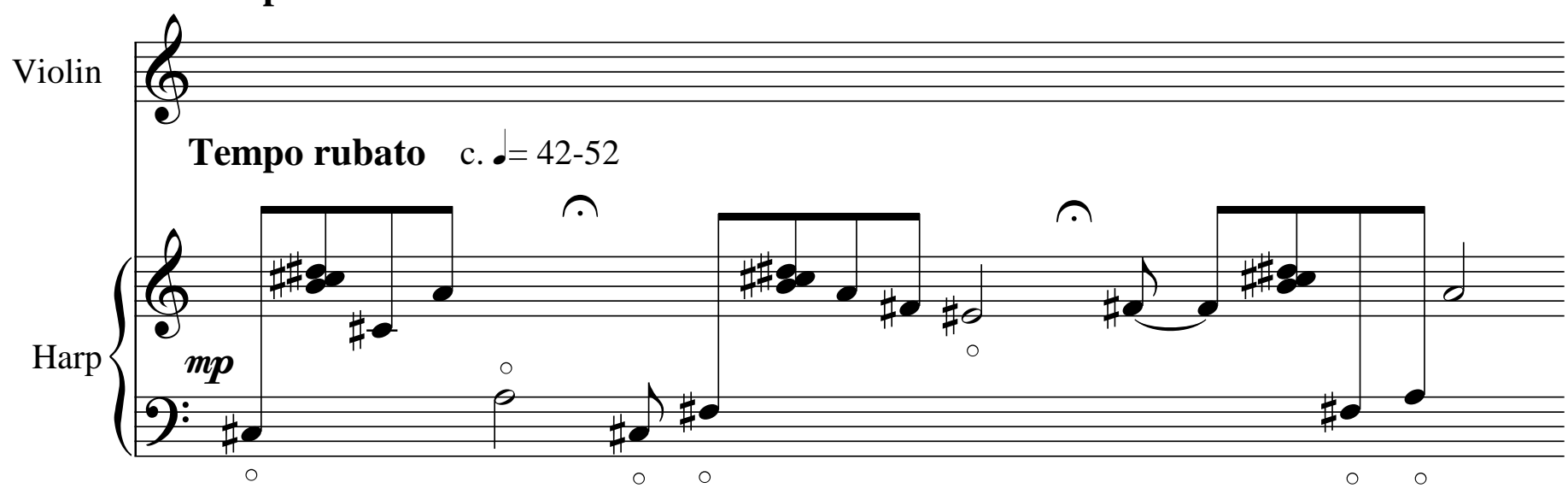

sul pont.

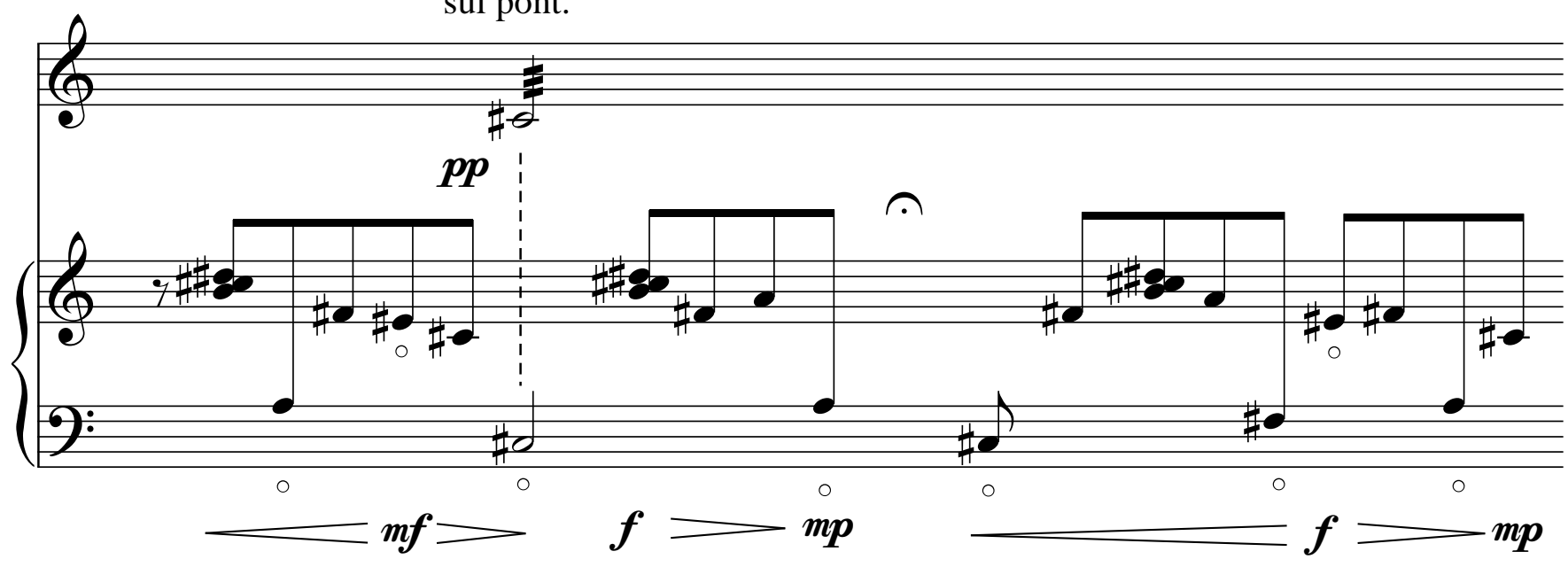

sul pont.

nat.

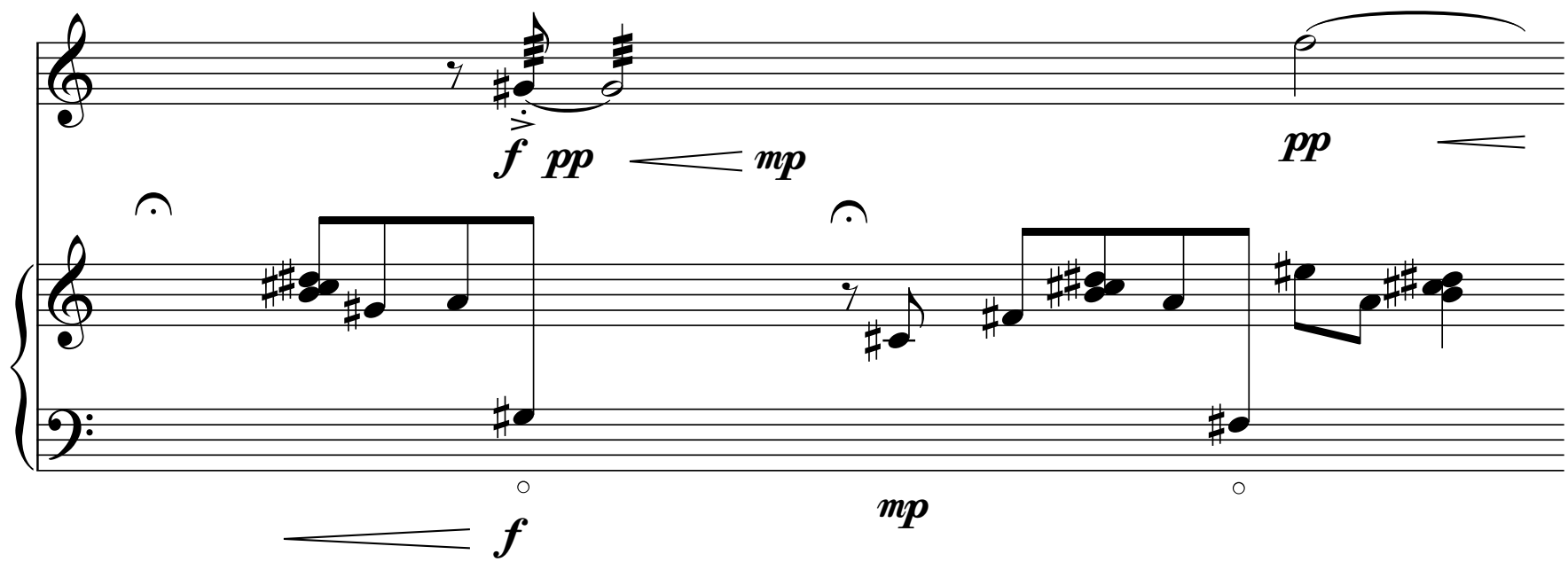



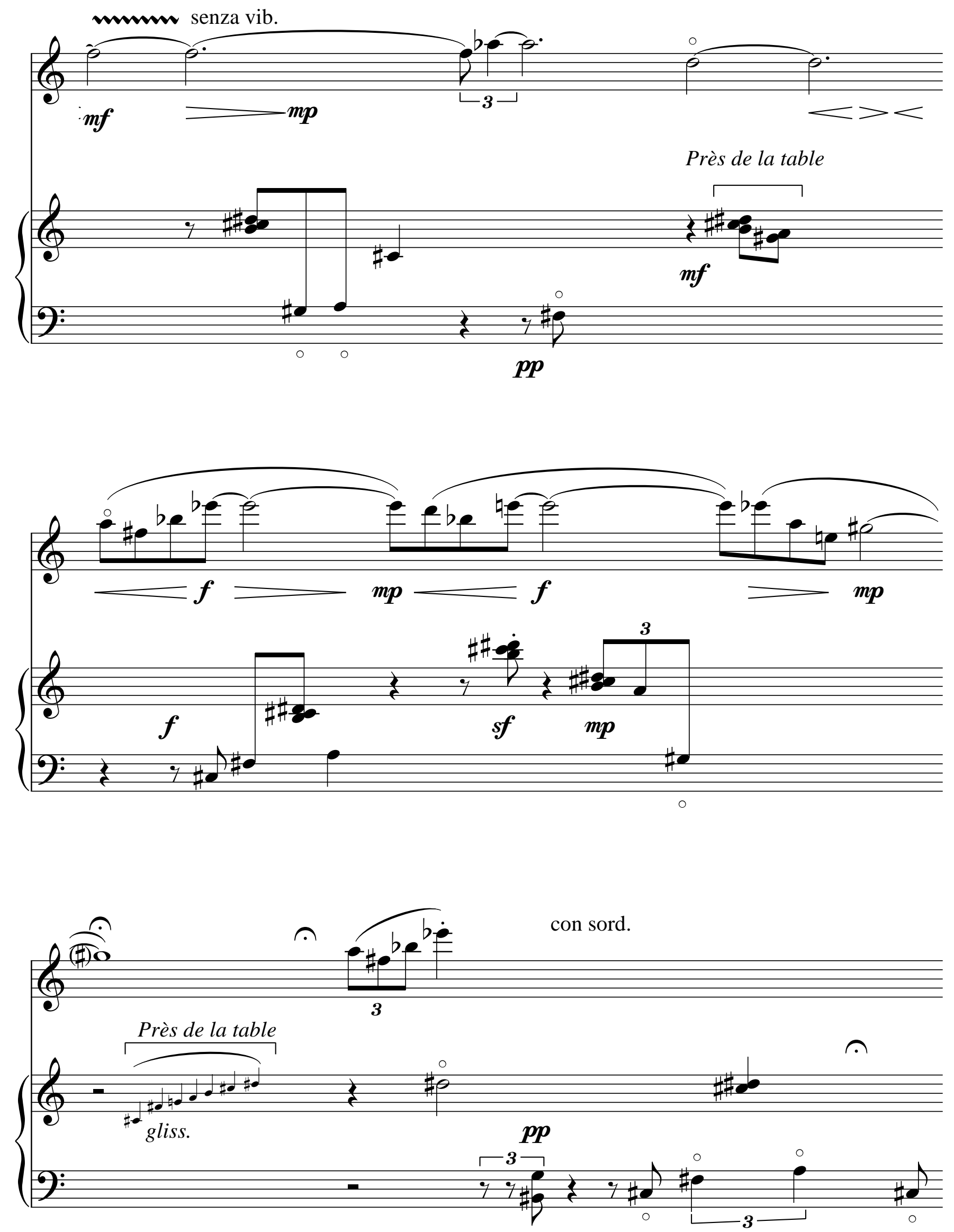

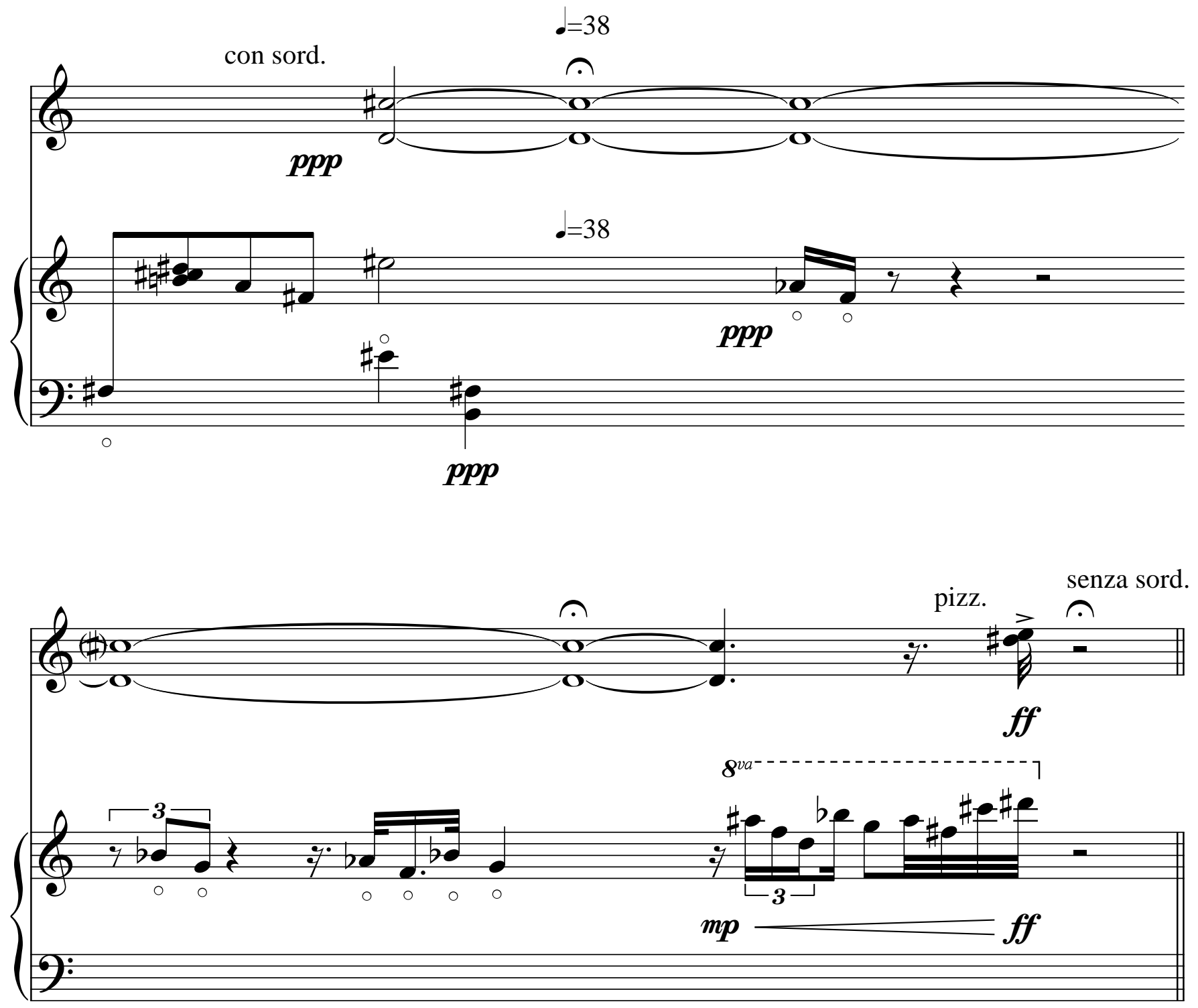
$d=74$
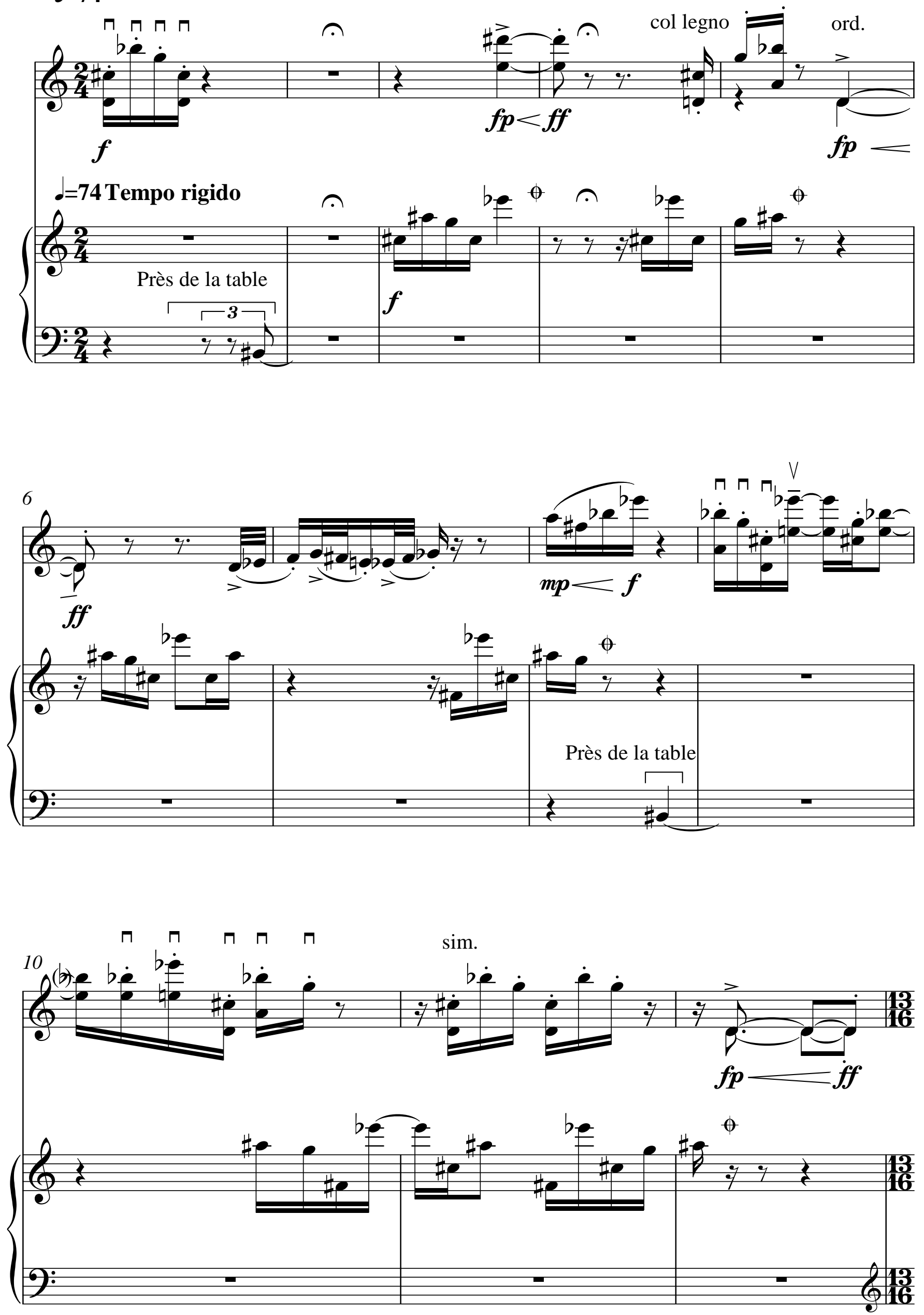
$A=0$

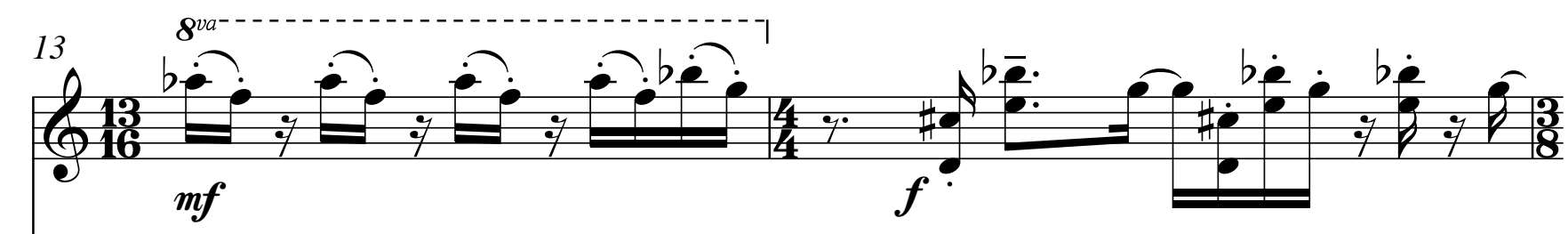
$\therefore=0$

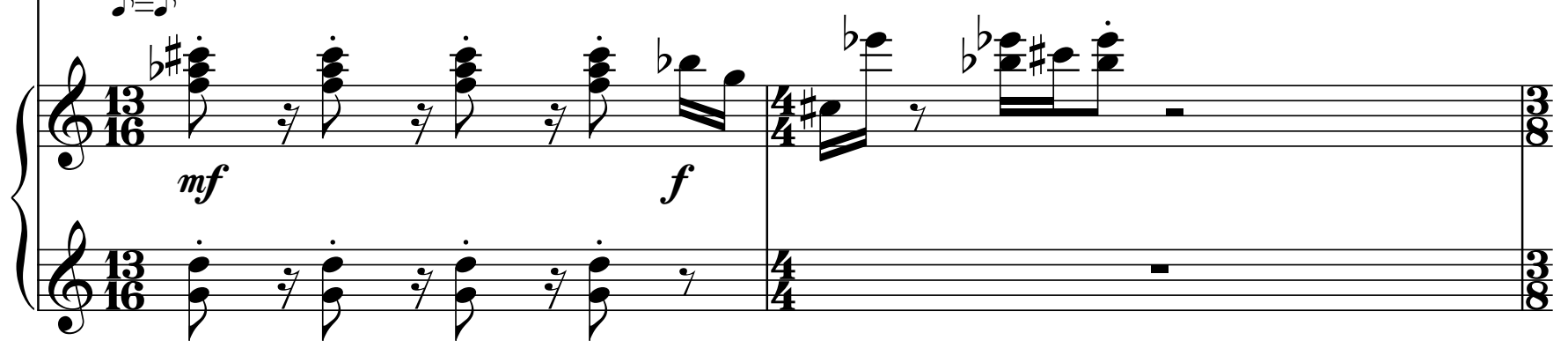
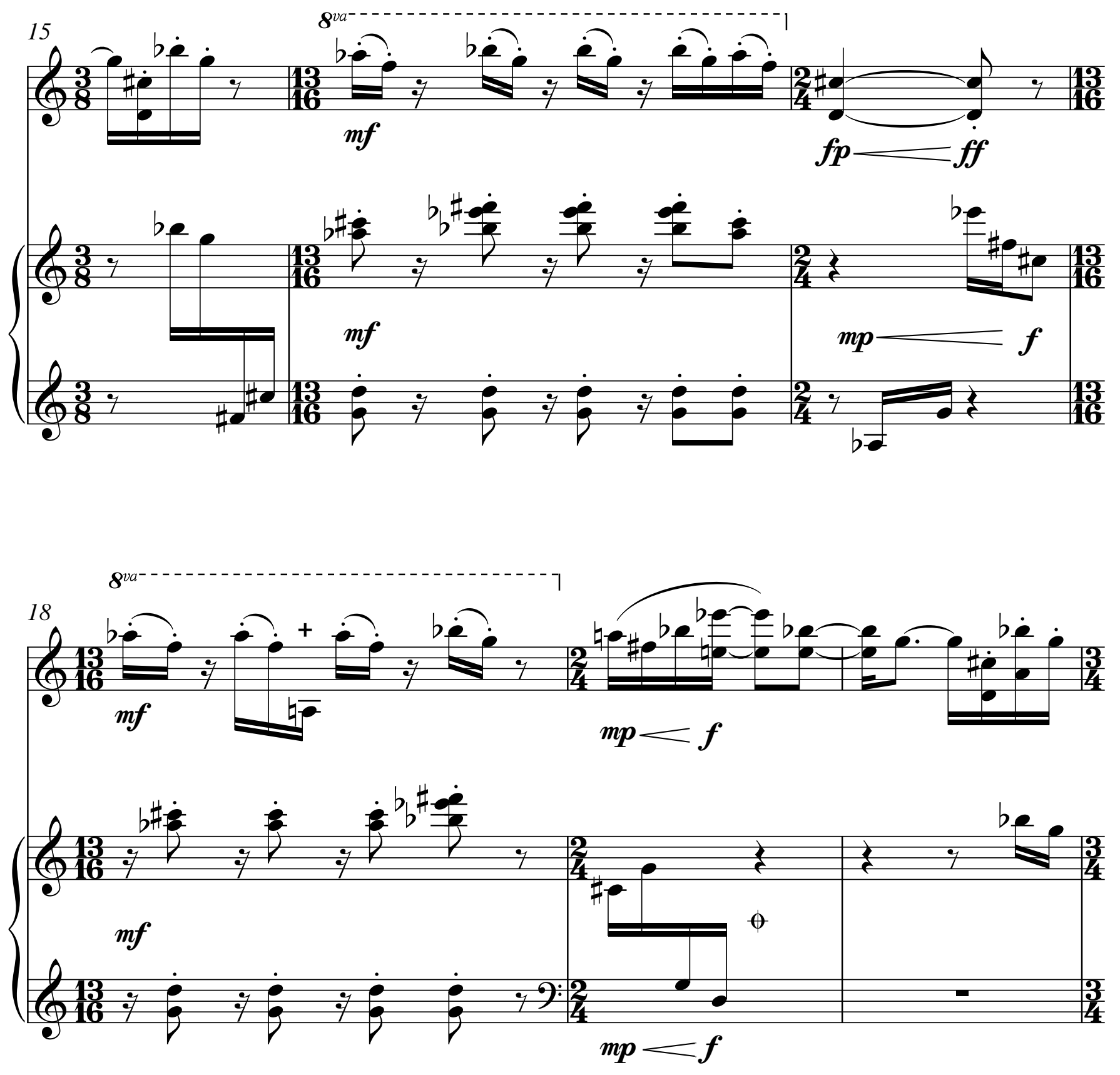

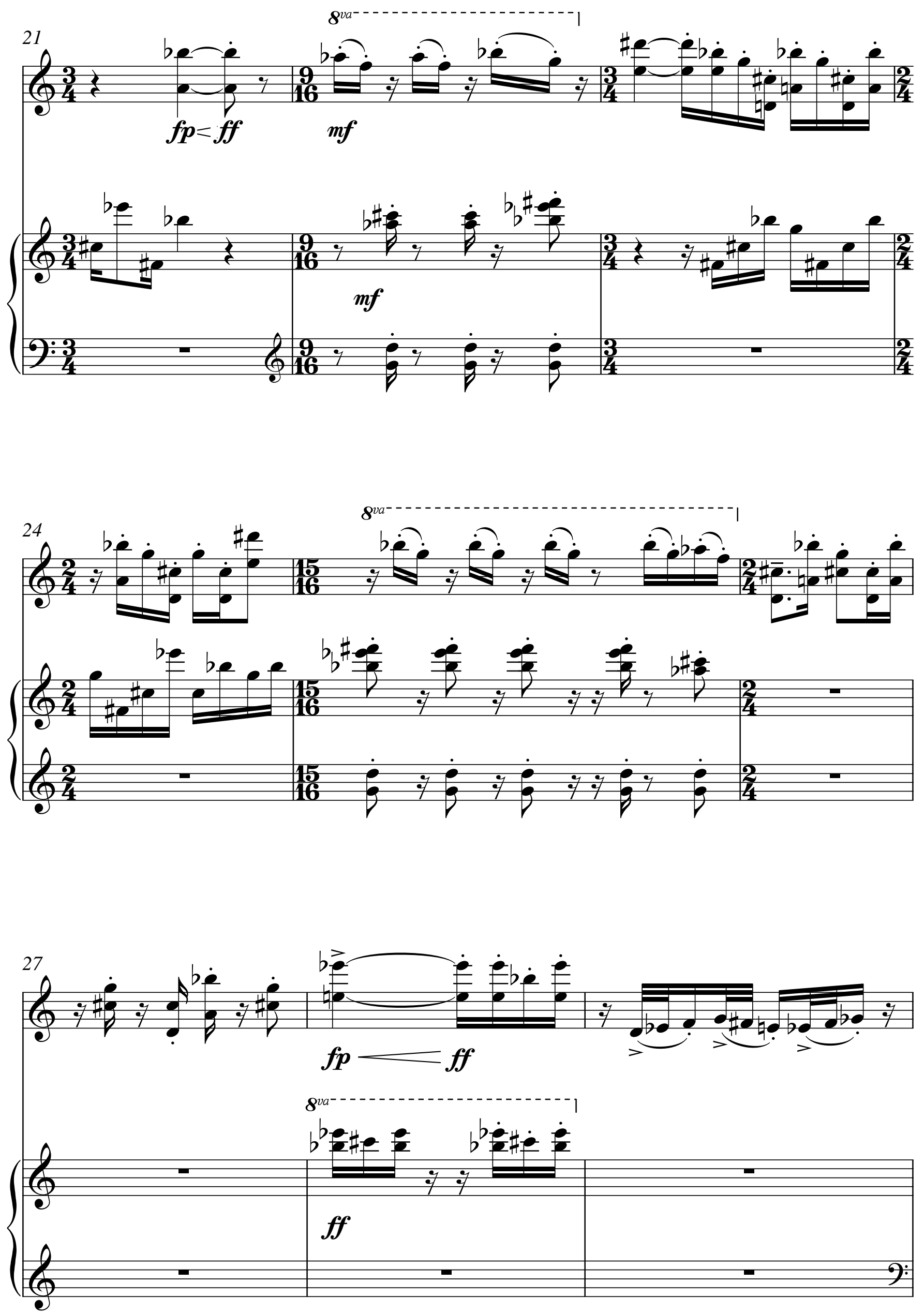
col legno

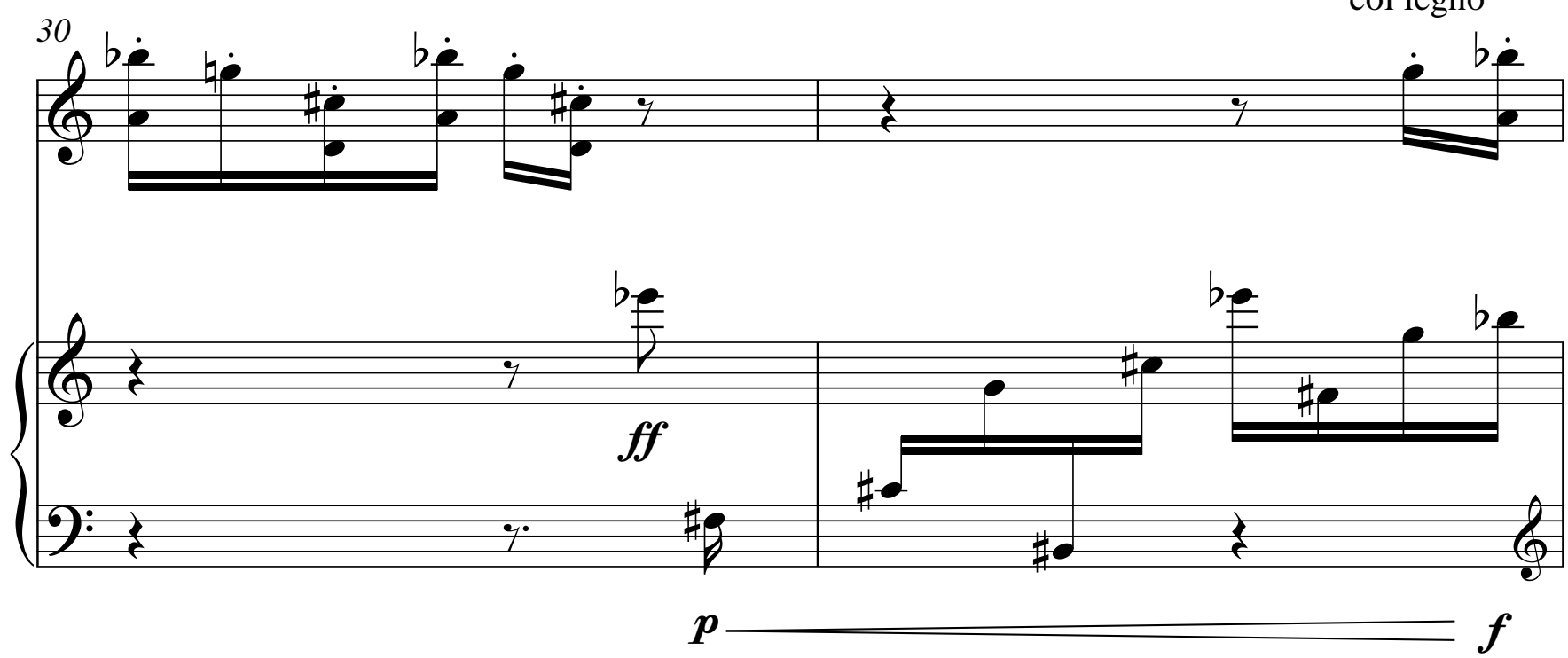

ord.
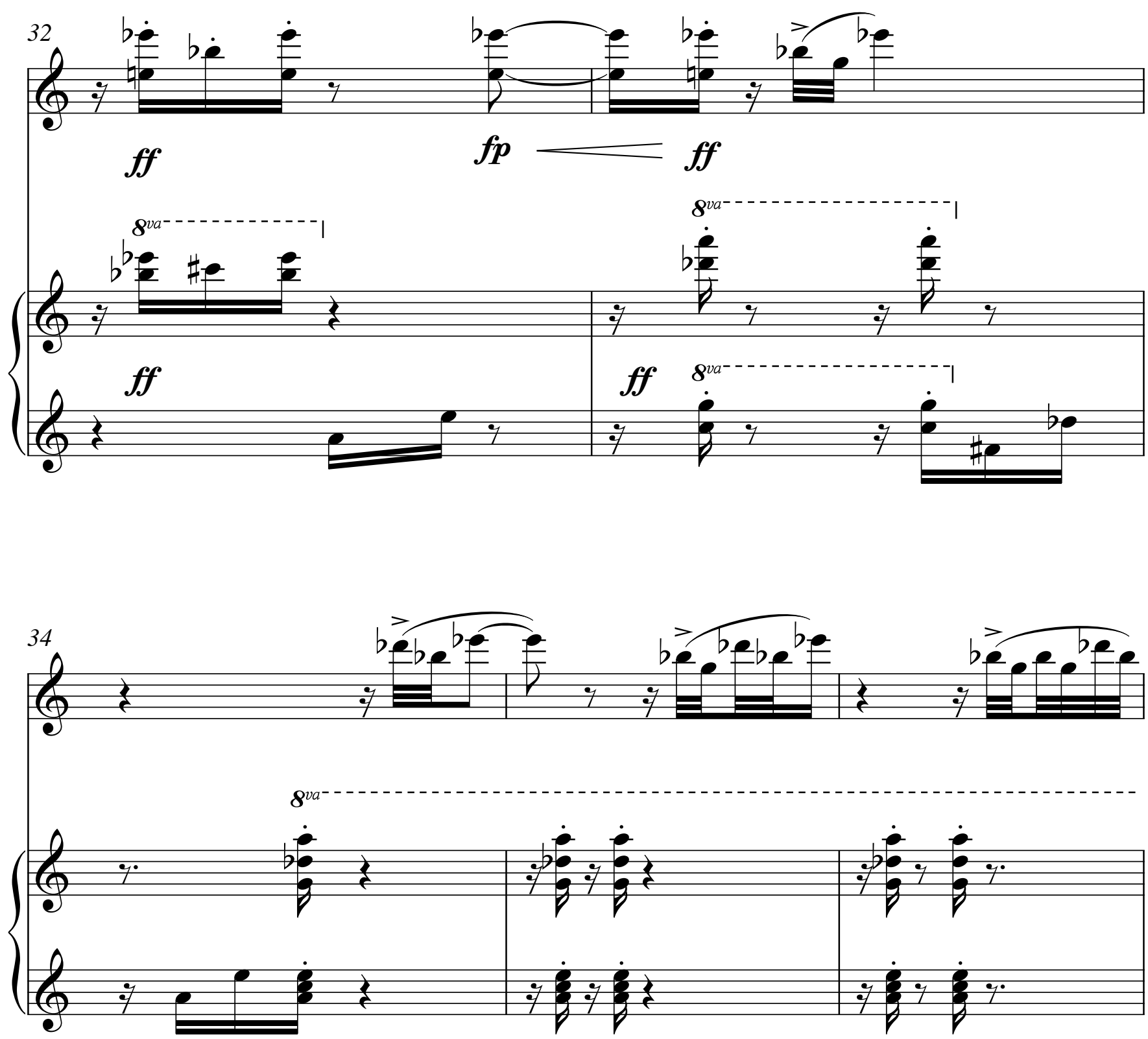

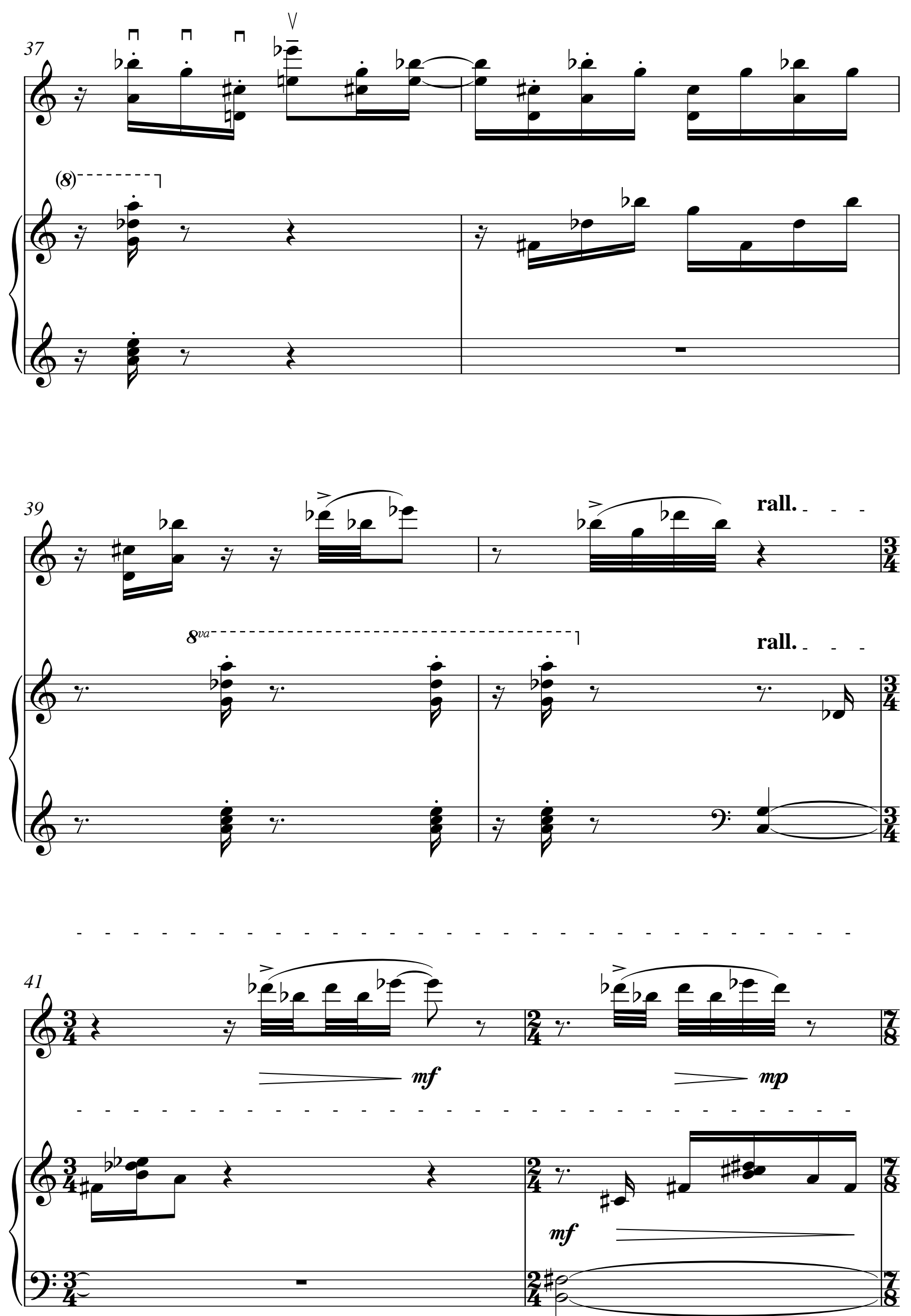

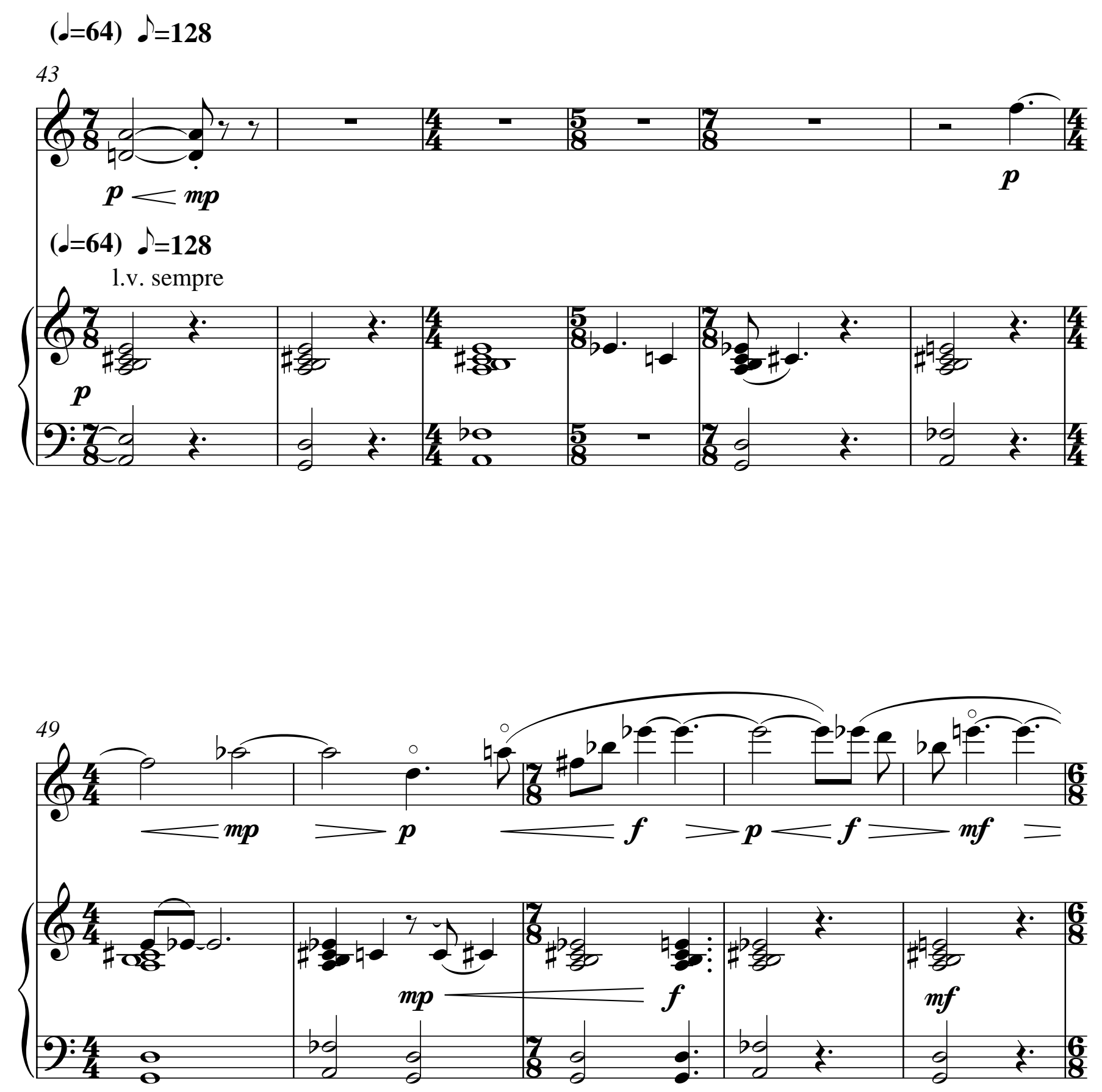

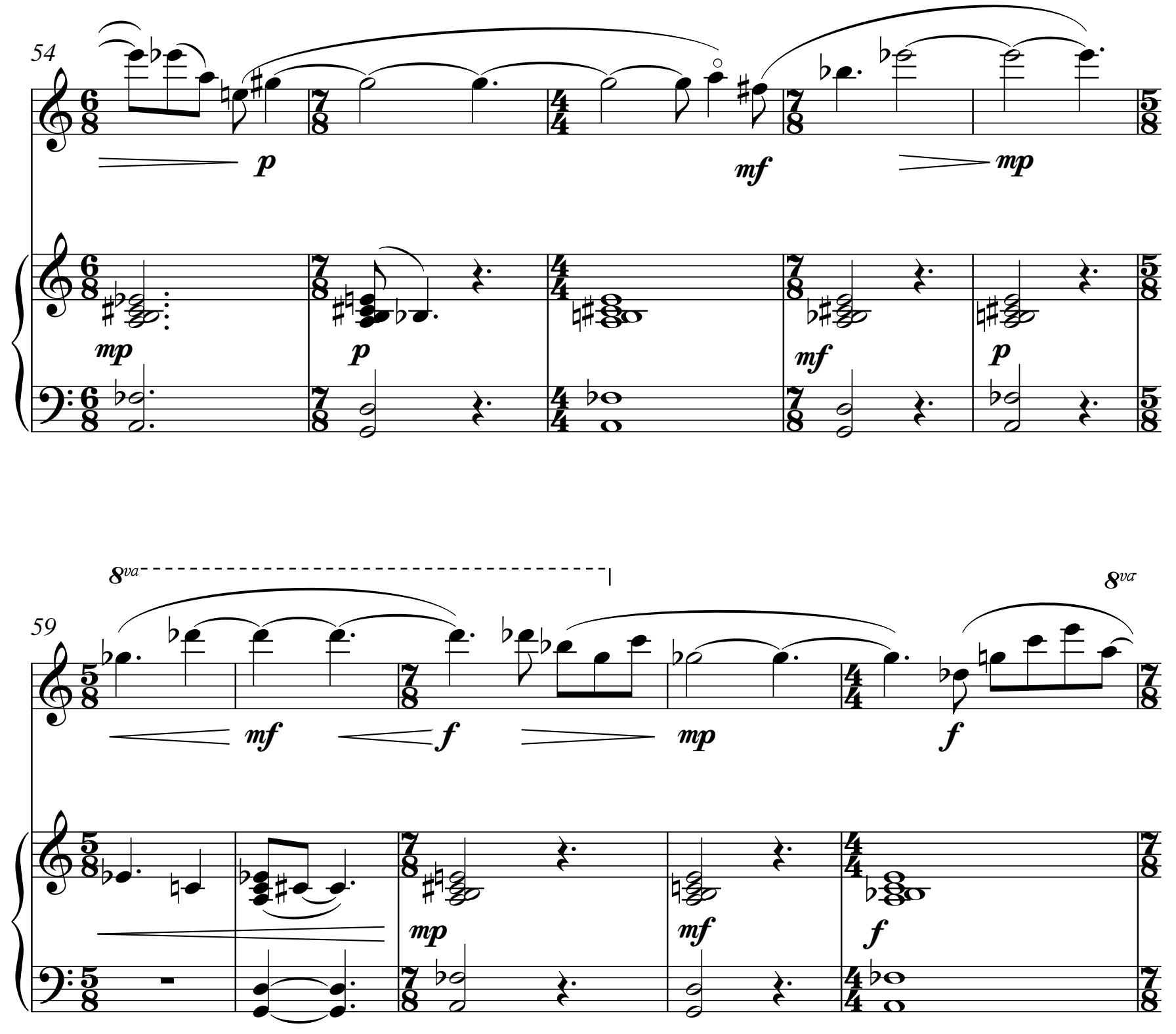

(8)

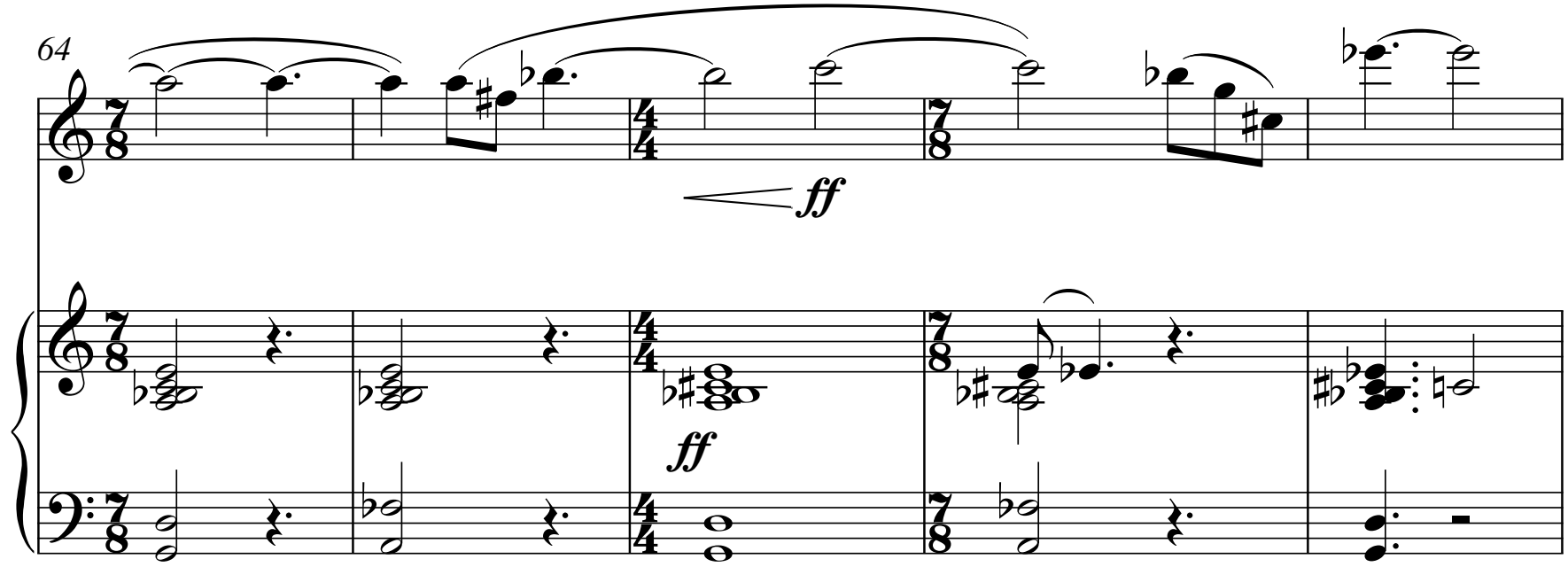



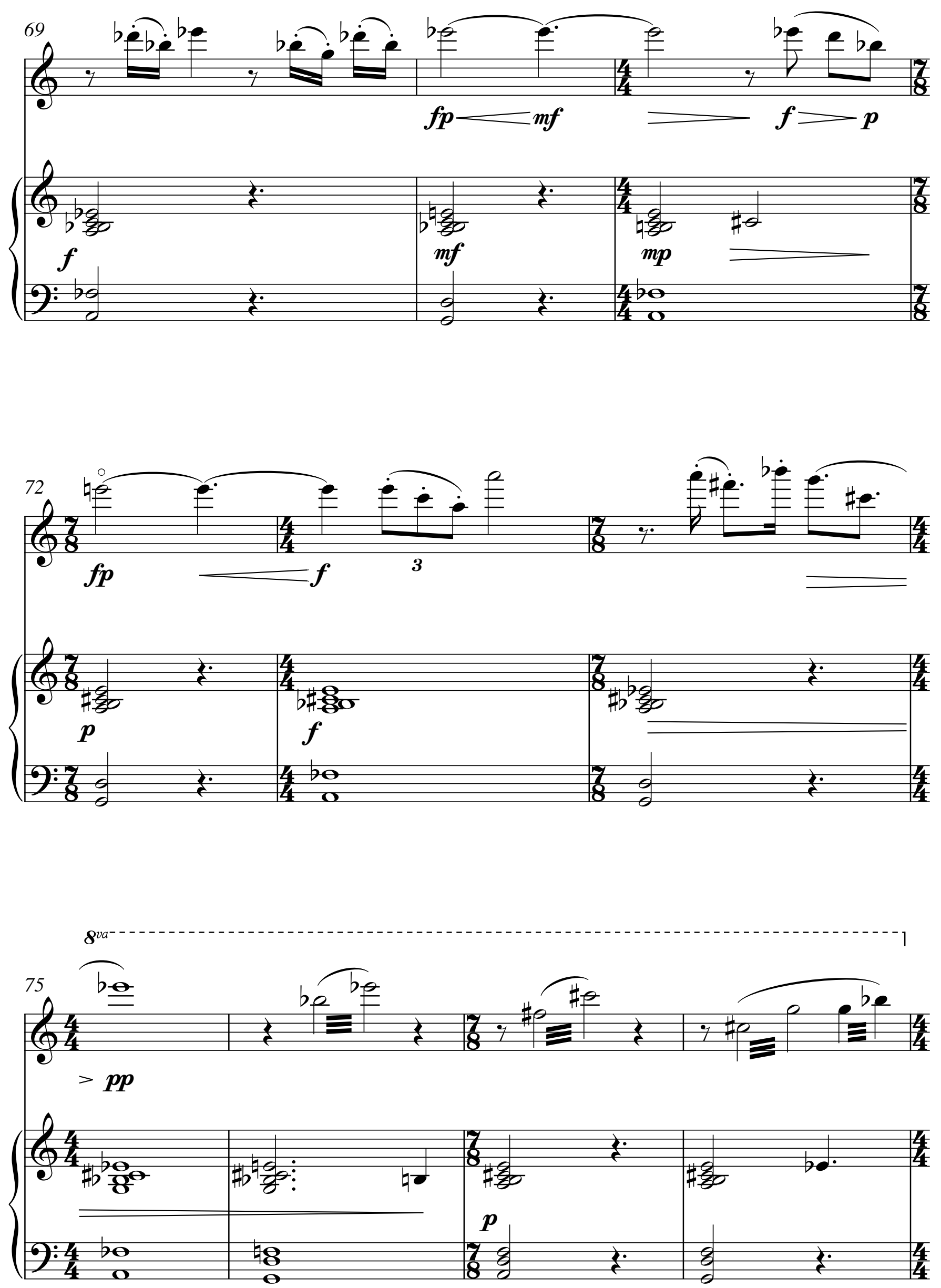


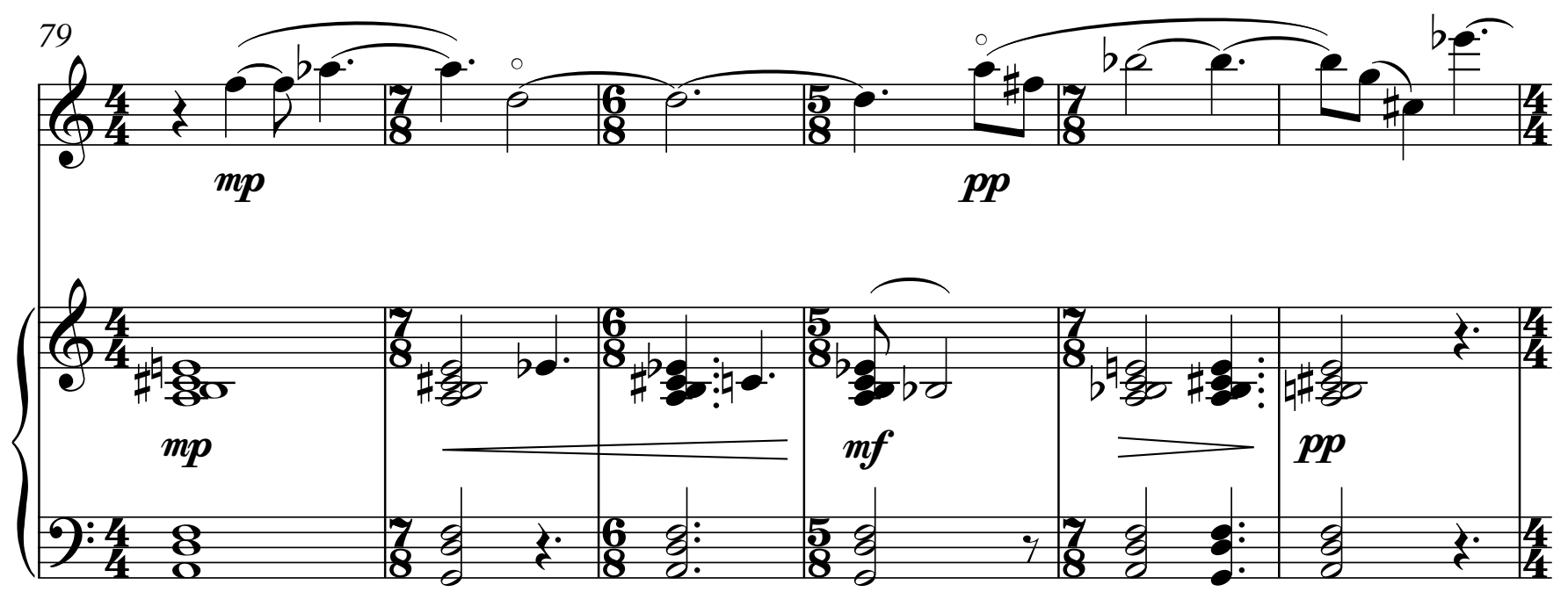

rall. -
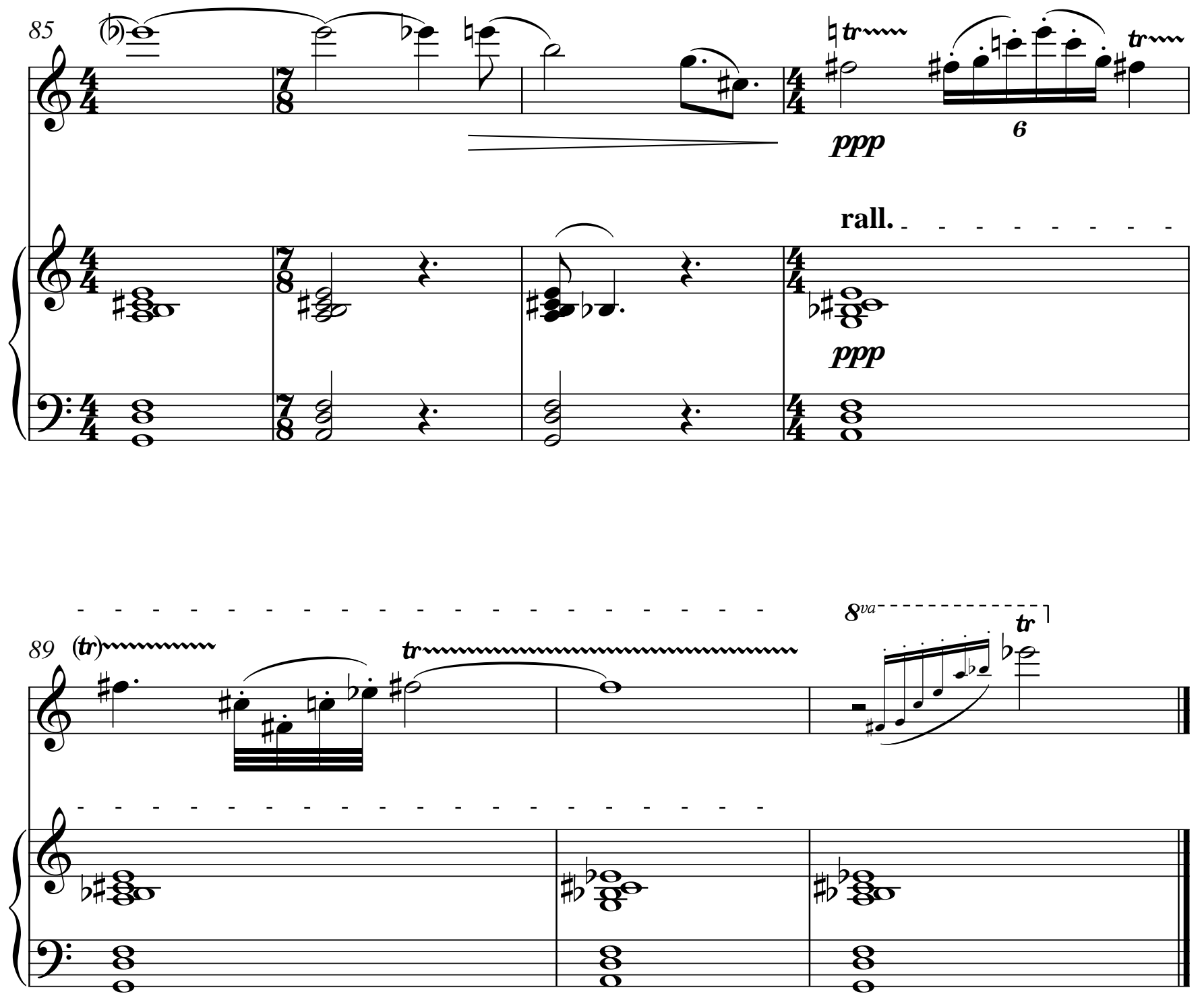


\section{Three Miniatures}

Three Miniatures, for clarinet, tuba and accordion explores the juxtaposition of exact material, or panels between three minature movements of highly distinct character. The first movement is based around a chromatic ostinato that is constantly interrupted and juxtaposed between instrumental colours. The accordion plays the simple chromatic figure first instrocued by a subito clarinet, but is hocketed between the two manuals, creating a timbral and special effect that allows for other patterns to emerge. These new patterns become the material for the tuba, who precedes to interrupt the flow of the instruments, as does the accordion with chromatic clusters. All the material in the first movement is based upon the chromatic figure, but these variations are contrasting in timbre and gesture, allowing for the form to be shaped by superimposition and juxtaposition.

The second movement is a folk like lament, a sharp contrast to the surrounding two movements. It consists of a sustained layer in the accordion which then repeats ad lib. as the clarinet plays an independent melody above, with insertions of the chromatic figure from the previous movement.

The third movement takes some of the superimposed material from the first movement and places it around a limpid groove. The material is highly fragmented and hocketed, but most of the material is exactly repeated from the first movement, but contrasts highly in character, as the interrupting material of the first now form the backbone of the third. Simple elements of the second also appear, such as the simple unit of a trilled clarinet. 
Glen Downie

\section{Three Miniatures}

for Clarinet, Tuba and Accordion 
Transposed Score

\section{Three Miniatures}

for Clarinet, Tuba and Accordion

I.

Glen Downie

b. 1991
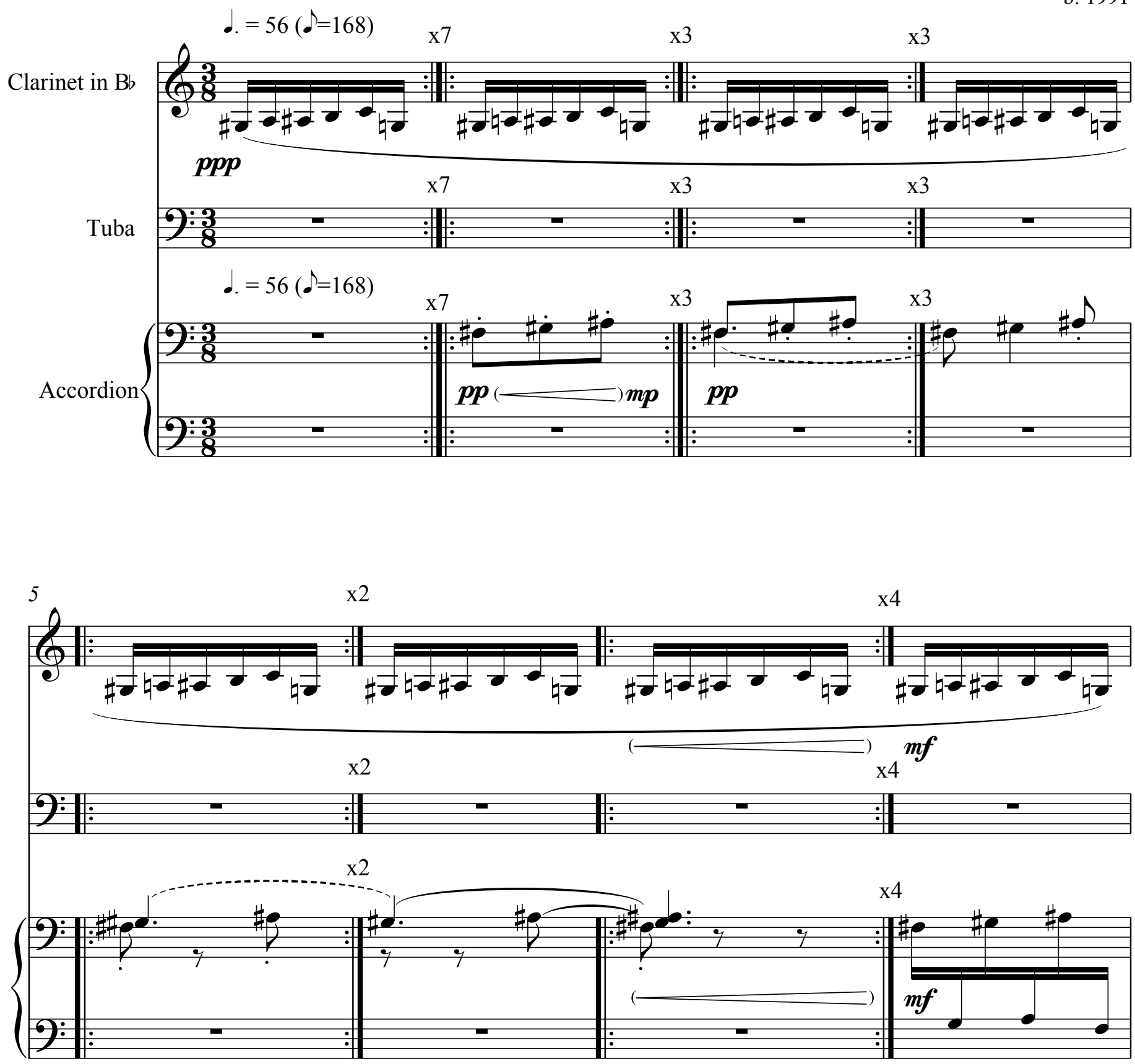

$(\longrightarrow)=$ crescendo over repeats

$+=$ a soft pitched slap tongue 

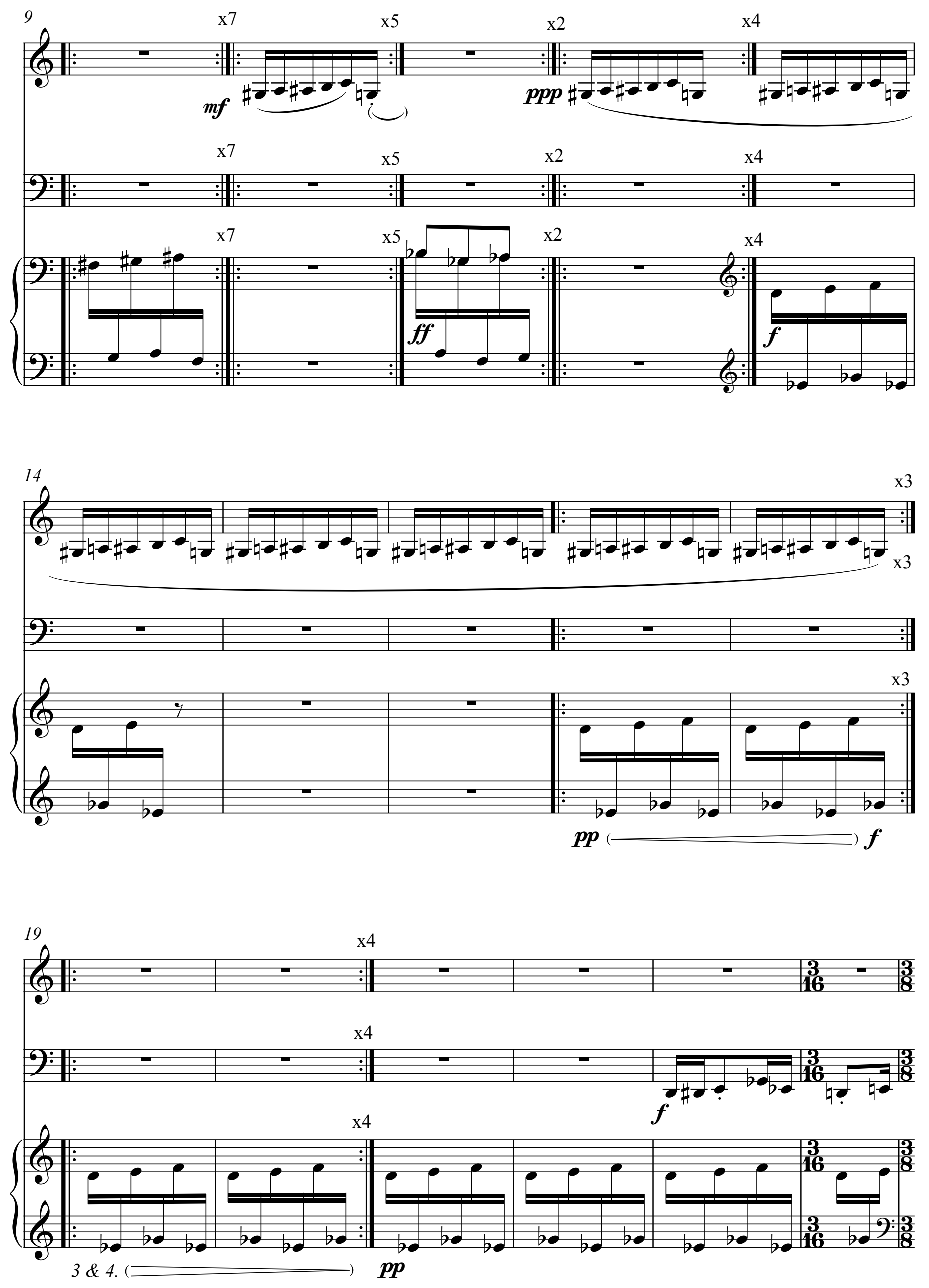

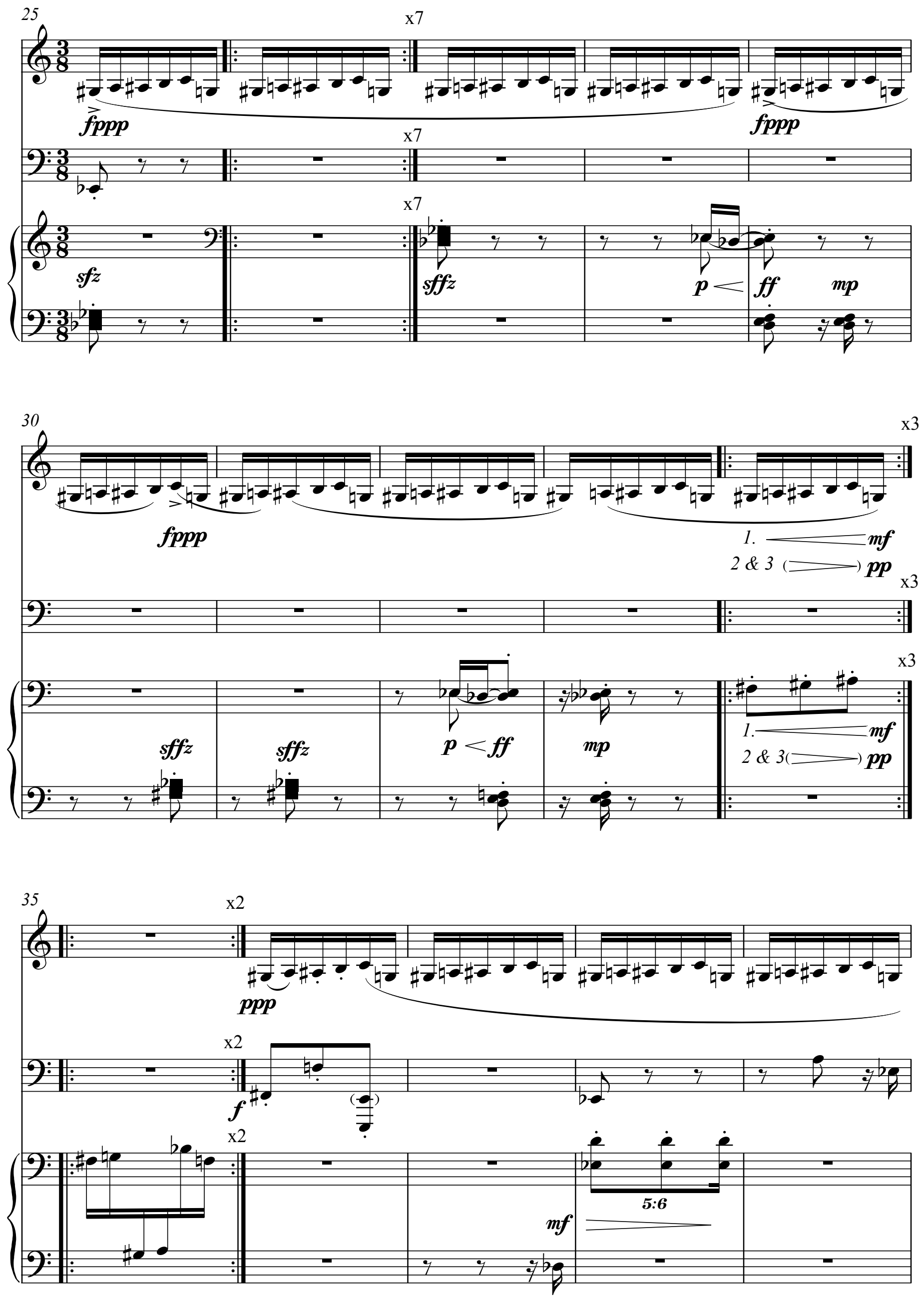
growl (play 2nd time only)
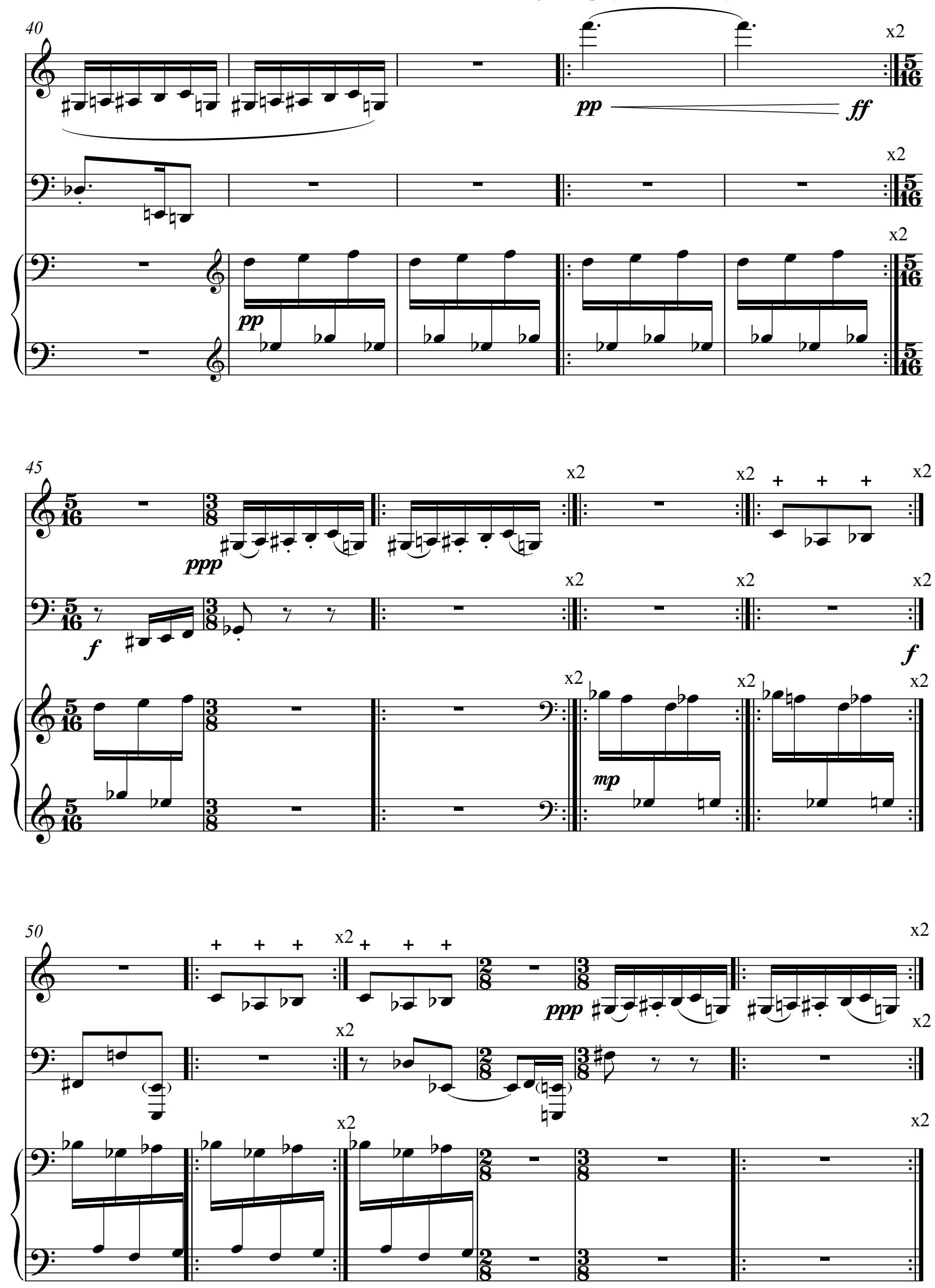

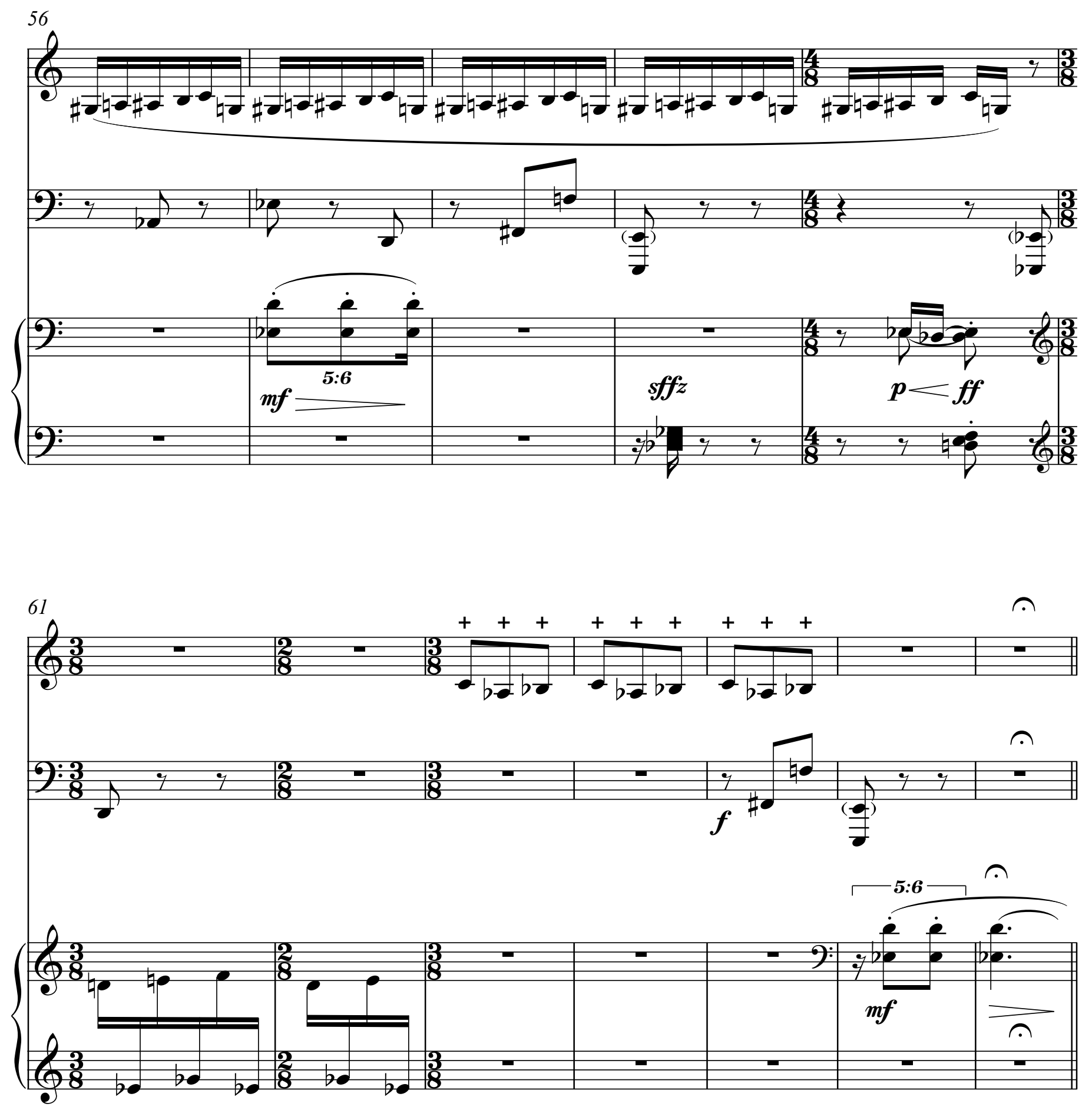
II.
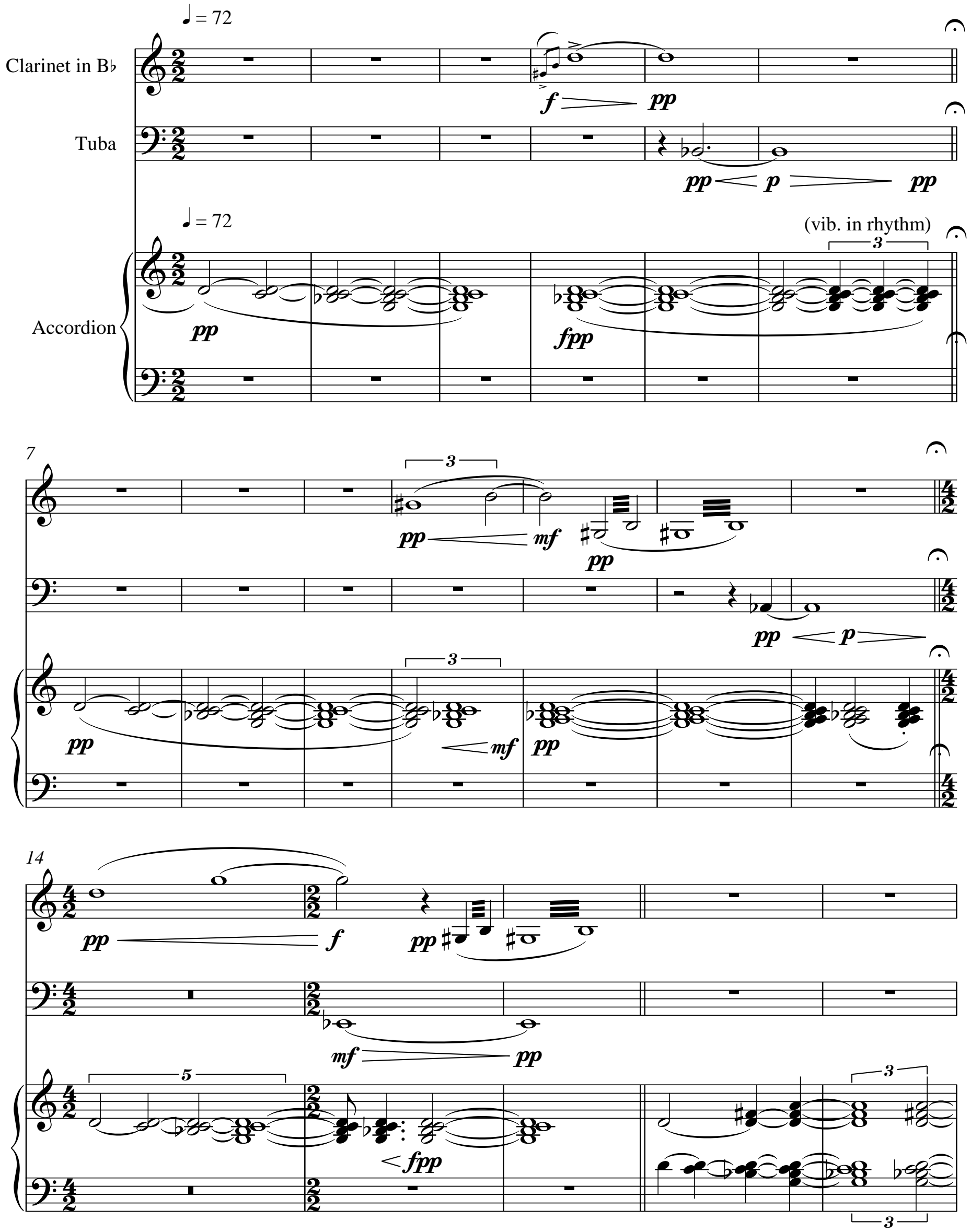

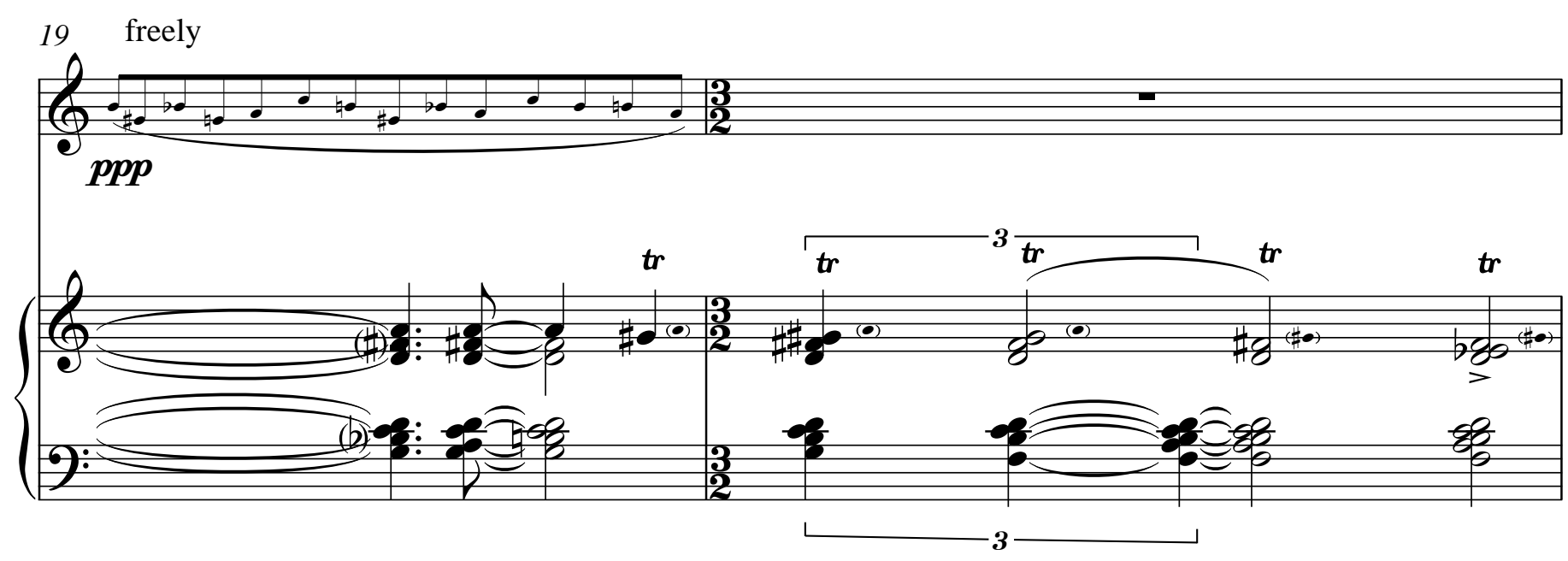

Repeat ad lib.

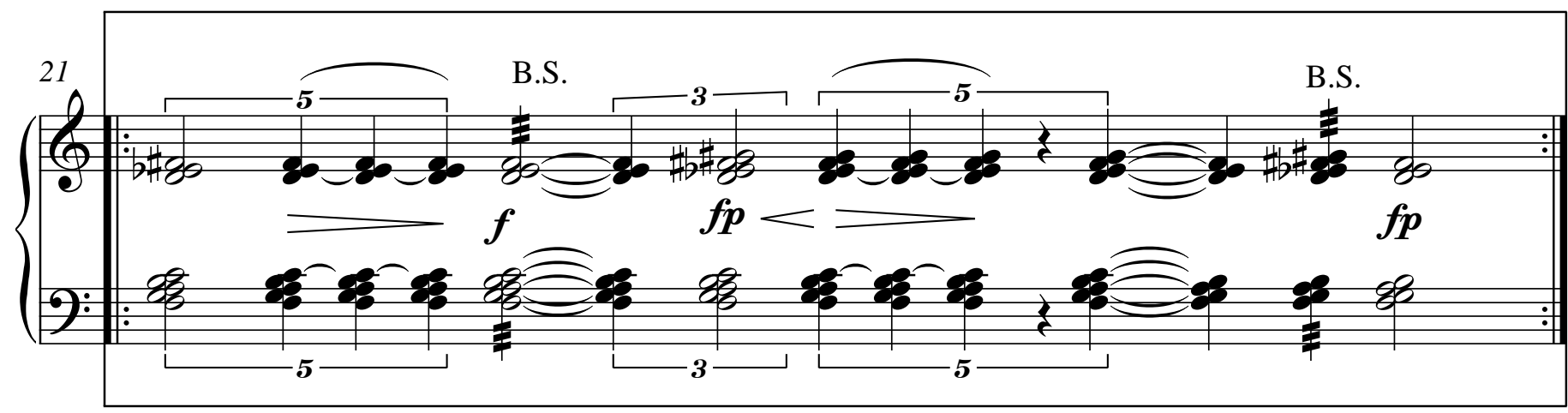

freely in your own time
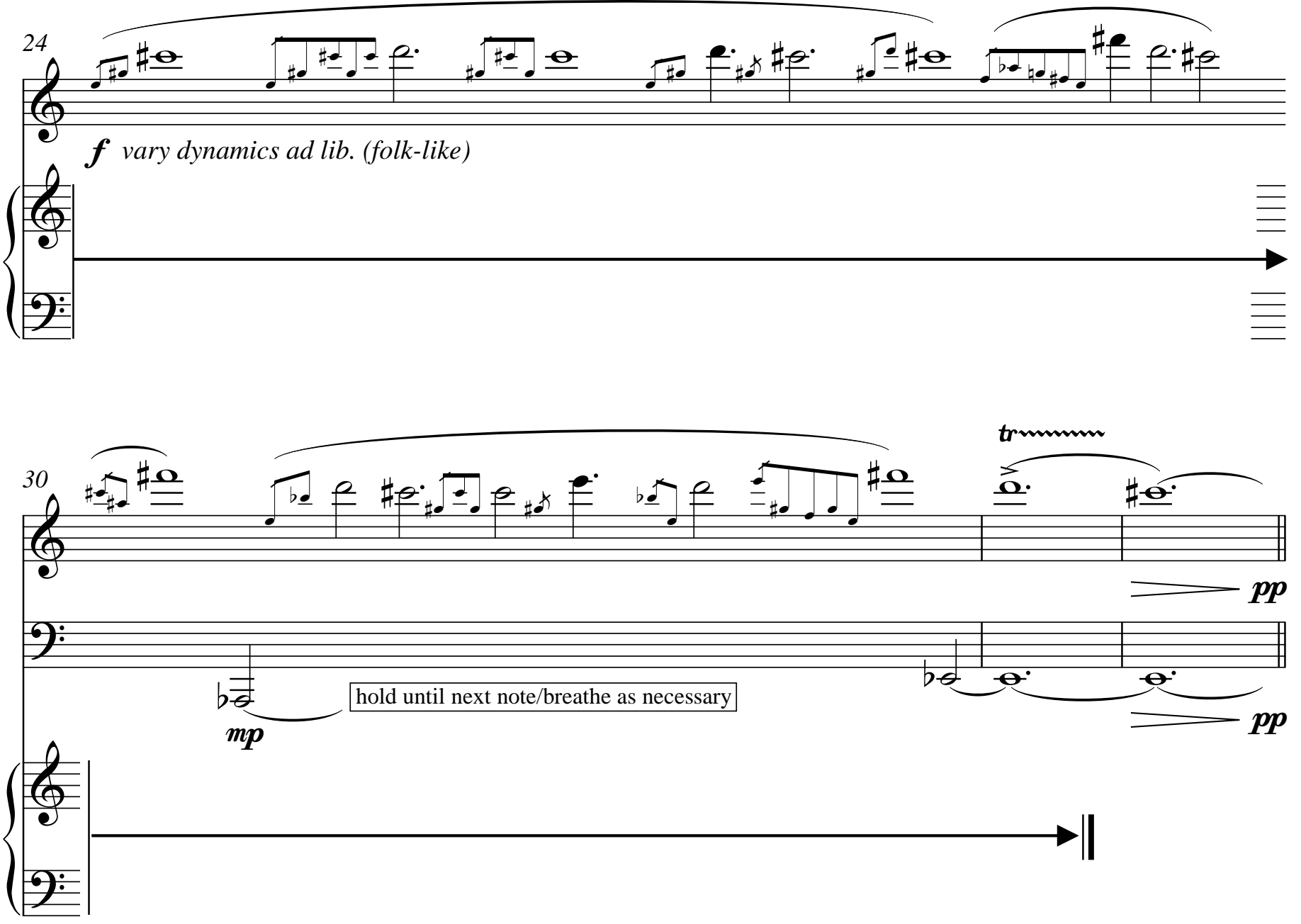

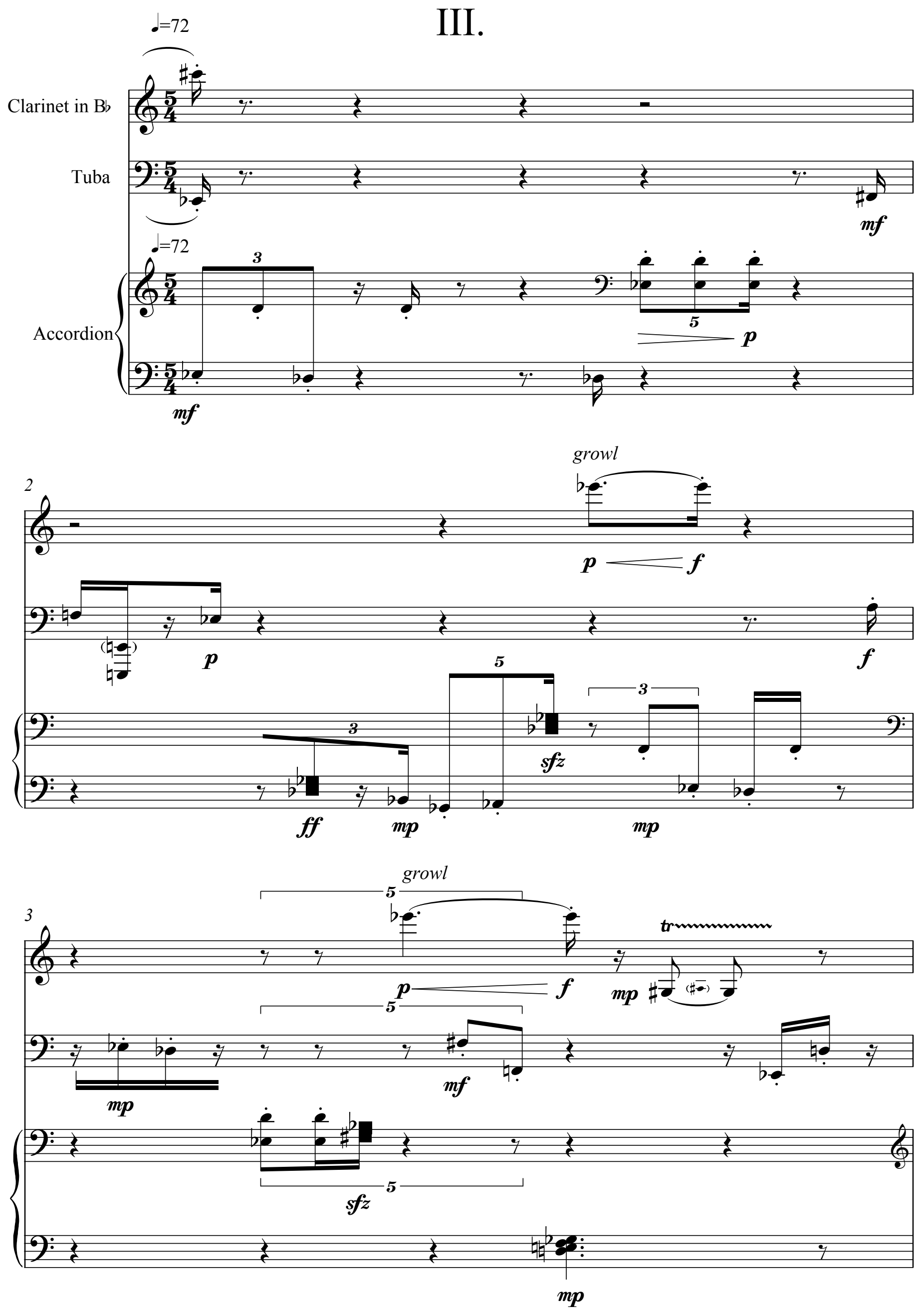

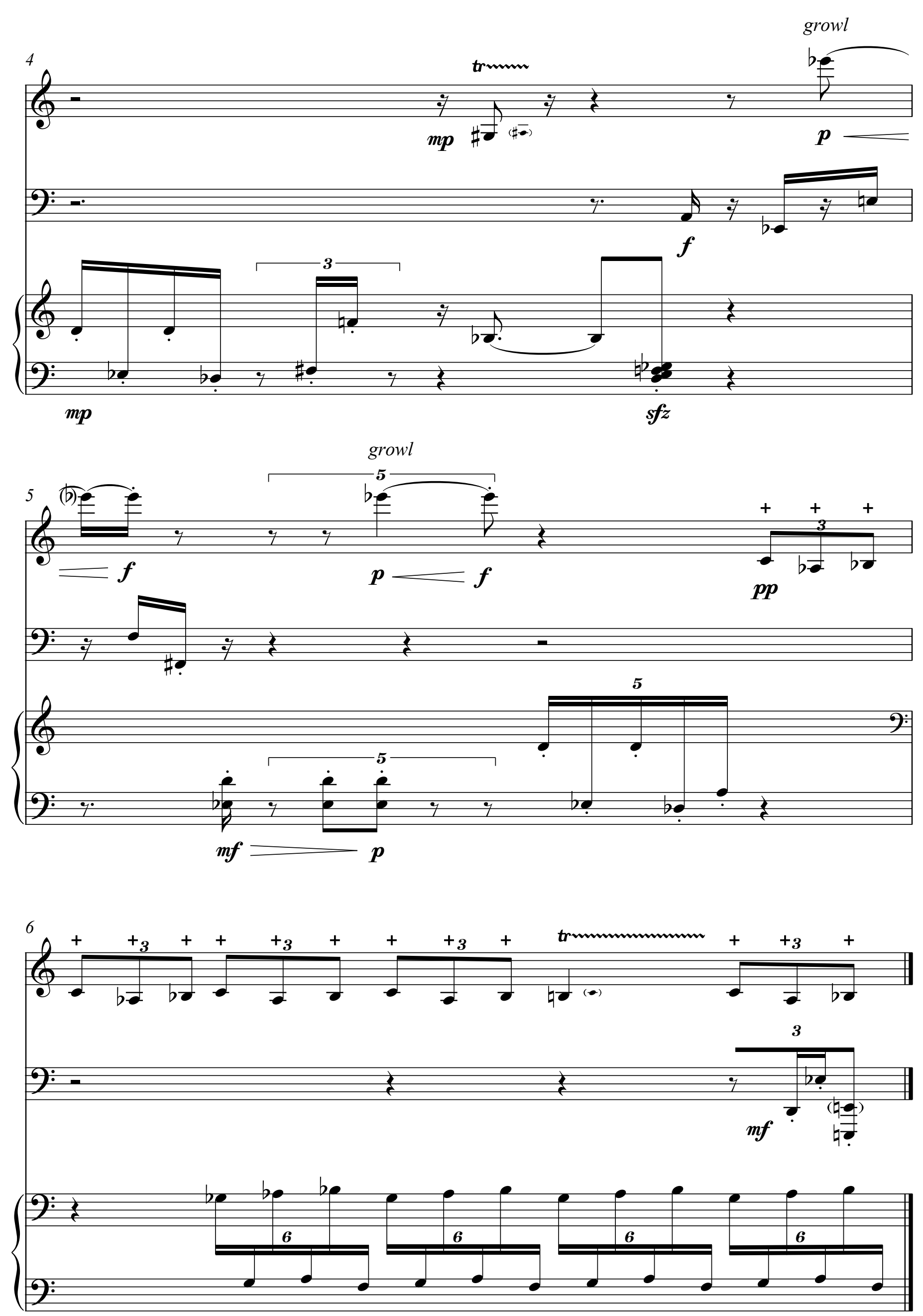
Glen Downie

Hot Coals 


\title{
Glen Downie
}

\section{Hot Coals}

\author{
Flute \\ Alto Flute \\ 2 Oboi \\ Clarinet in $\mathrm{B} b$ \\ Bass Clarinet \\ 2 Bassoons \\ 4 Horns in $\mathrm{F}$ \\ 2 Trumpets in $\mathrm{B} b$ \\ 2 Tenor Trombones \\ Bass Trombone \\ Sizzle Cymbal (Tam-tam) \\ Snare Drum (Wood Block) \\ Bass Drum \\ Harp \\ 6 Viole \\ 6 Violoncelli \\ 4 Contrabassi
}

Hot Coals was written over the period of 2016/2017 for the Auckland Philharmonia Composer Workshops. The work is inspired by the visual artwork Hot Coals by Jean Horsley, held in the Auckland Art Gallery. It was premiered on the 27th of April 2017 in the Auckland Town Hall under the baton of Hamish McKeich 
Hot Coals

inspired by Jean Horsley's painting of the same name
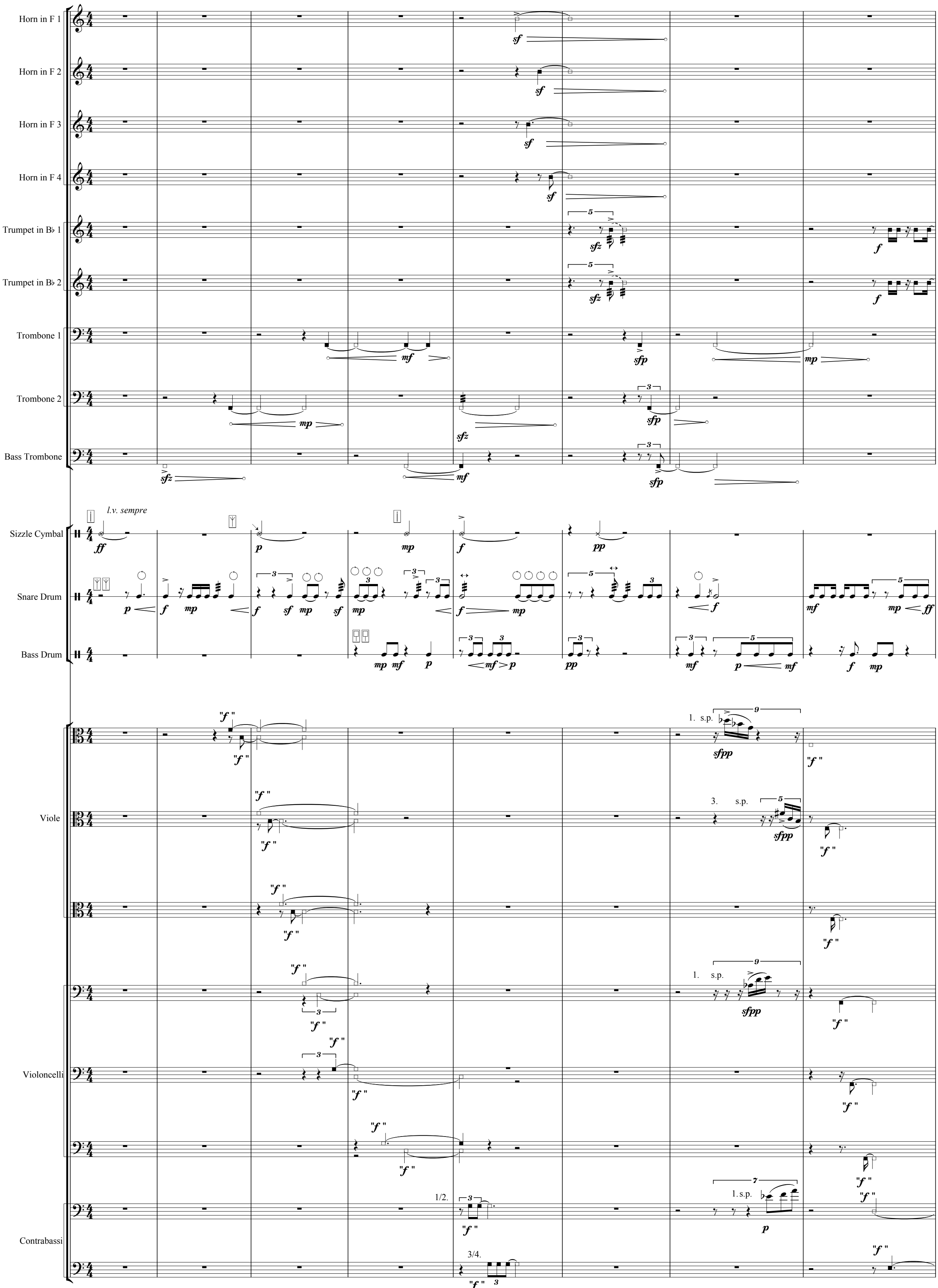

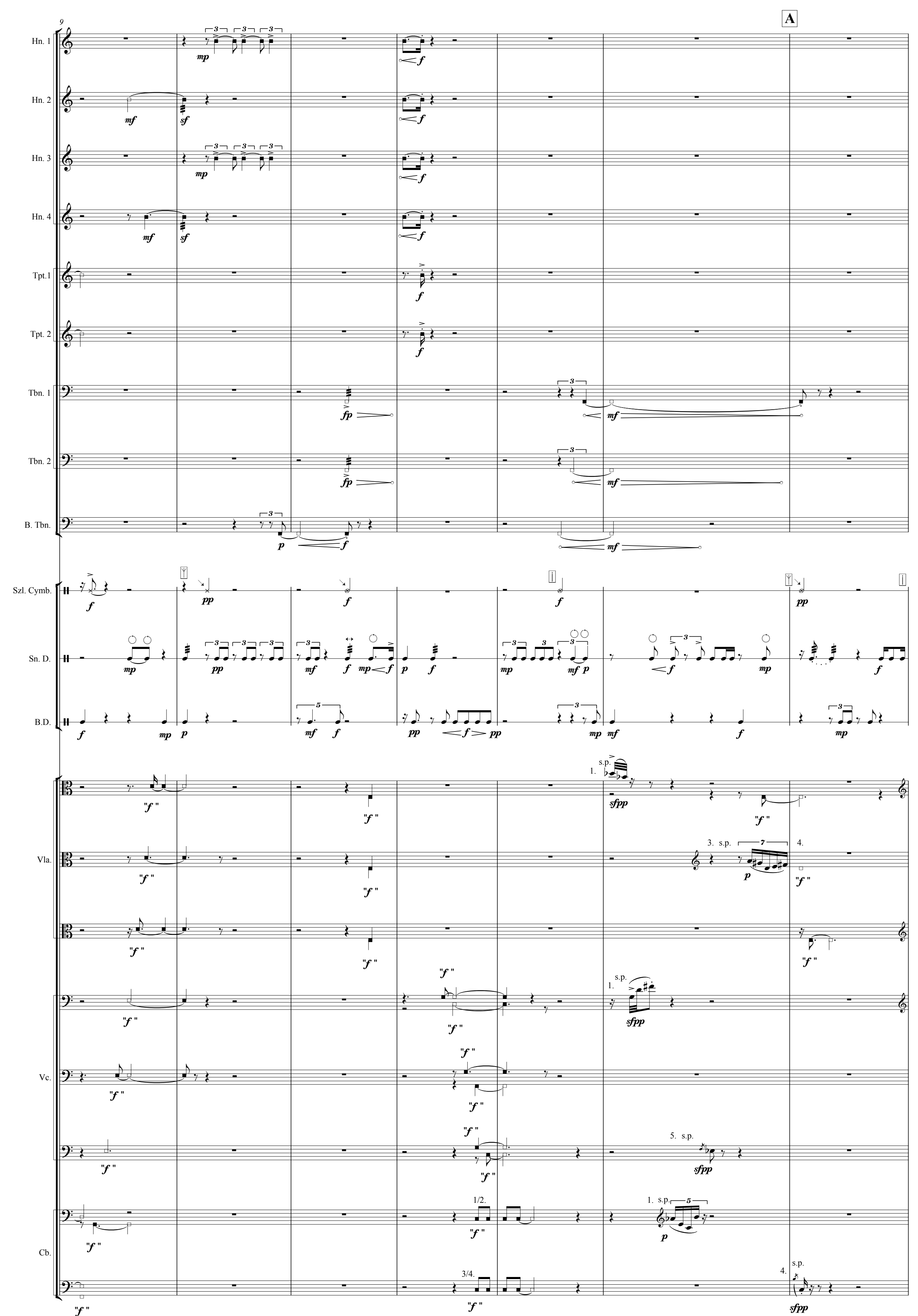

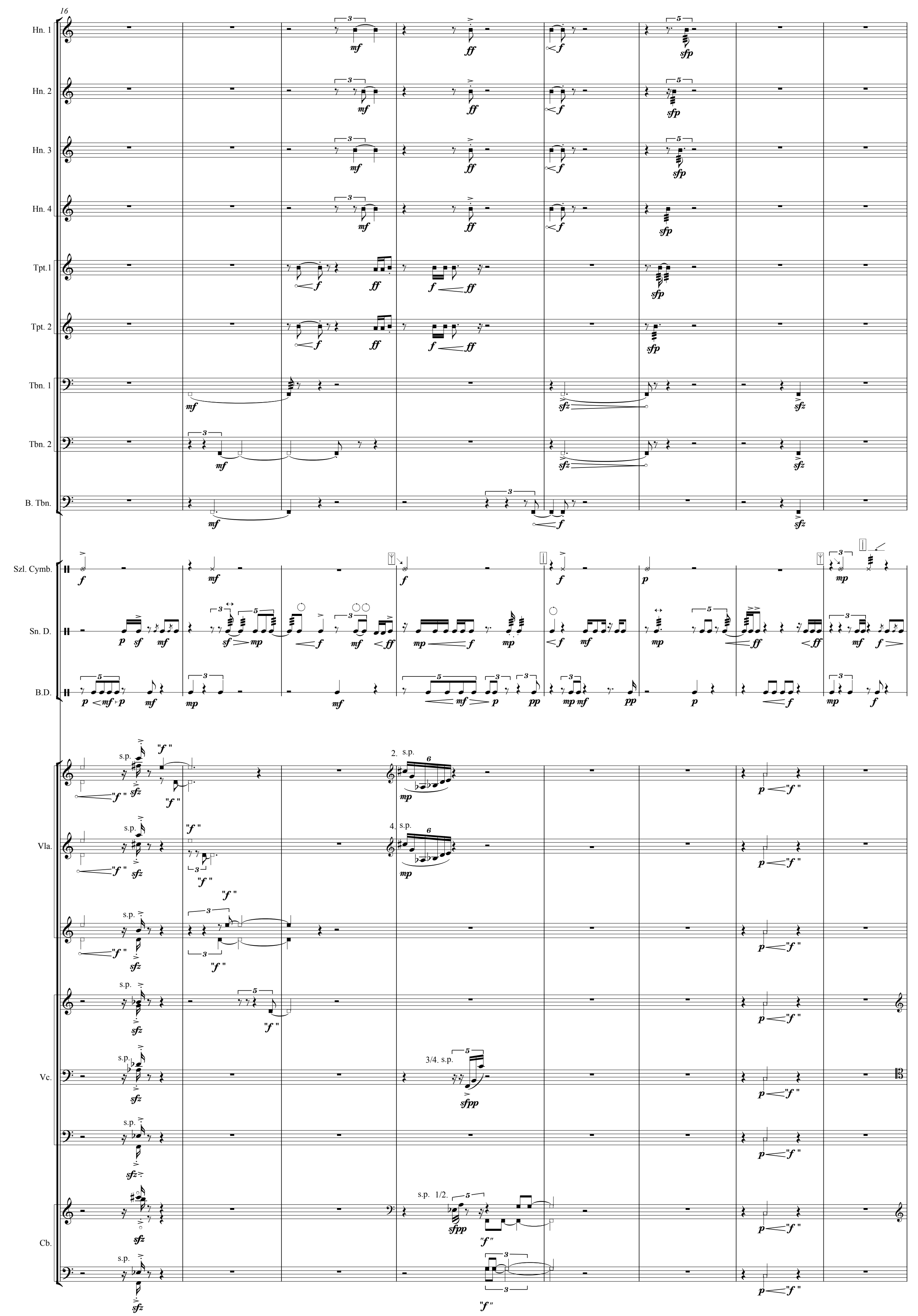


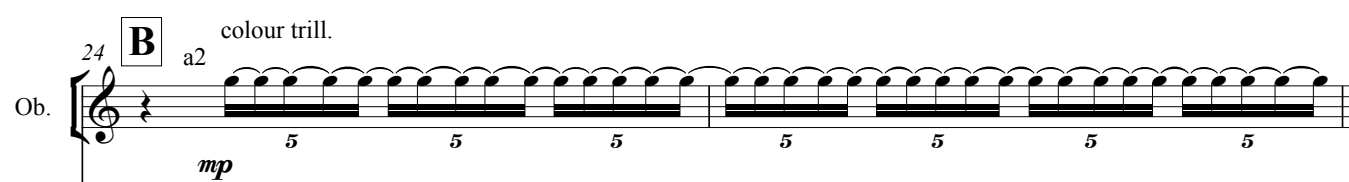
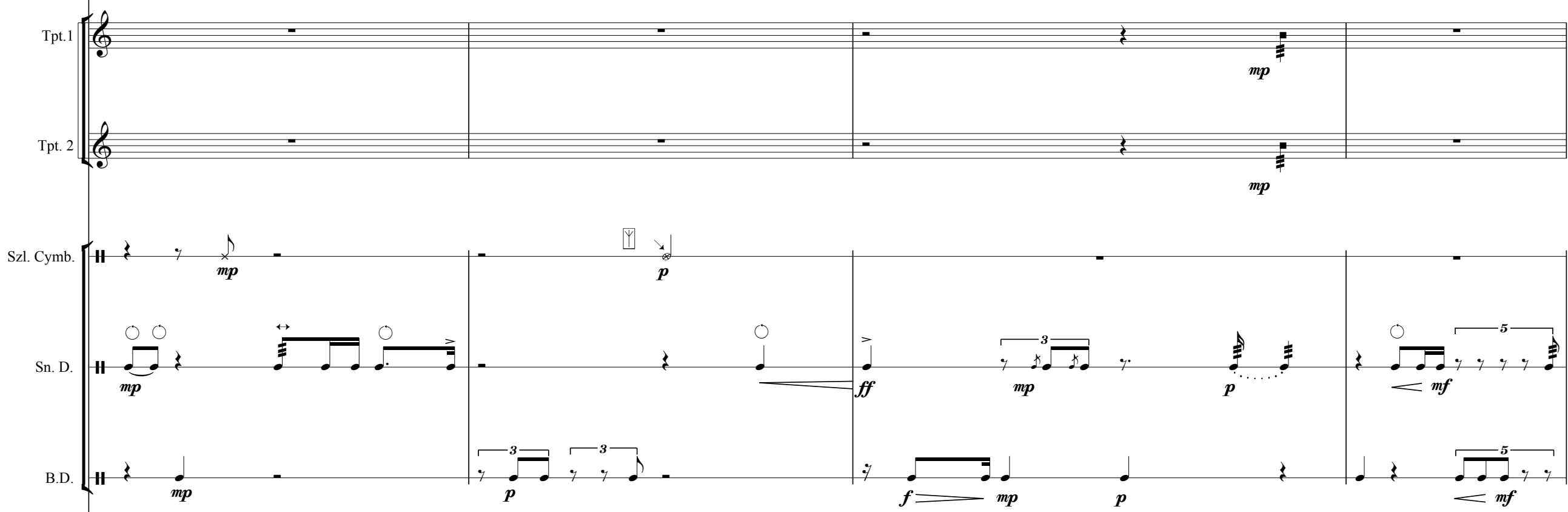

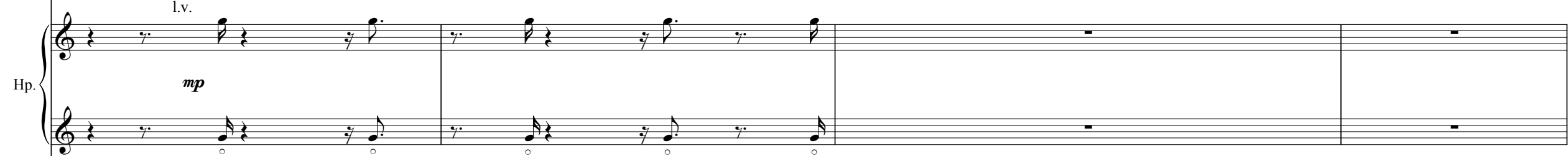

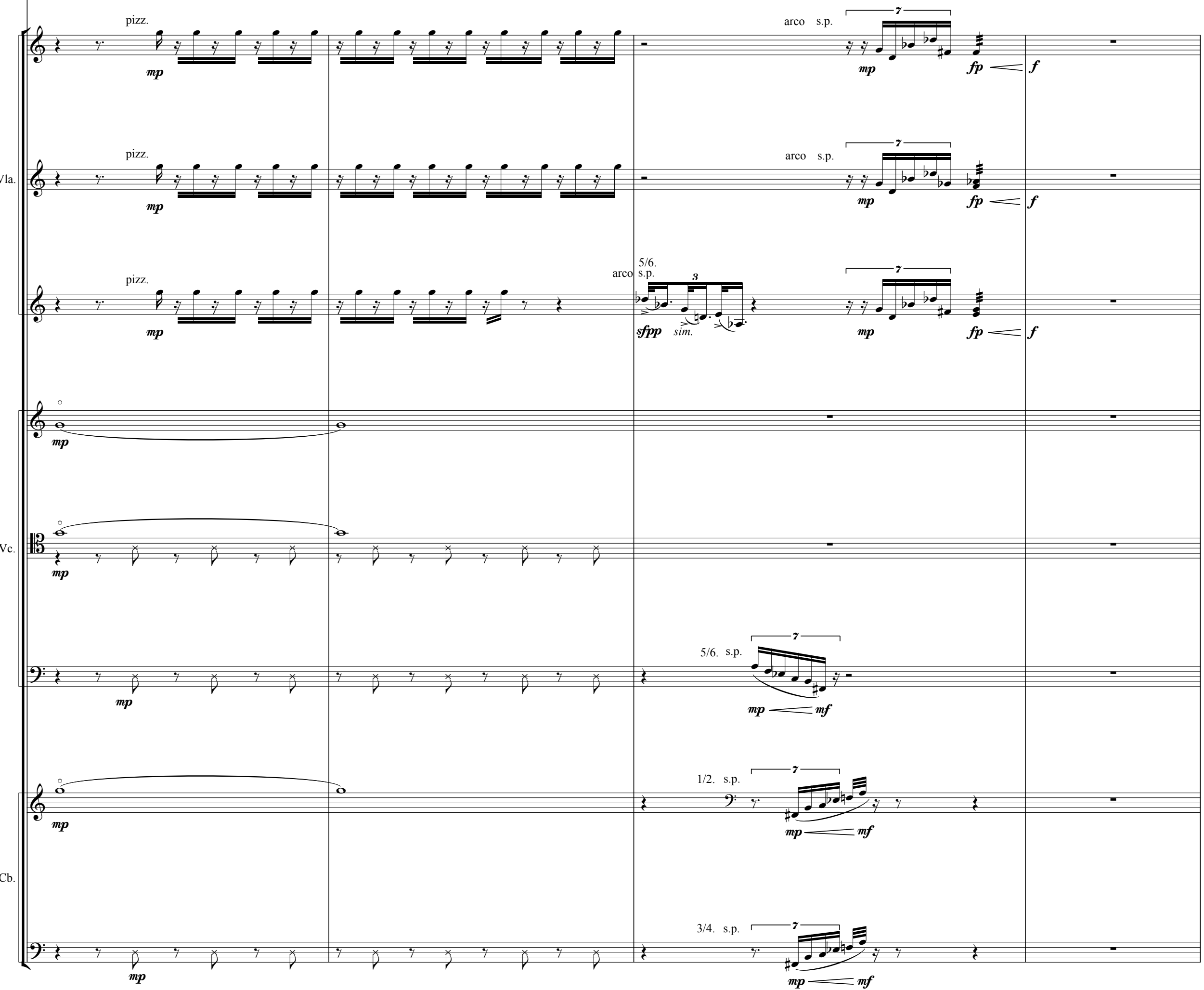




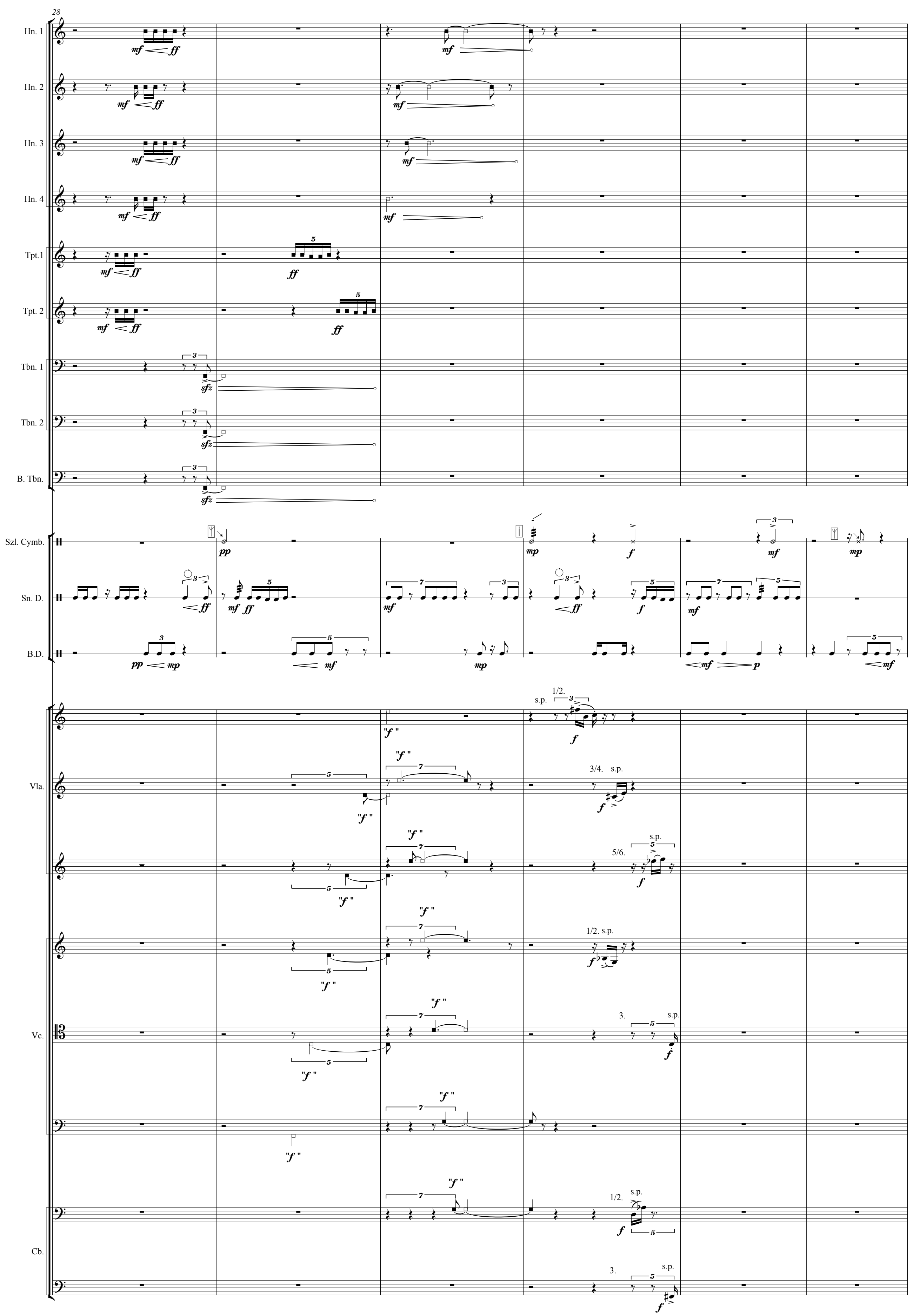




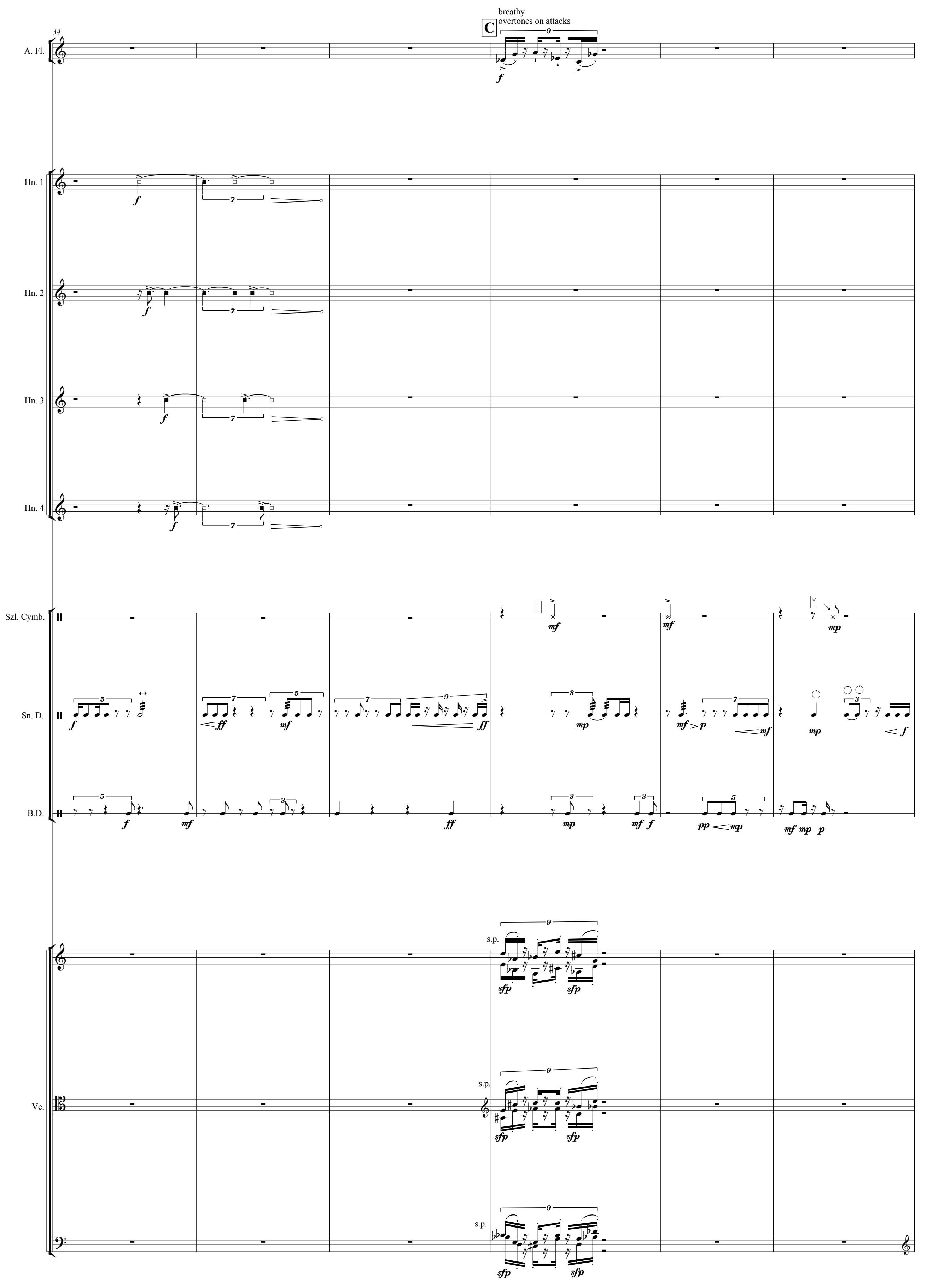




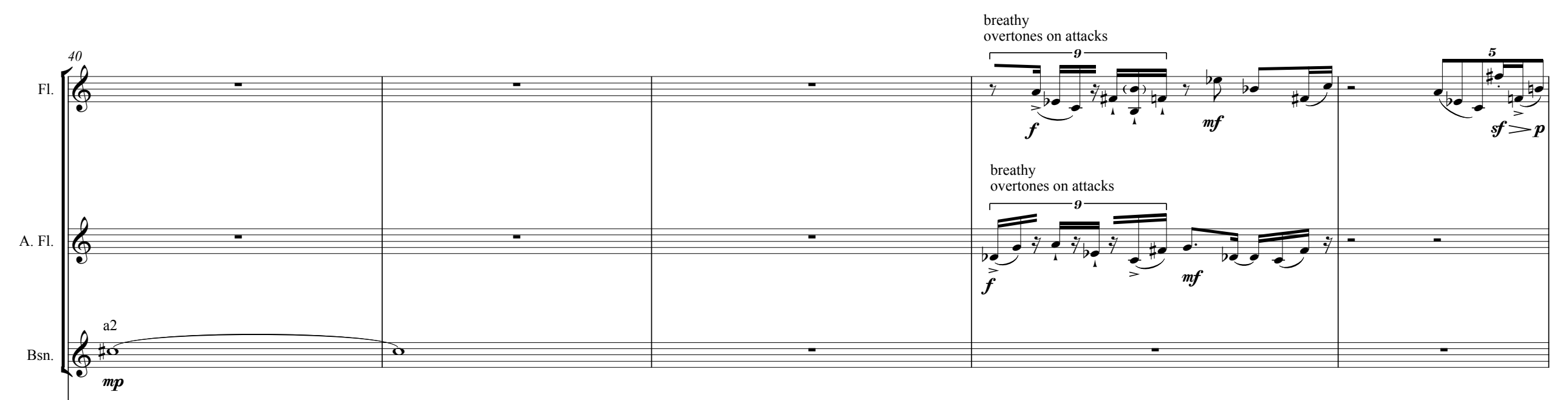

Tpt.1
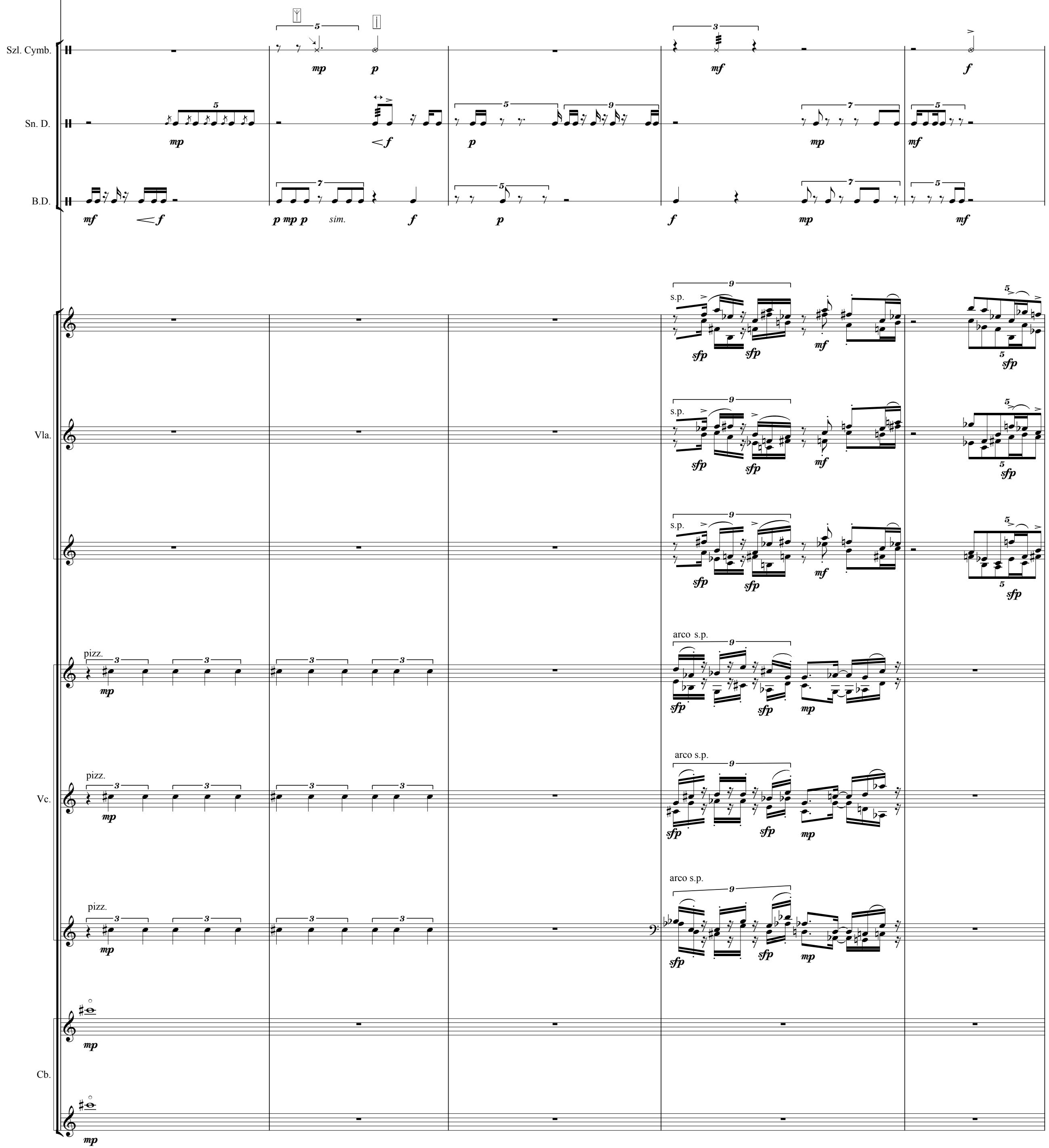

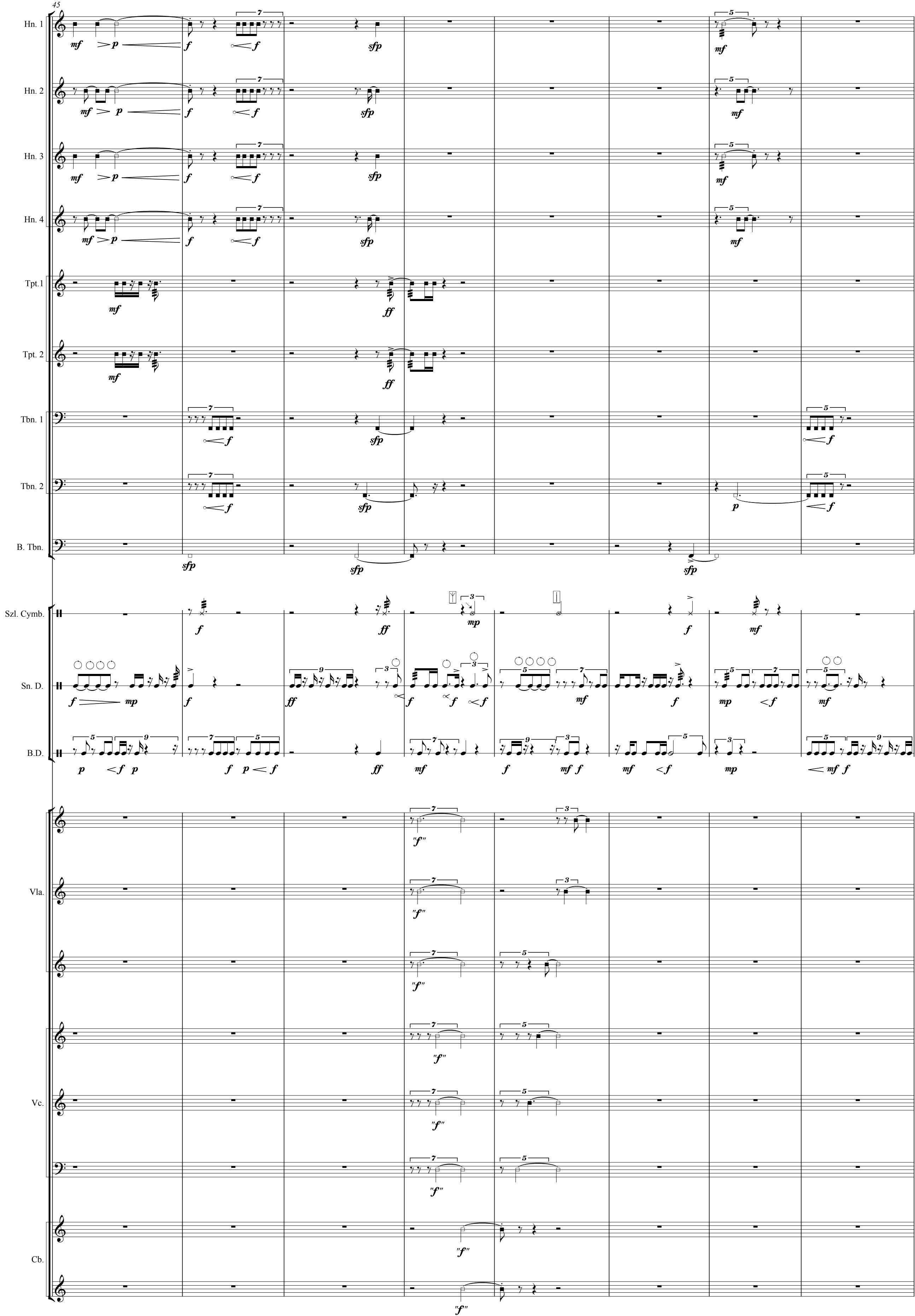

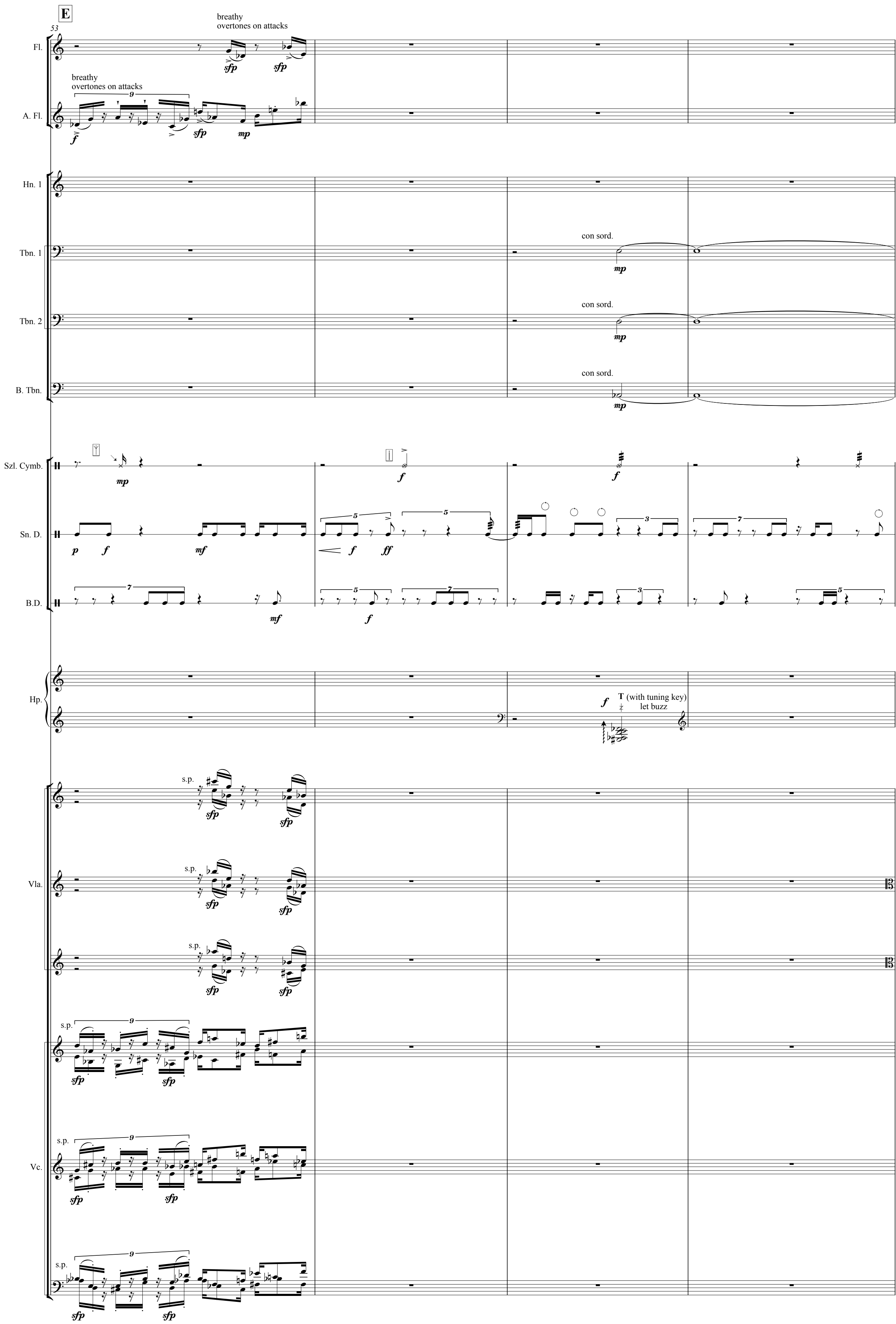

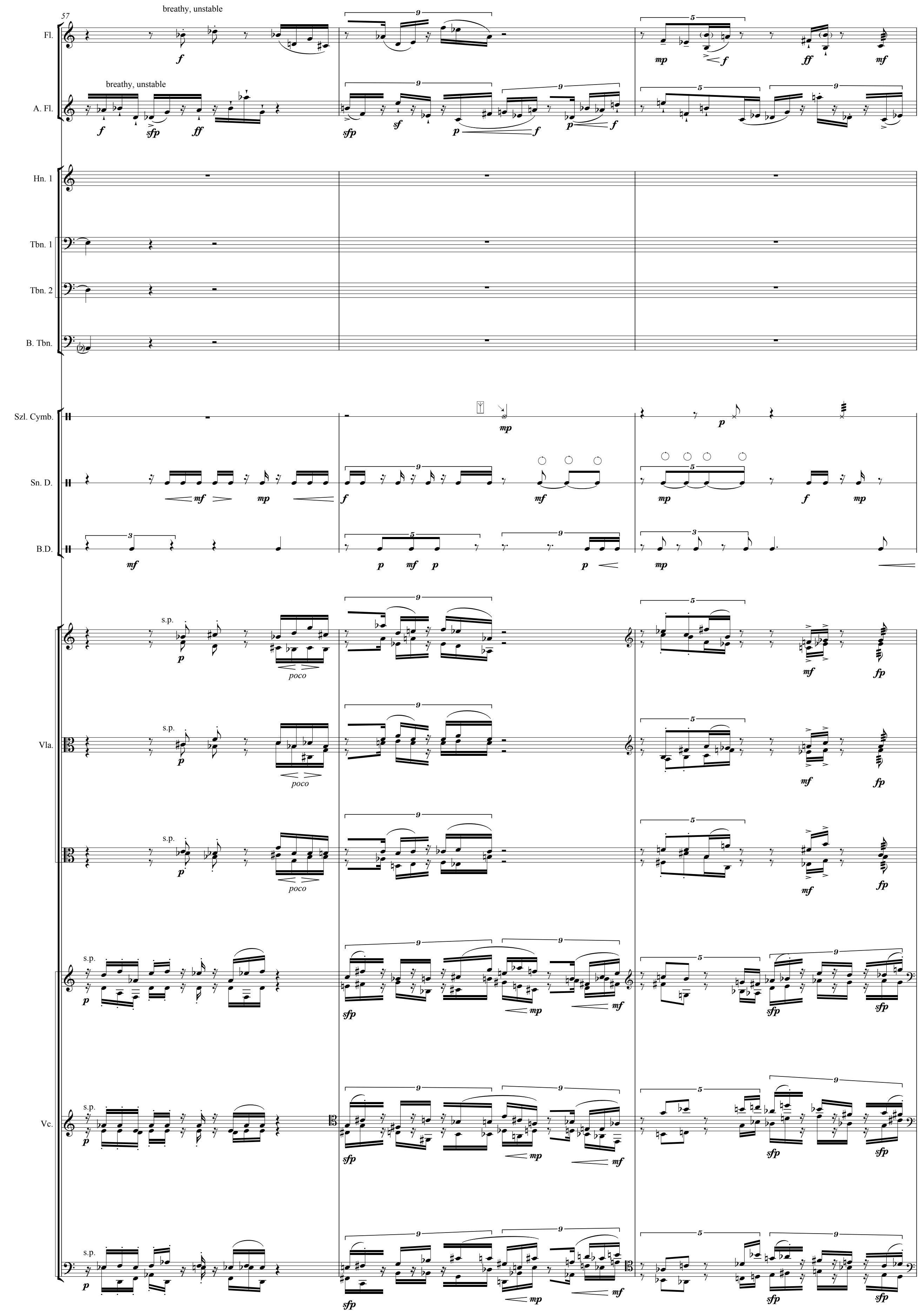

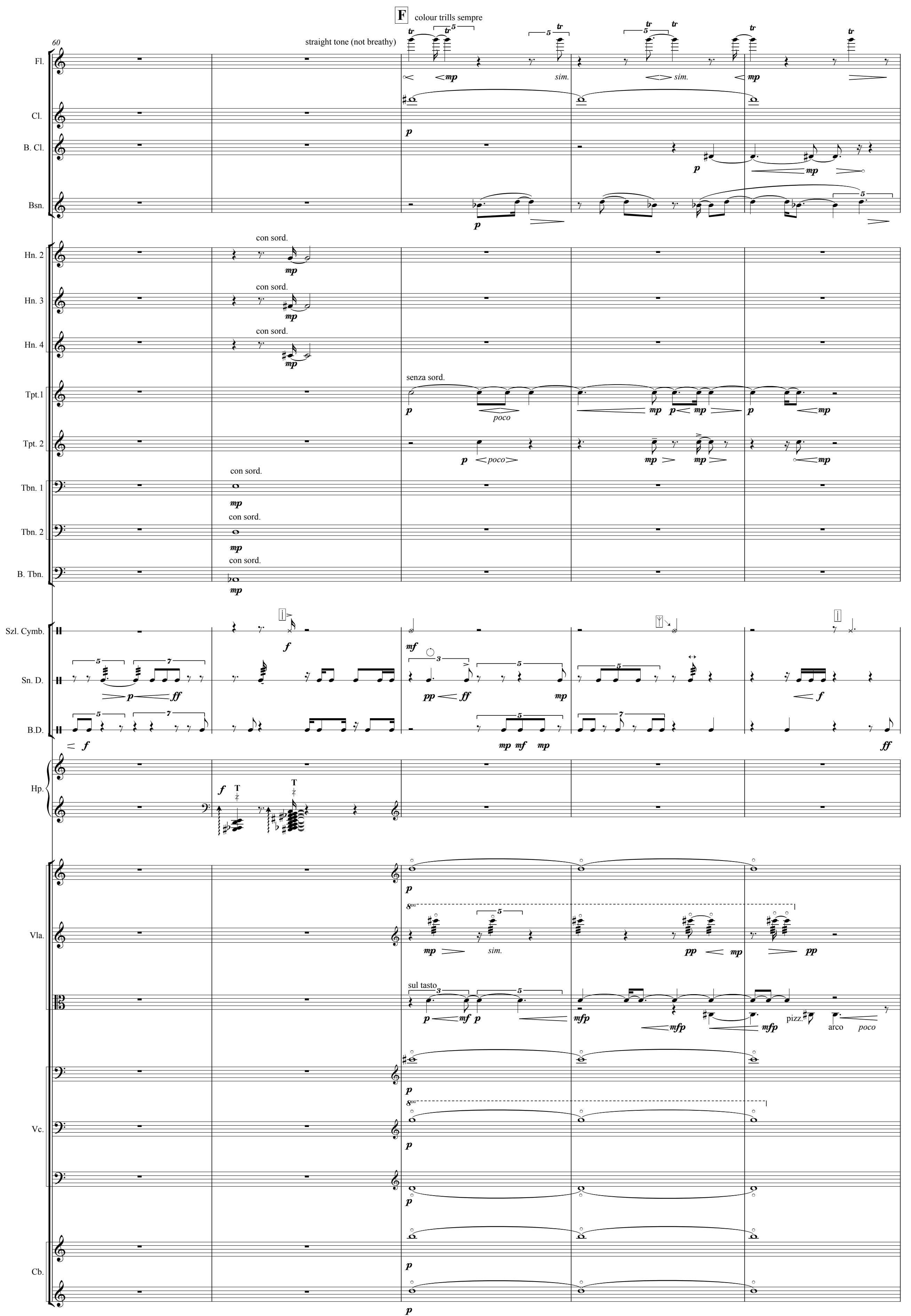

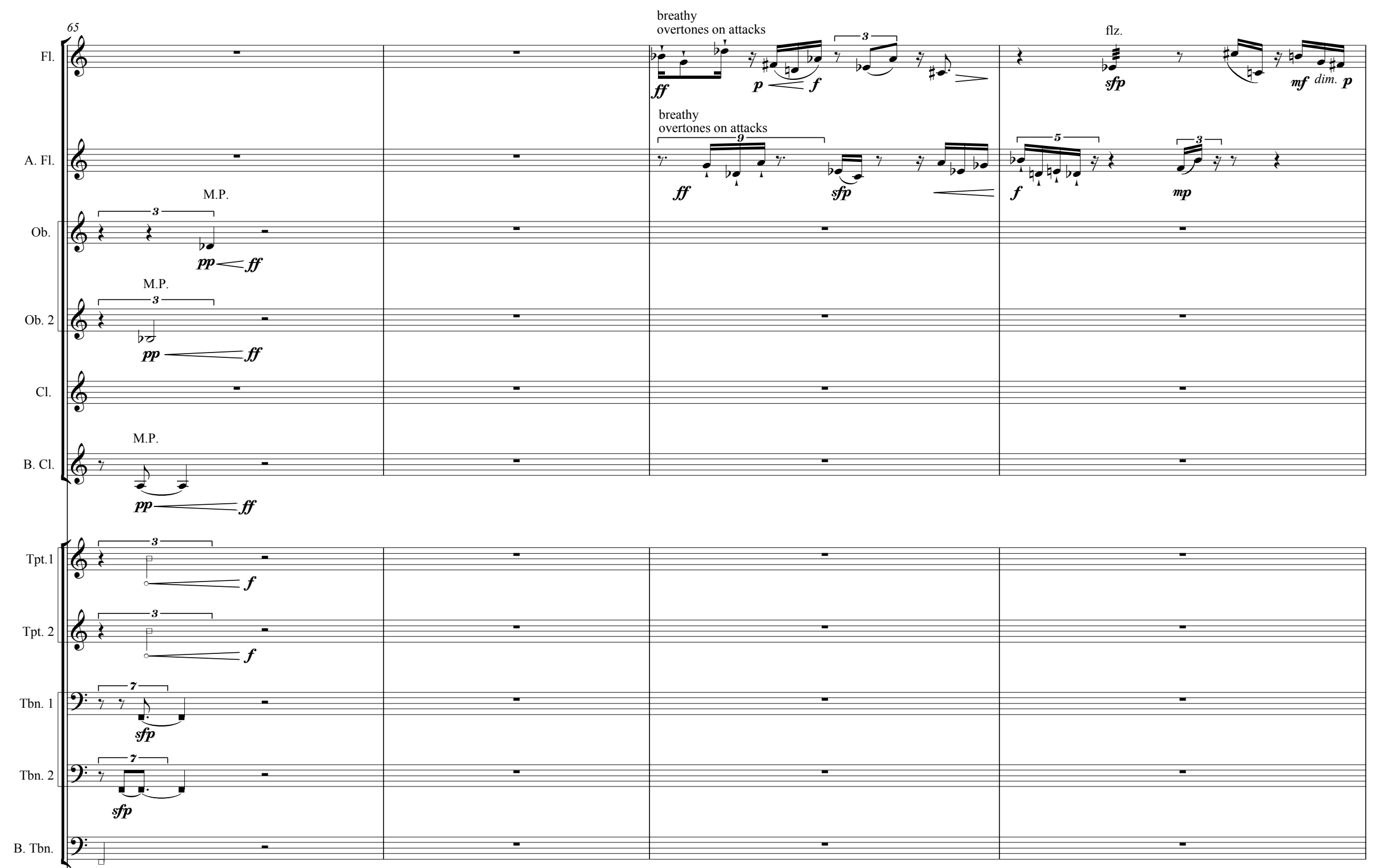

$s f p$
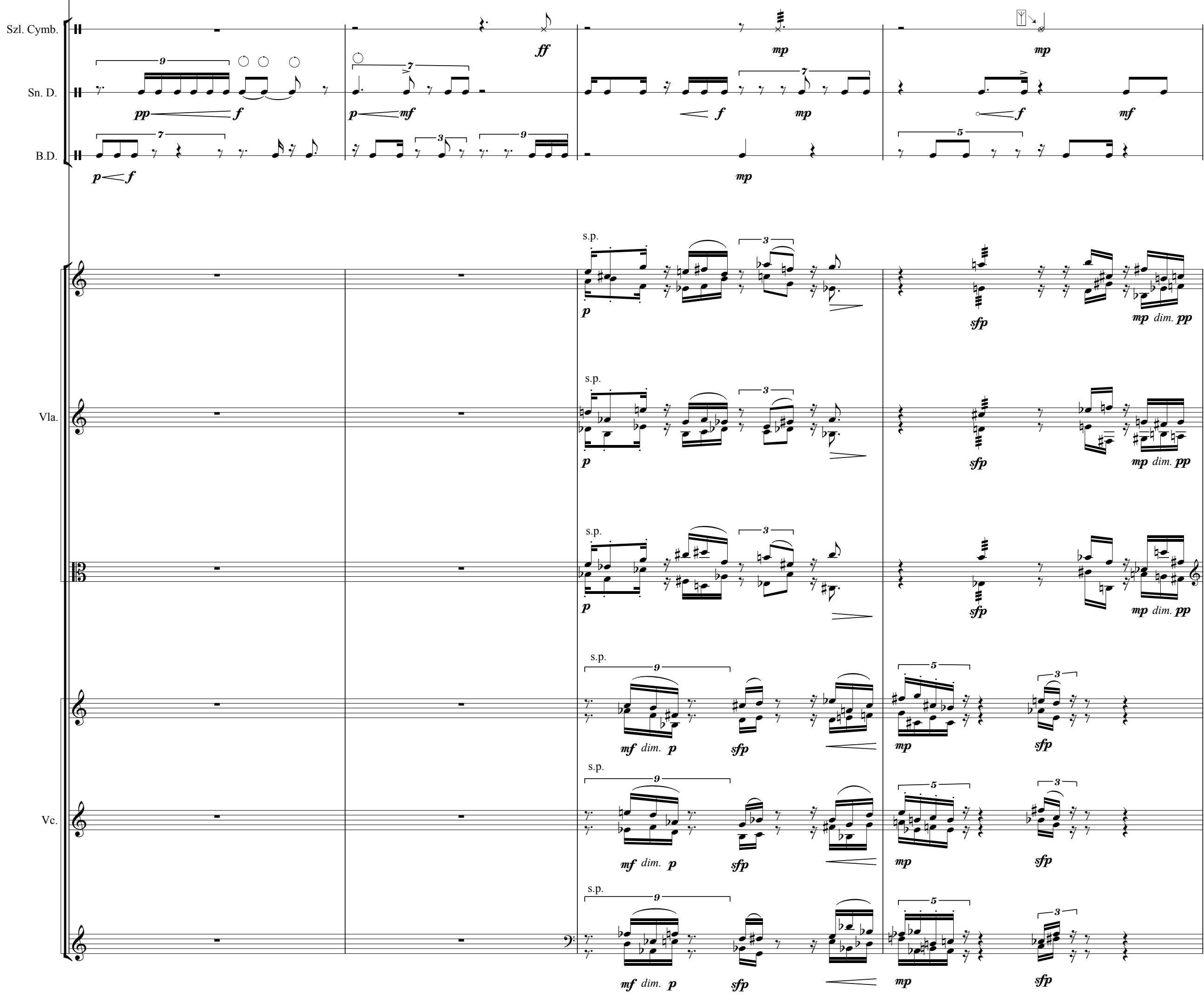


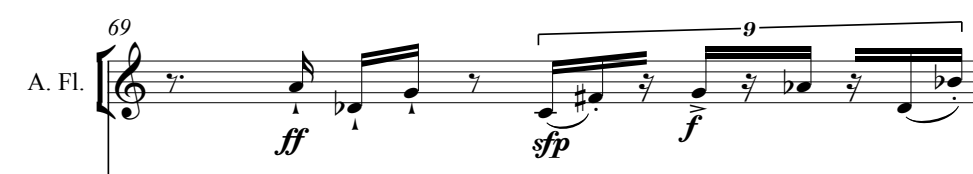
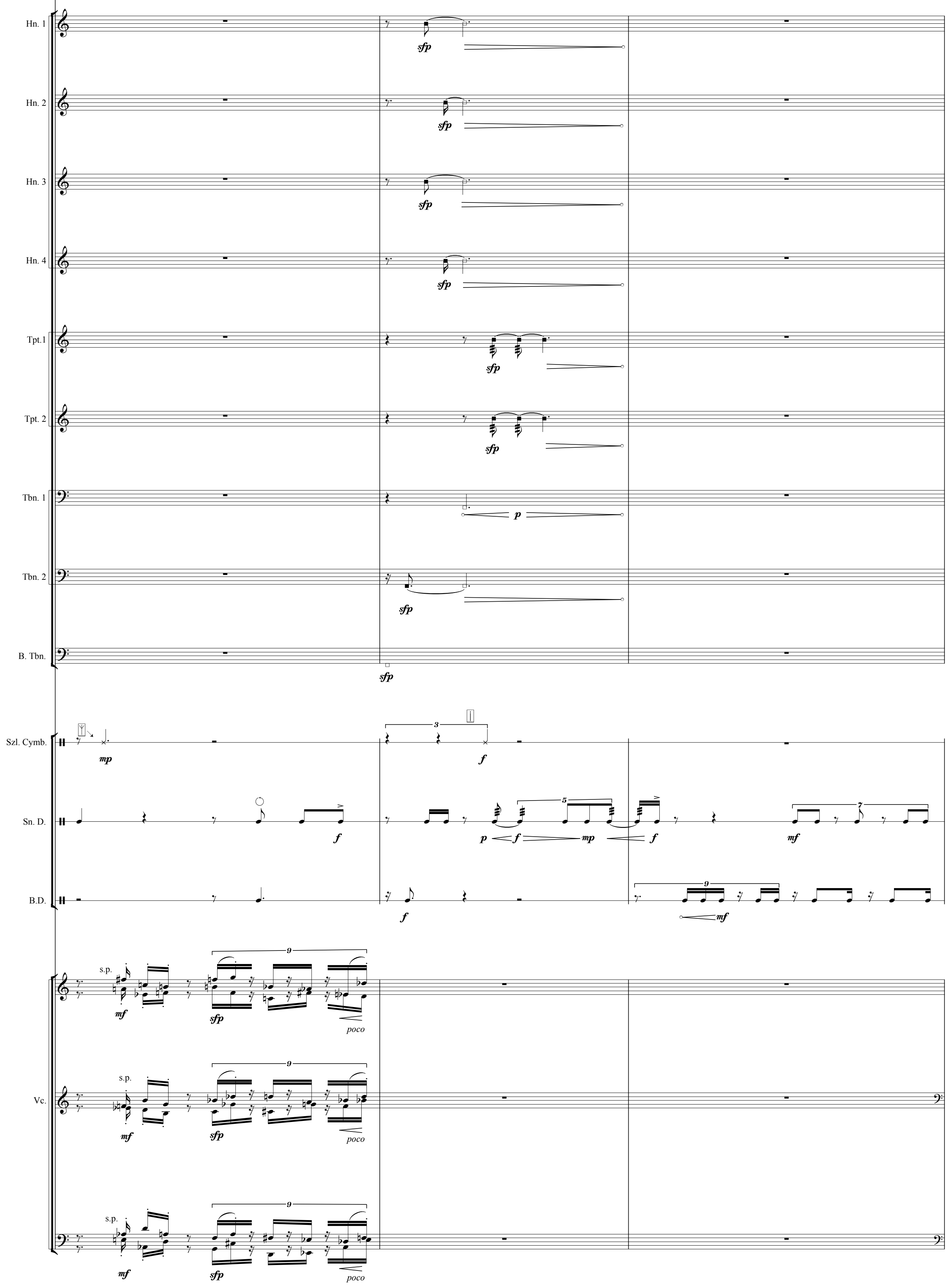


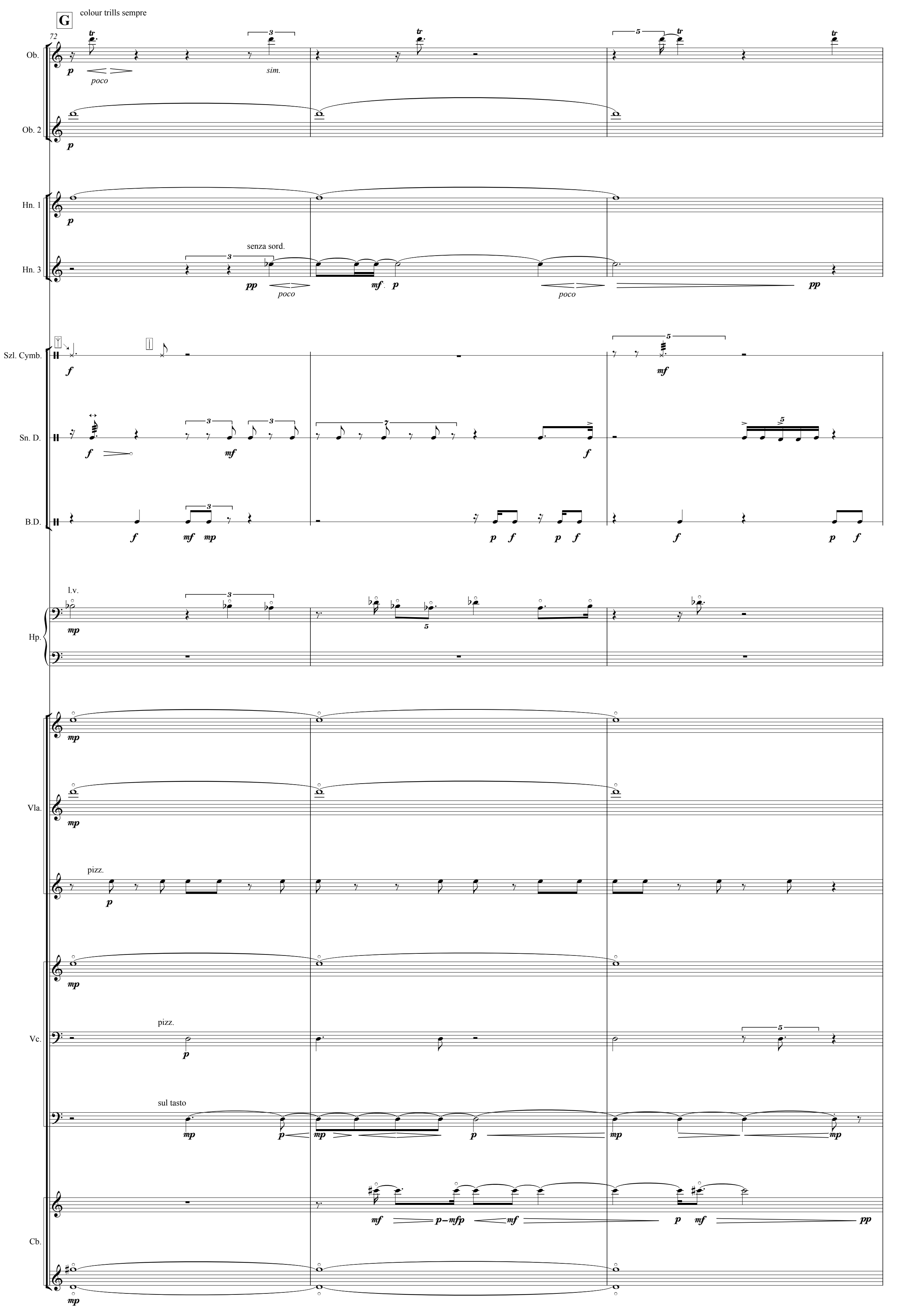



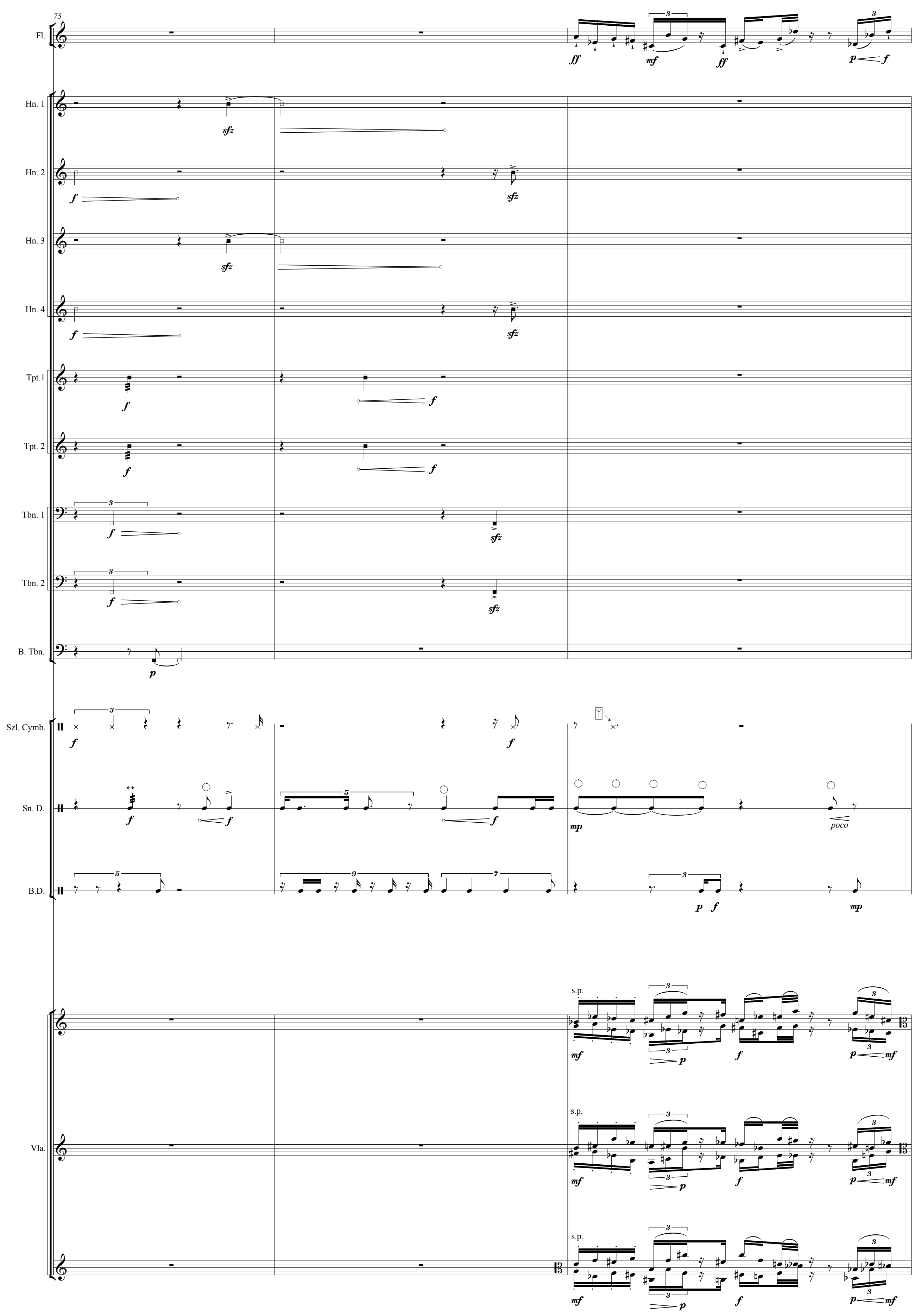

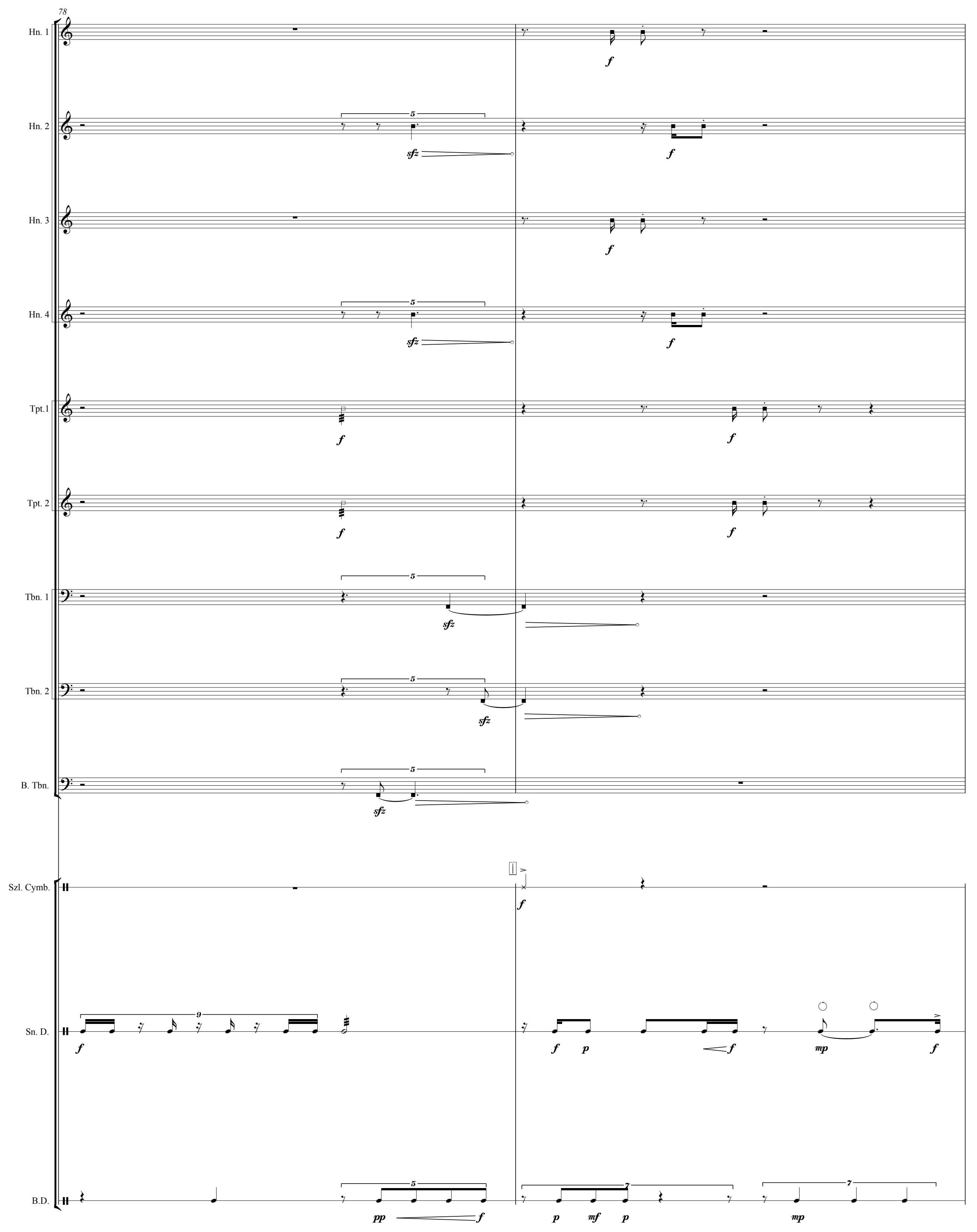
H breathy ${ }^{2}$ overtones on attacks

A. Fl.
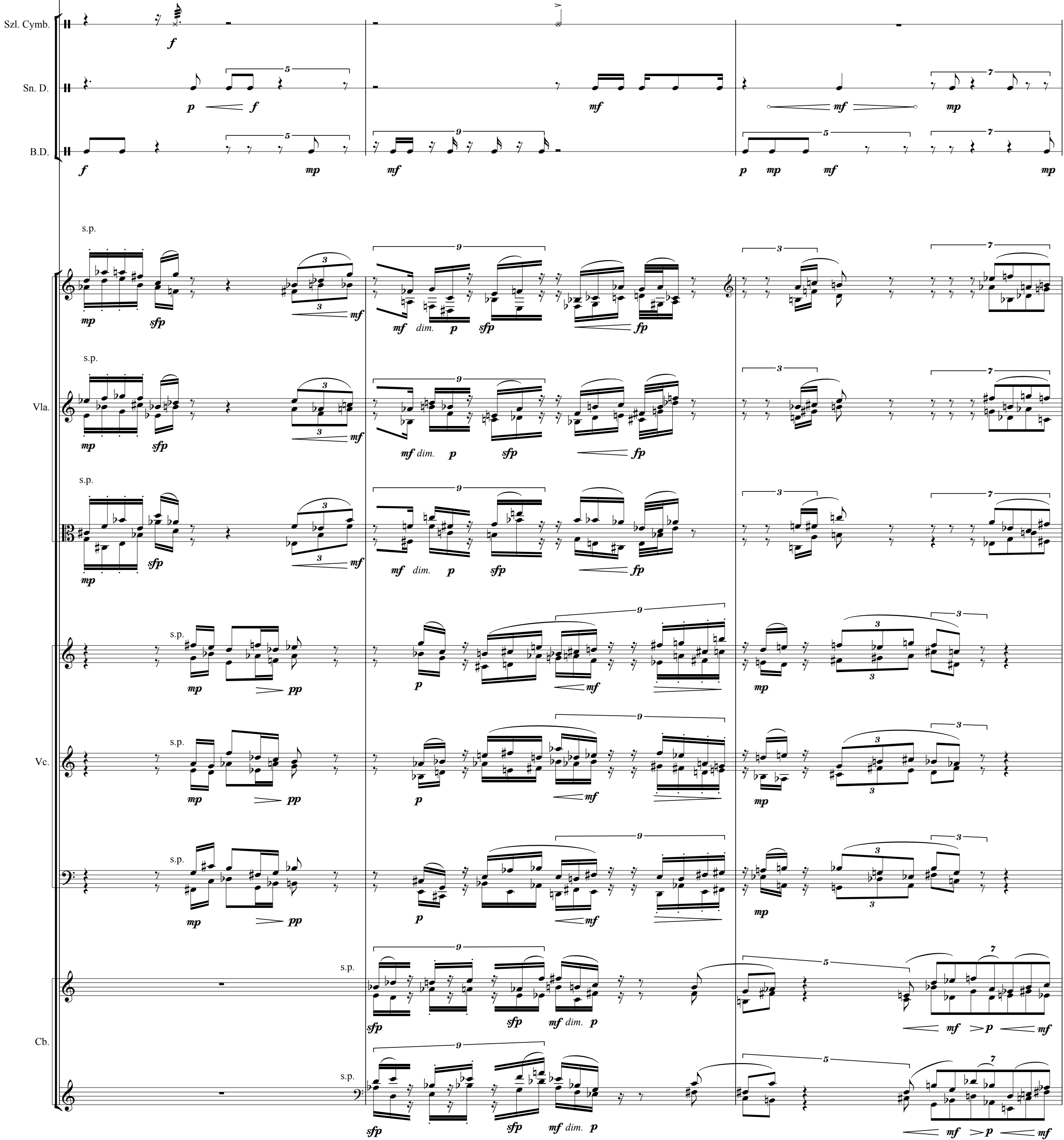

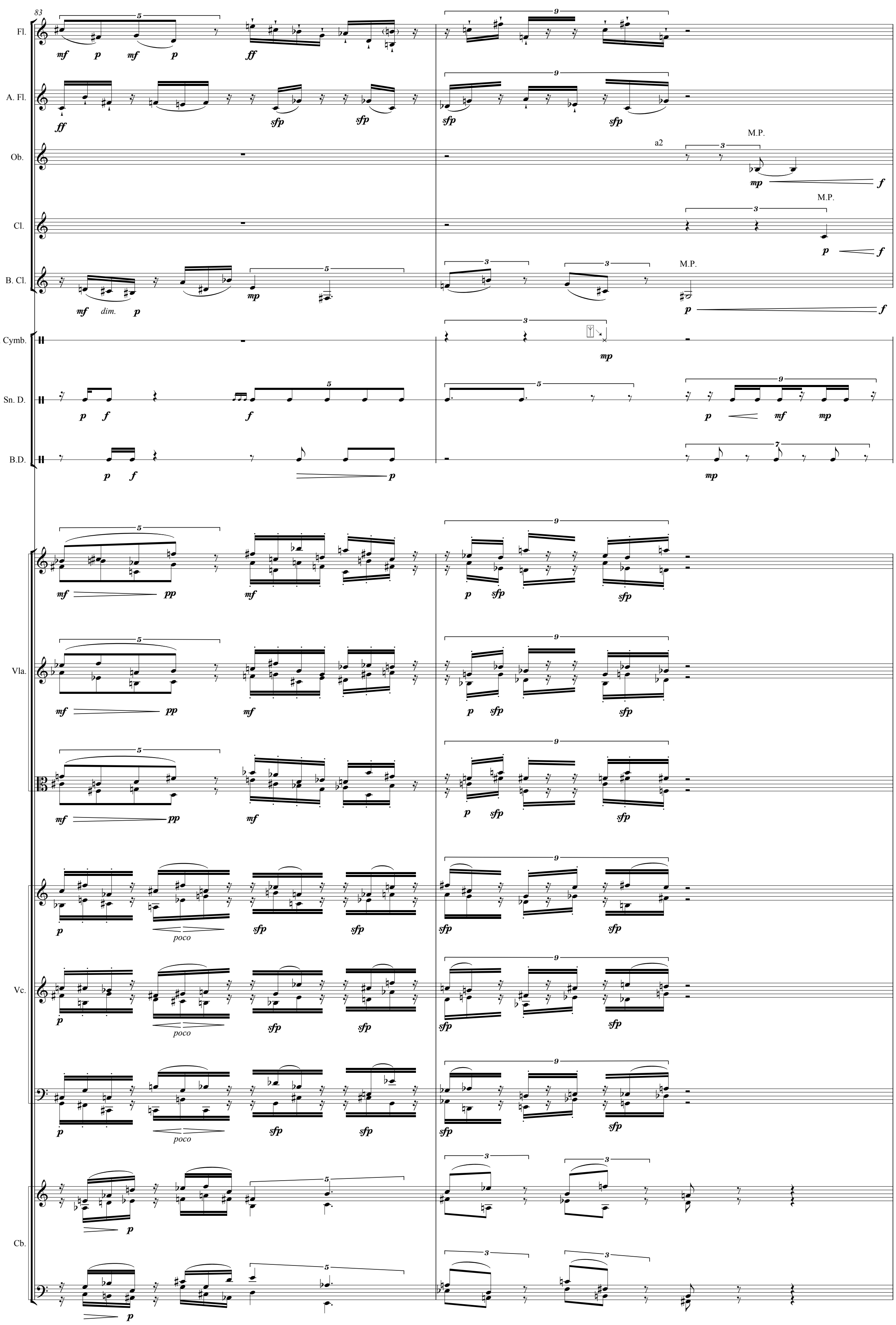

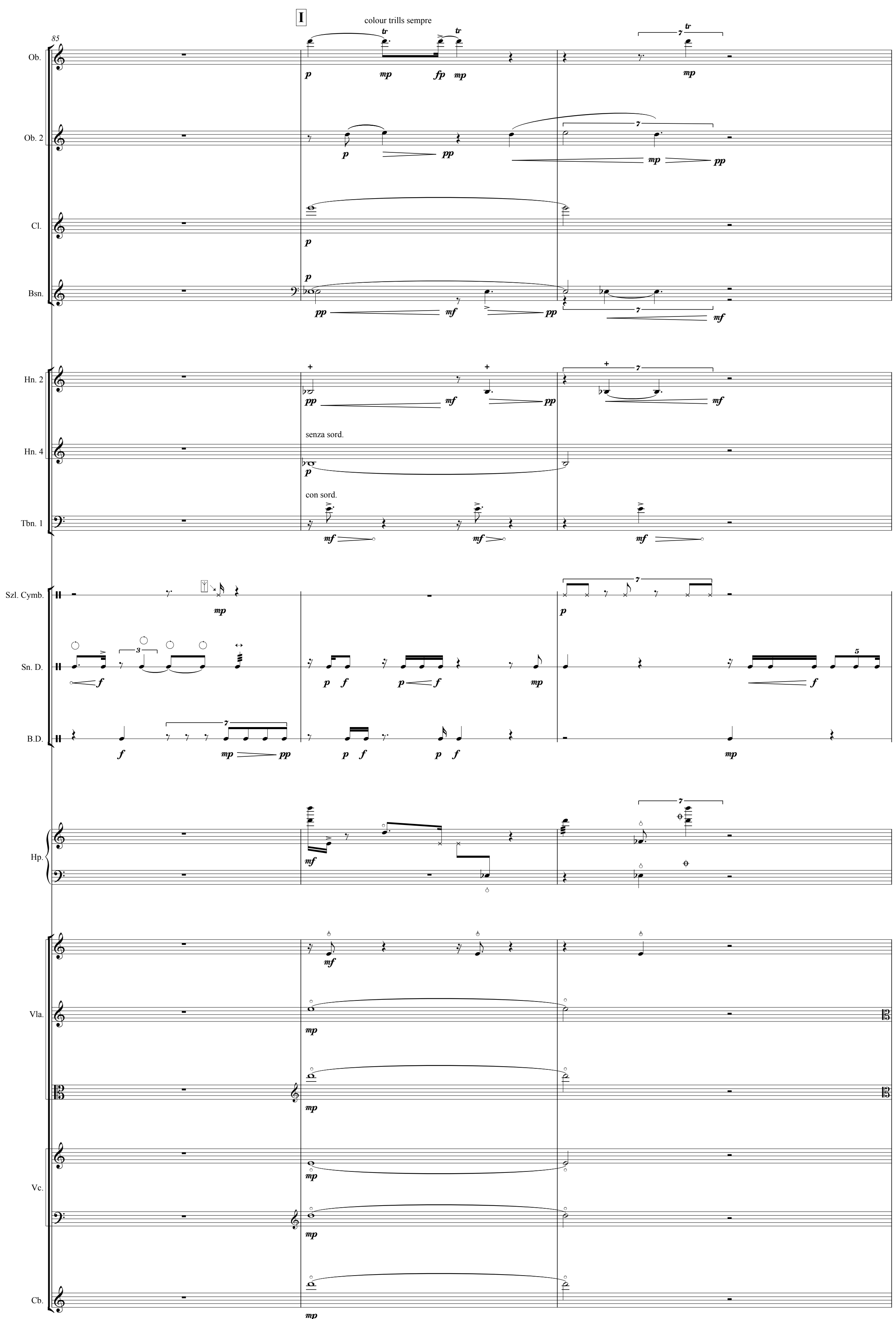

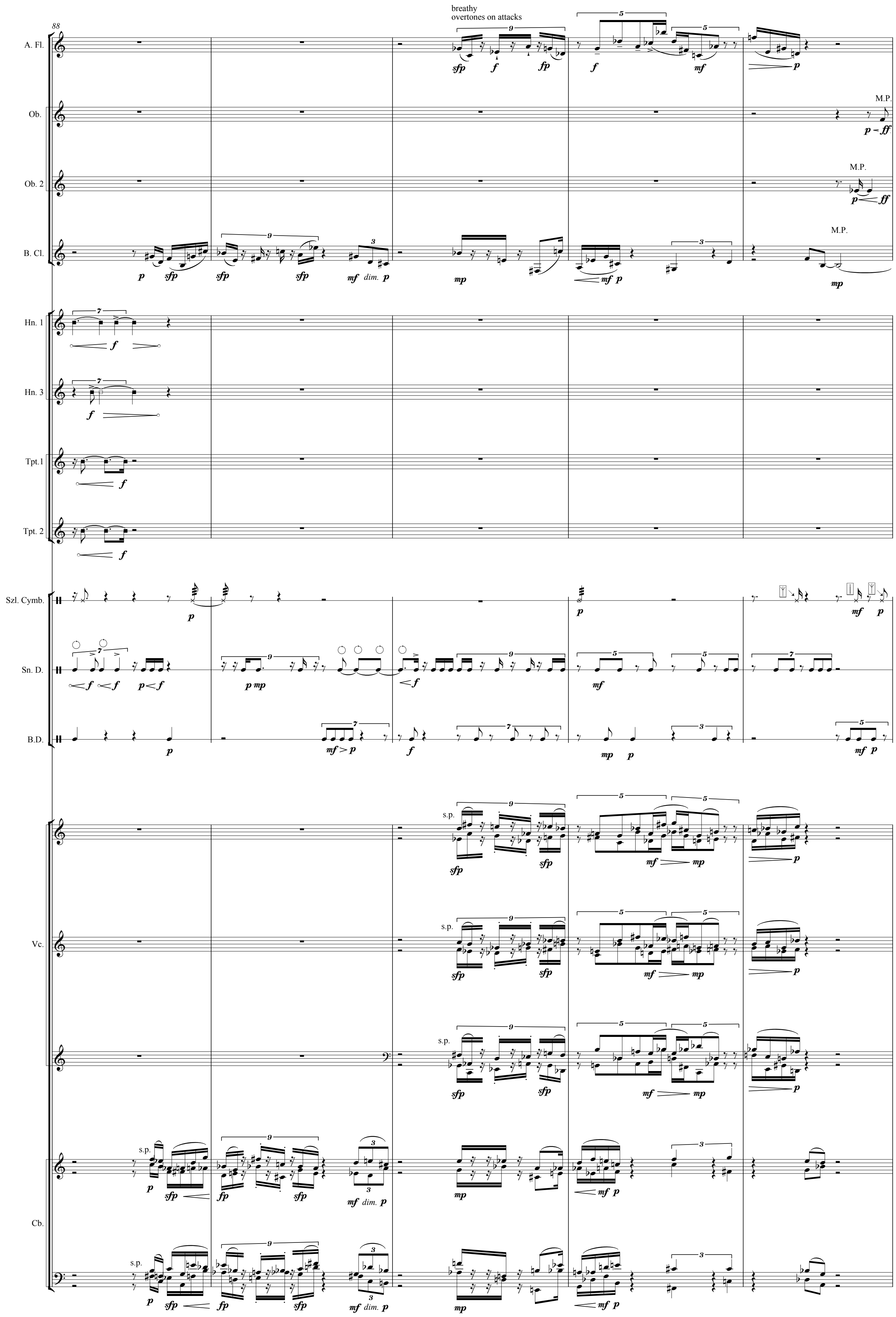

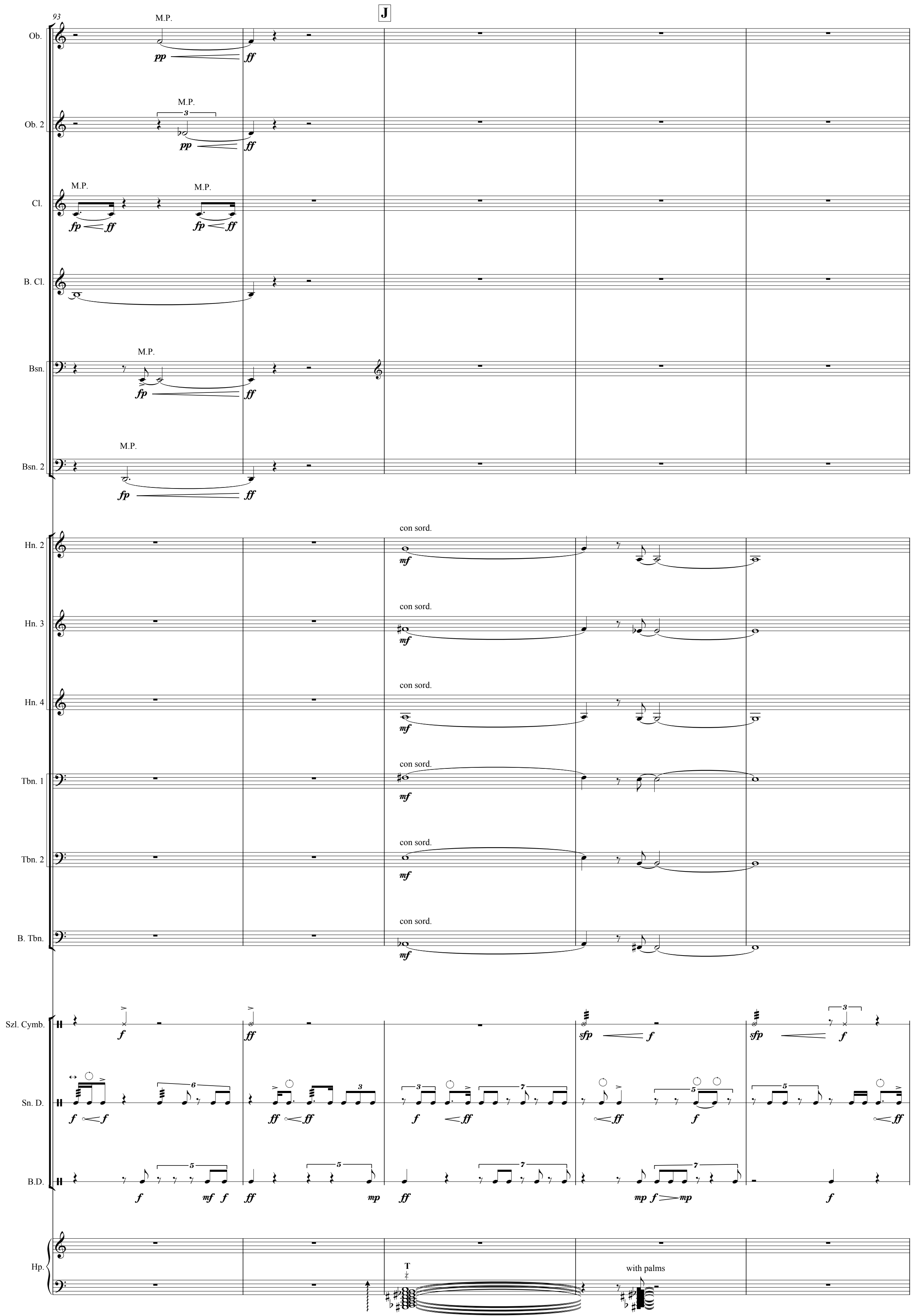

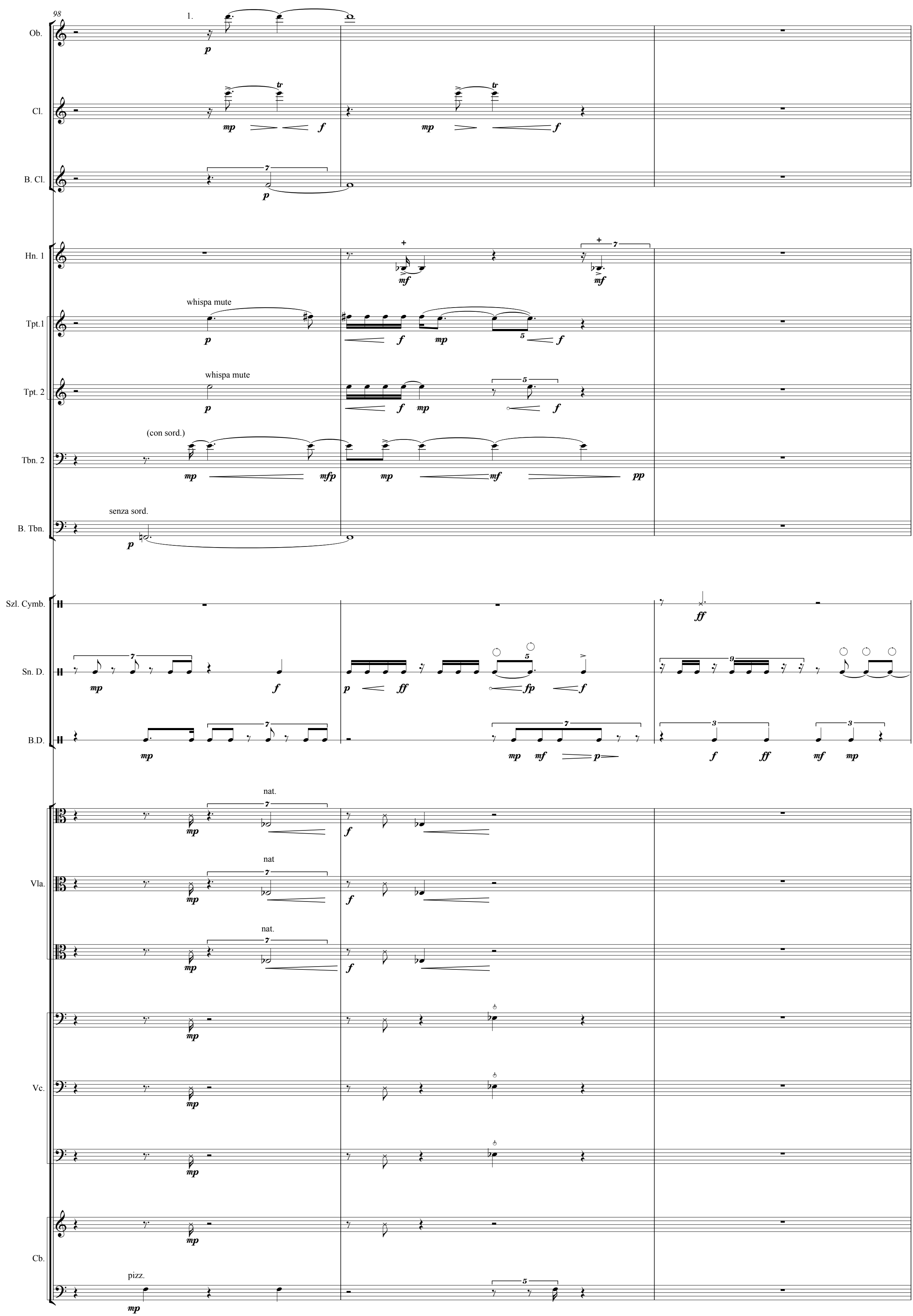

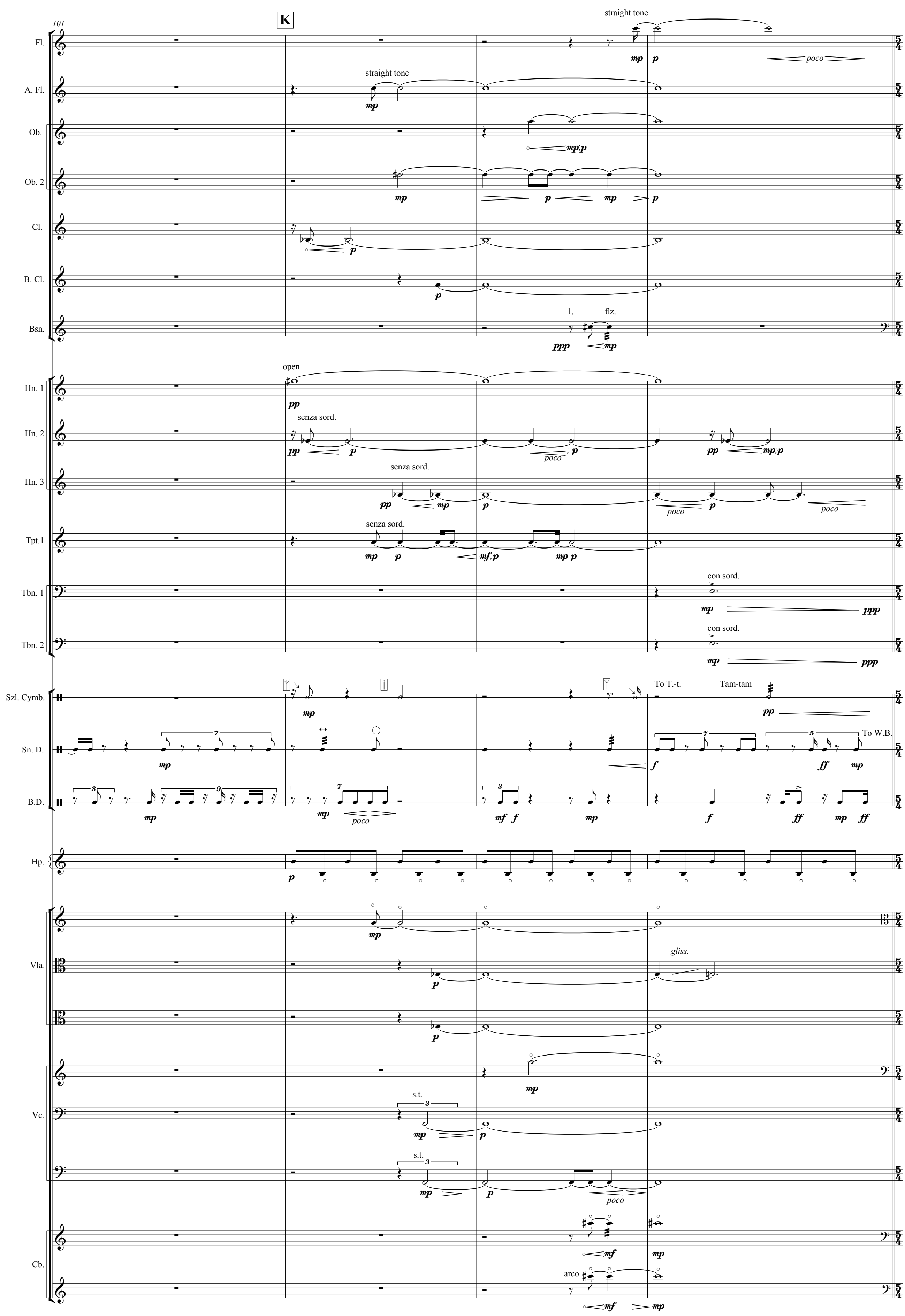
L

d $=60$

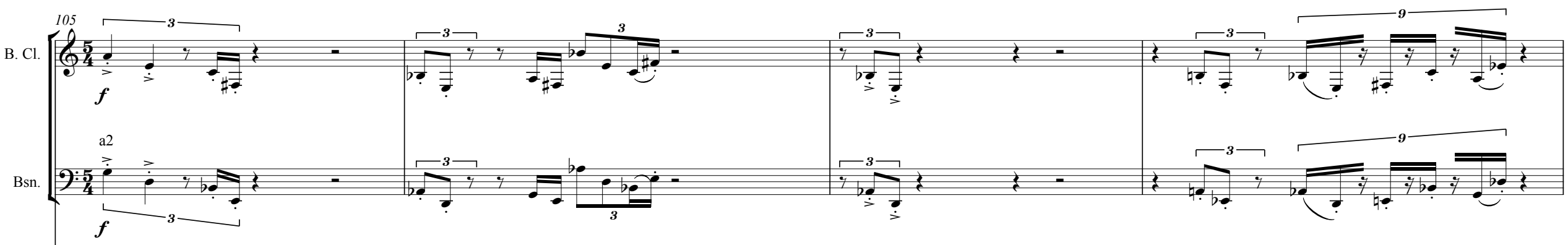
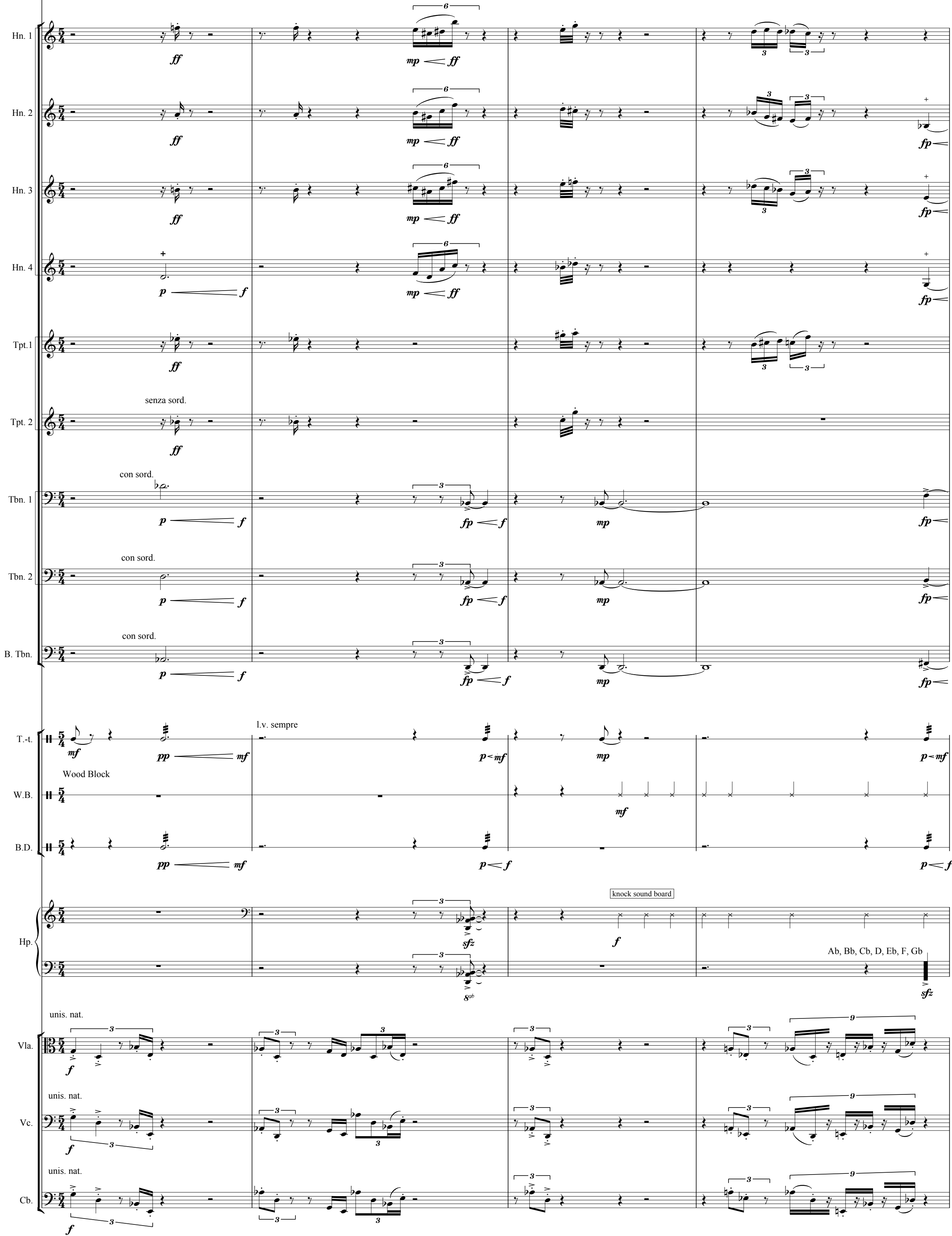

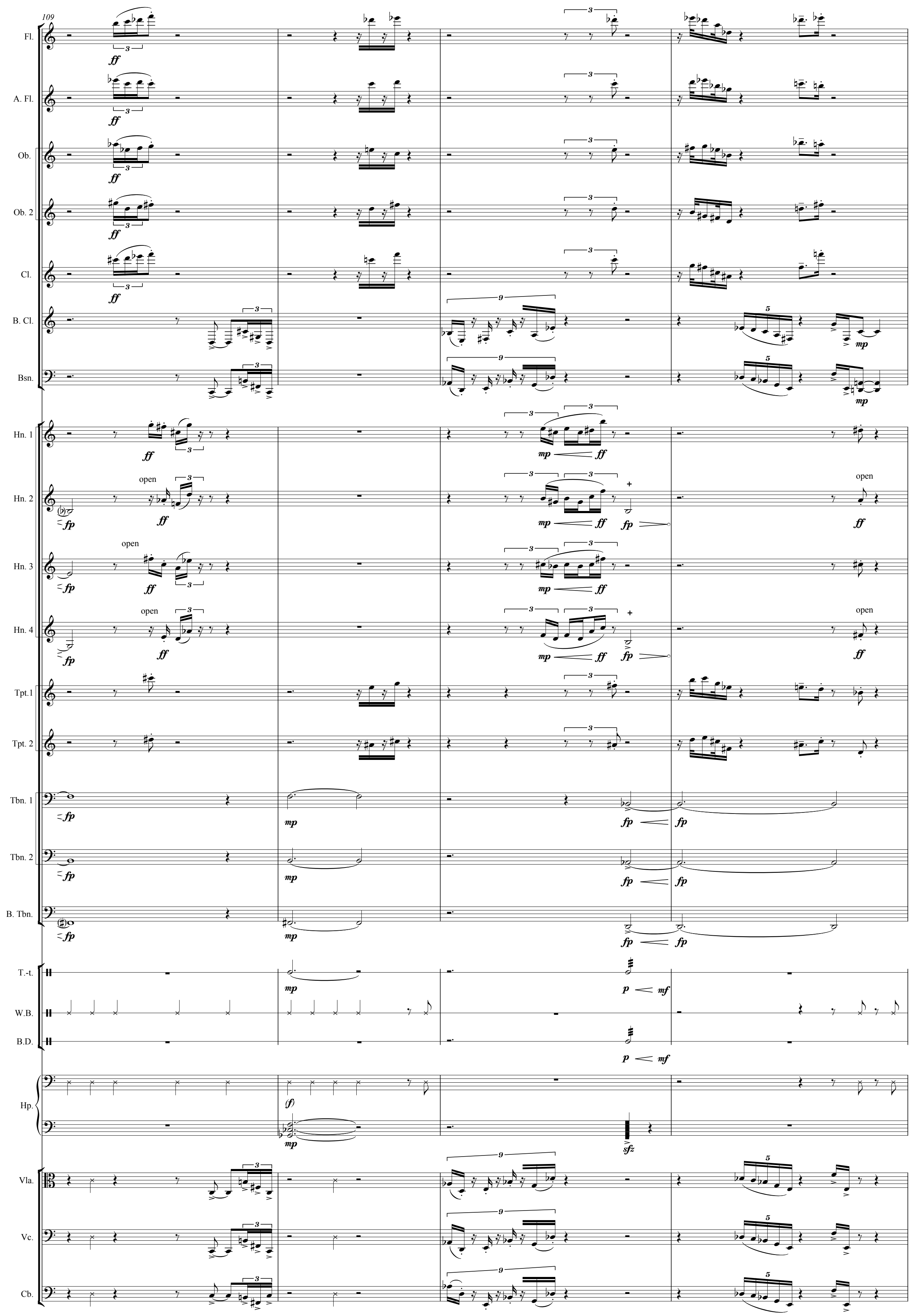

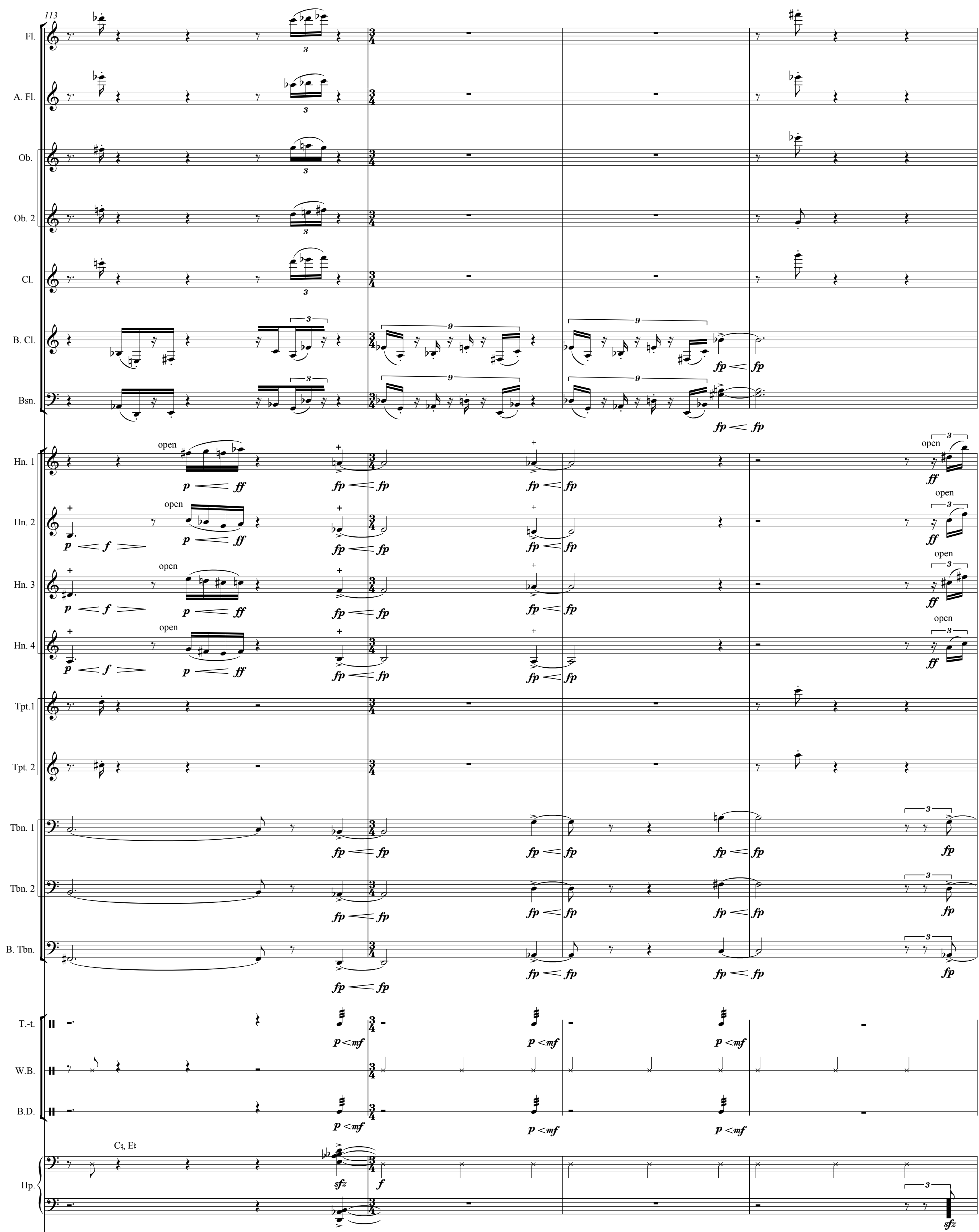

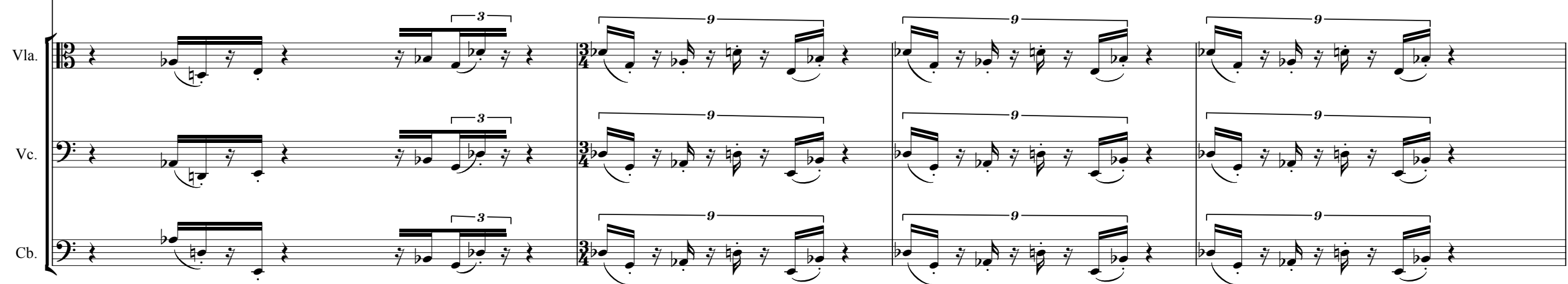



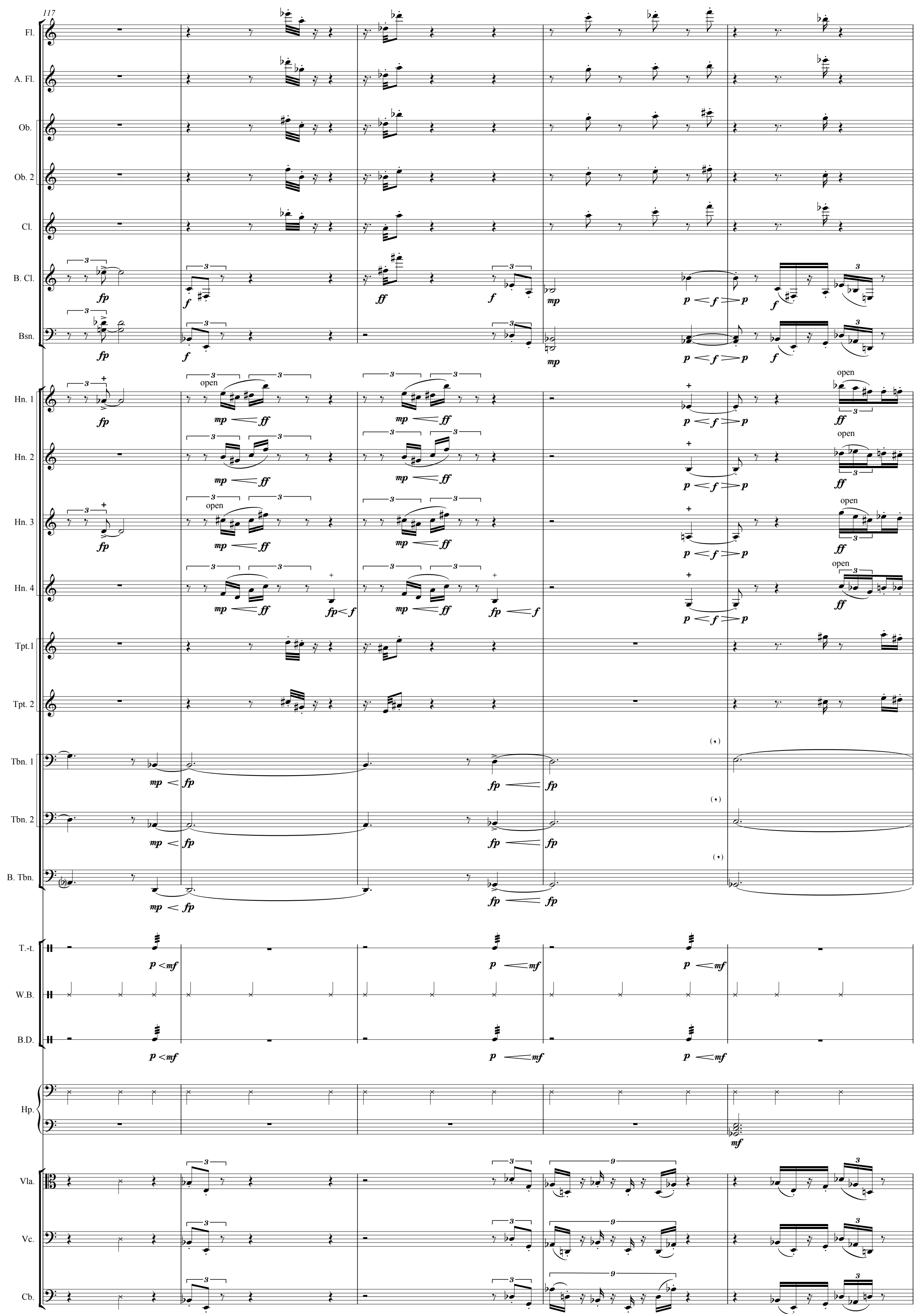

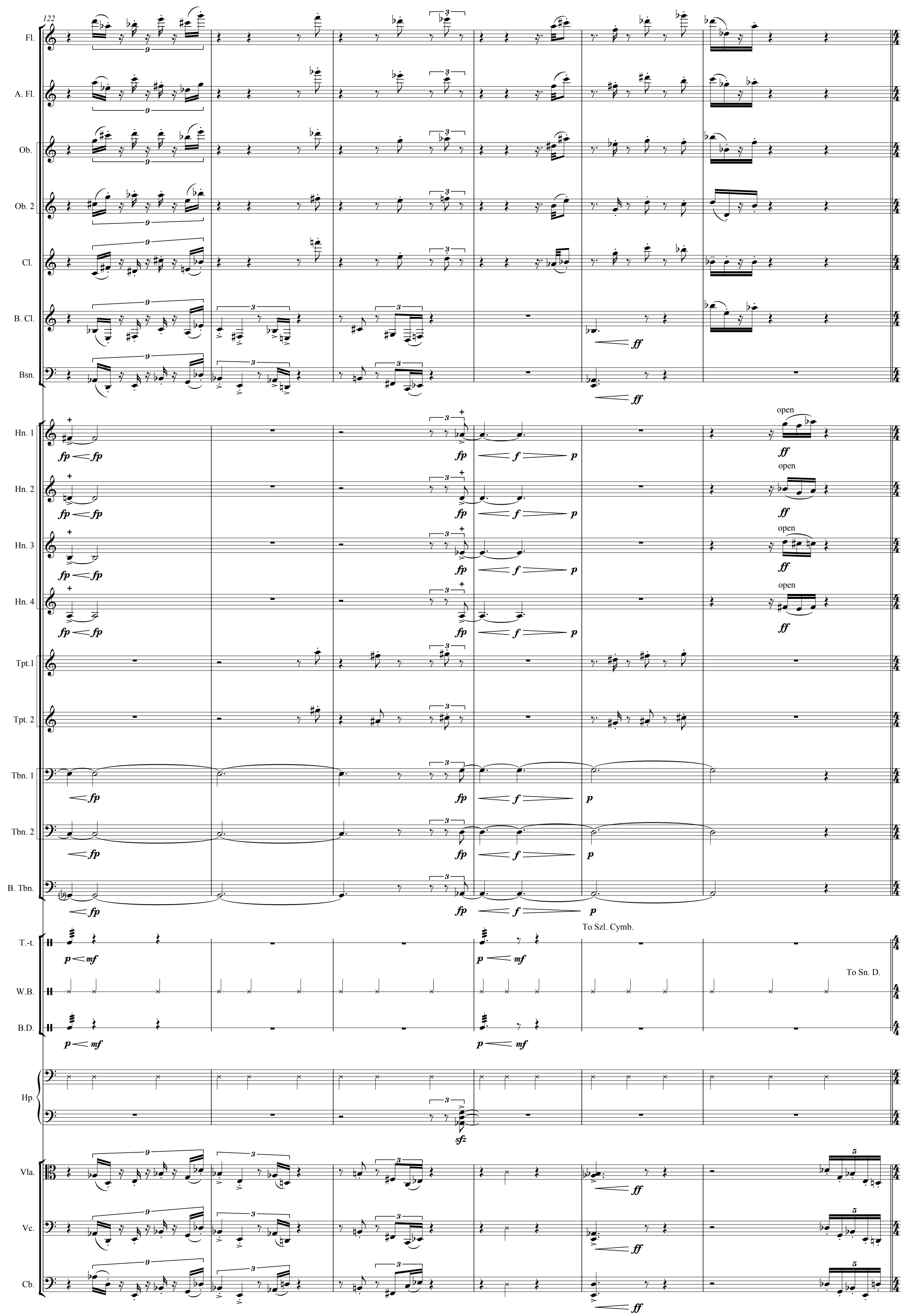

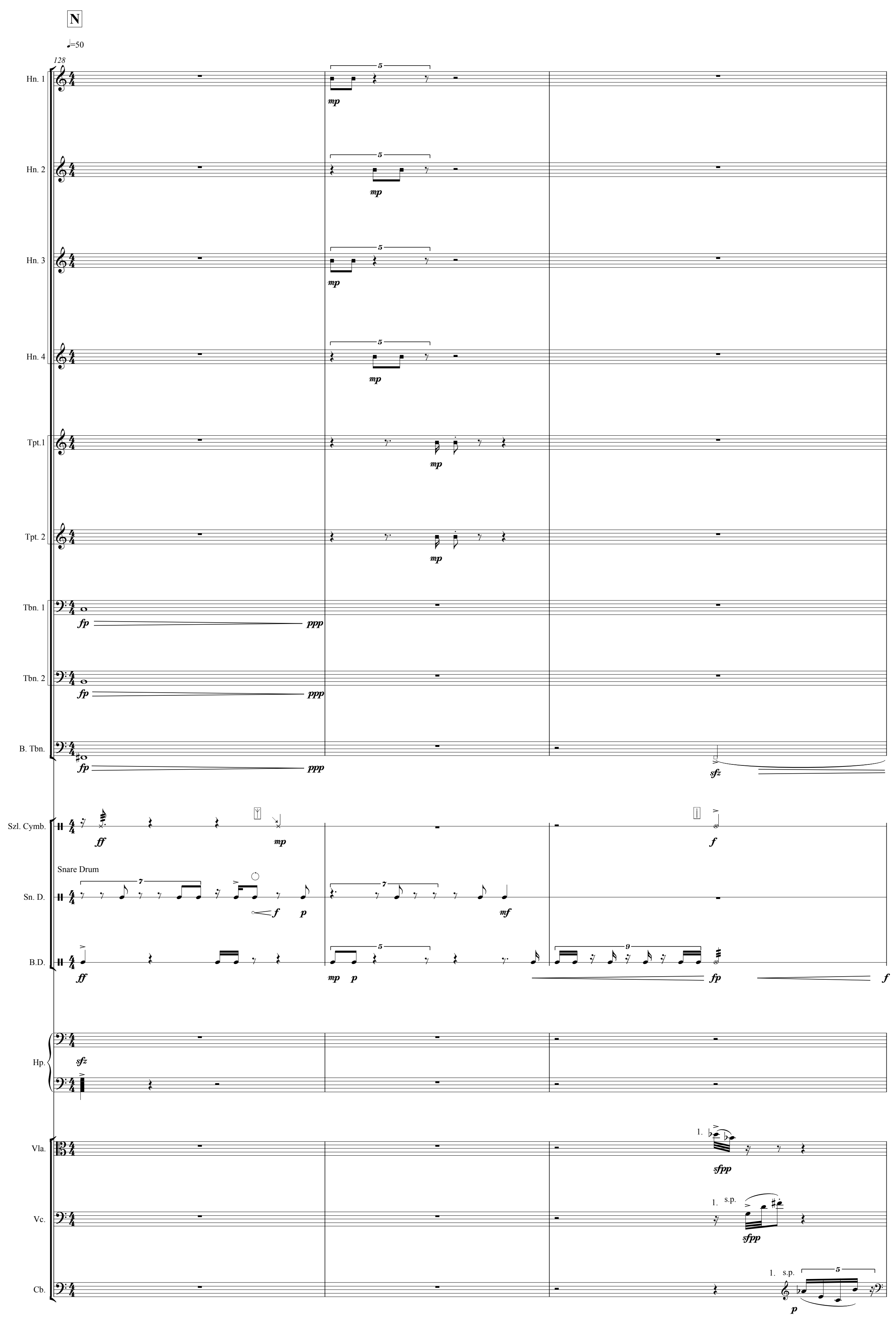

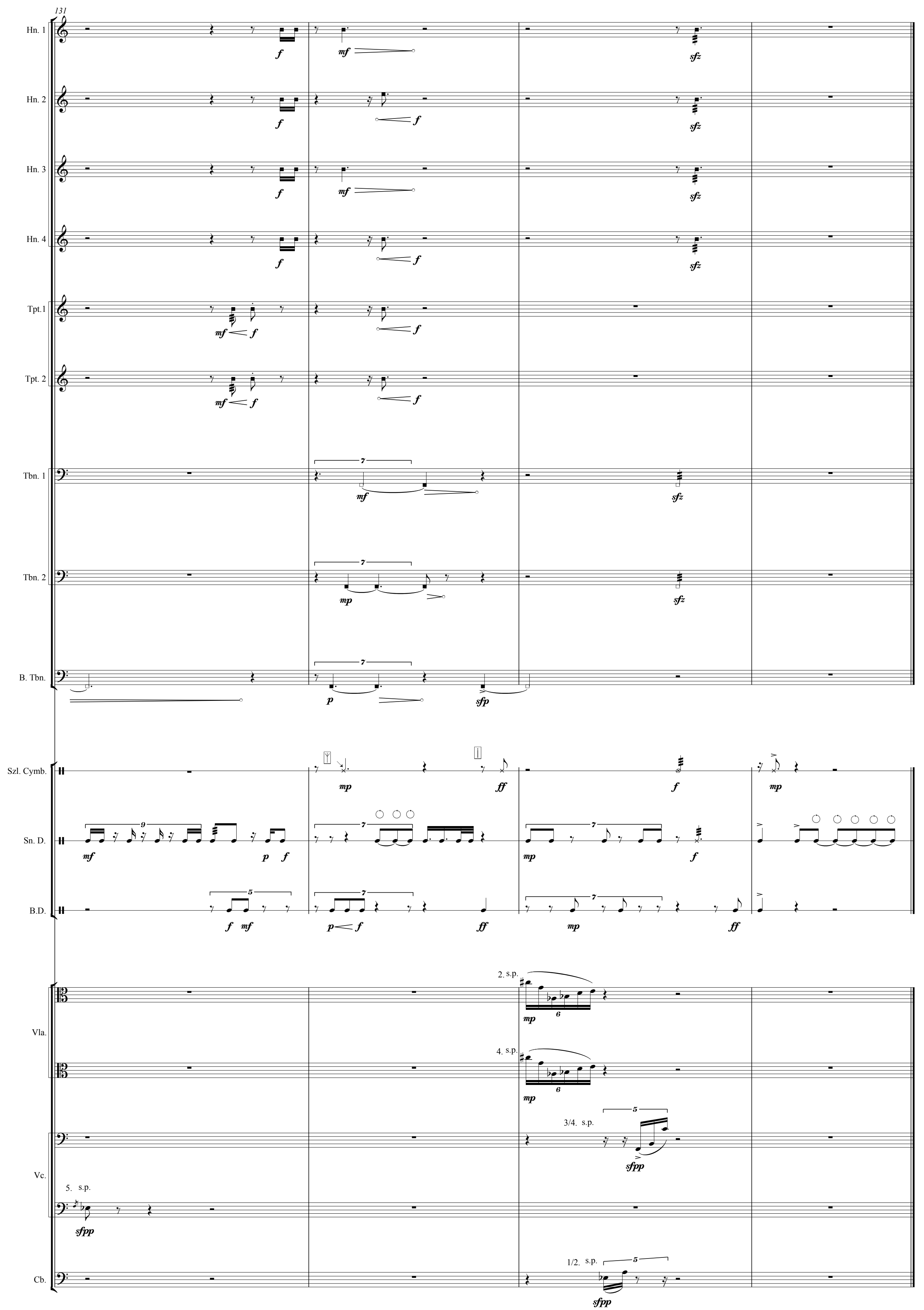